\title{
New observations on the role of accessory pathways in tachycardias in man
}

Citation for published version (APA):

Atie, J. (1990). New observations on the role of accessory pathways in tachycardias in man. [Doctoral Thesis, Maastricht University]. Maastricht University. https://doi.org/10.26481/dis.19900511ja

Document status and date:

Published: 01/01/1990

DOI:

10.26481/dis.19900511ja

Document Version:

Publisher's PDF, also known as Version of record

\section{Please check the document version of this publication:}

- A submitted manuscript is the version of the article upon submission and before peer-review. There can be important differences between the submitted version and the official published version of record.

People interested in the research are advised to contact the author for the final version of the publication, or visit the DOI to the publisher's website.

- The final author version and the galley proof are versions of the publication after peer review.

- The final published version features the final layout of the paper including the volume, issue and page numbers.

Link to publication

\footnotetext{
General rights rights.

- You may freely distribute the URL identifying the publication in the public portal. please follow below link for the End User Agreement:

www.umlib.nl/taverne-license

Take down policy

If you believe that this document breaches copyright please contact us at:

repository@maastrichtuniversity.nl

providing details and we will investigate your claim.
}

Copyright and moral rights for the publications made accessible in the public portal are retained by the authors and/or other copyright owners and it is a condition of accessing publications that users recognise and abide by the legal requirements associated with these

- Users may download and print one copy of any publication from the public portal for the purpose of private study or research.

- You may not further distribute the material or use it for any profit-making activity or commercial gain

If the publication is distributed under the terms of Article $25 \mathrm{fa}$ of the Dutch Copyright Act, indicated by the "Taverne" license above, 
New observations on the role of accessory pathways in tachycardias in man 

New observations on the role of accessory pathways in tachycardias in man

\section{PROEFSCHRIFT}

ter verkrijging van de graad van doctor aan de Rijksuniversiteit Limburg te Maastricht, op gezag van de Rector Magnificus, Prof. Dr. F.I.M. Bonke, volgens het besluit van het College van Dekanen, in het openbaar te verdedigen op vrijdag, 11 mei 1990 om 16.00 uur door Jacob Atié geboren te Tel-Aviv, Israel, 28 Januari 1953 
Promotores

Prof. Dr. P. Brugada

Prof. Dr. H.J.J. Wellens

Beoordelingscommissie Prof. Dr. R.S. Reneman (voorzitter)

Prof. Dr. M.A. Allessie

Prof. Dr. M.J. Janse

Prof. Dr. F.L. Meijler

Prof. Dr. O.C.K.M. Penn

Foreign Referees

Prof. Dr. Edson A. Saad

Dr. Jéronimo Farré

CIP-DATA KONINKLIJKE BIBLIOTHEEK, DEN HAAG

Atié, Jacob

New observations on the role of accessory pathways in tachycardias in man / Jacob Atié. - Maastricht :

Datawyse. - III.

Thesis Matastricht. - With ref. - With summary in Dutch.

ISBN 90-5291-023-5

SISO 605.12 UDC 616.12-072(043.3)

Subject headings: Wolf -Parkinson-White syndrome / Anti-

dromic tachycardia / Multiple accessory pathways.

Produktie en layout: Datawyse Maastricht. Ruud Leliveld Illustraties: Adri Van den Dool

Druk: Krips Repro Meppel

Publikatie van dit proefschrift werd mede mogelijk gemaakt door financiele steun van CNPq. Rescar, Nederlandse Hartstichting, Sanofi, Ciba, 3M Riker en Knoll b.v. 


\author{
À Angela, Hélène e Mauricio \\ Ao meu pai e minha saudosa mãe \\ Às paixōes da vida \\ Às grandes velejadas \\ Ao samba e canção \\ Ao sol e mar e \\ À terra carioca
}





\section{Foreword}

In Cardiology, and particularly in Rhythmology, orthodromic is an electric impulse in the heart which follows the normal, expected way. Contrarily the term antidromic refers to an electric stimulus which follows an unexpected, unusual or reversed way.

This thesis deals with several aspects of antidromic tachycardia, an arrhythmia where impulses follow a route which differs from the common one.

Initially, I did not know why I chose this topic, but suddenly I realized I was surrounded by antidromic people and antidromic facts.

The first antidromic way I took was many years ago when, at the age of 6 years, my family and I emigrated from Israel to Brazil. The orthodromic way for Jewish people has been the opposite, the emigration to Israel.

In the Middle Ages people followed the orthodromic way to discovery and adventure from Europe to South America. However, I took a couple of years ago the antidromic way and came to Europe for discovery, adventure and science.

I was received by Pedro Brugada, antidromic in his way of living, doing and teaching. Being with him provided me inspiration, stimulus and the necessary energy to undertake the realization of this thesis, which is the first by a Research Fellow in Electrophysiology in the University of Limburg. Without the antidromic initiatives of Pedro this thesis would not have been possible. Without any doubt the help, discussions and comments of Prof. Wellens (an antidromic scientist) were essential in the achievement of this goal.

Only with the company of another antidromic person could my life move in an appropriate antidromic way. It is always difficult to move against the orthodromic current. I would certainly have been drowned if Angela did not come to help me against the water. Since then, we moved up like the trouts, trying to reach the highest hills where the river starts. We searched, and found fulfillment in our lifes an created new ones. Like the trouts, we went back towards the sea with a small Hélène and a just born Mauricio. And there, Angela accepted the antidromic challenge to cross the Atlantic, of course,.... by other means ! The experience in Maastricht was unique for all of us. Angela was more than support and understanding. She is a real co-author of this thesis. 


\section{Contents}

Chapter I Cardiac preexcitation

Introduction 10

Historical Overview 10

The anatomic and electrophysiologic basis $\quad 13$

The electrocardiogram during sinus rhythm $\quad 17$

Tachyarrhythmias 20

Lacalization of the accessory pathway on the ECG 28

Multiple accessory pathways 41

Clinical consequences of accessory pathways 43

Chapter II Further support of the atrio-ventricular localization of so-called "Mahaim fibers" 53

Chapter III Clinical and electrophysiological characteristics of patients with antidromic circus movement tachycardia in the

Wolff-Parkinson-White syndrome 65

Chapter IV The diagnosis of multiple accessory pathways in the Wolff-Parkinson-White syndrome from the surface electrocardiogram in sinus rhythm 91

Chapter V The electrocardiogram in multiple accessory pathways 107

Chapter VI Clinical and electrophysiological characteristics of patients with multiple accessory pathways 121

Chapter VII Surgical treatment of multiple accessory pathways in the Wolff-Parkinson-White syndrome 141

Chapter VIII Longitudinal dissociation of atrio-ventricular accessory pathways 157

Chapter IX General conclusions, recommendations and implications for daily practice 171

Summary 175

Samenvatting $\quad 177$

Acknowledgments $\quad 179$

Curriculum Vitae 181 
Chapter I

\section{Cardiac preexcitation}




\section{Cardiac preexcitation}

\section{INTRODUCTION}

The Wolff-Parkinson-White syndrome, the most common type of preexcitation caused by an accessory pathway between the atrium and ventricle (1), can lead to a variety of cardiac arrhythmias. Among them, orthodromic circus movement tachycardia, atrial fibrillation, and less commonly, antidromic circus movement tachycardia.

Circus movement tachycardia in the Wolff-Parkinson-White syndrome is the classical model of reentry. The arrhythmia is easily reproduced in the catheterization laboratory by means of programmed electrical stimulation (2). It is not surprising, therefore, that the Wolff-Parkinson-White syndrome has been the subject of extensive study by cardiologists. Adequate understanding of this model of reentry may give answers to fundamental questions in relation to mechanisms and treatment of many other cardiac arrhythmias.

This doctoral thesis analyzes new aspects of the preexcitation syndromes. These include the diagnosis and mechanisms of antidromic circus movement tachycardia, multiple accessory pathways and accessory pathways with unusual electrophysiological properties. It also describes the results of treatment in these patients. Although the emphasis is on the use of invasive electrophysiologic techniques, new information is also presented concerning the 12-lead electrocardiogram. This is done by applying to the ECG data derived from the electrophysiologic study. It will be shown that this further increases the diagnostic power of the ECG, a simple and inexpensive tool.

\section{HISTORICAL OVERVIEW}

The first reported case of preexcitation goes back to 1915 when Wilson made his observation in a single patient (3). Wedd (4) in 1921 and Bach (5) and Hamburger (6) in 1929 described patients in whom the diagnosis of preexcitation was, in retrospect, quite certain. These investigators, however, gave a variety of explanations for the broad QRS complex which they considered to be a form of atypical bundle branch biock.

It were Wolff, Parkinson and White (7), who in 1930, described the clinico-electrocardiographic syndrome that now carries their names. In a series of 11 healthy young patients with intermittent $\mathrm{QRS}$ aberrancy and a short PR interval, they noticed a high incidence of attacks of paroxysmal 
palpitations. Interestingly, they made no reference to the possibility of accessory pathways, although these muscular connections had been described more than 50 years before by Paladino (8).

In 1893, Kent (9) identified muscular connections between atria and ventricles considering them, however, parts of the normall AV conduction system. In 1914, Mines (10) suggested that "bundles of Kent" could represent a pathway for re-entrant tachycardias. In 1929 de Boer (11) proposed that the narrow GRS complex tachycardia could result from the presence of an anomalous pathway connecting atria and ventricles.

Holzmann and Scherf in 1932 (12) and Wolferth and Wood in 1934 (13) were the first to combine the presence of preexcitation with circus movement tachycardia (fig. 1). In 1943, Wood et al (14) reported for the first time the anatomopathological correlation between the clinical finding of a short P-R interval and broad $\mathrm{QRS}$ complex with an anomalous A-V connection in the heart. This finding was supported by the description of Ohnell (15) one year later.
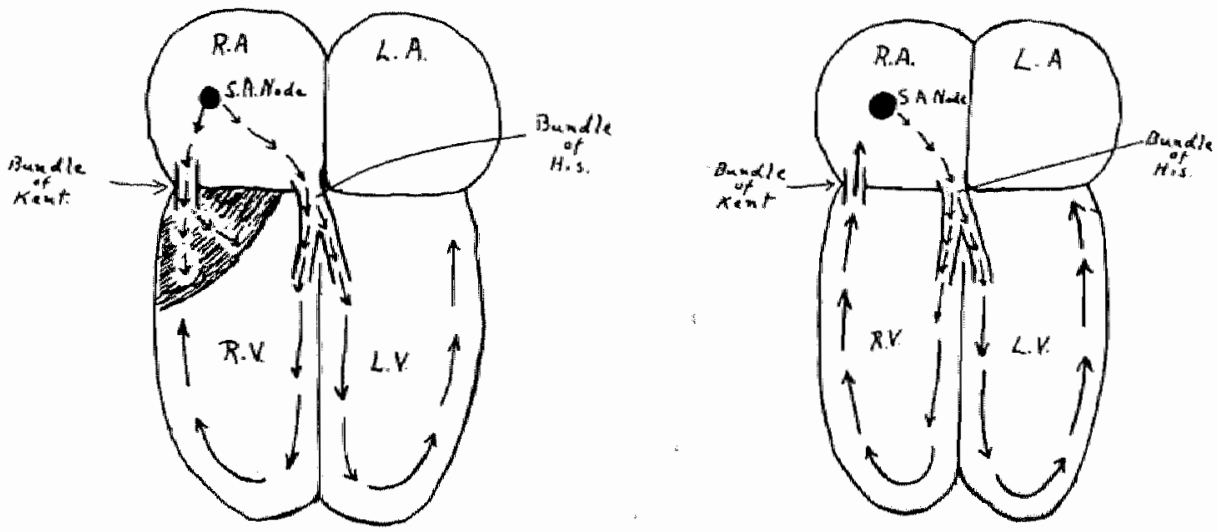

Figure 1. Dlagrams drawn in 1933, reproduced from the paper of Wolferth and Wood (13). showing possible mechanisms of pre-excitation and of circus movement tachycardia.

By permission of the Am. Heart J.

In 1945 Rosenbaum (16) classified the WPW syndrome in types A and B based on the precordial leads of the surface electrocardiogram. In 1948 Sodi Pallares (17) supported Rosenbaum's classification by recording potentials within the heart. Later on, Hecht (18) also supported this classification.

Definitive proof for the mechanism of preexcitation and the circus movement tachycardias occurring in patients with this anomaly was provided by Durrer and his coworkers when they first documented pre-excitation by 
epicardial mapping and then demonstrated the initiation and termination of the circus movement tachycardia during programmed electrical stimulation of the heart (2).

In 1971 Wellens described the electrophysiologic characteristics of the different accessory pathways leading to preexcitation (19). Thereafter many electrophysiology laboratories around the world further defined the various mechanisms of reciprocating tachycardias in patients with pre-excitation.

New types of accessory pathways were described in the mid 1970's. such as concealed accessory pathways, capable of only retrograde conduction (from ventricle to atrium), and therefore not showing anterograde pre-excitation $(20,21,22)$. In 1978, Gallagher (23) and thereafter Farré (24), described patients with circus movement tachycardia retrogradely using a concealed accessory pathway with a very long conduction time. The tachycardia was of the type previously described by Coumel (25) as the "permanent" or "incessant" form of A-V junctional reciprocating tachycardia.

The better understanding of the various preexcitation syndromes was inevitably followed by the recognition of its possible consequences. An anomaly which frequently causes paroxysmal palpitations, incessant tachycardias or even sudden arrhythmic death could not be considered anymore an electrocardiographic curiosity (26-27).

During matny years, the therapeutic armamentarium to manage these problems was limited. Decisions had to be made on an empirical basis. However, the ability to reproduce the arrhythmias during electrical stimulation studies opened the way to study the effects of antiarrhythmic drugs on the arrhythmia mechanisms (28-30).

An important breakthrough in the treatment of the Wolff-Parkinson-White syndrome was the successful first surgical division of an accessory pathway by Sealy (31). Surgical treatment rapidly became a reality and is now a fully accepted form of treatment $(32,33)$.

Nowadays, other types of treatment for the Wolff-Parkinson-White syndrome like electrical or radiofrequency percutaneous ablation are being applied or investigated $(34,35)$. In spite of the many advances in understanding and treatment of the Wolff-Parkinson-White syndrome, there are still questions to be answered.

Recently Jackman et al (36) suggested that accessory pathway potentials may be recorded during electrical mapping. In spite of discussions as to the validity of their interpretations this has resulted in a renewed interest in the pathophysiologic aspects of conduction over an accessory pathway. Also, we are still far from understanding why antiarrhythmic drugs affect (or fail to affect) conduction over an accessory pathway.

It is clear, therefore, that the Wolff-Parkinson-White syndrome will continue to puzzle and fascinate us for many years to come. Especially because it is such a beautiful model to study and understand arrhythmias occurring in other sites of the heart. 


\section{THE ANATOMIC AND ELECTROPHYSIOLOGIC BASIS OF THE PREEXCITATION SYNDROMES}

Normally, ventricular excitation follows conduction of a supraventricular impulse over the atrioventricular node, the bundle of His and the bundle branch-Purkinje system. When apart from the normal atrio-ventricular system another pathway for conduction is present, this pathway is called an accessory pathway. The normal atrioventricular node can be bypassed by a number of potentially different types of accessory pathways. It is believed that these accessory pathways are composed of normal myocytes. These cells can be arranged and localized in different ways causing a variety of anatomical and electrophysiological types of accessory pathways $(37,38)$ (fig. 2).

The type of accessory pathway found in 345 consecutive patients studied in our institution is shown in table I.

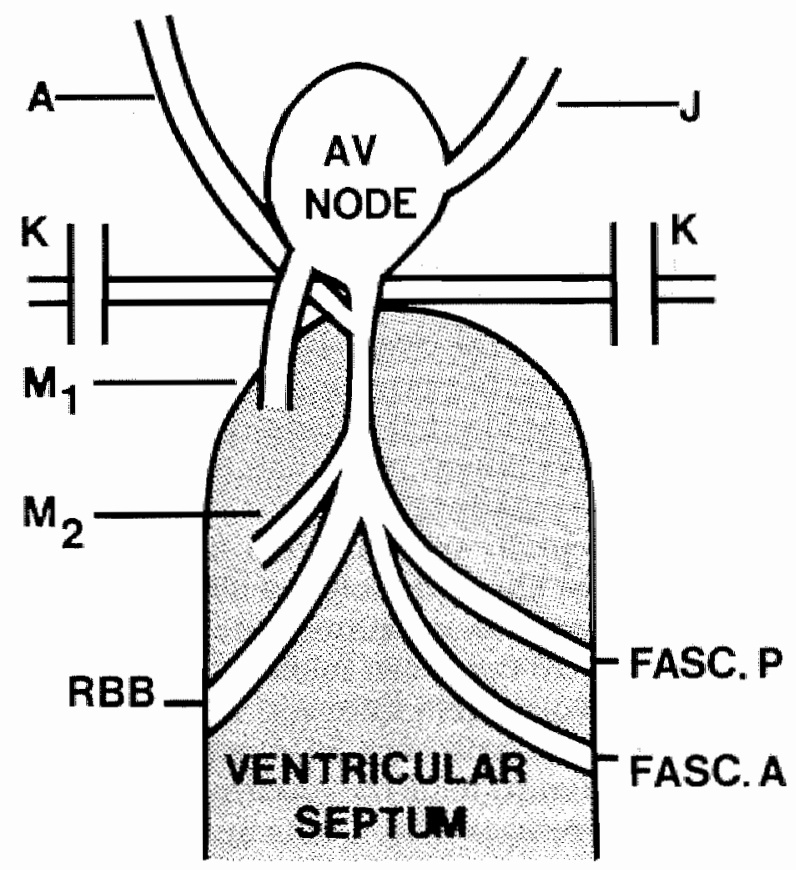

Figure 2. Scheme of the atrioventricular conduction system and possible accessory connection(s) partillly or totally bypassing that system. A. indicates an atriofascicular bypass tract: J, an atrionodal bypass tract: $K$, an accessory atrioventricular pathway: $M 1$, a nodoventricular pathway: M2, a fasciculoventricular pathway: Fasc P. the posterfor fasclcle of the left bundle branch: and fasc $A$, the anterior fascicle of the left bundle branch; RBB, the right bundle branch. (Reproduced from ref. 1, by permission] 
Table I. Type of accessory pathways in 345 patients

\begin{tabular}{lc}
\hline A.V AP "Kent" & $194 \mathrm{pts}$ \\
A-V AP slow CT & $3 \mathrm{pts}$ (ariterogradely) \\
A-VAP slow CT & $20 \mathrm{pts}$ (retrogradely) \\
Nodoventricular AP & $4 \mathrm{pts}$ \\
Concealed AP" & $124 \mathrm{pts}$ \\
\hline
\end{tabular}

Abbreviations $A-V=$ atriowentricular; $A P=$ accessary pathway; $C T=$ conduction time; ptss= patilents.

\section{a. Accessory atrioventricular pathways}

The most common type of accessory atrioventricular connection is the so-called Kent bundle, which is found in patients with the typical WolffParkinson-White syndrome (14) (fig. 2). The bundles of Kent originate and insert into the myocardium (from atrium to ventricle) and can be located endocardially or epicardially (38).

In the few anatomic descriptions available, the accessory pathway consisted of a thin strand of morphologically normal myocardium bridging the fibro-fatty epicardial gap between atrium and ventricle (38). This type of accessory pathway can be located at any site along the atrioventricular junction, including the area of aortic-mitral valve fibrous continuity (38) (ffig. 3).

The initial classification of the Wolff-Parkinson-White syndrome separated the electrocardiographic patterns into types $A$ and $B$ (16). In this classification, type A represented a left-sided accessory pathway and type B a right-sided connection. We know now that there are different possible localizations of the accessory pathways. They can be infero-septal (posteroseptal), para-hisian (mid-septal), supero-septal (antero-septal), left or right paraseptal or localized in the left or right free wall (39).

The dimensions of an accessory pathway seem to vary. They can be as short as $1 \mathrm{~mm}$ or as long as $10 \mathrm{~mm}$. Also the diameter may vary, and the way they branch out into the myocardium (38).

Atrioventricular accessory pathways in symptomatic patients are frequently capable of conduction in both the anterograde and retrograde direction (40). However, there are accessory pathways capable of conduction in only one direction. If only retrograde conduction is possible, the electrocardiogram during sinus rhythm does not show preexcitation. However, paroxysmal supraventricular tachycardia due to a reentry circus movement tachycardia using such a concealed accessory pathway retrogradely (orthodromic circus movement tachycardia) is possible $(20.21)$. Similarly, there are accessory atrio-ventricular pathways capable of only anterograde conduction. In those patients orthodromic circus movement tachycardia cannot occur. An 


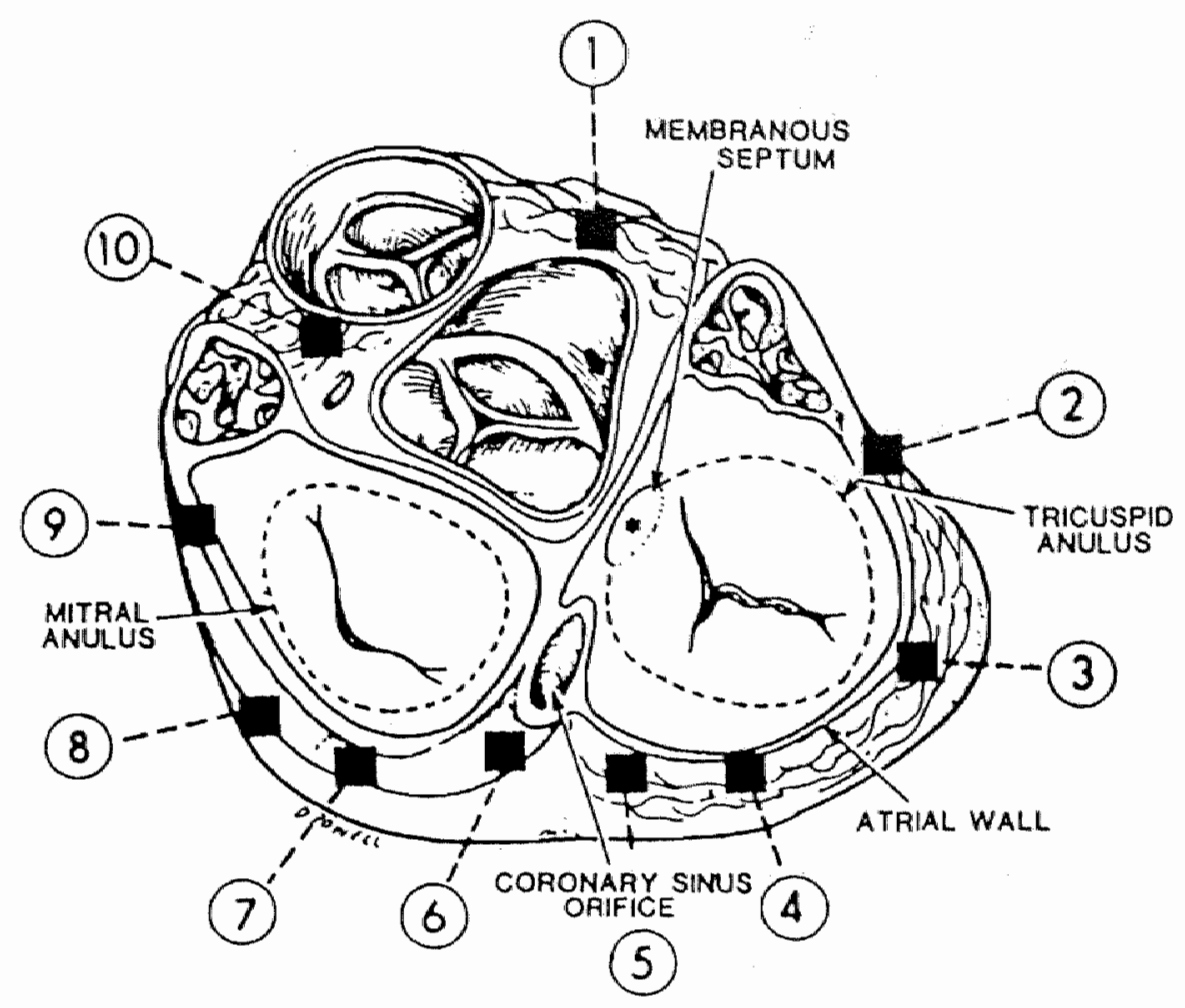

Figure 3. Possible localizations of accessory atrio-ventricular pathways as suggested by Gallagher (39). Ten representative sites are depicted on a schematic cross-section of the ventricles at the level of the atrioventricular ring.

antidromic circus movement tachycardia with the accessory pathway conducting anterogradely and the normal atrio-ventricular conduction system conducting retrogradely is possible, however.

Usually, the accessory atrioventricular pathway conducts the impulse with a short conduction time, from atrium to ventricle and vice-versa. However, there are accessory pathways with long conduction times. These accessory pathways with long conduction times are also capable to conduct retrogradely or anterogradely, or in both directions (23-24).

Patients with retrogradely conducting atrio-ventricular accessory pathways with long conduction times, generally, have incessant circus movement tachycardia (23-25).

Atrio-ventricular accessory pathways with long conduction times capable of anterograde conduction have electrophysiological properties very similar to nodo-ventricular accessory pathways $(19,42,43)$. Actually it has been 
demonstrated that in some patients in whom a nodo-ventricular accessory pathway was suspected, an accessory atrio-ventricular pathway with long anterograde conduction times was present (44-46) (Chapter II).

One of the most important properties of the accessory pathways is their capacity to conduct an impulse. The ability to do so is determined by the refractory period of the pathway. The effective refractory period of these structures is generally different in anterograde and retrograde direction.

The ventricular response during atrial fibrillation is determined by the electrophysiological properties of both AV (normal and accessory) conduction pathways. If the accessory atrioventricular pathway has a very short anterograde refractory period, an extremely rapid ventricular rate can develop during atrial fibrillation, which in some instances may degenerate into ventricular fibrillation $(27,47)$.

\section{b. Nodoventricular and Fasciculo-Ventricular Accessory Pathways}

Nodo-ventricular accessory pathways go directly from the AV node into the ventricle. Fasciculo-ventricular accessory pathways connect the common bundle of His to the ventricles (fig. 2). A nodo-ventricular accessory pathway was first described by Mahaim in 1941 (42). They are less common than true atrioventricular accessory pathways (39). At least that is true in symptomatic patients studied electrophysiologically because of a variety of preexcitation syndromes (table I).

Some concepts about nodo-ventricular accessory pathways have recently been revised (44-46). It seems that in selected patients, features suggestive of a nodo-ventricular accessory pathway are in reality caused by an accessory atrio-ventricular pathway with slow anterograde conduction. Further support of this hypothesis will be given in chapter II.

\section{c. Other Variants of The Preexcitation Syndromes}

In 1961, James (48) described an accessory pathway connecting the atrium with the distal fibers of the AV node (atrionodall or the common bundle (atriofascicular) (fig. 2). This type of accessory pathway should result in a short PR interval, a normal GRS complex without preexcitation and circus movement tachycardia (Lown-Ganong-Levine syndrome) (49). Definite proof on the existence and role of such an accessory pathway is missing. Some of the reported cases can also be explained by a short atrio-ventricular nodal conduction time and dual atrio-ventricular nodal pathways (50). 


\section{THE ELECTROCARDIOGRAM DURING SINUS RHYTHM IN THE PREEXCITATION SYNDROMES}

The incidence of ventricular preexcitation in patients with accessory pathways is estimated to be 1 to 3 per 1000 persons $[51$ ). However, it has to be realized that studies based on the electrocardiogram during sinus rhythm can only recognize patients with accessory pathways capable of anterograde conduction. Concealed accessory pathways cannot be recognized in the electrocardiogram during sinus rhythm. Also, preexcitation may be unapparent or intermittent on the electrocardiogram. The true incidence of accessory pathways in the general population therefore must certainly be underestimated.

The electrocardiogram in the preexcitation syndromes, may lead to 4 different patterns:

1. Short PR interval with a delta wave.

2. Short PR interval without delta wave.

3. Normal PR interval with delta wave.

4. Normal PR interval without delta wave.

\section{a. Atrio-ventricular accessory pathways with fast conduction times}

The most common variety of preexcitation is that associated with an atrioventricular accessory pathway of the so-called "Kent" type. The electrocardiogram during sinus rhythm shows a short PR interval, a delta wave and a wide QRS complex, when the accessory pathway is capable of anterograde conduction. These findings are the result of ventricular activation over both the normal atrioventricular conduction system and the accessory pathway (14). As pointed out by Wellens (1), the pattern of ventricular activation and therefore the degree of preexcitation is determined by several factors, as illustrated in figure 4. Among them, the localization of the accessory pathway, the intra-atrial conduction times and the conduction times over the accessory pathway and the AV nodal-His-Purkinje pathway.

When we take these factors into consideration, the electrocardiogram can vary from a normal electrocardiogram to an electrocardiogram with a pattern of maximal preexcitation (fig. 4). It has to be realized that the degree of preexcitation on the 12 lead electrocardiogram during sinus rhythm does not indicate the electrophysiologic properties of the accessory pathway. Accessory pathways with very short refractory periods can produce minimal preexcitation on the electrocardiogram during sinus rhythm. This is particularly common in left lateral accessory pathways because of their distance from the sinus node (fig. 4). On the contrary, a right-sided or septal accessory pathway with a long refractory period may give rise to a very preexcited QRS complex. simply because of its proximity to the sinus node. 

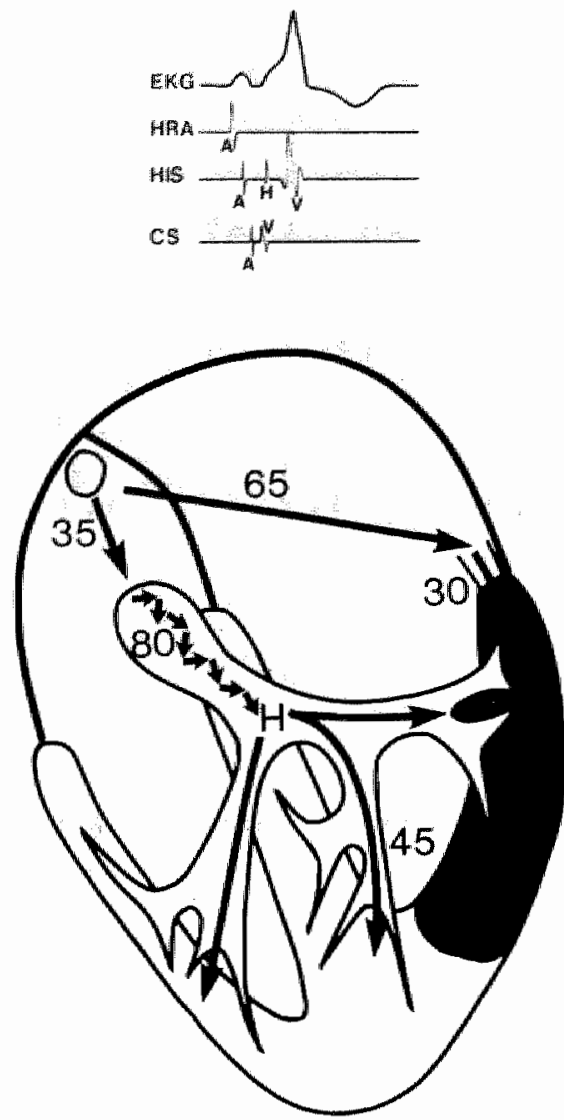
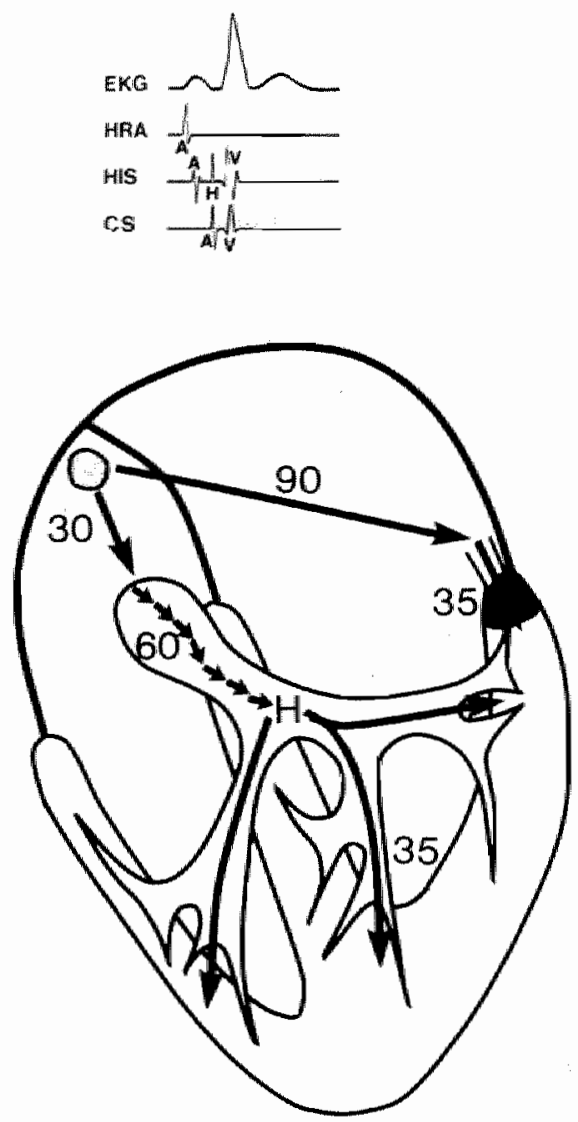

FIgure 4. Schematic representation of factors determining the degree of ventricular preexcitatton in the Wolff-Parkinson-White patient during sinus rhythm. The corresponding electrocardiogram and intracavitary recordings from the hygh right atrium (HRA), His bundle region (HIS), and coronary sinus ICS] are shown in the upper part of the figure.

(Left) The atrloventricular conduction time from the sinus node region over the nomal AV pathway measures $160 \mathrm{~ms}$ (the time required to travel from the sinus node to the AV node. PA interval, of 35 msec; the transnodal conduction time. AH interval, of 80 msec; and the time needed to travel through the bundle of His and the bundle branches to the ventricular myocardium. HV interval, of $45 \mathrm{msec}$. The time required to travel from the sinus node to the atrial insertion of the $\mathrm{AP}$ measures 65 msec. and the conduction time over the AP measures $30 \mathrm{msec}$. The total AV conduction time to travel from the sinus node to the ventricle using the AP measures 95 msec. Under these circumstances, the corresponding electrogram will show a P-delta Interval of $95 \mathrm{msec}$ and a wide QRS complex with ventricular excitation starting $160-95=65$ msec earlier than expected.

(Right) In this example, as compared to the left panel, there is (1) a longer conduction time from sinus node to the atrial insertion of the AP, (2) a longer conduction time over the accessory pathway, and (3) a shorter conduction time over the normal AV conduction system (shorter PA. AH and HV times). As a result of these differences, the AV conduction times over either the normal or the accessory pathway are identical (both $125 \mathrm{msec}$ ). Now the electrocardiogram shows a PR interval of $125 \mathrm{msec}$ and a QRS complex without evident preexcitation. (reproduced from ref 1 , by permission] 
Sudden and unexpected loss of the delta wave (normalization of the QRS complex) has been observed already a long time ago in the preexcitation syndromes (15). Loss of the delta wave can be related to a critical rapid for slow) heart rate, although, most often, loss of delta wave occurs unexpectedly (52). These patients have an accessory pathway with a long anterograde refractory period and are not at risk for rapid ventricular rates when atrial fibrillation occurs (53).

Patients with an accessory atrio-ventricular pathway that conducts only retrogradely, have a normal P-R interval without delta wave on the electrocardiogram during sinus rhythm. However, they often suffer from circus movement tachycardia, depending upon the electrophysiological properties of the AV nodal and accessory pathway (54).

The presence of a normal PR interval without delta wave, can also be present in patients with inapparent preexcitation. In these patients a delta wave may appear during sinus tachycardia or bradycardia (53).

\section{b. Nodoventricular and fasciculoventricular accessory pathways}

Patients with "Mahaim fibers" may have a normal ECG or a normal PR interval with a delta wave at the beginning of the QRS complex $(19,53)$. This occurs because there are two varieties of nodoventricular accessory pathways, those which arise from the transitional zone of the AV junction and those which arise from the deep, compact nodal portion of the AV junction (37).

Nodoventricular fibers, depending on the level of takeoff relative to the area of physiologic AV nodal delay, can be associated with either a short or a normal PR interval. Ventricular activation results from fusion of impulse conduction via the nodoventricular and the normal conduction system, resulting in a GRS complex of variable morphology depending upon the degree of anomalous ventricular activation.

Fasciculoventricular fibers, arising from the His bundle or bundle branches, result in minor abbreviations of the $\mathrm{H}-\mathrm{V}$ interval and some degree of anomalous QRS morphology. The PR interval, however, is usually normal in the absence of other abnormalities of AV conduction [55].

\section{c. "James" fibers}

Patients with "James fibers", present a short PR interval with a normal QRS complex $(19,49)$. These findings, when associated with paroxysmal tachycardia, are known as the Lown-Ganong-Levine syndrome. 


\section{d. Accessory pathways with long conduction time}

The electroeardiogram of patients having an atrioventricular accessory pathway with long conduction times able to conduct anterogradely is similar to the ECG in nodo-ventricular accessory pathways $(44,45)$.

Patients having atrioventricular accessory pathway with long conduction times only conducting retrogradely, frequently suffer from incessant tachycardias. During tachycardia the PR interval is much shorter than the R-P interval because of slow retrograde conduction over the accessory pathway. Usually these accessory pathways are not able to conduct anterogradely and the electrocardiogram during sinus rhythm has a normal PR interval without a delta wave (24).

In summary, the electrocardiogram during sinus rhythm in patients with the preexcitation syndromes may differ, depending upon the type, localization and electrophysiologic characteristics of the accessory pathway.

\section{TACHYARRHYTHMIAS IN THE PREEXCITATION SYNDROMES}

A variety of tachyarrhythmias may occur in patients with accessory pathways. Some of those tachyarrhythmias are well tolerated (39), however, other patients may suffer from incapacitating or even life threatening arrhythmias (26). Treatment is therefore necessary in many patients with an accessory pathway. The best therapy will depend upon the type of arrhythmia, their impact on quality of life, its prognosis and the ease of treatment.

\section{Orthodromic circus movement tachycardia}

The most common type of tachycardia in patients with an accessory pathway is orthodromic circus movement tachycardia (fig. 5). This tachycardia utilizes the AV node as the anterograde limb and the accessory pathway as the retrograde limb of the circuit. The atria, the ventricles, the normal conduction system of the heart and the accessory pathway are all necessary links in the circuit.

Orthodromic circus movement tachycardia may occur with any type of accessory pathway. The only necessary condition is that the accessory pathway must be able to conduct impulses retrogradely. That may be possible with rather short ("fast" type of accessory pathway) or rather long conduction times ("slow" type of accessory pathway).

The anterograde and retrograde conduction properties of the accessory pathway determine the mode of spontaneous or electrically induced initiation of circus movement tachycardia. These aspects will be discussed later. 


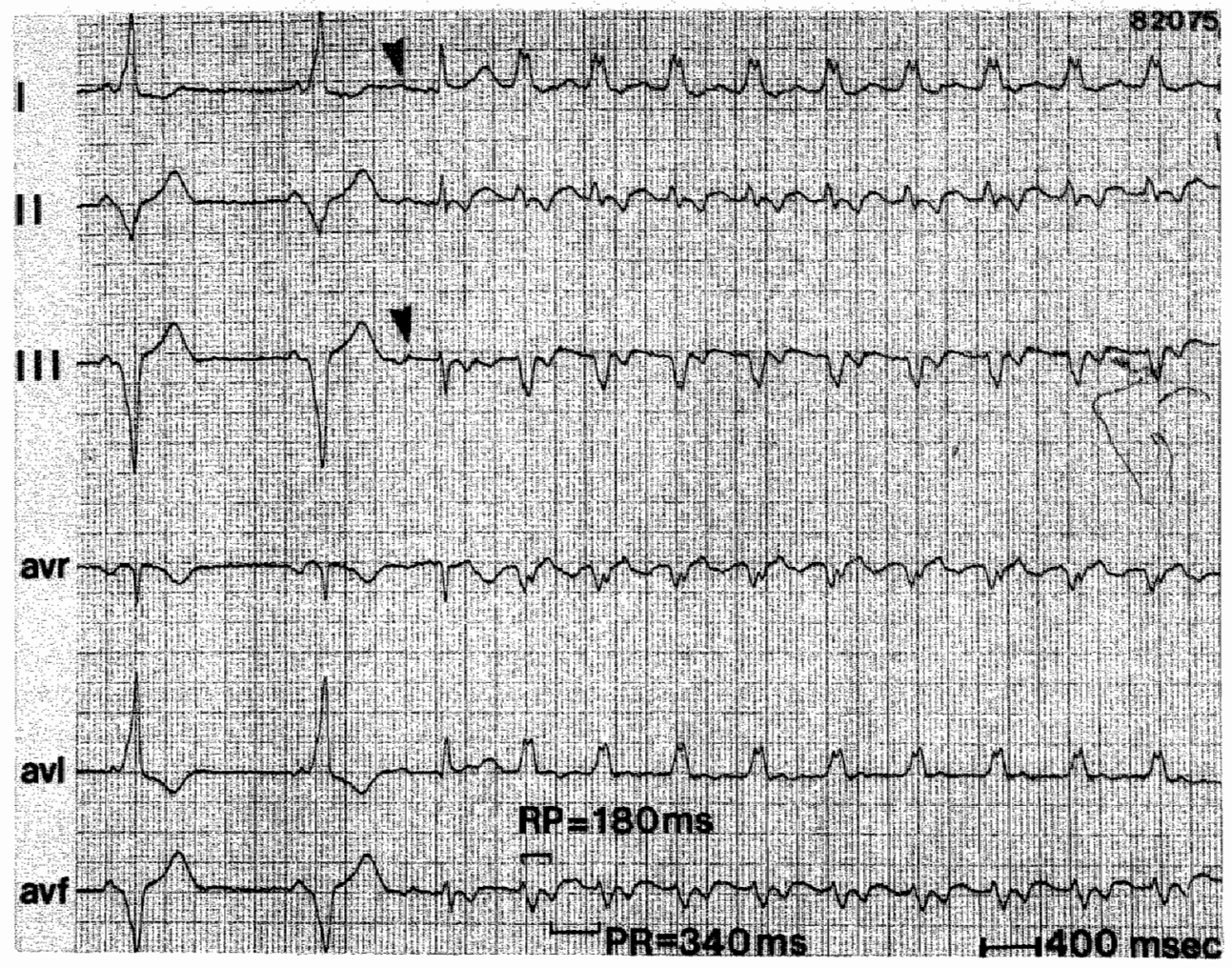

Figure 5. Six simultaneous electrocardlographic leads from a patient with the Wollf-Parkinson-White syndrome and a left postero-septal accessory pathway. The flrst two beats show sinus rhythm. An atrial premature beat (arrow) blocks in the accessory pathway and is conducted to the ventricle with a long PR interval only over the AV node pathway. Retrograde conduction occurs over the accessory pathway followed by orthodromic clrcus movenient tachycardia with left bundle brunch block. The RP interval is $180 \mathrm{~ms}$ and is shorter than the PR interval ( $340 \mathrm{~ms})$.

In orthodromic circus movement tachycardia, ventricular activation occurs by way of the AV node-His-Purkinje system only. The GRS complex is normal. Bundle branch block may occur and can be the result from a variety of mechanisms. This will lead to a wide QRS complex with the typical features of aberrant conduction (56).

During orthodromic circus movement tachycardia, the RP interval is usually shorter than the PR interval when the pathway is of the "fast" type (most common) (fig. 5). The RP interval is longer than the PR interval when during orthodromic tachycardia retrogradely an accessory pathway with long conduction times is used (57) (fig. 6). This type of accessory pathway is usually septally located, does not conduct anterogradely during sinus rhythm 


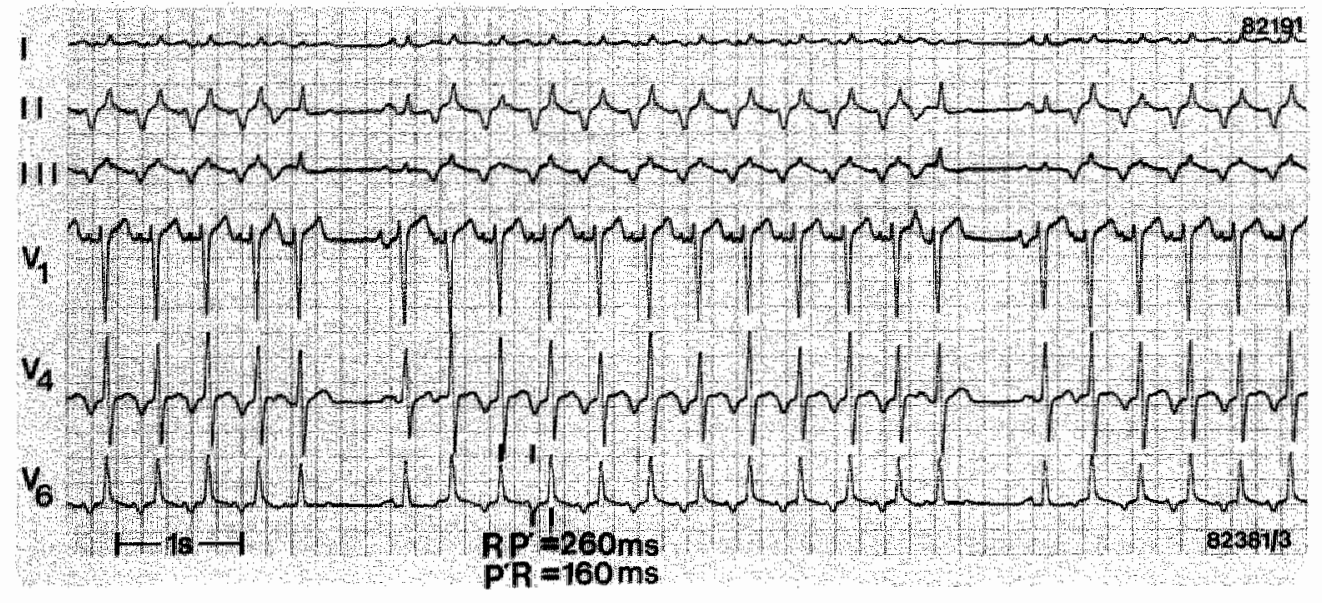

Figure 6. Stx simultaneous electrocardiographic leads from a patient with incessant supraventricular tachycardia caused by a retrogradely conducting accessory pathway with long conduction times. The RP interval is $260 \mathrm{~ms}$ and the PR $160 \mathrm{~ms}$. Orthodromic circus movement tachycardla is interrupted twice by an atrial premature beat. The first beat following termination of tachycardia is a stnus beat after which tachycardia initiates spontaneously.

(when atrio-ventricular conduction over the normal pathway is intact) and causes the "incessant" or permanent tachycardia as described by Coumel (25).

The value of the relation of the RP/PR interval during tachycardia to distinguish between different mechanisms of tachycardia is relative. Most. patients with a fast accessory pathway have indeed a shorter RP than PR interval during orthodromic circus movement tachycardia. However, if atrioventricular nodal conduction time shortens while the RP interval remains the same, the RP interval can become longer than the PR interval. That is particularly the case in children and is responsible for the poor value of the $\mathrm{RP} / \mathrm{PR}$ relation to determine the mechanism of a supraventricular tachycardia in children. Therefore, it is much better to measure the RP interval on the 12 lead electrocardiogram. This is usually in between 120 to $180 \mathrm{~ms}$ during an orthodromic circus movement tachycardia using an accessory pathway with fast conduction times and above $200 \mathrm{~ms}$ in accessory pathways with long conduction times. 

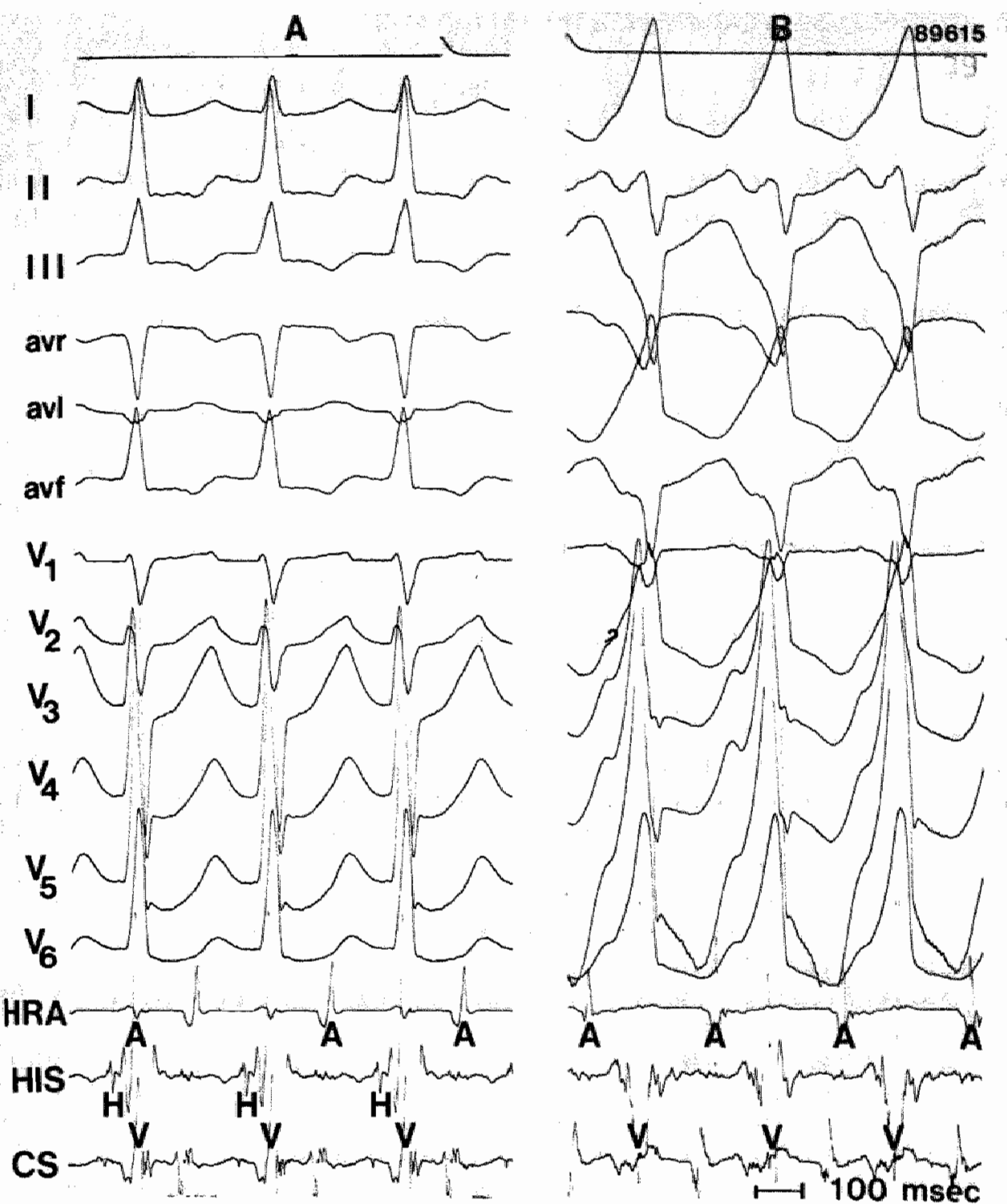

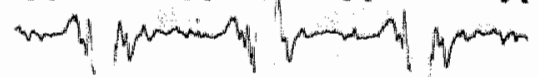

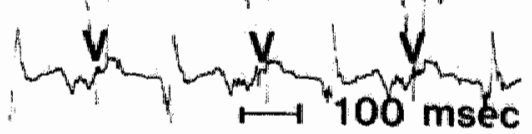

Figure 7. Panel A shows orthodromic circus movement tachycardia with activation of the bundle of His before the gRS complex. Panel B shows antidromic circus movement tachycardia with a wide $\mathrm{QRS}$ complex (140 msec). In each panel. 12 electrocardlographic leads are shown with 3 intracardiac leads, high right atrium (RA), bundle of His (HIS) and coronary sinus ICS). 


\section{Antidromic circus movement tachycardia}

A second type of tachycardia in patients with atrioventricular accessory pathways is antidromic circus movement tachycardia. This tachycardia utilizes the accessary pathway in the anterograde direction and the AV node or a second accessory pathway as the retrograde limb $(56,58)$ (fig. 7). This type of tachycardia occurs less frequently than orthodromic circus movement tachycardia.

In antidromic tachycardia, ventricular activation occurs solely via the accessory pathway, resulting in a wide gRS complex with maximal preexcitation.

There is a wide spectrum of regular tachycardias with wide QRS complexes in patients with atrio-ventricular accessory pathways (56). Programmed electrical stimulation with intracardiac recordings is usually necessary to avoid misdiagnosis. The difficulties to recognize the retrograde $P$ wave during a wide QRS complex tachycardia make the 12-lead electrocardiogram frequently unreliable in diagnosing the exact tachycardia pathways.

\section{Atrial fibrillation and atrial flutter}

The incidence of atrial fibrillation in patients with an accessory pathway varies from $11.5 \%$ to $32 \%$ in different series (59). It is not clear whether the incidence of atrial fibrillation in patients with an accessory pathway is higher than in the general population or that the arrhythmia in the presence of an accessory pathway leads to more serious consequences and therefore earlier and easier recognition.

The accessory pathway may play a role in the initiation of this arrhythmia. As pointed out by Wellens $(60)$, atrial fibrillation may be initiated by an atrial premature beat, by a retrogradely conducted premature ventricular beat, by deterioration of an orthodromic circus movement tachycardia and even by rapid pacing of the ventricle because of the ventriculo-atrial conduction.

The incidence of atrial fibrillation in patients with overt preexcitation is higher than in patients with a "concealed" accessory pathway (61). It seems therefore that the electrophysiologic properties of the accessory pathway may be important to determine whether atrial fibrillation will occur.

The ventricular rate during atrial fibrillation in patients with an accessory pathway is primarily determined by the refractory period of the accessory pathway but other factors like effective refractory period of the ventricle and adrenergic tone by changing the properties of the accessory pathway and ventricle do play a role (62). An increase in sympathetic tone, as during exercise, may cause the accessory pathway to conduct more impulses to the ventricle. If conduction during atrial fibrillation occurs over an accessory pathway with a very short refractory period, the ventricular rate can become so high that degeneration into ventricular fibrillation occurs (27). 


\section{6}
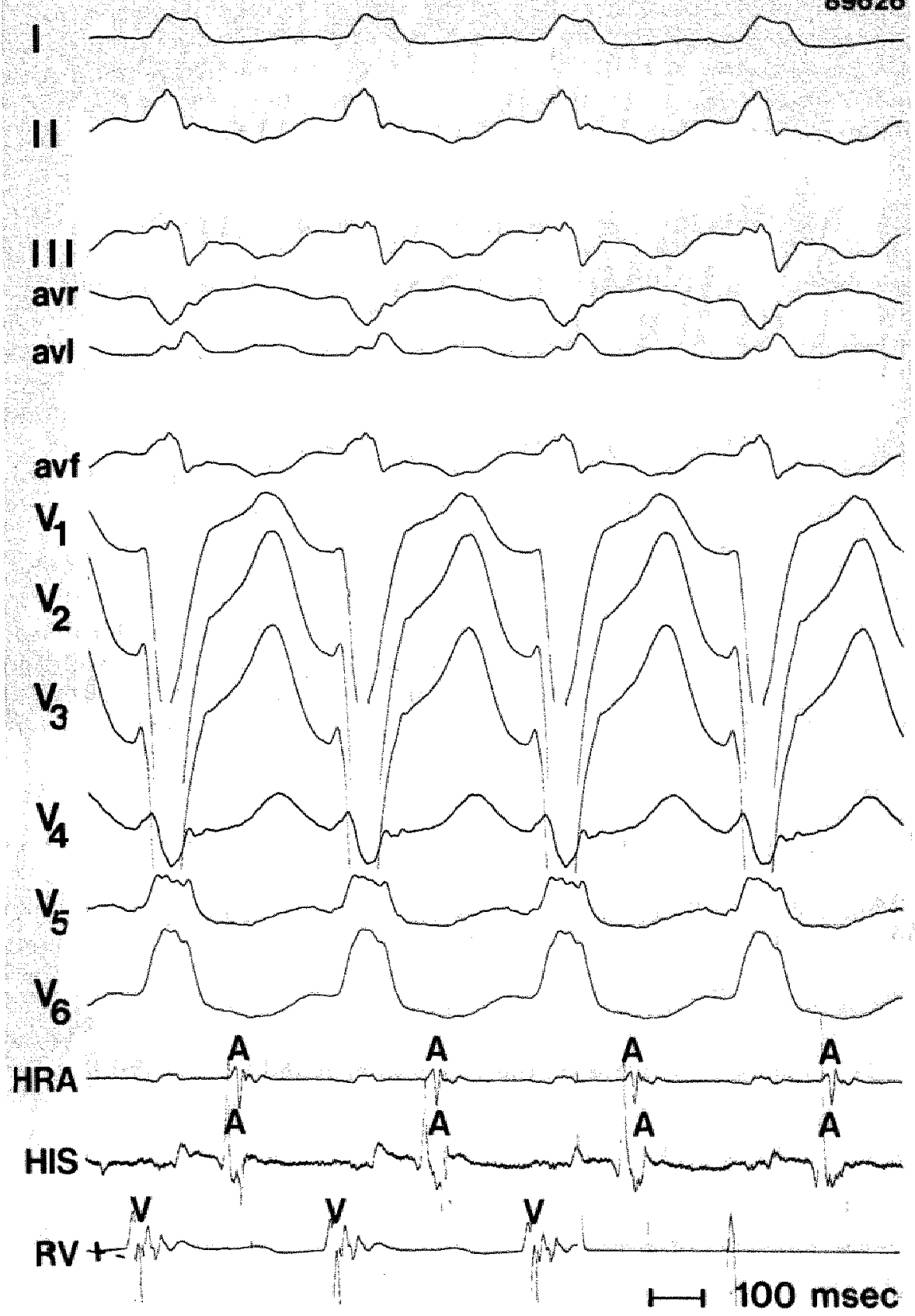

Figure 8. Example of a circus movement tachycardia with left bundle branch block morphology using anterogradely a nodoventricular accessory pathway. The A-V interval is longer than the $\mathrm{V}$-A interval. Twelve electrocardiographic leads are shown and 3 intracardiac leads, high right atrium (RA), bundle of His (HIS) and right ventricle (RV). 
Spontaneous atrial flutter in patients with an accessory pathway is rare (63). During electrophysiological study, however, it is frequently possible to induce atrial flutter. One-to-one conduction over the accessory pathway may cause diagnostic problems such as the differential diagnosis with antidromic circus movement tachycardia and ventricular tachycardia.

\section{Circus movement tachycardia using a Mahalm fiber}

A variety of arrhythmias have been described in patients with nodoventricular accessory pathways. The fiber may participate as a component of a tachycardia circuit, where anterograde conduction occurs over the nodoventricular fiber and retrograde conduction is via the His-Purkinje- AV node $(19,55)$. Alternatively, the fiber may function as an "innocent bystander" during AV nodal tachycardia, atrial flutter or atrial fibrillation (64).

Invasive electrophysiological study is necessary to document the presence of a nodoventricular connection and its participation in the observed arrhythmias (43).

Patients with nodoventricular pathways have tachycardias with left bundle branch block morphology resulting from preexcitation of the right ventricle via the nodo-ventricular fiber (43) (fig. 8). Atrioventricular dissociation during tachycardia provides the diagnostic clue of a nodo-ventricular accessory pathway. This is, however, a rare observation (65). Recent studies suggest that nodo-ventricular fiber may in fact be an accessory atrio-ventricular pathway with long anterograde conduction times (44-47).

\section{Ventricular fibrillation}

Ventricular fibrillation is the most serious arrhythmia in patients with the Wolff-Parkinson-White syndrome $(27,47)$. Although the exact incidence of this complication in this population remains unknown it is likely to be low $(66,67)$.

Several studies have recognized that the risk of ventricular fibrillation in the Wolff-Parkinson-White syndrome is primarily determined by the occurrence of atrial fibrillation in the presence of a very short anterograde refractory period of one or more accessory pathways $(27,47)$ (fig. 9). 


\section{A}

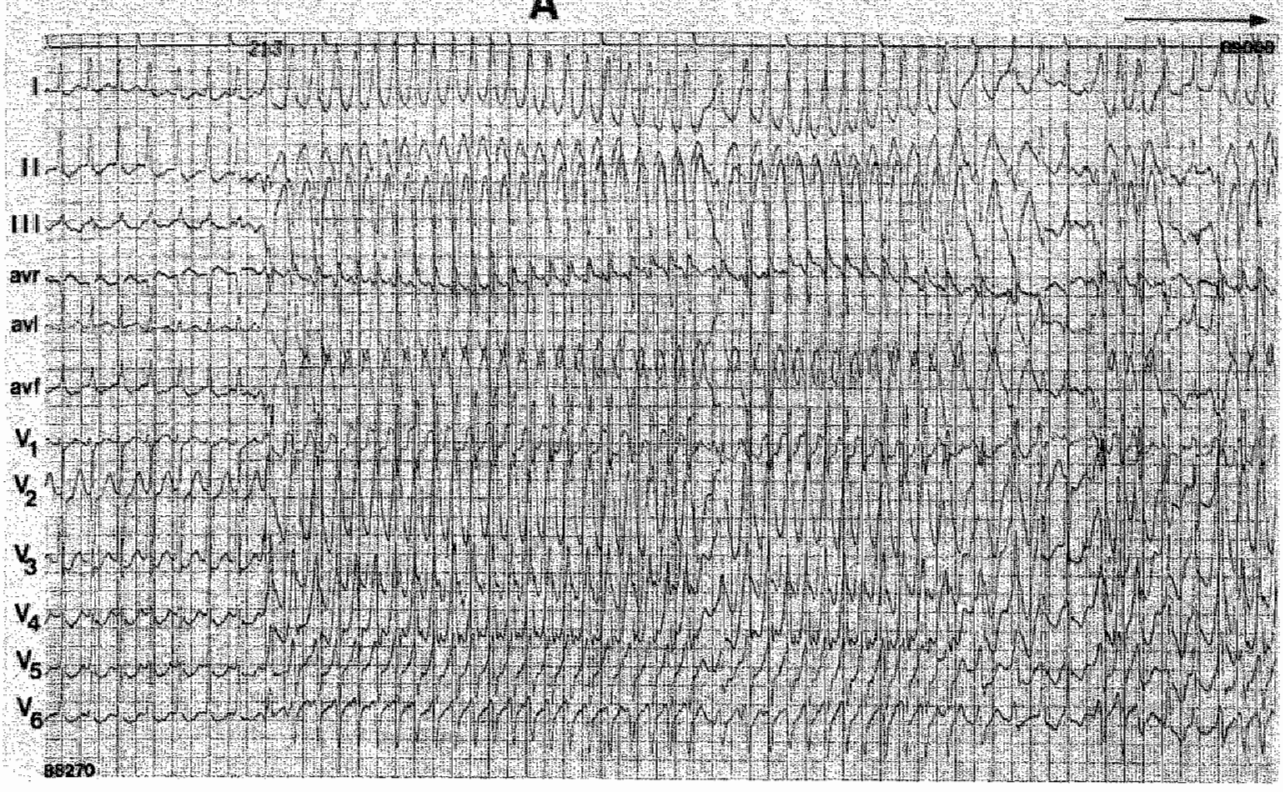

\section{B}

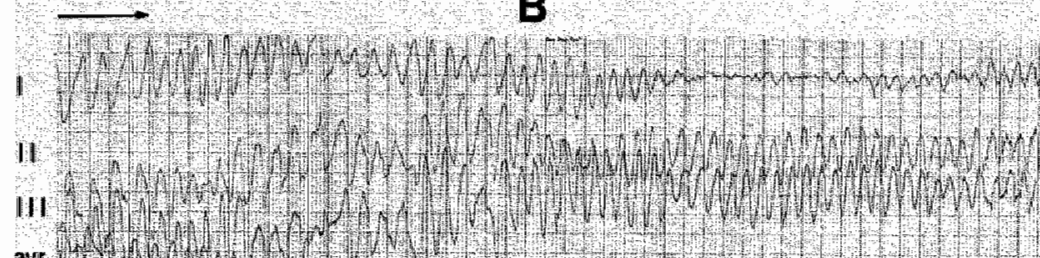

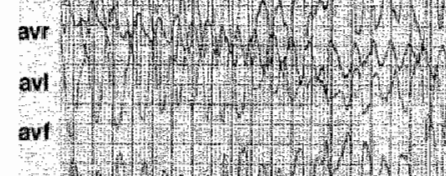

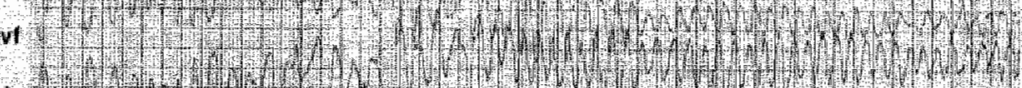

$v_{1}$

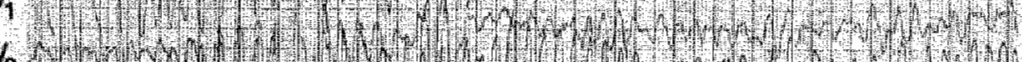
$v_{2}$ W $v_{3}$ r. 1. $\mathrm{v}_{4}$ w $\mathrm{v}_{\mathrm{s}}$ (1)

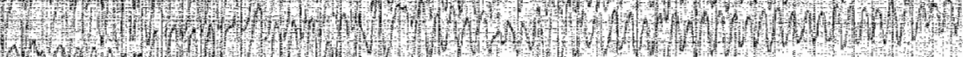
3a27.

$4400 \mathrm{mgec}$

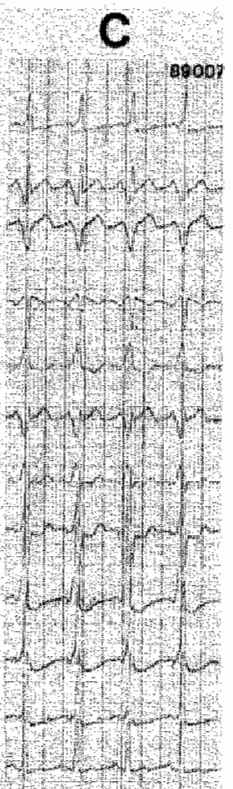

+1 400 mingetc

Figure 9. Twelve lead electrocardiogram showing during orthodromic circus movernent tachycardia the development of atrial fibrillation (upper panel) degenerating into ventricular fibritlation (bottom panel). Both recordings are continuous. The electrocardlogram of the same patient during sinus rhythm is shown in panel $\mathrm{C}$. 


\section{LOCALIZATION OF THE ACCESSORY PATHWAY ON THE 12 LEAD ELECTROCARDIOGRAM}

\section{During sinus rhythm}

Localization of the site of the accessory pathway is not difficult in the Wolff-Parkinson-White syndrome when preexcitation is evident in the electrocardiogram during sinus rhythm (1,67-70). Accurate localization of the accessory pathway when the preexcitation is minimal is usually impossible (1).

Different authors have studied the value of the polarity of the delta wave (first $40 \mathrm{~ms}$ ) on the 12 lead ECG during sinus rhythm to localize the accessory pathway. These data have usually been correlated with the localization of the accessory pathway by epicardial mapping during surgery (68-70) (table II).

Table II. The polarity of delta wave in the different possible localizations of accessory atrio-ventricular pathways.

\begin{tabular}{lllll}
\hline LEADS & LL & PS & RL & AS \\
\hline I & -1 & + & + & + \\
II & + & $-1+$ & + & + \\
III & + & - & $+1-$ & + \\
aVL & - & + & + & + \\
aVF & + & - & + & + \\
V1 & + & +-1 & -1 & - \\
V2 & + & + & -1 & - \\
V6 & $-1+$ & $1-+$ & + & +
\end{tabular}

Abbreviations: $\mathrm{Ll}=$ = left lateral; $\mathrm{PS}=$ postero septal; $\mathrm{RL}=$ right lateral; $\mathrm{AS}=$ anteroseptal; $1=$ polarity of delta wave isoelectric; - = polarity of delta wave negattve; + = polarity of delta wave posttive. From reference 39.

For the purpose of localization of the accessory pathway, it is important to have an electrocardiogram showing sufficient preexcitation, and to obtain several electrocardiographic simultaneous leads to identify isoelectric portions of the delta wave (fig. 10-13).

Reddy and Schamroth (71) recently described the importance of the GRS axis in the frontal plane to localize the site of implantation of accessory atrioventricular pathways. The mechanisms leading to a different axis of the QRS complex following AV conduction over accessory pathway are simple: Normal ventricular activation occurs transversely and synchronously through the free wall of both ventricles, from endocardial to epicardial surfaces. 


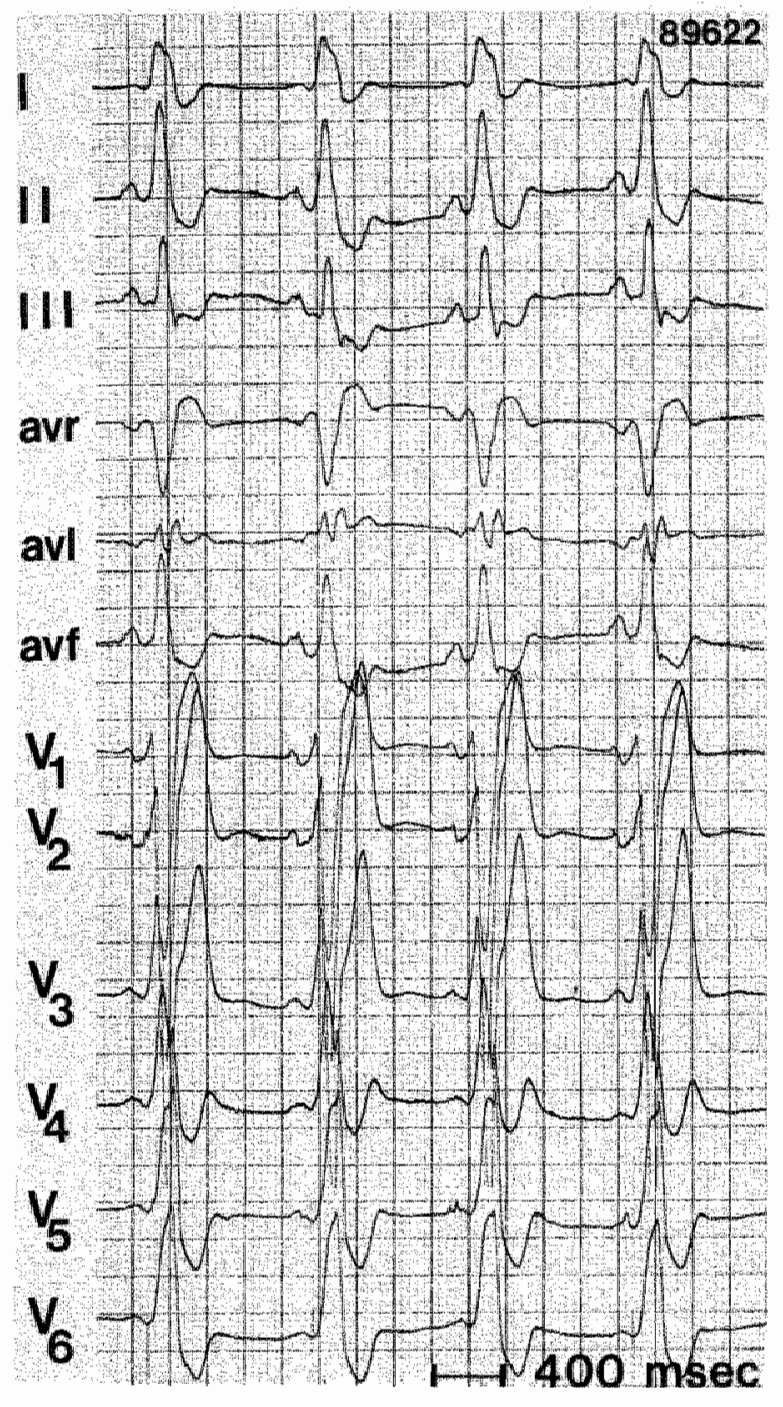

Figure 10. Twelve lead electrocardiogram during sinus rhythm of a pattent with preexcitation caused by an anteroseptal accessory pathway. The delta wave is positive in leads I, II, III, aVL, aVF and V1. The gRS axis in the frontal plane is $+60^{\circ}$.

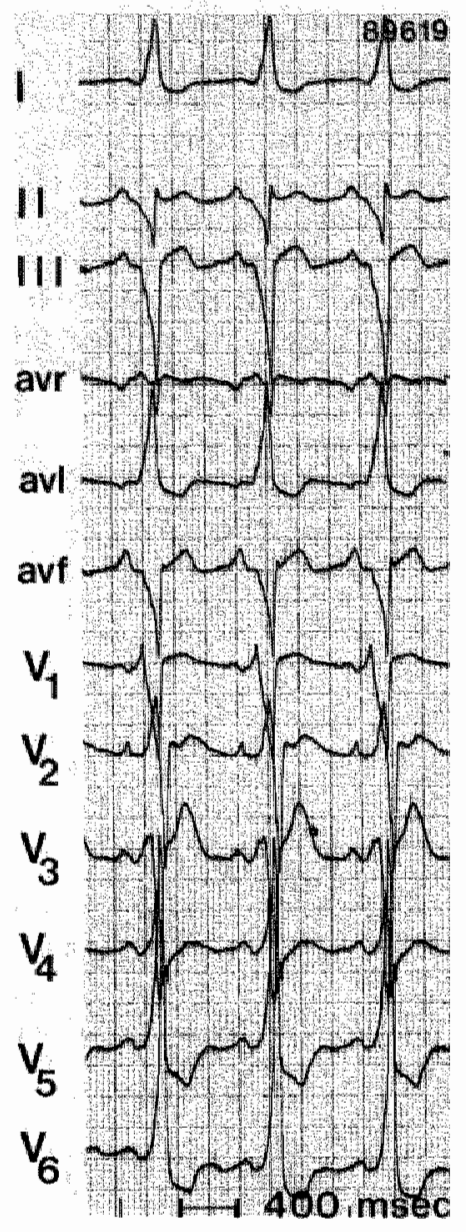

Figure 11. Twelve lead electrocardiogran of a patient with a posteroseptal accessory pathway. The delta wave is posituve in leads $I_{*}$ aVL and $V 1$, negative in leads II, III and aVF. The gRS axis in the frontal plane is $-60^{\circ}$. 
In the Wolff-Parkinson-White syndrome the area where the accessory pathway enters the ventricle is excited before arrival of the normal impulse. The direction of excitation in the preexcited area is therefore changed, disturbing the normal balance of electrical forces. A right sided accessory pathway, preempts the right free wall forces, resulting in a dominant role of the forces leading to deviation of the axis of the QRS complex to the left. The same mechanism explains the different axis observed in different locations of accessory pathways. Each site of insertion of an accessory pathway will result in a different axis of the QRS complex (fig. 14).

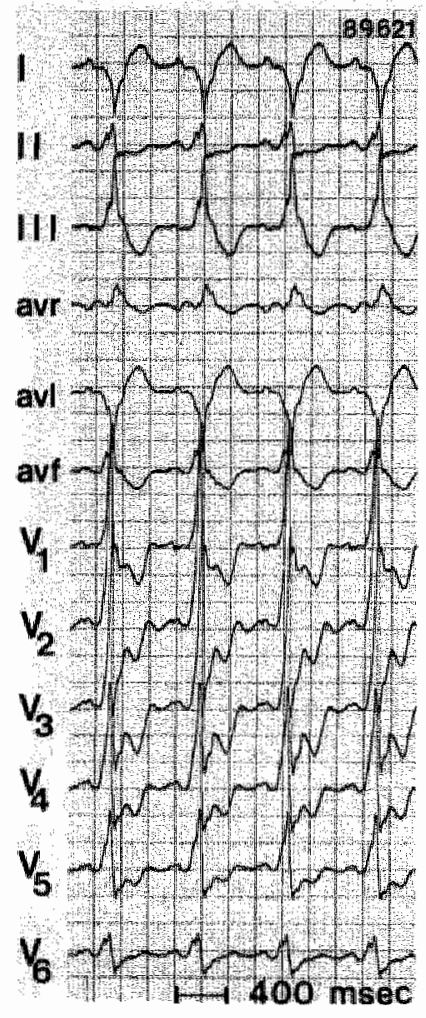

Figure 12. Electrocardiogram of a pattent with a lleft lateral accessory pathway. The delta wave is positive in leads II, III, aVF and V1, negative in leads II and aVL. The QRS axis in the frontal plane is $+120^{\circ}$.
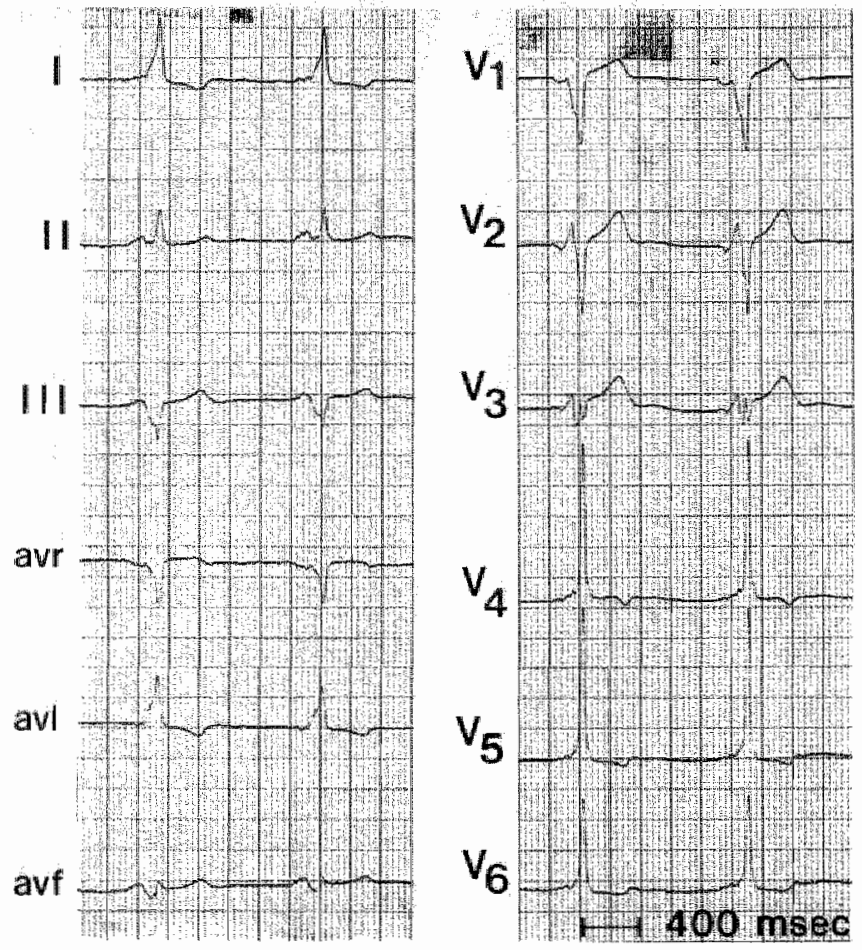

Figure 13. Electrocardiogram of a patient with a right lateral accessory pathway. The delta wave is positive in leads $I$ and aVL, negative in leads III, aVF and V1. The gRS axis in the frontal plane is $-10^{\circ}$. 

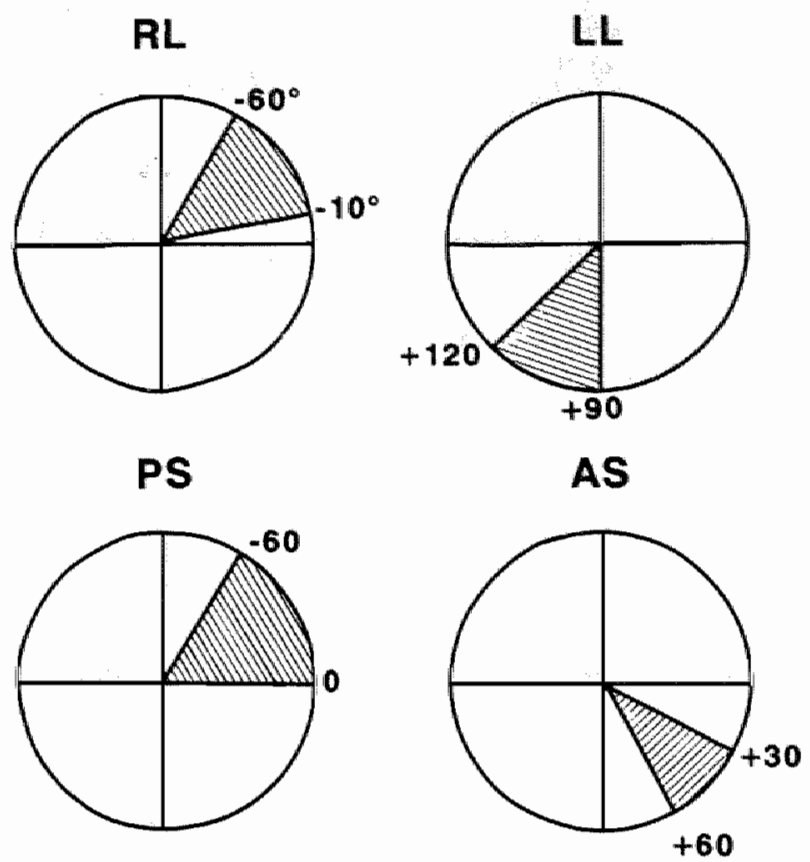

Figure 14. Diagrams illustrating the $Q R S$ axis in the frontal plane in the different locations of accessory pathways. $\mathrm{RL}=$ right lateral ${ }_{n} \mathrm{LL}=$ left lateral; $\mathrm{PS}=$ posteroseptal; AS = anteroseptal. ladapted from Reddy and Schamroth (71).

\section{During orthodromic tachycardia}

Examination of the electrocardiogram during tachycardia provides important additional information to localize the site of an accessory pathway (72). During orthodromic circus movement tachycardia the atria are retrogradely activated over the accessory pathway. That results in a specific axis, morphology and duration of the P wave on the 12 lead electrocardiogram depending upon the localization of the atrial insertion of the accessory pathway (56,72,73).

It has been reported that in patients with orthodromic circus movement tachycardia utilizing a left lateral accessory pathway, the $P$ wave is usually negative in leads I and aVL (fig. 15). In contrast, when orthodromic circus movement tachycardia utilizes a right sided accessory pathway, the $\mathrm{P}$ wave is usually positive in those leads (fig. 16). In inferoseptal accessory pathways the $\mathrm{P}$ wave is negative in leads II, III and aVF (fig. 5). Table III shows the morphologies of the retrograde $\mathrm{P}$ wave in different localizations of the accessory pathway. 


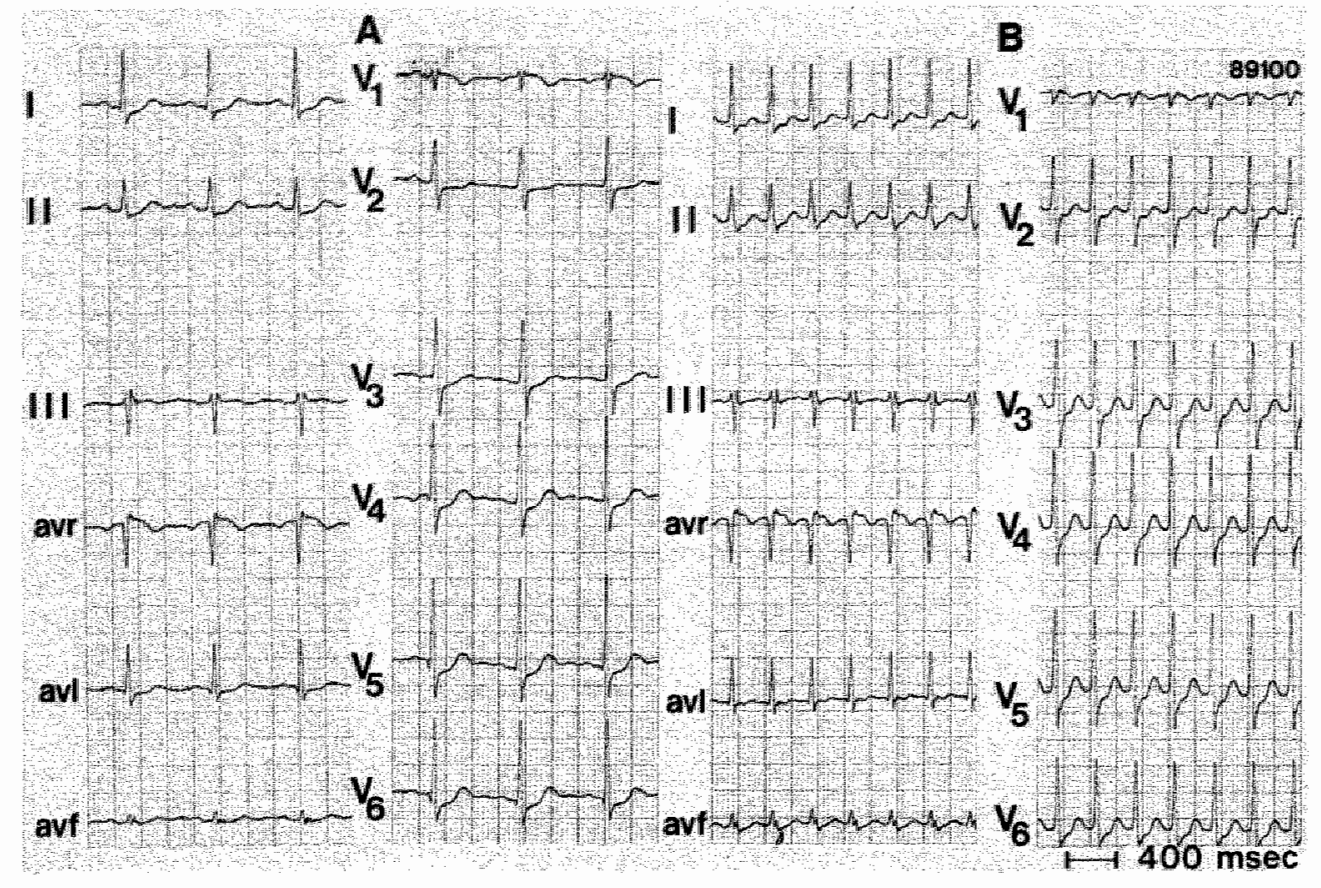

FIgure 15. A patient with a left lateral concealed accessory atrioventricular pathway. In the left panel the electrocardlogram during sinus rhythm shows a normal PR interval and no preexcitation. In the right panel orthodromic circus movement tachycardia is present with a $P$ wave $140 \mathrm{~ms}$ after the onset of the gRS. The $P$ wave is negative in leads $I$, aVL which is very suggestive of a left lateral accessory pathway.

During orthodromic circus movement tachycardia using a left or right lateral accessory pathway, the duration of the P wave will be longer than in a septally located accessory pathway. That occurs because in septally located accessory pathways the two atria are simultaneously activated, whille they are sequentially activated in right or left sided accessory pathways.

Localization of the accessory pathway by means of the retrograde atrial activation pattern is important in:

a. Confirming that the same accessory pathway is used retrogradely during orthodromic circus movement tachycardia and anterogradely during sinus rhythm.

b. Recognizing the presence of multiple accessory pathways when different pathways are used anterogradely during sinus rhythm, antidromic circus movement tachycardia, or atrial fibrillation and retrogradely during orthodromic circus movement tachycardia (see Chapter V).

c. Identifying the use of a concealed accessory pathway during orthodromic circus movement tachycardia. 


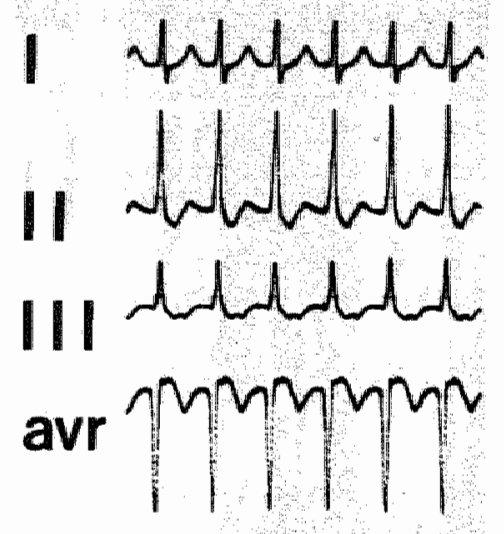

avl ypupupres
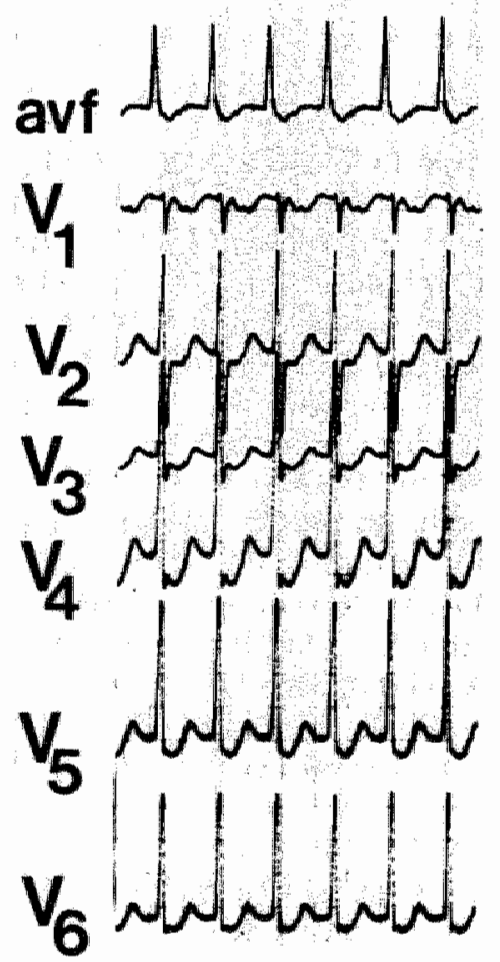

Figure 16. Electrocardiogram during orthodromic circus movement tachycardia, in a pattent with a right sided accessory pathway. The $\mathbb{P}$ wave during ortho dromic tachycardia which is seen $140 \mathrm{~ms}$ after the onset of the GRS and is positive in leads I and aVL and negat ive bimodal in lead III and VI. 
Table Irr. Polarity of the P wave during orthodromic circus movement tachycardia in the different possible localizations of the accessory atrio-ventricular pathways

\begin{tabular}{lllll}
\hline LEADS & LL & PS & RL & AS \\
\hline I & - & 1 & + & +-1 \\
II & + & - & + & + \\
III & ++ & -- & - & + \\
aWL & - & 1 & + & +-1 \\
aVF & + & - & + & + \\
VI & + & $+\mathbb{1}$ & - & -+ \\
\hline
\end{tabular}

Abbrevlations: $\mathrm{LL}=$ left lateral; $\mathrm{PS}=$ postero septal: $\mathrm{RL}=$ right lateral; $\mathrm{AS}=$ anteroseptal; $i=$ polarity of delta wave isoelectric; $-=$ polarity of delta wave negative; + = polarity of delta wave positive.

During orthodromic circus movement tachycardia there are several additional clues to help in localization the accessory pathway:

a. The occurrence of bundle branch block during orthodromic circus movement tachycardia can give additional information to localize the accessory pathway during tachycardia (74). Functional bundle branch block during tachycardia, may result in slowing in rate of the tachycardia, if the tachycardia utilizes an accessory pathway ipsilateral to the bundle branch where conduction block occur (74). The mechanisms leading to slowing of tachycardia are illustrated in figures 17-19. Bundle branch block ipsilateral to the accessory pathway forces the stimulus to follow a longer route and to cross the septum in order to activate the accessory pathway. Transseptal conduction takes $\pm 40 \mathrm{msec}(75)$, and such an increase in ventriculo-atrial conduction time will minimally develop when ipsilateral bundle branch block occurs during orthodromic tachycardia. This prolongation in ventriculo-atrial interval ( $R$-P interval on the surface electrocardiogram) may not lead to a change in cycle length of the tachycardia if the prolongation of the R-P interval is accompanied by a shortenIng of the PR interval (76). Bundle branch block does not affect the ventriculo-atrial conduction time or rate of the tachycardia, in truly septal accessory pathways.

b. Orthodromic tachycardia may have at times an alternation pattern of long RR cycles. This usually indicates alternation between two different anterograde limbs of the reentry circuit. For example, in patients with dual AV nodal pathways and an accessory pathway. orthodromic circus movement tachycardia may utilize alternately the fast and the slow AV nodal pathway as the anterograde limb of the tachycardia circuit (fig. 20,21). 


\section{A}

1 gunana unapa

$11 \mathrm{~h} p \mathrm{pr} p$

$1112 \sqrt{ } \sqrt{ }$

avr worworers

avl hun L

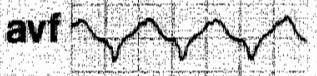

$v_{1} \cap \Omega \cap \Omega$

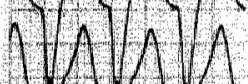
$v_{2}$.

$v_{3}$
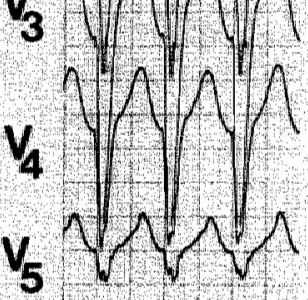

$v_{6}$

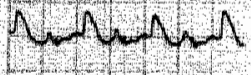

86374
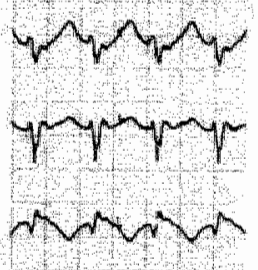

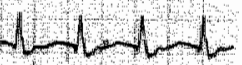

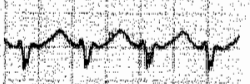

LNand M.M. Mh huppar
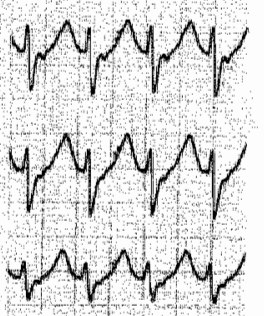

G

$\mathrm{D}$

andul

yrary

yryryey

manas

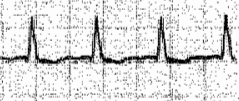

yrury<smiles>CCCC(C)(C)CCC(C)(C)CCC</smiles>

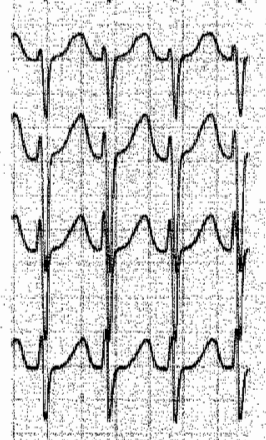

Manpla
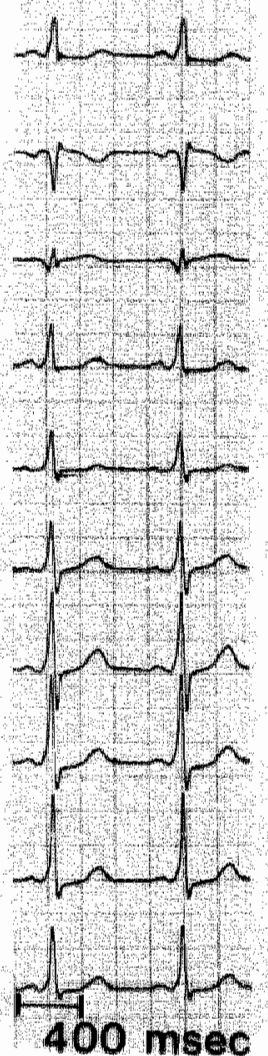

Figure 17. Four electrocardiograms from the same patient having a left sided accessory atrioventricular pathway. In pane1 $\mathrm{D}$, sinus rhythm shows a negattue delta wave in aVL. In panel $\mathrm{C}$, orthodromic circus movement tachycardia with nomal intraventricular conduction is observed. In panel $B$, orthodromic circus movement tachycardia with right bundle branch block is present. Panel A shows orthodromic ctrcus movement tachycardia with left bundle branch block. The cycle length of the tachycardia during right bundle branch block is the same as the tachycardia with normal intraventricular conduction. The cycle length of the tachycardia during left bundle branch block is $40 \mathrm{~ms}$ longer then during non-aberrant conductlon or right bundle branch block. This is typical of a left sided located accessory atrioventricular pathway (see text). 


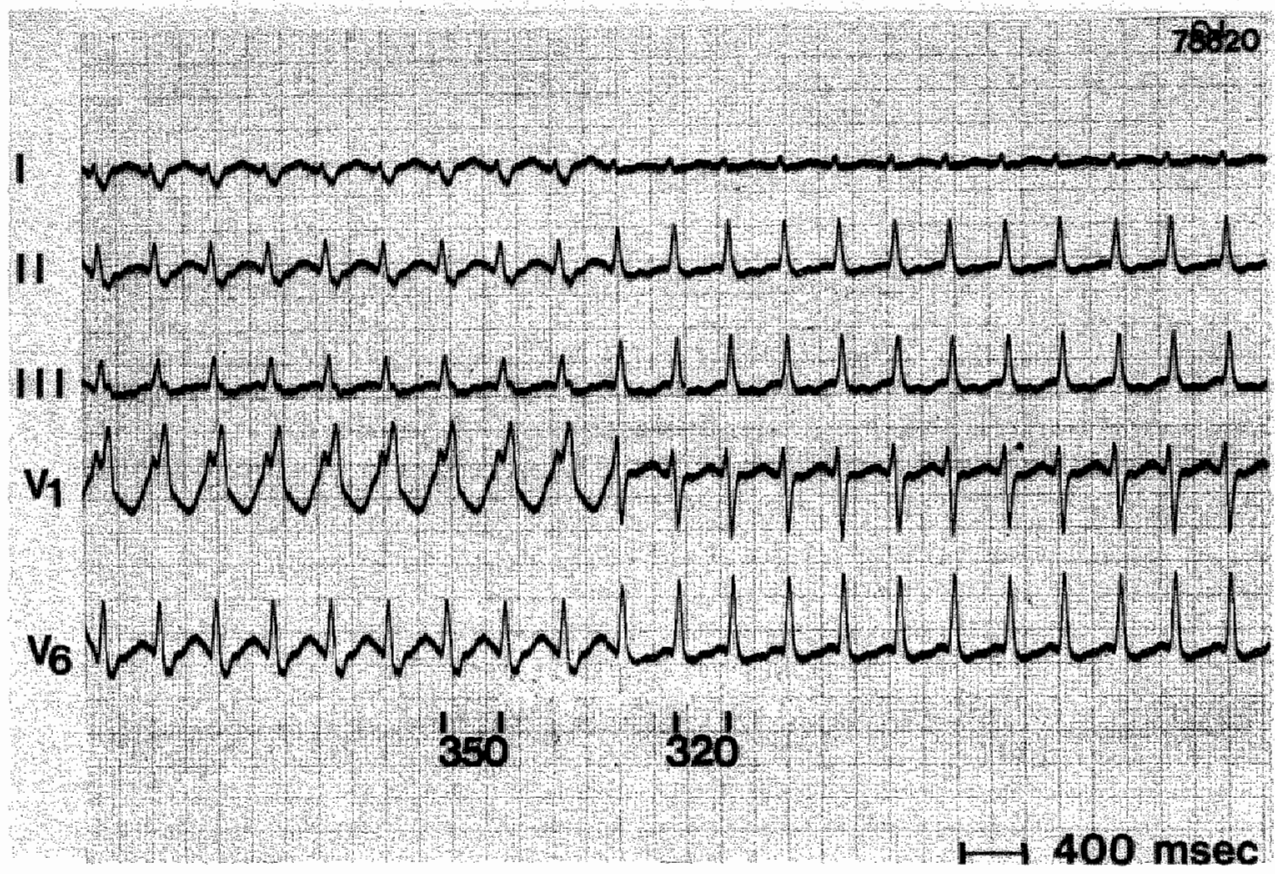

Figure 18. Five simultaneous electrocardiographic leads showing a change from an orthodronite circus novement tachycardla with right bundle branch block aberrant conduction into a tachycardia with non-aberrant conduction. The cycle length of the tachycardla during right bundle branch block is $30 \mathrm{~ms}$ longer than during non-aberrant conduction indicating a right lateral accessory pathway. (see text). 


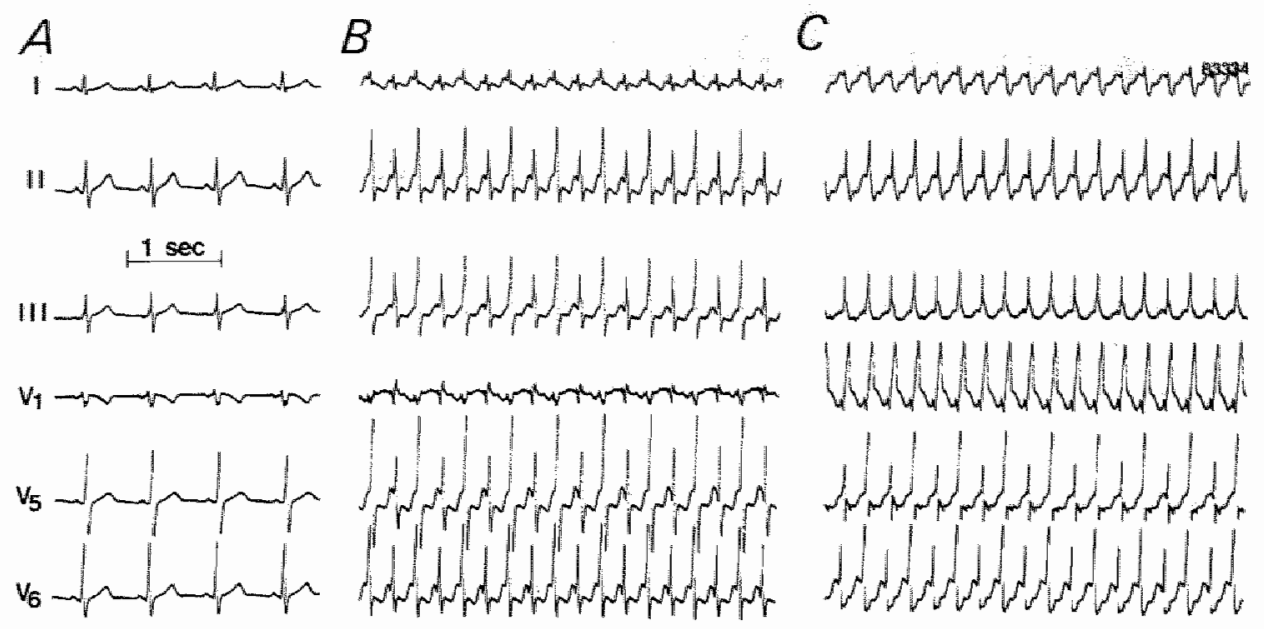

Figure 19. Three recordings from the same pattent. In panel A sinus rhythm without preexcitation is present. In panel B orthodromic circus movement tachycardia with electrical alternans and in panel $\mathrm{C}$ an orthodromic tachycardia with right bundle branch block and electrical alternans are shown. The cycle length does not change with and without bundle branch block, thereby excluding the use of a right sided accessory pathway.

c. A right ventricular premature beat given during a narrow QRS orthodromic circus movement tachycardia using a left lateral accessory pathway in the retrograde direction, will have a longer $\mathrm{V}$-A interval $(\mathrm{R}-\mathrm{P}$ interval in the surface electrocardiogram) than during tachycardia with normal intraventricular conduction (fig. 22). The R-P interval will decrease after a right ventricular premature beat during orthodromic circus movement tachycardia using a right lateral accessory pathway (paradoxical capture) (fig. 23), and will not change in patients with a truly septal accessory pathway (exact capture) (75) (fig. 24).

\section{During antidromic tachycardia}

In the case of this less frequent type of circus movement tachycardia, resulting from conduction over the accessory pathway in the anterograde direction and the AV node or another accessory pathway in the retrograde direction (antidromic circus movement tachycardia). it is easy to localize the anterogradely conducting accessory pathway, because during tachycardia there is maximal preexcitation of the QRS complex.

The incidence of multiple accessory pathways in patients presenting antidromic circus movement tachycardia is high (Chapter III). 


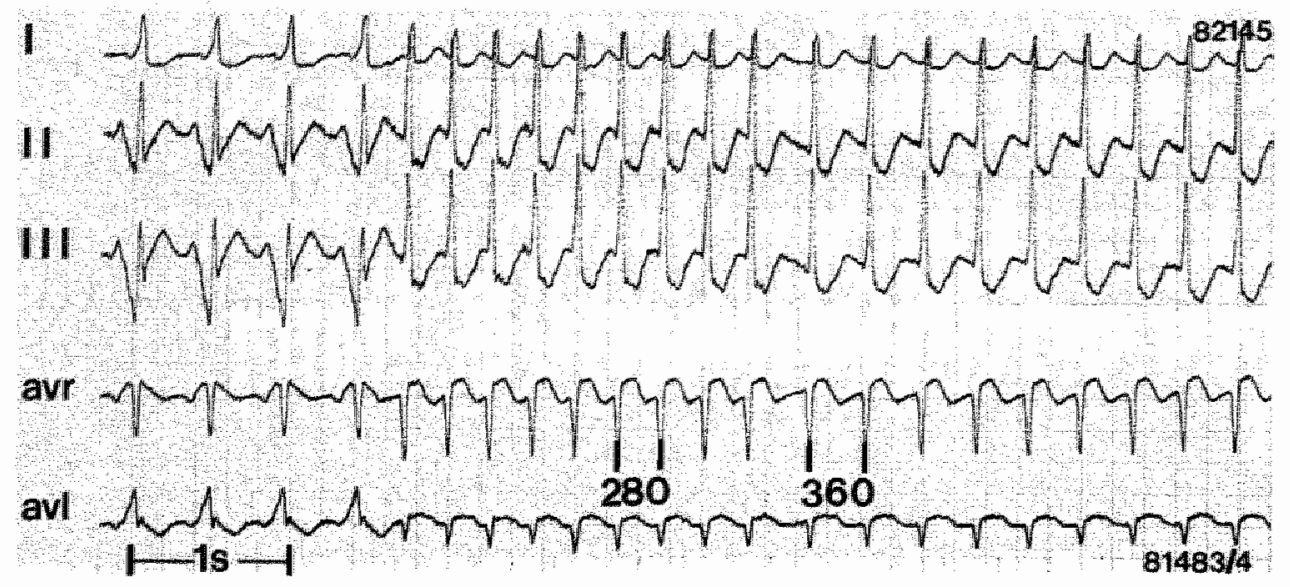

Figure 20. Five simultaneous electrocardiographic leads from a patient with a posteroseptal accessory pathway and dual AV nodal pathways. The first 4 beats are sinus beats and show preexcttation. One atrial premature beat initiates orthodromic circus movement tachycardia. This tachycardila shows a sudden slowing in rate without change in RP interval. The change in cycle length is caused by a shift in anterograde conduction from a fast to a slow intranodal pathways.

The electrophysiologic mechanisms leading to tachycardias in the WolffParkinson-White syndrome have been extensively studied $(1,19)$. However, there are relatively few studies on antidromic circus movement tachycardia $(77,78)$.

\section{During atrial fibrillation}

During atrial fibrillation, three types of $A V$ conduction pattern can be observed:

a. Exclusive conduction over the accessory pathway with a maximally preexcited QRS complex.

b. Exclusive conduction over the normal AV conduction pathway with a normal QRS complex or typical bundle branch block.

c. Fusion complexes resulting from conduction over both (the normal and accessory] pathways.

The ventricular rate during atrial fibrillation is determined by the electrophysiologic properties of both, normal AV conduction system and accessory pathway (60). 

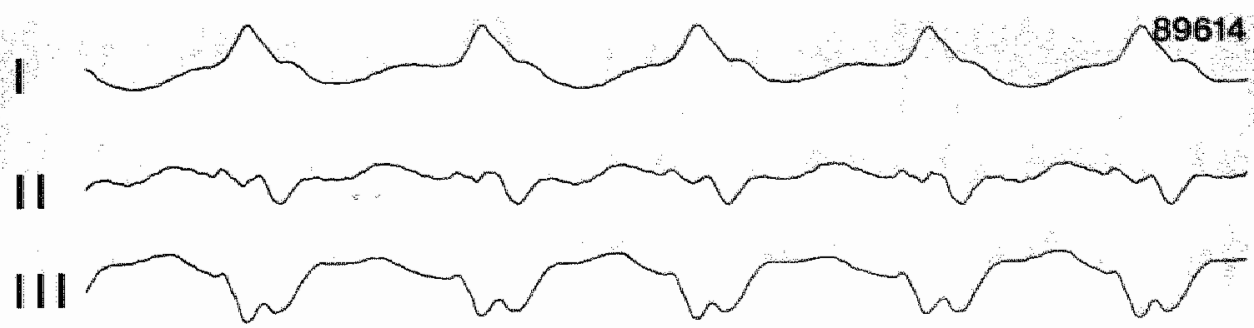

HRA $\rightarrow$ H
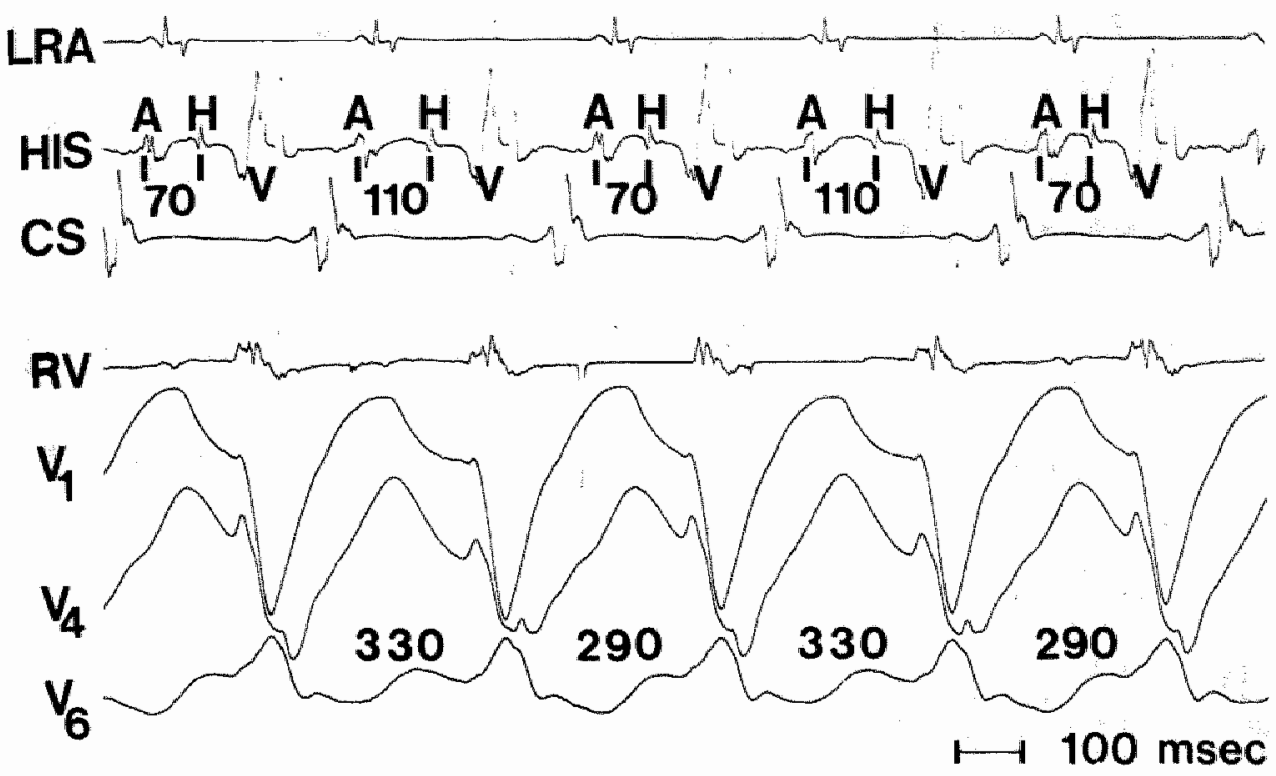

Figure 21. Cycle length alternation by $40 \mathrm{~ms}$ due to a change in the A-H interval (from 110 to $70 \mathrm{~ms}$ ) in a patient with orthodromic circus movement tachycardla with left bundle branch block. Six simultaneous electrocardlographtc leads and five intracardiac leads are shown, high right atrium (HRA), low right atrium (LRA), bundle of His (HIS) and coronary sinus (CS).

The QRS configuration during atrial fibrillation can give important clues to diagnose multiple accessory pathways. When two different accessory pathways capable of anterograde conduction are present, it is very likely to observe in the 12 lead electrocardiogram two different patterns of preexcitation during atrial fibrillation (Chapters V, VI). 

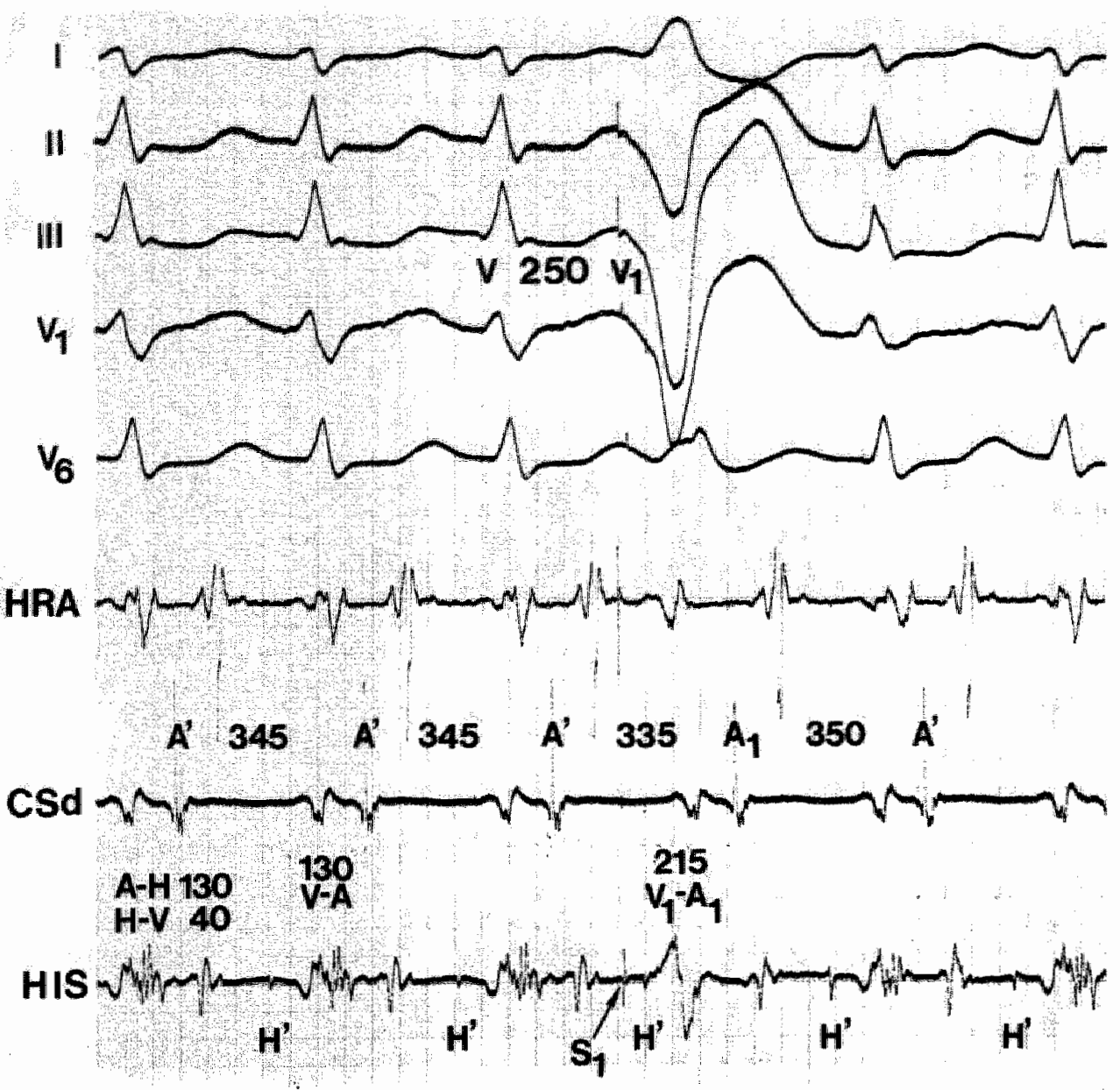

Figure 22. Five simultaneous recorded electrocardiographic leads and 3 intracardiac leads, high right atrim (HRA), distal coronary sinus (CSd) and bundle of His (HIS), showing the effect of a right ventricular aplcal premature beat given during orthodromic circus movement tachycardia. As shown this premature beat given at the time when the bundle of His is refractory. advances atrial activation. The $V$ - A interval of the premature beat increases by 85 ms as compared to the V-A interval during tachycardta. This occurs because of the left lateral locallation of the accessory pathway. 


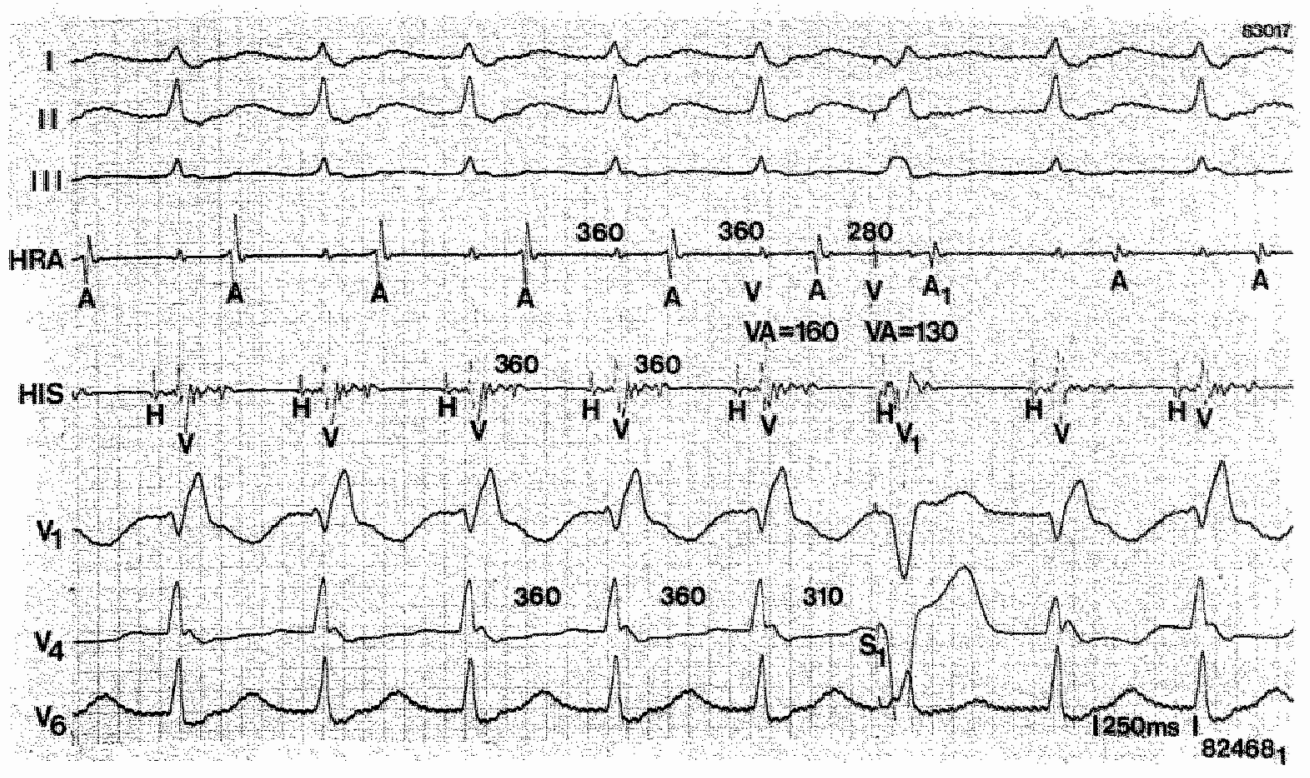

Figure 23. Example of paradoxical capture in a pattent with a right lateral accessory pathway. During orthodromic circus movement tachycardia with a cycle length of 360 msec, a premature beat is given at the right ventricle (S1), at the time when the bundle of His is refractory. Subsequent atrial activation is advanced. The V-A interval following the ventricular premature beat measures $130 \mathrm{~ms}$ as compared to $160 \mathrm{~ms}$ during tachycardia.

\section{MULTIPLE ACCESSORY PATHWAYS}

The existence of multiple accessory pathways in the same patient, was first suggested in 1964 by the electrocardiographic observation of alternating type $A$ and $B$ of preexcitation in the same patient (79). Subsequently, the existence of multiple pathways has been confirmed during electrophysiological study and intraoperative mapping $(77,78)$. The prevalence of multiple accessory pathways ranges between 3.7 and $15 \%$ in different studies $(77.78)$.

Different drugs can demonstrate the presence of multiple accessory pathways on the 12 lead electrocardiogram during sinus rhythm (30) (fig. 25,26).

Failure to recognize the presence of multiple accessory pathways is a common cause for failure of surgical therapy in patients with the WolffParkinson-White syndrome (80) (Chapter VII). Therefore, the presence and exact localization of accessory pathways must be clearly defined during electrophysiological study. As it will be described in Chapters IV and V. however, there are certain clues on the 12 lead electrocardiogram that should make the physician suspicious of the presence of more than one accessory pathway. 


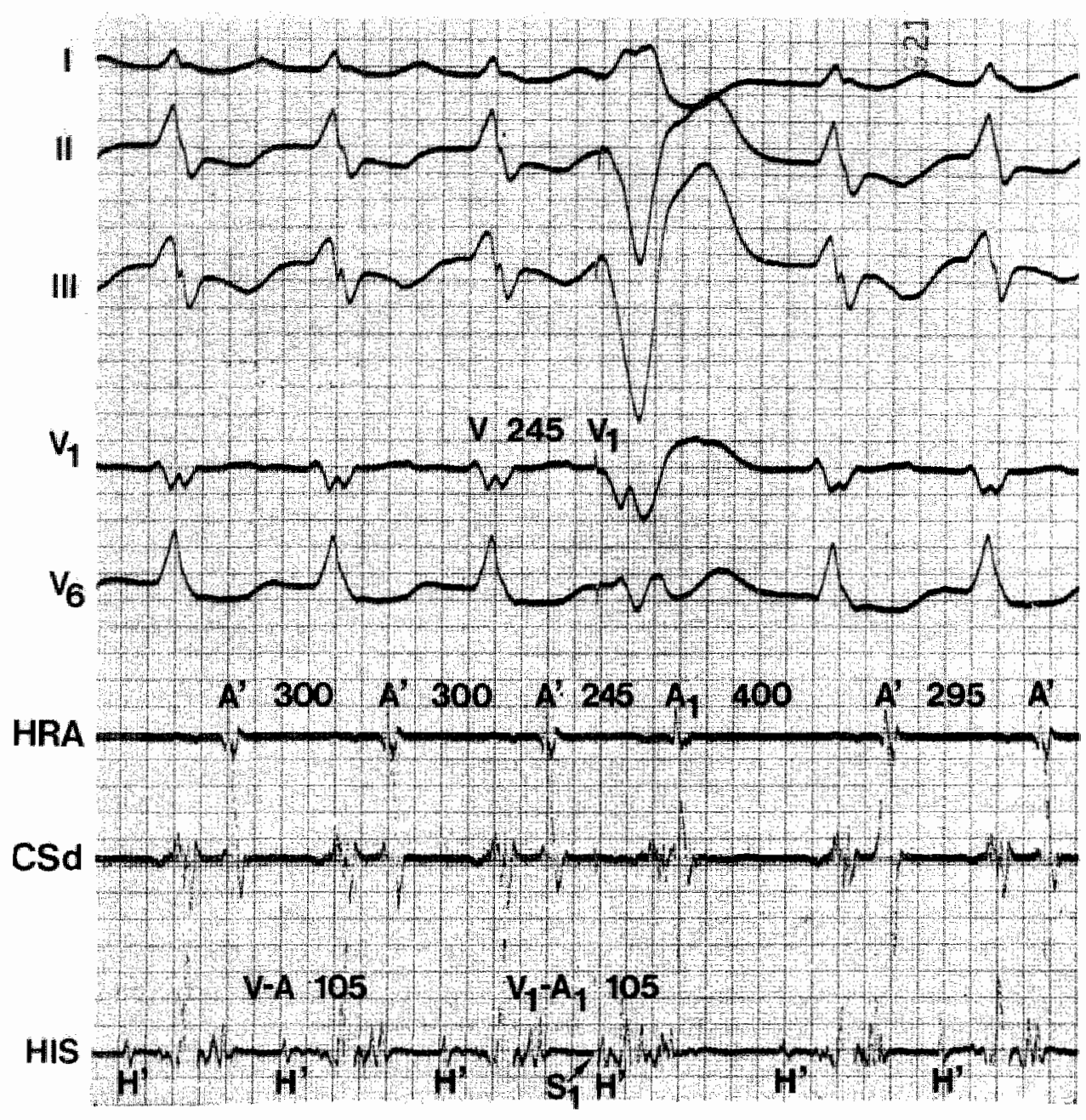

Figure 24. Five surface electrocardiographic leads and 3 intracardiac leads are shown, high right atrium (HRA), distal coronary sinus (CSd) and bundle of His (HIS). As shown, the ventricular premature beat has the same V-A interval as the V-A interval during tachycardia. Behawour of the V-A interval following a right ventricular apical premature beat in septally located accessory pathway (exact capture). 


\section{CLINICAL CONSEgUENCES OF ACCESSORY PATHWAYS}

The clinical significance of accessory pathways depends upon the type of arrhythmias the patient suffers from. This may vary from palpitations, dizziness, syncope or result on sudden cardiac death. In the symptomatic patient these arrhythmias do affect quality of life and may influence prognosis.

Quality of life is affected by the complaints, but also the recognition of preexcitation may result in social, job and insurance problems (1).

If the tachycardia occurs very frequently it may lead to a "tachycardiomyopathy" with progressive dilatation of the heart eventually resulting in congestive heart failure (81).

While a symptomatic patient will suffer from these problems, the asymptomatic patient with the Wolff-Parkinson-White syndrome is not without risks. Asymptomatic patients with the Wolff-Parkinson-White syndrome, may have a very short anterograde refractory period of the accessory pathway, and the first symptom may be sudden cardiac death. In a multicenter study from 7 european centers (67), ventricular fibrillation was the first manifestation of the Wolff-Parkinson-White syndrome in 7 out of 23 patients (30\%).

At present diagnostical and therapeutical possibilities for patients with the Wolff-Parkinson-White syndrome are extensive. By making the correct diagnosis and prescribing the appropriate treatment it is possible to return them to a fully normal life. 
ISOPROTERENOL

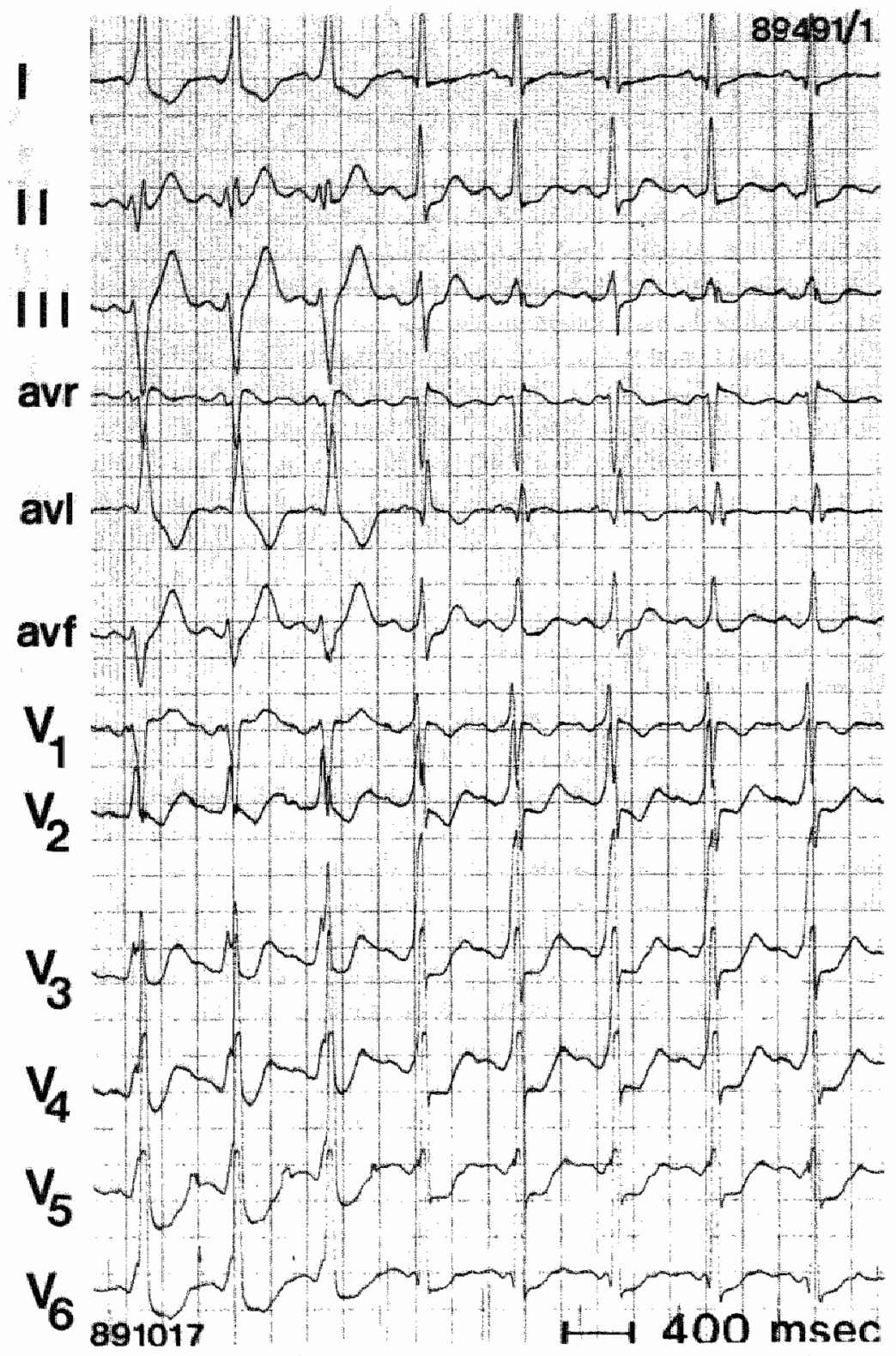

Figure 25. Exposure of two accessory atrioventricular pathways by iso. proterenol in a patient with the Wolf-Parkinson-White syndrome. A change in preexcltation pattern is shown after the third $\mathrm{QRS}$ complex. The figure illustrates how, because of different electrophysiologic properties, the presence of two accessory atriowentricular pathways can be exposed during the administration of isoproterenol. 


\section{PROCAINAMIDE}
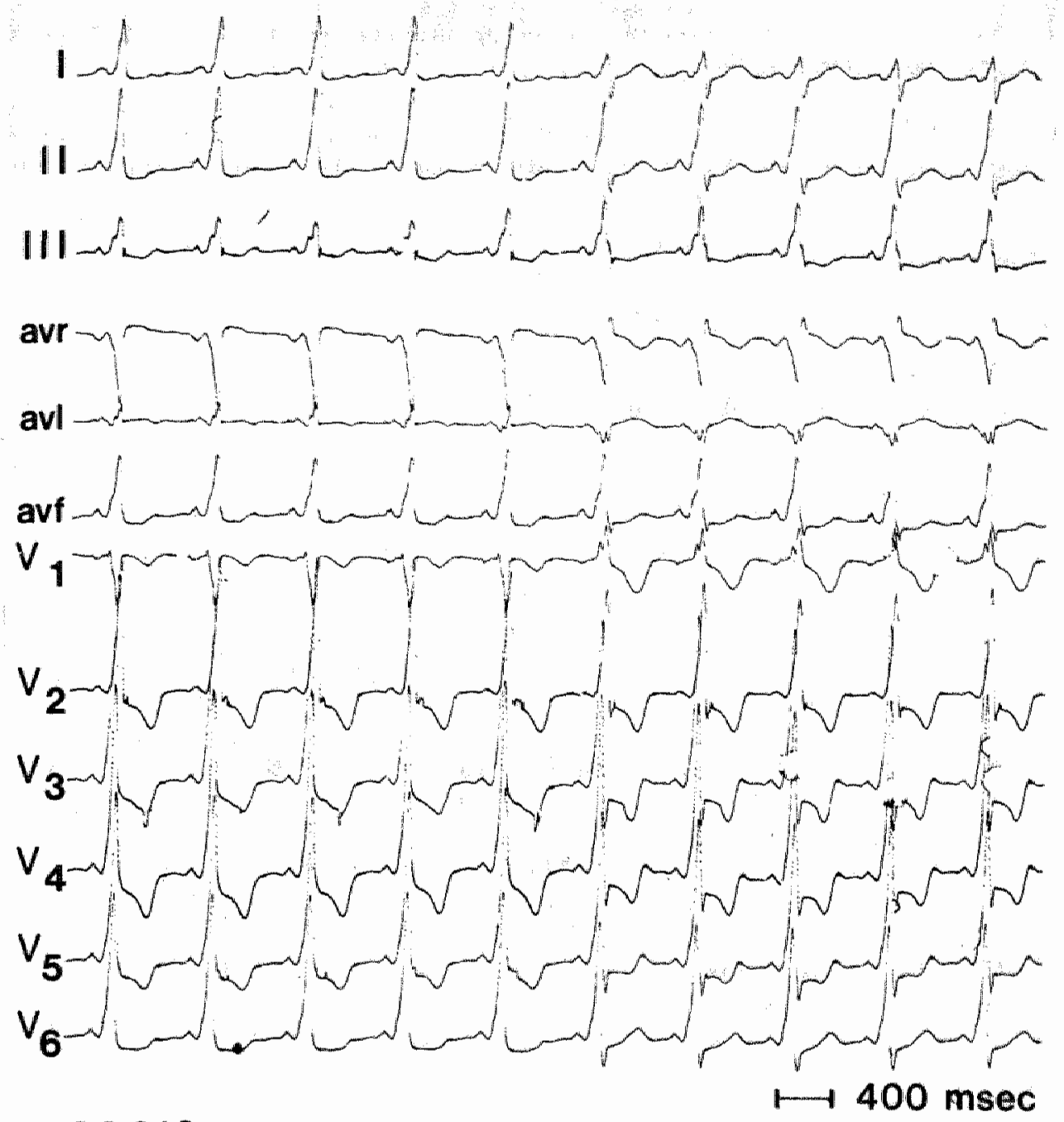

88213

Figure 26. Exposure of two accessory atrioventricular pathways by procatnamide in a pattent with the Wolff-Parkinson-White syndrome. The left part of figure shows a different preexcitation paltern from the right side. 


\section{REFERENCES}

1. Wellens HuJ, Brugada P, Penn OC: The management of preexcitation syndromes. JAMA $257: 2325,1987$.

2. Durrer D, Schoo $L_{;}$Schullenburg FM. Wellens $H_{J} J$ J: The rolle of premature beats in the initiation and termunation of suprawentricular tachycardia in Wolf-Parkinson-White syndrome. Circulation $36: 644,1967$.

3. Wilson FN: A case in which the vagus influenced the form of ventricular complex of the electrocardiogram. Arch Intern Med 16: 1008, 1915.

4. Weed AM: Paroxysmal tachycardla. With reference to momotoplc tachycardia and the role of the extrinsic cardiac nerves. Arch Intern Med 27: 571, 1921.

5. Bach R: Paroxysmal tachycardia of 48 years duration and right bundle branch block. Proc Royal Soc Med 22: 314, 1929.

6. Hamburger WW: Bundle branch block. Four cases of intraventricular blocks showing some Interesting and unusual clinical features. Med Clin North Am. 1.3: 343, 1929.

7. Wollf L. Parkinson J, White PD: Bundle branch block with short P-R interval in healthy young people prone to paroxysmal tachycardia. Am Heart J 5: 685, 1930.

8. Paladino G: Contribuzlone a l'anatomia, istologia e fisiologia del cuore. Moiv Med Chir (Napoli) 8: 428, 1876.

9. Kent AFS: Researches on structure and function of mammalian heart. J Physiol 14: 233, 1876.

10. Mines GR: On circulating excitation in heart muscles and their possible relation to tachycardia and fibrillation. Trans R Soc Can Ser 8: 43, 1914.

11. de Boer S. Herzwhilen, Flimmern, Flattern: Gehaufte extrasystolle, parozysmale tachykardle. Pllugers Arch 187: 193, 1921.

12. Holzman $M$ and Scherf $D$ : Uber elektrokardiogramme mit vorkurzten vorhol Kanner-Distanz and positwen P-Zacken. Z Klin Med $121 ; 404,1932$.

13. Wollerth $\mathrm{CC}$ and Wood $\mathrm{FC}$ : The mechanism of production of short $\mathrm{P} . \mathrm{R}$ intervals and prolonged $\mathrm{QRS}$ complexes in patients with presumably undamaged hearts. Hypothesis of an accessory pathway of auriculoventricular conduction (bundle of Kent]. Am Heart $J$ 8:297. 1933. 
14. Wood FC, Wolferth $\mathrm{CC}$, and Geckele $\mathrm{GD}$. Histological demonstration or accessory muscular connections between auricle and ventricle in a case of short $\mathrm{P}-\mathrm{R}$ interval and prolonged QRS complex. Am Heart J 252: 454. 1943.

15. Ohnell RF: Preexcitation, a cardiac abnomality. Acta Med Scand 152: 74, 1944.

16. Rosenbaum FF, Hecht HH, Wilson FN, Johnson FD: The potential vartation of the thorax and the esophagus in anomalous atrioventricular excitation. Am Heart $₫ 19: 281,1945$.

17. Sodi Pallares D. Soberon J, Thomsen . Fishleder BL, Estandia A: Contribucion al estudio del Sindrome de WPW por las derivaciones intracavitarias. Arch Instit Cardiol Mex $8: 1$. 1948 :

18. Hecht HH: Further observations on the spread of ventitcular excitation. Anomalous atrioventricular excitation. The electrophysiology of the heart. Ann $\mathrm{N} Y$ Acad Sci 65:841. 1957.

19. Wellens HJJ: Electrical stimulation of the heart in the study and treatment of tachycardias. University Park Press, Baltimore, Maryland, 1971.

20. Slama $R$. Coumel $P$, Bouvrain $Y$ : Les syndromes de Wolf-Parkinson-White de type $A$ inapparents ou latent en rhythm sinusal. Arch Mal Coeur 66: 639, 1974.

21. Zipes DP, De Joseph RL, Rothbaum DA: Unususal properties of accessory pathways. Circulation 49: $1200,1974$.

22. Wellens HJJ Durrer D: The role of an accessory atrioventricular pathway in reclprocal tachycardia. Observations in patients with and without the Wolff-Parkinson-White syndrome. Circulation 52: 58, 1978.

23. Gallagher Ju, Sealy WC: The permanent form of junctional reciprocating tachycardia: further elucidation of the underlying mechanism. Eur $J$ Cardiol $8: 413,1978$.

24. Farré J. Ross D, Wiener I, Bar FW, Vanagt EJ, Wellens HJJ: Reciprocal tachycardias ustng accessory pathways with long conduction times. An J Cardiol 44: 1.099, 1979.

25. Coumel $P$, Attuel $P$, Mujica $J$ : Junctional reciprocating tachycardia. The permanent form. In: Re-entrant Arthythmias, Mechanisms and Treatment, edited by Kubertus HE. England. Lancaster, MTP Press; 1977: p 170.

26. Dreifus LS, Haiat R, Watanabe $Y$ ei al; Ventricular fibrillation. a possible mechanism of sudden death in patients with the Wolf-Parkinson-White syndrome. Circulation 43: 520 . 1971

27. Klein GJ. Bashore TM, Seller TD et al: Ventricular fibrillation in the Wolf-Parkinson-White syndrome. N Engl J Med 301: 1080, 1979. 
28. Wellens HuJ. Durrer D: Effect of digitalis on atrio-ventricular conduction and circus movernent tachycardia in patients with the Wolf-Parkinson-White syndrome. Circulation 47: 1229,1973 .

29. Rosen KM, Barwoll C, Ehsari A, Rahimtoola SM." Efect of lidocaine and propranolol on the norrial and anomalous pathways in patients with preexcitation. Am J Cardiol 30: 801. 1972 .

30. Wellens HWJ, Durrer D: Effect of procainamide, quinidine and ajmaline on the WolffParkjnson-White syndrome. Circulation 50; 114, 1974.

31. Cobb FR. Blumenschein SD. Sealy WC, Bolneau JP. Wagner GS, Wallace AG: Successful surgical interruption of the bundle of Kent in a patient with Wolff-Parkinson-White syndrome. Circulation $38: 1018,1968$.

32. Gallagher JJ, Sealy WC, Cox JL. Kasell JH: Results of surgery for pre-excitation in 200 cases. Circulation 64: $146,1981$.

33. Guiraudion GM, Klein GJ, Sharma AD. Milstein S. McLellan DG: Close-Heart technique for the Wolf-Parkinson-White syndrome: Further experdence and potential limitations. Ann Thorac Surg 42: 651, 1986.

34. Morady F. Scheinman MM, Kou WH, Griffin JV, Dick M, Herre J, Kadish AH, Langberg J: Long-term results of catheter ablation of a posteroseptal accessory atrioventricular connection in 48 patients. Circulation $79 ; 1160,1989$

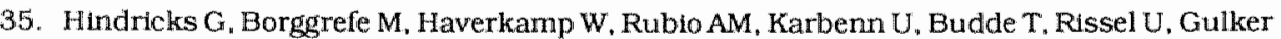
$H$. Brethardt $Q$ : Significant of monttoring catheter tip temperature during radiof requency ablation in patients with supraventricular tachyarthythmias. Am Heart J 10: 165, 1989. (Abstr)

36. Jackman WM, Frtday KJ, Scherlag BJ: Direct endocardial reconding from an accessory pathway: localization of the site of block, effect of antiaarrhythmic drugs, and attemp of non surgical ablation. Circulation 68: 906, 1983.

37. Anderson RH, Becker AE, Brechenmacher C, Davles MJ. Rossi: Ventricular preexcitation: A proposed nomenclature for its substrates. Eur J Cardiol 31: 27, 1975.

38. Becker $A$ G, Anderson RW, Durrer D, Wellens HJJ: The anatomical substrates of WolrParkinson-White syndrome. A clindcopathologic correlation in seven patients. Circulation 57: 870,1978 .

39. Gallagher JJ, Pritchett ELC. Sealy WC, Kasell J, Wallace AG: The preexcitation syndromes. Prog Cardiovase Dis 20: 285, 1978. 
40. Wellens HuJ: Contribution of cardac pacing to our understanding of the Wollf-ParkinsonWhite syndrome. Br Heart J 37: 231. 1975.

41. Critelli G, Gallagher JJ, Thtene G. Perticone F. Coltort F, Rossi L: Electrophysiologic and histopathologic correlations in a case of permanent form of reciprocating tachycardlia, Eur Heart J 6: 130, 1985.

42. Mahaim I, Winston MR: Recherchers d'anatomie comparée et de pathologie experimentale sur les connexions hautes de His-Tawara. Cardiologia 5: 189, 1941.

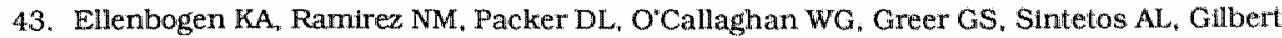
MR, German LD: Accessory nodoventricular (Mahaim) fbers: A clinical review. PACE 9: 868, 1986.

44. Tchou P, Lehmann MH, Jazayeri M, Akhtar M: Atriofascicular connection or a nodoventricular Mahaim fiber? Electrophysiologic elucidation of the pathway and associated reentrant circuit. Circulation 77: 837, 1988.

45. Klein GJ, Gutraudon GM, Kerr CR, Sharma AD, Yee R, Szabo T, Yeung Lalwah JAY. "Nodoventricular" accessory pathway: Evidence for a distinct accessory atrioventricular pathway with atrloventricular node-like properties. J Am Coll Cardiol 11: 1035. 1988.

46. Atiê J, Brugada P, Smeets JLRM, Cruz FES, Penn OCKM, Wellens HJJ: Further suppont of the atrio-ventricular locallzation of so-called "Mahaim Fibers", I Am Coll Cardiol 13: 232. 1989. (Abstr).

47. Kaplan MA, Cohen KL: Ventricular fibrillation in the Woll-Parkinson-White syndrome. Am J Cardio》 24: 259, 1969.

48. James TN: Morphology of the human AV node, with remarks pertinent to tts electrophyslology. Am Heart J 62: 756, 1961.

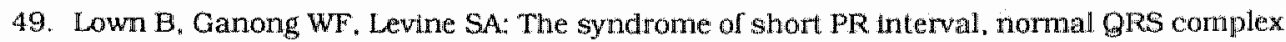
and paroxysmal rapid heart action. Circulation $5: 593,1952$.

50. Brechenmacher C: Atrio-His bundle tracts. Brit Heart J 37: 853, 1975.

51. Chung KY, Walsh TI, Massie E: Wolff-Parkinson-White syndrome. Am Heart J 69: 116. 1965.

52. Kleln GJ, Gulamhusein SS: Intermitent pre-excitation in the Wolf-Parkinson-White syndrome.. Am J Cardiol 52: 292, 1983.

53. Wellens HJJ, Farrë J, Bär FW. The Wolff-Parkinson-White syndrome. In: Cardlac arrhythmias, WJ Mandel (Ed). Lippicott, Pliladelphya, 1980 p 342. 
54. Sung RJ, Gelbatid H, Castellanos A, Aranda JM, Myerburg RI: Clinical and electrophy. slological observations in pattents with concealled accessory bypass tracts. Am $J$ Cariol $40: 839,1977$.

55. Gallagher JJ, Smith WM, Kasell JH et al: Role of Mahaim fibers in cardiac arrhythmias in man. Circulation $64: 176,1981$.

56. Benditt DG, Pritchett ELC. Gallagher JU: Spectrum of regular tachycardias with wide GRS complexes in patients with accessory atrioventricular pathways. Am $J$ Cardiol 42: 828. 1978.

57. Bar FW, Brugada P. Dassen WRM, Wellens HJJ: Differential diagnosis of tachycardia with narrow QRS complex (shorter than 0.12 second). Am J Cardiol 54: 455, 1984.

58. Fontaine $G$, Frank $R$, Coutte $R$, Vedel JP, Grosgogeat $Y$ : Rhythme reciproqué antidromique dans un syndrome de Wolff-Parkinson-White de type A. Ann Cardiol Angeiol 24: 59, 1975.

59. Laham J: Les syndrome de Wolff-Parkinson-White. Paris "Librarie Maloine SA 1969: p 102.

60. Wellens HJJ: The electrophysiologic properties of the accessory pathway in the Wolf Parkinson Whote syndrome. In: The conduction system of the heart. Wellens HJJ, Lie KI, Janse MJ (Eds), Lea and Febiger. Philadelphla 1976, p 567.

61. Della Bella P, Brugada P, Talafic M, Torner P, Lemery R, Dugemier T, Wellens HJJ: Atrial fibrillation in patients with accessory pathways: differences between patients with the Wollf-Parkinson-Whtte syndrome and those with concealed accessory pathways. J Am Coll Cardiol 9: 12A, 1987. (Abstr)

62. Wellens HJJ, Durre D: Wolff-Parkinson-White syndrome and atrial fibrllation. Relation between refractory period of accessory pathway and ventricular rate during atrial fibrillation. Am J Cardilll 34: 771. 1974.

63. Stevens RH, Muler HC, Gallagher JJ et al: Electrophysiological evaluation of the WolfParkinson-White syndrome. Problems in assessing anterograde and retrograde conduction over the accessory pathway. Circulation 52: 552 . 1975.

64. Sung RJ, Styperelk JL: Electrophysiologic identification of dual atrioventricular nodal pathways conduction in pattents with reciprocating tachycardia using anomalous bypass tracts. Circulation 60: $1464,1979$.

65. Saulner JP. Nouvlatfe $R$, Altot $\mathbb{E}$, et al: Reentry tachycardia with complete atrioventricular dissoctation probably connected with the right Mahaim bundle. Arch Mal Coeur 72: 1259. 1979.

66. Milstein S. Sharma AD. Klein GJ: Electrophystologicic proflle of asymptomatic WolfParkinson-White pattern. Am J Cardiol 57: 1097. 1986. 
67. Tomer PM, on behalf of the European Registry on Sudden Death in the Woll-ParkinsonWhite syndrome: Ventricular fibrillation in the Wolf-Parkinson-White syndrome. PACE 11: $46,1988$.

68. Tonkin AM, Wagner GS, Gallagher JJ, Cope CD, Kasell J, Wallace AG: Initial forces of ventricular depolarization in the Wolf-Parkinson-Whtte syndrome. Circulation 52: 1030 . 1975.

69. Lindsay $\mathrm{BD}$. Crossen $\mathrm{KJ}$. Cain ME: Concordance of distinguishing electrocardiographic features during sinus rhythm with the location of accessory pathways in the Wolf-Parkinson-White syndrome. Am J Cardiol 59: 1093, 1987.

70. Milstein S, Sharma AD, Guiraudon GM, Klein GJ: An algorithm for the electrocardlographic localization of accessory pathways in the Wollf-Parkinson-White syndrome. PACE 10: $555,1987$.

71. Reddy GV. Schamroth L: The localization of bypass tracts in the Wollf-Parkinson-White syndrome from the suxface electrocardiogram. Am Heart J 113: 984, 1987.

72. Civera RC. Ferrero JA, Sanjuan R, Insa L, Rodrigues M. Segui J, Merino VL, Llavador J: Retrograde $\mathrm{P}$ wave polarity in reciprocating tachycardia utilizing lateral bypass tracts. Eur Heart J 1: 137, 1980.

73. Puech P, Grolleau R, Cinca J: Reciprocating tachycardia using a latent left-sided accessory pathway. Diagnostic approach by conventional ECG. In: Re Entrant Arrhythmias, edited by Kulbertus H. Lancaster, England: MTP Press 1977: p 117.

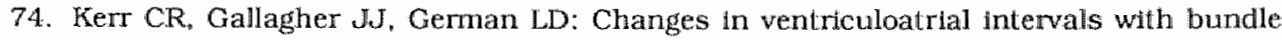
branch block aberration during reciprocating tachycardia in patients with accessory pathways. Circulation 66: 196, 1982.

75. Weiss J, Brugada P, Roy D, Bar FWHM, Wellens HJJ: Localization of the accessory pathway in the Wolff-Parkinson-White syndrome from the ventriculo-atrial conduction time of right ventricular apical extrasystoles. PACE 6: 260, 1983.

76. Wellens $H_{y} J_{J}$, Ross DL, Farré J, Brugada P: Functional bundle branch block during supraventricular tachycardla in man. Observations on mechantsms and their incidence. In: Cardtac Electrophysiology and Arhythmias. Zipes D and Jaliff $J$ (Eds). Grune and Stratton. Orlando, 1985, p 435.

77. Galllagher JJ, Sealy WC, Kasell $\mathrm{J}$, Wallace AG: Multiple accessory pathways in patients with the pre-excitation syndrome. Circulation 54:571, 1976.

78. Colavita PG. Packer DL, Pressley JC. Ellenbogen KA, O'Callaghan WG, Gllbert MR, German LD: Frequency, diagnosis and clinical characteristics of patients with multiple accessory atriowentricular pathways. Am J Cardiol 59:601. 1987. 
79. Matter BJ, Hayes WL: Wolf-Parkinson-Whte syndrome, report of a case with both type A and type B preexcttation. Am J Cardiol 13: 284, 1964.

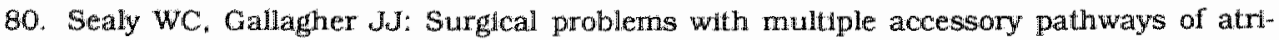
oventricular conduction. J Thorac Cardiovasc Surg 81: 707, 1981.

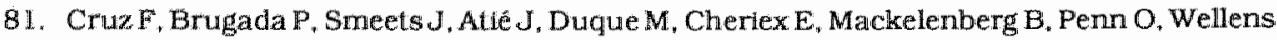
HJJ: Reversiblity of tachycardia induced cardionryopathy after surgical cure of incessant supraventricular tachycardia. Eur Heart J 10:226, 1989. (Abstr). 
Chapter II

\title{
Further support of the atrio-ventricular localization of so-called "Mahaim Fibers"
}

\author{
Jacob Atié \\ Pedro Brugada \\ Joep L.R.M. Smeets \\ Fernando E.S. Cruz \\ Olaf C.K.M. Penn \\ Marie P. Roukens \\ Hein J.J. Wellens
}




\title{
Further support of the atrio-ventricular localization of so-called "Mahaim Fibers"
}

\begin{abstract}
SUMMARY
To further characterize the type of pathway of apparently nodo-ventricular accessory pathways, data of 7 patients suggesting the diagnosis of a Mahaim accessory pathway were analyzed. In 2 patients, ventricular activation could be advanced during tachycardia by a right atrial premature beat given simultaneously with the onset of retrograde atrial activation suggesting a direct atrio-ventricular connection of the accessory pathway. In one of these patients the atrio-ventricular localization of the accessory pathway was confirmed during surgery. In a third patient epicardial dissection of the right lateral atrio-ventricular groove interrupted anterograde pre-excitation and tachycardia, demonstrating a direct atrio-ventricular connection of the accessory pathway. In the other 4 patients, analysis of the electrophysiological studies suggested a classical nodo-ventricular accessory pathway. However. an atrio-ventricular accessory pathway with anterograde decremental conduction properties could not be excluded. In conclusion. 3 of our 7 patients suspected to have nodo-ventricular accessory pathways had an atrio-ventricular accessory pathway with decremental conduction.
\end{abstract}

Presented at the Amertcan College of Cardtology. J Am Coll Cardiol 1989; 13:232, and at the European Society of Cardiology. Eur Heart J 1989;10:382.

Submitted for publication 


\section{INTRODUCTION}

In 1941 Mahaim described the existence of islands of conducting tissue running from atrio-ventricular node into the ventricular myocardium (1). In 1971, one of us reported the results of a electrophysiologic study in a patient with such connection (2). Since then, several authors have analyzed the electrocardiographic and electrophysiological features attributed to these fibers [3-9]. Hallmark of the diagnosis of a nodo-ventricular fiber was: 1) Lengthening of the stimulus-delta interval on shortening the atrial pacing rate or atrial premature beat interval and 2) The demonstration that the atrium was not participating in the reentry circuit $(2,3)$. In 1979 however Farré et al (10) reported a patient with an atrioventricular accessory pathway that showed anterograde decremental conduction properties (10). In 1985 Critelli et al (11) reported a patient presenting with a concealed accessory atrio-ventricular pathway having retrograde decremental conduction in whom the accessory pathway conducted anterogradely with a long conduction time after ablation of the bundle of His. Recently, observations during electrophysiologic study and surgery in patients with an accessory pathway that behaved as a typical nodo-ventricular fiber demonstrated that the accessory pathway was truly atrio-ventricular with slow anterograde conduction (12,13).

This study, reports our findings in 7 patients initially considered as having a nodo-ventricular accessory pathway.

\section{PATIENTS AND METHODS}

\section{Patients}

The seven patients in our study were selected from 314 consecutive studied in our hospital between 1979 and April 1988 for evaluation and treatment of various preexcitation syndromes. Three patients were studied after publication of the articles by Tchou (12) and Klein (13). In the other 4 patients the data were analyzed retrospectively. Six patients were male and one female. The mean age was 25 years ( 18 to 41 years). All patients had a complete electrophysiological study using previously described techniques (14). Two patients underwent surgery for ablation of the accessory pathway.

\section{Electrophysiological study}

The criterium for the diagnosis of the nodo-ventricular accessory pathway was: Progressive prolongation of the A-H and A-delta interval during incremental right atrial pacing and atrial premature beats with progressively shorter premature beat intervals. During the prolongation of the A-H interval the QRS morphology showed progressive preexcitation because the A-H interval prolonged more than the A-delta interval (fig. 1). 
A

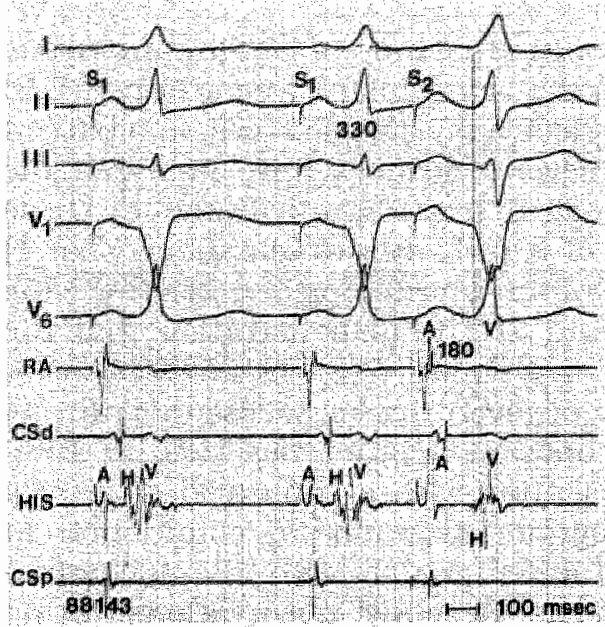

B

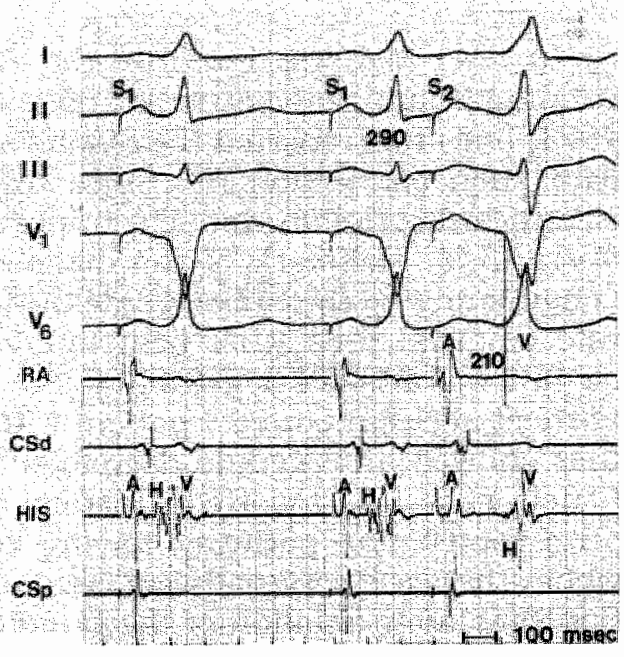

Figure 1. Five surface electrocardiographic leads and intracardlac electrograms from the high right atrium (RA), bundle of His (His), right ventricle (RV), proximal (CSp) and distal (CSA) coronary stnus. During atrial pacing with a cycle length of $500 \mathrm{~ms}$ the $\mathrm{QRS}$ complex is slightly preexcited. Maxdrnal preexcitation accurs following the atrial premature beat given after an S1 - S2 interval of $330 \mathrm{~ms}$ (panel A). The AV conduction time is $180 \mathrm{~ms}$. After a further decrease in the S1-S2 interval by $40 \mathrm{~ms}$, the $\mathrm{AH}$ and AV conduction tine continues to prolong, with displacement of the His deflection into the ventricular electrogram and maximal preexcitation (panel B).

The criteria for the diagnosis of an atrio-ventricular accessory pathway with slow anterograde conduction were all the criteria described for the nodo-ventricular accessory pathway, associated with: (1) Advancement of ventricular activation during tachycardia by an atrial premature beat delivered just at the onset of retrograde atrial activation (time of $\mathrm{A}-\mathrm{V}$ nodal refractoriness) (fig. 2,3), demonstrating dissociation at the atrial level of the two pathways involved in tachycardia. (2) Successful ablation of the accessory pathway after epicardial surgical dissection and mobilization of the right atrio-ventricular fat pad with exposure and cryoablation of the atrio-ventricular Junction at the right free wall (15).

\section{Surgery}

Operative therapy was carried out using the close-heart technique described by Guiraudon et al (15). A ventricular ring map was obtained during sinus rhythm, atrial pacing and tachycardia, and an atrial ring map during ventricular pacing and tachycardia. 


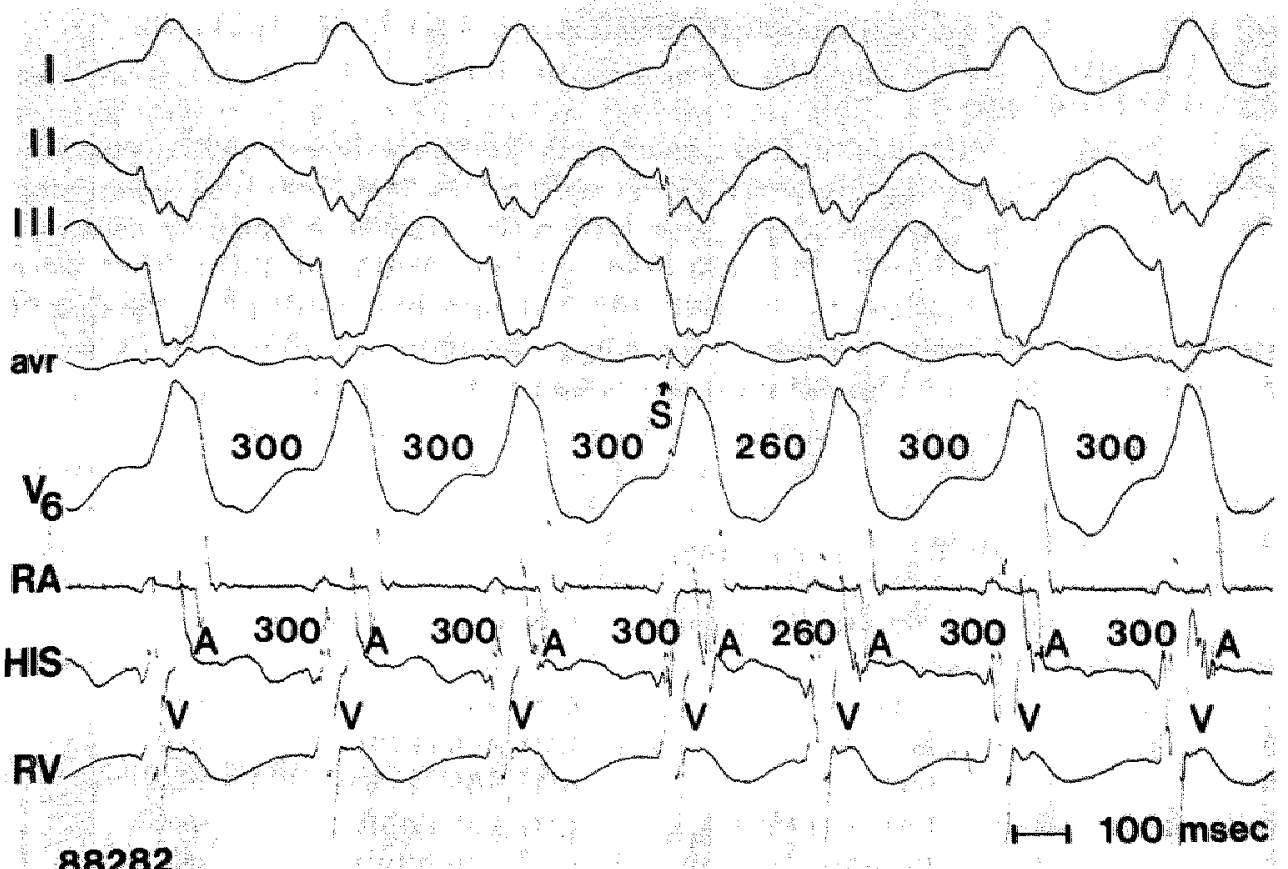

\section{2}

Figure 2. Surface and intracardiac electrograms recorded during reclprocating tachycardia from a pattent with an atrio-ventricular accessory pathway with decremental conduction. Five surface leads and three endocavitary bipolar electrograms are shown. An atrial premature beat given in the low right atrium (S) advances ventricular activation by $40 \mathrm{~ms}$, without modifying retrograde atrial activation.

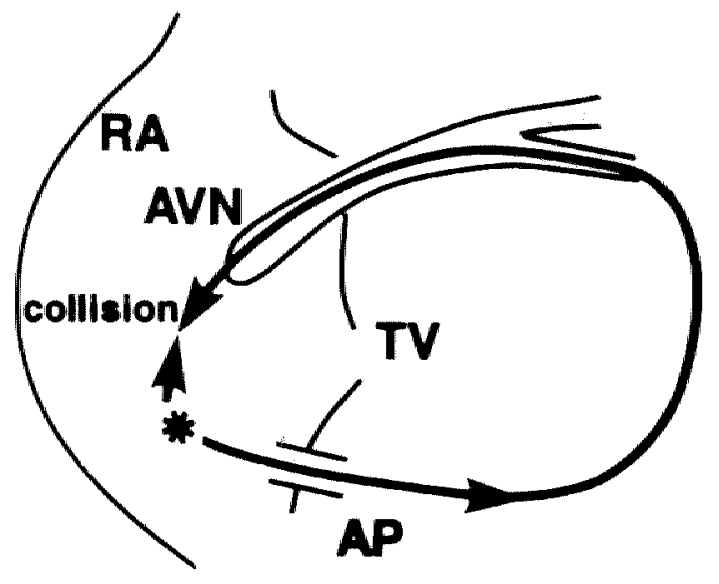

FIgure 3. Schematic representation of how an atrial premature beat given. at the time of onset of retrograde atrial activation can advance ventricular activation and show proximal dissociation of the two pathways. $\lfloor\mathrm{AP}=$ accessory pathway: $\mathrm{AVN}=$ atrio-ventricular node: $\mathrm{RA}=\mathrm{rght}$ atrium; TV = tricusplde valve). 


\section{RESULTS}

\section{Clinical Findings}

From our 7 patients, one had associated Ebstein's disease with ventricular septal defect, another hypertrophic cardiomyopathy. Two had associated dual atrio-ventricular pathways. Two had also another accessory pathway than the nodo-ventricular "Mahaim fiber". Other cardiac abnormalities were not found in these patients. All patients but one had multiple episodes of circus movement tachycardia and syncope, one patient suffered from incessant tachycardia. The clinical data are presented in table I.

Table I. Clinical data

\begin{tabular}{llllll}
\hline Pt & Age & sex & Assoctated anomalies & Presenting arrhythmia & Syncope \\
\hline 1 & 18 & M & none & CMT with LBBB & yes \\
2 & 41 & F & mone & CMT with LBBB & yes \\
3 & 24 & M & none & CMT with LBBB & no \\
4 & 18 & M & Ebstetn + VSD & CMT with LBBB & yes \\
5 & 16 & M & Hypertrophic CMP & CMT with RBBB & yes \\
& & & none & CMT with LBBB & yes \\
7 & 18 & M & Atrial fbrillation & yes \\
\hline
\end{tabular}

Abbreviations: $\mathrm{CMT}=$ circus movement tachycardia; $\mathrm{CMP}=$ cardiomyopathy; $\mathrm{VSD}=$ ventricular septal defect; VF = ventricular fibrillation; $L B B B=$ left bundle branch block morphology:

$\mathrm{RBBB}=$ right bundle branch block morphology

\section{Electrocardiographic findings}

At rest, the surface electrocardiogram showed a short PR interval in three patients and a normal PR interval in the remaining four. In two patients a delta wave was present, one of them had also a Kent type atrio-ventricular pathway. During tachycardia all patients had a QRS duration of. 12 seconds or more, 6 patients had a left bundle branch block morphology with an axis between 0 and $-60^{\circ}$ in the frontal plane and one a right bundle branch block morphology with a $\mathrm{QRS}$ axis of $+120^{\circ}$.

\section{Electrophysiological findings}

All patients fulfilled the criteria for a nodo-ventricular accessory pathway, six had the classical left bundle branch morphology during incremental atrial pacing and tachycardia, and one had a right bundle branch morphology. 
In three patients atrial stimuli were introduced during tachycardia at the low right atrium. The atrial stimuli were delivered just at the onset of retrograde atrial activation. In two patients an atrial premature beat advanced subsequent ventricular activation (fig. 2,3). The ability to preexcite the ventricle during tachycardia at the time of $A-V$ nodal refractoriness, indicated that the accessory pathway originated directly from the atrium (fig. 3).

\section{Surgery}

Surgical dissection of the accessory pathway was carried out in the normothermic beating heart in two patients. Epicardial mapping during both atrial pacing and antidromic tachycardia showed earliest epicardial activation at the right free wall (fig. 4) in both patients. Earliest retrograde activation during ventricular pacing and tachycardia was observed in the septal area. Epicardial dissection performed at the right atrio-ventricular groove, followed

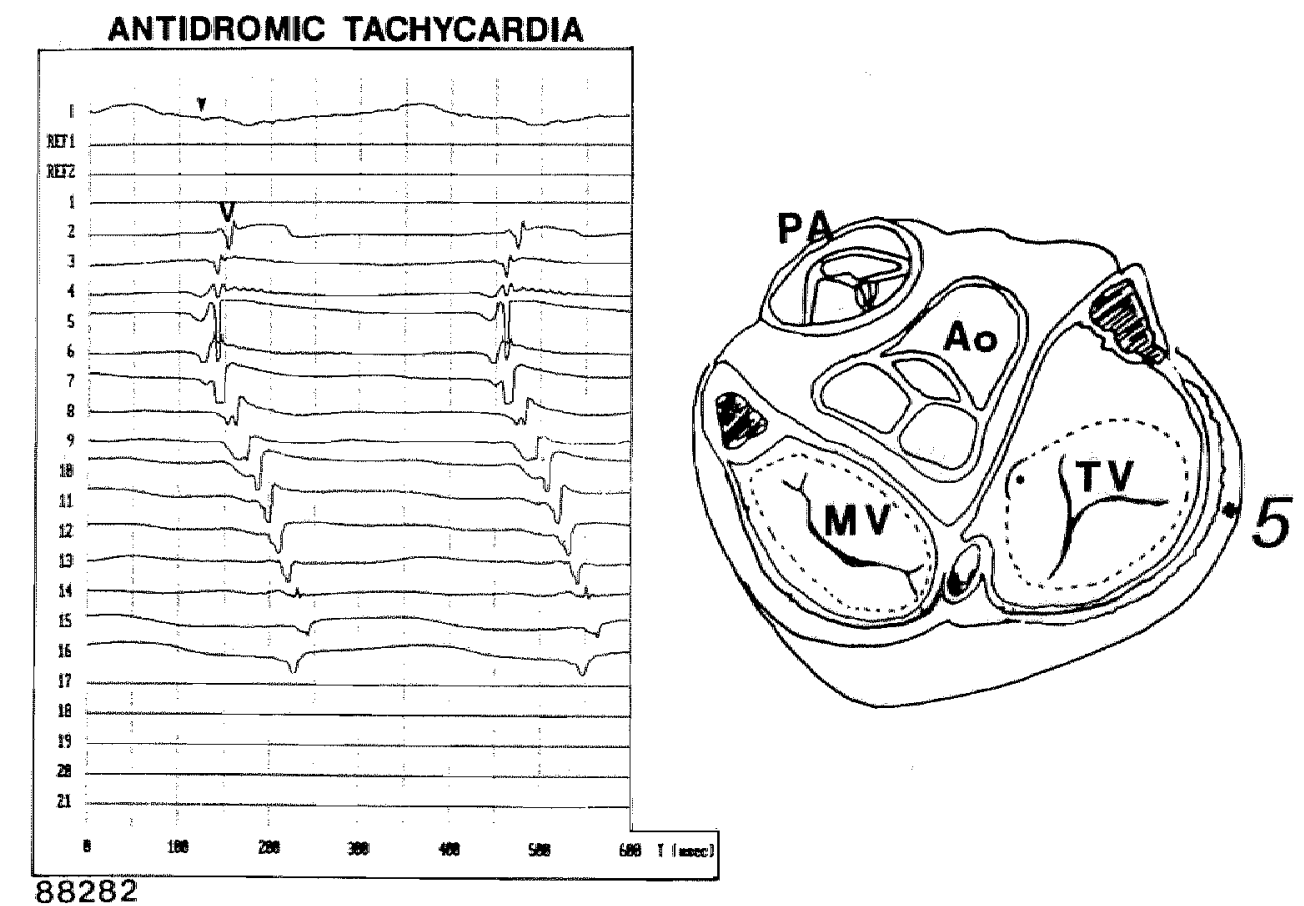

Fligure 4. Peroperative epicardial ventricular mapping during antidromic tachycardia. The earliest epicardial activation is recorded in electrode 5, corresponding to the right free wall as showed in the diagram of the superior view of the heart. $(M V=$ mitral valve, $P A=$ pulmonary artery, $T V=$ tricuspid valve, $A O=$ Aorta). 


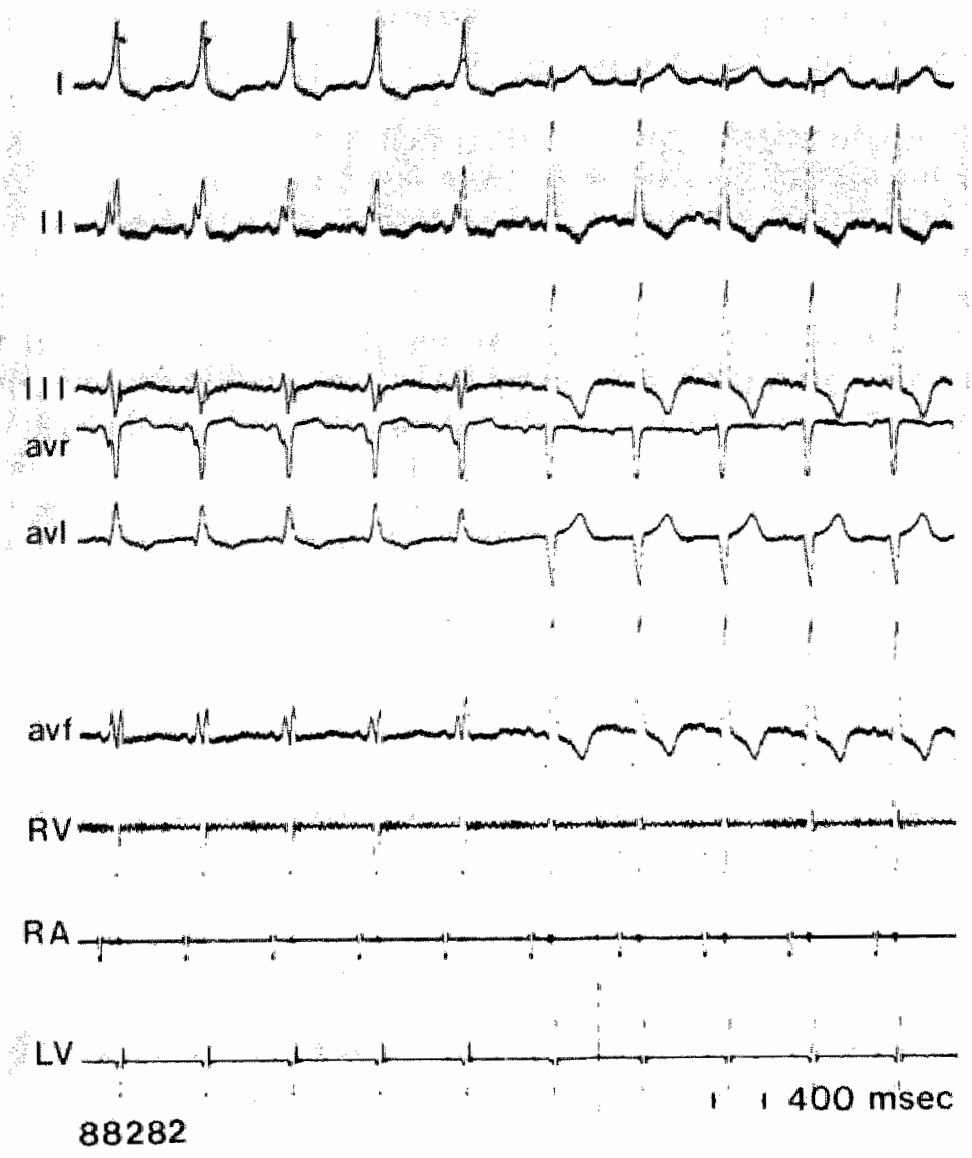

Figure 5. Surface ECG and eptcardiall leads at the very moment of interruption of preexcitation during surgery perlormed in the right A-V groove. In the left part a preexcited QRS complex is observed, which disappears in the right part after a single cycle.

by cryoablation, abolished pre-excitation and no tachycardia could be induced in both patients (fig. 5). After a follow-up of four and seven months these patients remain free of arrhythmias.

In the other 4 patients no sufficient data were available to exclude an accessory atrio-ventricular pathway with slow anterograde conduction. Late atrial premature beats had not been given during tachycardia in these patients in whom data were analyzed retrospectively. 


\section{DISCUSSION}

The data from this partially prospective and partially retrospective study come to further support an atrio-ventricular localization of accessory pathways presenting with electrocardiographic and electrophysiologic features suggestive of a nodo-ventricular accessory pathway. Like in the previous reports by Tchou et al (12) and Klein et al (13), only detalled electrophysiologic studies along with data from surgery allowed the exact localization of the implantation of the accessory pathway. This is confirmed by the impossibility to exactly localize the accessory pathway implantation in the 4 retrospectively analyzed patients. In them very late atrial premature beats (at the time of onset of retrograde atrial activation) were not given and made it impossible to exclude an atrio-ventricular implantation of the accessory pathway. One has to realize however, that even the inability to advance subsequent ventricular activation by a very late atrial premature beat not influencing onset of retrograde atrial activation does not allow the positive diagnosis of a nodoventricular accessory pathway. The decremental anterograde conduction properties of the accessory pathway may make it impossible to advance subsequent ventricular activation even when the accessory pathway is truly atrio-ventricular. The only criterium which positively can demonstrate a nodo-ventricular accessory pathway is the presence of atrio-ventricular dissociation during tachycardia $(16,17)$.

Data from this and previous studies $(12,13)$ demonstrating the existence of atrio-ventricular accessory pathways with anterograde slow decremental conduction are of importance when surgery is considered. Epicardial dissection at the right atrio-ventricular groove cured our two patients undergoing surgery and definitely proved the atrio-ventricular localization of the accessory pathway. Because of their possible nodo-ventricular implantation, patients with findings suggestive of a Mahaim accessory pathway have been considered a separate problem as compared to patients with the classic Wolf-Parkinson-White syndrome. The results of this and previous $(12,13)$ studies show that the only difference may be the electrophysiologic properties and not the localization of the accessory pathway.

In patients with features suggesting a Mahaim accessory pathway a slowly conducting atrio-ventricular accessory pathway has to be considered. Detailed electrophysiologic study is necessary to prove this hypothesis, because accessory atrio-ventricular pathways can be easily dissected surgically resulting in permanent cure of the arrhythmia. 


\section{REFERENCES}

1. Mahaim 1, Whiston MR. Recherches danatomic comparee et du pathologie experimentale sur les connections hautes du faisceau et du pathologie experimentale sur les connexions hautes du faisceau de His-Tawara. Cardiologia 1941:5: 189-260.

2. Wellens Hus. Electrical Stimulation of the Heart in the Study and Treatment of Tachycardias. Baltmore:Untversity Park Press 1971; $97-109$

3. Bard CH, German LD, Packer DL, Coltorti F, Gallagher JU. Mechanism of tachycardia using a nodofascicular Maham fiber. Am J Cardiol 1984;1: 1140-1141.

4. Lerman BB, Waxman HL, Proclemer A Jasephson ME. Supraventricular tachycardia assoclated with nodowentricular and concealed atrioventricular bypass tracts. Am Heart J 1982:104: 1097-1102.

5. Gmeiner R, Keung $\mathrm{N}$ C, Hammer $\mathrm{I}$. Becker AE. Tachycardia caused by an accessory nodoventricular tract: a clinic-pathologic correlation. Eur Heart J 1984;5: 233-242.

6. Ellenbogen KA, Ramirez NM, Packer DL, O'Callaghan WG, Greer GS, Sintetos AL, Gubert MR, German LD. Accessory nodoventricular (Mahaim fibers: a clinical review. Pace 1986:9: 868.884

7. Gallagher JU, Smith WM, Kassell JH, Benson DWJ, Sterba R, Grant AO. Role of Mahaim fibers in cardiac arrhythmias in man. Circulation 1981;64: 176-189.

8. Mottê G, Brechenmacher C. Davy JM. Belhassen B. Association des fibres nodo-ventriculaires et atrio-ventriculaires à l'origine de tachycardies réciproques. Arch Mal Coeur $1980 ; 6: 737 \div 746$.

9. Smith WS, Broughton A Reiter MJ, Benson DWJ, Grant AO, Gallagher JJ. Bystander accessory pathway during AV node re-entrant tachycardia. Pace 1983;6: $537-547$.

10. Farre J, Ross D, Wiener I, Bar FW, Vanagt EJ, Wellens HJJ. Reciprocal tachycardias using accessory pathways with long conduction times. Am $J$ Cardiol 1979;44: 1098-1109.

11. Critelli $\mathrm{G}$, Gallagher JJ, Thiene $\mathrm{G}$. Perticone $\mathrm{F}$, Coltorti $\mathrm{F}$, Rossi L. Electrophysiologic and histopathologic correlations in a case of permanent form of reciprocating tachycardta. Eur Heart J 1985; 6(2): $130-137$.

12. Tchou $\mathbf{P}$, Lehmann $\mathrm{H}$, Jazayeri $M$, Akhtar $M$. Atriofascicular connection or a nodoventricular Mahatm lber? Electrophysiologic eluctdation of the pathway and associated reentrant circuit. Circulation 1988:77: 837-848. 
13. Flein GJ, Guiraudon GM, Kerr CR, Sharma AD, Yee R, Szabo T, Yeung Latwah JAY. "Nodoventricular" accessory pathway: Evidence for a distinct accessory atrioventricular pathway with atrioventricular node-like propenties. J Am Coll Cardiol 1988: 11: 1035-1040.

14. Wellens HJJ. Durrer D. The role of an accessory atrioventricular pathway in reciprocal tachycardia. Observations in patients with and without the Wolf-Parkinson-White syndrome. Circulation 1975;52: 58-64

15. Guiraudon GM, Klein GJ, Sharma AD, Miltsein S, MsLellan DG. Closed-heart technique for WolfT-Parkinson-White syndrome: Further experience and potential limitations. Ann Thorac Surg 1986:42:651-657.

16. Morady F, Scheinman MM, Gonzalex $R$, Hess $D$. His-ventricular dissoclation in at pattent with reciprocating tachycardia and a nodoventricular bypass tract. Circulation 1981;64: $839-852$.

17. Shimizu A, Ohe T, Takaki H, Kamakura S, Matsuhisa M, Sato I, Shimomura K. Narrow QRS complex tachycardia with atrioventricular dissociation. Pace $1988 ; 11: 384-393$.

18. Guiraudon GM, Klein GJ, Sharma AD, Jones DL, McLellan DG. Surgical ablation of posterior septal accessory pathways in the Wolff-Parkinson-White syndrome by a close heart technique. $J$ Thorac Cardiovase Surg 1986;92:406-413. 
. 
Chapter III

\section{Clinical and electrophysiological characteristics of patients with antidromic circus movement tachycardia in the Wolff-Parkinson-White syndrome}

Jacob Atié

Pedro Brugada Joep L.R.M. Smeets Marie P. Roukens Fernando E.S. Cruz Ayrton Peres Josep Brugada Hein J.J. Wellens 


\title{
Clinical and electrophysiological \\ characteristics of patients with antidromic circus movement tachycardia in the Wolff-Parkinson-White syndrome
}

\begin{abstract}
SUMMARY
Antidromic circus movement tachycardia was documented in 36 out of 345 consecutive patients with the Wolff-Parkinson-White syndrome undergoing detailed electrophysiologic evaluation. Twenty six patients were malle and 10 female, the mean age was $26 \pm 12$ years (12-45). Multiple accessory pathways were identified in 12 of these 36 patients $(33 \%)$. Of patients withclinically documented antidromic tachycardia, $10(67 \%)$ had multiple accessory pathways. Dizziness and syncope occurred in 61 and $50 \%$ of patients with antidromic circus movement tachycardia. Six patients had clintcal documentation of atrial fibrillation, and 4 patients ( $11 \%$ ) were resuscitated from ventricular fibrillation. In the 36 patients, 56 distinct antidromic tachycardias were recorded and several different pathways were observed. Orthodromic tachycardia was the most frequently associated arrhythmia (72\%). Dual A-V nodal pathways were present in 12 patients (33\%), however in only 2 of them A-V nodal tachycardia could be initiated. Interruption of the accessory pathway was successfully performed in all 20 patients undergoing surgery.
\end{abstract}

Accepted for presentation at the North American Soclety of Pacing and

Electrophysiology in 1990

Submitted for publication 


\section{INTRODUCTION}

Accessory atrioventricular connections in patients with Wolff-ParkinsonWhite syndrome may participate in a variety of paroxysmal tachycardias (1-4). The most commonly observed arrhythmia is orthodromic circus movement tachycardia in which the reentrant circuit utilizes the normal $\mathrm{A}-\mathrm{V}$ conducting system in the anterograde direction and the accessory pathway in the retrograde direction. The resulting QRS complex during tachycardia is, therefore, normal or shows the typical intraventricular features of aberrant conduction $(5,6)$. In 1975, Fontaine (7) used the term antidromic to define a tachycardia using the accessory pathway in the anterograde direction and the AV node in retrograde direction. The resulting tachycardia has a wide $\mathrm{QRS}$ complex with maximal preexcitation. A variant of true antidromic circus movement tachycardia was also described in which the retrograde limb of the circuit was a second accessory pathway $(8,9)$. Furthermore, tachycardia due to reentry within the A-V node and anterograde conduction over the accessory pathway has been reported to occur in patients with Wolff-Parkinson-White syndrome. That may result in a paroxysmal regular tachycardia with preexcited GRS complexes that mimics antidromic tachycardia $(10,11)$. The electrophysiologic mechanisms leading to tachycardias in the Wolff-ParkinsonWhite syndrome has been extensively studied $(12,13)$. However, there are relatively few studies on antidromic circus movement tachycardia (14-15) and consequently little is known about the clinical characteristics and the electrophysiological substrate necessary for its occurrence.

This report reviews the clinical and electrophysiologic characteristics and results of treatment in patients with the Wolff-Parkinson-White syndrome presenting antidromic circus movement tachycardia.

\section{PATIENTS AND METHODS}

The 36 patients of this study were selected from 345 consecutive patients seen between 1979 and august 1989 in our institution for evaluation and treatment of various pre-excitation syndromes.

\section{Definition of antidromic tachycardia}

Antidromic circus movement tachycardia was defined as a tachycardia that used an accessory pathway in the anterograde direction and the His/AV node or a different accessory pathway in retrograde direction. 


\section{Criteria for diagnosis of antidromic tachycardia in patients with a single accessory pathway:}

1. The QRS configuration during tachycardia was essentially identical with that obtained during atrial pacing with maximal preexcitation.

2. Participation of the ventricles in the reentry circuit:

Demonstration of participation of the ventricles in the tachycardia mechanism was obtained by observing that: 1) Ventricular premature beats terminated tachycardia, without depolarizing either the His bundle or the atria (this criteria excludes atrial flutter, and atrial tachycardias with $1: 1$ conduction over the accessory pathway), 2) Atrial premature beat advanced the tachycardia with the same pattern of ventricular activation during tachycardia. This criterium excludes ventricular tachycardia, and 3) Atrial premature beats could advance the tachycardia, with the next atrial activation occurring after the same $\mathrm{V}$-A interval and with the same sequence of retrograde atrial activation. This criterium excludes A-V nodal tachycardia with 1:1 conduction over a bystander accessory pathway.

3. Participation of the atria in the reentry circuit:

Demonstrated by the following: 1] An atrial premature beat terminated tachycardia without conduction to the ventricles. This observation excludes ventricular tachycardia, 2) Ventricular premature beats conducted to the atrium with the same retrograde atrial activation sequence, advancing tachycardia. This phenomenon also excludes ventricular tachycardia, 3l Ventricular premature beats, conducting to the atrium, could advance tachycardia with the next ventricular activation having the same $\mathrm{A}-\mathrm{V}$ interval as during the tachycardia. This criterium excludes $\mathrm{A}-\mathrm{V}$ nodal tachycardia with 1:1 conduction over a bystander accessory pathway).

4. Atrial and ventricular pacing showed that the conduction properties of each limb of the reentrant circuit were capable of sustaining the tachycardia.

5. Atrial flutter, atrial tachycardia and dual A-V nodal tachycardia using the accessory pathway as a "bystander", were excluded by at least one of the above criterium.

6. Circus movement tachycardia using a nodoventricular fiber in the anterograde conduction were also excluded.

\section{Criteria for diagnosis of antidromic tachycardia in the presence of multiple accessory pathways}

The criteria discussed above, were also used for the diagnosis of antidromic tachycardia in patients with multiple accessory pathways. However, configuration of the $\mathrm{QRS}$ complex during tachycardia could be different from that obtained during atrial pacing. depending upon the accessory pathway(s) used for anterograde conduction. Also, a second accessory pathway could sometimes be used as the retrograde limb of the tachycardia circuit. In one case fusion between both accessory pathways occurred during anterograde conduction over both pathways. 


\section{Electrophysiological study}

After informed consent all patients underwent a complete electrophysiologic study in the nonsedated state. At the time of study, 16 of the 36 patients were taking different antiarrhythmics drugs.

Catheters were passed through both femoral veins using the Seldinger technique and positioned in the heart under fluoroscopic guidance. Multiple electrode catheters were used to record and pace from the right atrium, coronary sinus and right ventricular apex. His bundle electrograms were obtained with a bipolar electrode catheter positioned over the septal leaflet of the tricuspid valve. The methods for stimulation and recording used in our laboratory and the definitions used have been previously described in detail (16). All patients underwent a complete electrophysiologic investigation.

\section{Surgery}

Twenty of the 36 patients underwent surgery. In these patients, intraoperative mapping was used to confirm the location(s) of the accessory pathway(s) determined before surgery.

\section{RESULTS}

\section{Clinical characteristics}

Of the 345 patients studied, 36 patients $(11 \%)$ had antidromic circus movement tachycardia induced during the electrophysiologic study. Twenty four of them $(67 \%)$ had a single accessory pathway and 12 patients $(33 \%)$ had two or more accessory pathways (three patients had 3 different accessory pathways).

The clinical data of these patients are listed in table $I$. The age of the patients ranged from 12 to 45 years (mean $26 \pm 12$ ), 26 patients were male $(72 \%)$ and $10(28 \%)$ female. The mean duration of symptoms before electrophysiologic study was 8 years. The mean age at onset of symptoms was $16 \pm$ 6 years (in 6 patients the first symptoms of arrhythmia occurred less than 6 months before electrophysiologic studyl. The mean number of attacks was 4.5 \pm 3 a month, in the last 6 months before the electrophysiologic study. Clinical symptoms included palpitations ( 34 patients - 94\%), dizziness (22 patients $61 \%$ ) and syncope (18 patients - $50 \%$ ). Fifteen patients (42\%) had exercise-induced tachycardia. 
Table I. Clinical data of the 36 patients studied

\begin{tabular}{|c|c|c|c|c|c|c|c|}
\hline Pts & Sex & Age & $\begin{array}{l}\text { Onset of } \\
\text { arrhythmia }\end{array}$ & $\begin{array}{l}\text { Incidence } \\
\text { of attacks } \\
\text { per month } \\
\text { (last } 6 \mathrm{~min} \text { ) }\end{array}$ & Symuptomas & $\begin{array}{l}\text { Exercise } \\
\text { tnduced } \\
\text { tachycardia }\end{array}$ & $\begin{array}{l}\text { Clinical } \\
\text { documented } \\
\text { arrhythmia }\end{array}$ \\
\hline
\end{tabular}

\begin{tabular}{|c|c|c|c|c|c|c|c|}
\hline 1 & $F$ & 40 & 20 & 1 & $\mathrm{PL} / \mathrm{DZ} / \mathrm{SN}$ & YES & $\mathrm{O}$ \\
\hline 2 & $M$ & 23 & 13 & 30 & PL/DZ/SN & YES & $\mathrm{A} / \mathrm{AF}$ \\
\hline 3 & $\mathrm{~F}$ & 27 & 26 & 1 & $\mathrm{PL} / \mathrm{SN}$ & No & $O / A F / V F$ \\
\hline 4 & $M$ & 21 & 12 & 6 & $\mathrm{PL} / \mathrm{DZ} / \mathrm{SN}$ & YES & $\mathrm{A} / \mathrm{O}$ \\
\hline 5 & M & 45 & 30 & 4 & $\mathrm{PL}$ & NO & A \\
\hline 6 & $\mathrm{M}$ & 12 & 10 & 1 & PL & NO & A/O/AVN \\
\hline 7 & $\mathrm{M}$ & 28 & 28 & 0 & ASYMPT: & NO & NAD \\
\hline 8 & $\mathrm{~F}$ & 22 & 13 & 1 & $\mathrm{PL} / \mathrm{DZ} / \mathrm{SN}$ & YES & $\mathrm{A} / \mathrm{O} / \mathrm{F}$ \\
\hline 9 & $\mathrm{M}$ & 28 & 28 & 1 & PL & NO & A \\
\hline 10 & $\mathrm{M}$ & 19 & 19 & 5 & $\mathrm{PL} / \mathbb{D Z} / \mathrm{SN}$ & YES & $\mathrm{A} / \mathrm{O} / \mathrm{VF}$ \\
\hline 11 & $F$ & 41 & 41 & 1 & $\mathrm{PL} / \mathrm{DZ} / \mathrm{SN}$ & YES & $\mathrm{O} / \mathrm{AF}$ \\
\hline 12 & $\mathrm{M}$ & 15 & 10 & 5 & $\mathrm{PL} / \mathrm{DZ}$ & YES & A \\
\hline 13 & $\mathrm{M}$ & 17 & 14 & 1 & $\mathrm{PL} / \mathrm{DZ} / \mathrm{SN}$ & YES & NAD \\
\hline 14 & $\mathrm{M}$ & 17 & 14 & $\mathbb{1}$ & $\mathrm{PL} / \mathrm{DZ} / \mathrm{SN}$ & YES & $\mathrm{A} / \mathrm{O} / \mathrm{AVN}$ \\
\hline 15 & $\mathrm{~F}$ & 12 & 8 & 2 & $\mathrm{PL} / \mathrm{DZ} / \mathrm{SN}$ & YES & $\mathrm{A} / \mathrm{O}$ \\
\hline 16 & $\mathrm{M}$ & 12 & 12 & 1 & $\mathrm{PL}$ & NO & A \\
\hline 17 & $M$ & 48 & 19 & 1 & $\mathrm{PL}$ & NO & NAD \\
\hline 18 & $M$ & 28 & 24 & 2 & $\mathrm{PL} / \mathrm{DZ} / \mathrm{SN}$ & YES & $\mathrm{O}$ \\
\hline 19 & M & 42 & 14 & 1 & $\mathrm{PL} / \mathrm{DZ} / \mathrm{SN}$ & YES & O \\
\hline 20 & M & 15 & 13 & 30 & $\mathrm{PL} / \mathrm{DZ} / \mathrm{SN}$ & YES & A \\
\hline 21 & $\mathrm{~F}$ & 45 & 12 & 3 & $\mathrm{PL} / \mathrm{DZ} / \mathrm{SN}$ & YES & $\mathrm{A}$ \\
\hline 22 & $\mathrm{~F}$ & 17 & 7 & 4 & PL & NO & 0 \\
\hline 23 & $\mathrm{M}$ & 32 & 22 & 1 & $\mathrm{PL} / \mathrm{DZ}$ & YES & $A$ \\
\hline 24. & $M$ & 18 & 18 & 1 & ASYMPT. & NO & NAD \\
\hline 25 & M & 23 & 15 & $\mathbb{1}$ & $\mathrm{PL} / \mathrm{DZ} / \mathrm{SN}$ & YES & $\mathrm{A} / \mathrm{O} / \mathrm{VF}$ \\
\hline 26 & ‘ $\mathbf{M}$ & 38 & 30 & 1 & $\mathrm{PL}$ & NO & NAD \\
\hline 27 & $\mathbf{M}$ & 28 & 20 & 5 & $\mathrm{PL} / \mathrm{DZ} / \mathrm{SN}$ & YES & 0 \\
\hline 28 & $\mathrm{M}$ & 16 & 14 & 1 & $\mathrm{PL}_{.} / \mathrm{DZ} / \mathrm{SN}$ & YES & $\mathrm{A} / \mathrm{O}$ \\
\hline 29 & $\mathrm{~F}$ & 28 & 20 & 1 & PL & NO & A \\
\hline 30 & $\mathrm{~F}$ & 30 & 20 & 5 & $\mathrm{PL} / \mathrm{DZ}$ & YES & $\mathrm{AF}$ \\
\hline 31 & M & 32 & 28 & 4 & $\mathrm{PL}$ & $\mathrm{NO}$ & $\mathrm{O}$ \\
\hline 32 & $\mathrm{M}$ & 42 & 30 & 1 & $\mathrm{PL} / \mathrm{DZ}$ & YES & $\mathrm{O}$ \\
\hline 33 & $M$ & 31 & 20 & 4 & $\mathrm{PL} / \mathrm{DZ} / \mathrm{SN}$ & YES & $\mathrm{A} / \mathrm{VF}$ \\
\hline 34 & $\mathrm{M}$ & 20 & 10 & 10 & $\mathrm{PL} / \mathrm{DZ}$ & YES & $\mathrm{O} / \mathrm{AF}$ \\
\hline 35 & $r$ & 29 & 20 & 0 & PL & NO & $\mathrm{NAD}$ \\
\hline 36 & $\mathrm{M}$ & 28 & 20 & 4 & PL & NO & $\mathrm{NAD}$ \\
\hline
\end{tabular}

Abbreviations: $A=$ antidromic circus movement tachycardia; $\mathrm{AF}=$ atrial fibrillation; $\mathrm{ASYMPT}=$ asymptomatic; $A V N=A V$ nodal tachycardla; $D Z=d i z z i n e s s ; ~ N A D=n o$ arrhythmia documented; $\mathrm{O}=$ orthodromic circus movement tachycardla; $\mathrm{PL}=$ palpitation; $\mathrm{SD}=$ standard deviation; $\mathrm{SN}=$ syncope; $\mathrm{VF}=$ ventricular fibrillation; $\mathrm{m}=$ months.; $\mathrm{Pts}=$ pattent number 
Eighteen of the 36 patients (50\%) had clinically documented antidromic circus movement tachycardia, 18 patients $(50 \%)$ had documented orthodromic circus movement tachycardia, 7 patients (19\%) had both tachycardias clinically. A history of atrial fibrillation was present in 6 patients (16\%). Four patients $(11 \%)$ had a previous history of ventricular fibrillation.

\section{Electrophysiological characteristics}

The location of the accessory pathways is presented in table II. The most common Iocation was left lateral (15 accessory pathways 29\%) and left posteroseptal ( 15 accessory pathways $29 \%$ ).

The mean atrial refractory period was $212 \pm 28 \mathrm{~ms}$, the mean ventricular effective refractory period was $198 \pm 23 \mathrm{~ms}$. The anterograde effective refractory period of the AV node was $227 \pm 25 \mathrm{~ms}$ and the retrograde effective refractory period of the AV conduction system $222 \pm 21$ ms. The mean shortest measured anterograde refractory period of the accessory pathway was $238 \pm 35 \mathrm{~ms}$ (range from $\leq 190 \mathrm{~ms}$ to $410 \mathrm{~ms}$ ). In patients with more than one accessory pathway only the value of the accessory pathway with the shortest refractory period was considered. The atrial, ventricular, A-V node and accessory pathway refractory periods are shown in Table III.

\section{Antidromic tachycardia}

Antidromic circus movement tachycardia was the only inducible arthythmia in 10 patients (28\%). In the remaining 26 patients ( $72 \%$ ) both antidromic and orthodromic tachycardia could be initiated.

Nine patients had 2 different types of antidromic tachycardias, 4 patients presented 3 different types, and 1 patient 4 different types of tachycardia. The remaining 22 patients presented only one type of antidromic circus movement tachycardia. The different types of antidromic tachycardias were based upon: 1) Differences in cycle length because of differences in the retrograde pathway, as shown by different retrograde atrial activation patterns. 2) Different: patterns of preexcitation, because of anterograde conduction over different accessory pathways (fig. 1). 3) Differences in cycle length because of an increase in the $\mathrm{V}$-A interval as a result of $\mathrm{V}-\mathrm{H}$ prolongation due to a change in bundle branch used for retrograde conduction during tachycardia (fig. 2) (14). 4) Differences in cycle length because of an increase in the VA interval as a result of $\mathrm{H}-\mathrm{A}$ prolongation, caused by the presence of retrograde dual $\mathrm{AV}$ nodal pathways (fig. 3). 5) Differences in cycle length because of an increase in the AV interval due to anterograde longitudinal dissociation in the accessory pathway or alternating conduction over two very closely located accessory pathways (fig. 4) (17). 
Table II. Localization of the accessory pathway and cycle length during antidromic tachycardia.

\begin{tabular}{|c|c|c|c|c|c|}
\hline $\begin{array}{l}\text { Patlent } \\
N^{*}\end{array}$ & $\begin{array}{l}\text { Locallowation } \\
\text { of AP }\end{array}$ & $\begin{array}{l}\text { Cycle length } \\
\text { (ms) }\end{array}$ & $\begin{array}{l}\text { VA interval } \\
\text { (ms) }\end{array}$ & $\begin{array}{l}\text { AV interval } \\
\text { (ms) }\end{array}$ & $\begin{array}{l}\text { QRS duration } \\
\text { (ms) }\end{array}$ \\
\hline \multirow[t]{2}{*}{1} & \multirow[t]{2}{*}{$\mathrm{RL}$} & 370 & 170 & 200 & 130 \\
\hline & & 330 & 130 & 200 & 130 \\
\hline \multirow[t]{2}{*}{2} & \multirow[t]{2}{*}{$\mathrm{RE}$} & 360 & 180 & 180 & 140 \\
\hline & & 400 & 180 & 220 & 140 \\
\hline 3 & LPS & 360 & 230 & 130 & 140 \\
\hline \multirow[t]{3}{*}{4} & \multirow[t]{3}{*}{ AS, LL, RPS } & 260 & 70 & 190 & 130 \\
\hline & & 300 & 230 & 70 & 130 \\
\hline & & 290 & 200 & 90 & 140 \\
\hline 5 & LPS & 340 & 210 & 130 & 140 \\
\hline 6 & $\mathrm{RPS}$ & 250 & 150 & 100 & 130 \\
\hline 7 & RPS & 380 & 280 & 100 & 150 \\
\hline \multirow[t]{2}{*}{8} & \multirow[t]{2}{*}{ LL } & 260 & 200 & 60 & 160 \\
\hline & & 300 & 220 & 80 & 140 \\
\hline \multirow[t]{2}{*}{9} & \multirow[t]{2}{*}{ LL } & 300 & 180 & 120 & 160 \\
\hline & & 240 & 130 & 110 & 160 \\
\hline \multirow[t]{3}{*}{10} & \multirow[t]{3}{*}{ LL, LPS } & 290 & 200 & 90 & 140 \\
\hline & & 270 & 150 & 120 & 140 \\
\hline & & 320 & 170 & 150 & 120 \\
\hline 11 & LL & 330 & 210 & 120 & 130 \\
\hline 12 & RPS & 320 & 200 & 120 & 140 \\
\hline 13 & $\mathrm{RL}$ & 280 & 180 & 100 & 160 \\
\hline 14 & LPS & 250 & 120 & 130 & 130 \\
\hline \multirow[t]{2}{*}{15} & \multirow[t]{2}{*}{ RL. LL } & 380 & 220 & 160 & 160 \\
\hline & & 300 & 170 & 130 & 160 \\
\hline \multirow[t]{3}{*}{16} & \multirow[t]{3}{*}{ RL, LPS } & 270 & 190 & 80 & 130 \\
\hline & & 280 & 160 & 120 & 130 \\
\hline & & 270 & 140 & 130 & 140 \\
\hline 17 & $\mathrm{LL}$ & 280 & 180 & 100 & 160 \\
\hline 18 & $\mathrm{LL}$ & 280 & 150 & 130 & 140 \\
\hline 19 & $\mathrm{LL}$ & 380 & 220 & 160 & 130 \\
\hline \multirow[t]{3}{*}{20} & \multirow[t]{3}{*}{ LPS. NV } & 440 & 290 & 150 & 140 \\
\hline & & 430 & 210 & 130 & 140 \\
\hline & & 370 & 200 & 170 & 140 \\
\hline 21 & RL. & 320 & 170 & 150 & 130 \\
\hline 22 & LLL & 360 & 230 & 130 & 140 \\
\hline 23 & LL & 340 & 210 & 130 & 140 \\
\hline 24 & RL, NV & 320 & 180 & 140 & 140 \\
\hline \multirow[t]{2}{*}{25} & \multirow[t]{2}{*}{ RPS, LPS } & 340 & 170 & 170 & 150 \\
\hline & & 320 & 220 & 110 & 130 \\
\hline 26 & LL & 250 & 150 & 100 & 130 \\
\hline
\end{tabular}




\begin{tabular}{llllll}
\hline $\begin{array}{l}\text { Patient } \\
\mathbb{N}^{\circ}\end{array}$ & $\begin{array}{l}\text { Localization } \\
\text { of AP }\end{array}$ & $\begin{array}{l}\text { Cycle length } \\
\text { (ms) }\end{array}$ & $\begin{array}{l}\text { VA interval } \\
\text { (ms) }\end{array}$ & $\begin{array}{l}\text { AV interval } \\
\text { (ms) }\end{array}$ & $\begin{array}{c}\text { QRS duration } \\
\text { (ms) }\end{array}$ \\
\hline 27 & LL & 330 & 210 & 120 & 130 \\
28 & RL, PS & 310 & 170 & 140 & 140 \\
29 & LPS & 270 & 150 & 120 & 140 \\
& & 300 & 230 & 70 & 130 \\
30 & RL, LL, LPS & 380 & 240 & 140 & 140 \\
& & 320 & 200 & 120 & 130 \\
& & 280 & 160 & 120 & 130 \\
31 & 240 & 140 & 100 & 140 \\
32 & LPS & 250 & 120 & 130 & 130 \\
& LPS & 250 & 120 & 130 & 130 \\
33 & LL & 300 & 170 & 130 & 140 \\
34 & LPS. RPS & 300 & 240 & 160 & 160 \\
35 & PS, LPS, RL & 280 & 180 & 130 & 140 \\
36 & & 250 & 140 & 140 & 140 \\
& LPS & 280 & 160 & 90 & 150 \\
\hline
\end{tabular}

Abbreviations: AP=accessory pathway; $A S=a n t e r o s e p t a l ; L L=l e f t$ lateral; $L P S=l e f$ posteroseptal; $\mathrm{NV}=$ nodowentricular; $\mathrm{PS}=$ posteroseptal; $\mathrm{RL}=$ right lateral; $\mathrm{RPS}=$ right posteroseptal

In the 36 patients, 56 distinct antidromic tachycardias were recorded with different mechanisms. In figure 5 the mechanisms are shown. Representative recordings of antidromic circus movement tachycardia are illustrated in figs $1-4,6-9$.

The cycle length of antidromic tachycardia ranged between 240 and 440 $\mathrm{ms}$ (mean $=317 \pm 38$ ). The mean VA interval was $188 \pm 32 \mathrm{~ms}$ (range from 120-290). The mean AV interval was $129 \pm 29 \mathrm{~ms}$ (range 60-200).

During antidromic tachycardia a sudden increase in cycle length was observed in 10 patients ( $28 \%$ ). In 6 patients (17\%) it was caused by a change in retrograde conduction over a bundle branch (14) (sudden increase of the $\mathrm{V}-\mathrm{H}$ interval) (fig. 2). In 4 patients (11\%) it was caused by a shift from a fast to a slow retrograde $\mathrm{A}-\mathrm{V}$ nodal pathway (prolongation of $\mathrm{H}-\mathrm{A}$ interval) (fig. 3 ).

The retrograde limb of antidromic tachycardia was the AV node in 28 patients (78\%) and a second accessory pathway in the remaining 8 patients.

During antidromic tachycardia the mean duration of the QRS complex was $138 \mathrm{~ms} \pm 8 \mathrm{~ms}(130-160)$ in patients who were on antiarrhythmic drugs. and $142 \mathrm{~ms} \pm 8 \mathrm{~ms}(130-160)$ in patients off drugs. There were no differences in the duration of the GRS complex in relation to the localization of the accessory pathway. The narrowest $(130 \mathrm{~ms})$ and the widest $(160 \mathrm{~ms})$ gRS complexes were found in two different patients both having a right lateral 
Table Iil. Refractory periods of atrium, ventricles, av node and accessory pathway

\begin{tabular}{|c|c|c|c|c|c|c|}
\hline Pus & $\begin{array}{l}\text { AEKP (PCL) } \\
\text { (ms) }\end{array}$ & $\begin{array}{l}\text { VERP (PCL) } \\
\text { (ms) }\end{array}$ & $\begin{array}{l}\mathrm{AV}-\mathrm{AERP}(\mathrm{PCL}) \\
\text { (m)s] }\end{array}$ & $\begin{array}{l}\text { AV-RERP (PCL) } \\
\text { (ms) }\end{array}$ & $\begin{array}{l}\text { AP-AERP (PCL) } \\
\text { (ms) }\end{array}$ & $\begin{array}{l}\text { AP-RERP (PCL } \\
\text { (ms) }\end{array}$ \\
\hline 1. & $250(428)$ & $220(500)$ & $\leq 250(428)$ & $310(248)$ & $\leq 250(428)$ & $380(428)$ \\
\hline 2 & $210(428)$ & $170(428)$ & $240(428)$ & $180(428)$ & $240(428)$ & $250(428)$ \\
\hline 3 & $160(500)$ & $190(500)$ & $190(500)$ & NA & $\subseteq 160(500)$ & $280(500)$ \\
\hline 4 & $220(428)$ & $180(428)$ & $\leq 220(428)$ & $\leq 180(428)$ & $280(500)$ & $\leq 180(428)$ \\
\hline 5. & $270(500)$ & $210(428)$ & NA & $\leq 210(428)$ & $\leq 270(500)$ & $300(4.28)$ \\
\hline 6. & $\mathrm{NA}$ & $180(428)$ & NA & $210(428)$ & $120(428)$ & $\leq 180(428)$ \\
\hline 7. & $220(428)$ & $220(500)$ & $280(428)$ & $250(600)$ & $280(428)$ & $400(600)$ \\
\hline 8. & $190(600)$ & $210(428)$ & $\leq 190(600)$ & $250(428)$ & $260(500)$ & $\leq 210(428)$ \\
\hline 9. & $260(600)$ & $190(428)$ & $280(500)$ & $\leq 190(428)$ & $280(600)$ & $270(428)$ \\
\hline 10 & $190(428)$ & $220(428)$ & $200(428)$ & $\leq 220(4.28)$ & $\leq 190(500)$ & $240(428)$ \\
\hline 11. & $190(428)$ & $200(500)$ & $\leq 190(428)$ & $\leq 200(500)$ & $\leq 190(428)$ & $\leq 200(500)$ \\
\hline 12. & $220(428)$ & $220(428)$ & $280(428)$ & $\leq 220(428)$ & $270(428)$ & $\mathrm{NA}$ \\
\hline 13. & $230(428)$ & $190(4.28)$ & $\leq 230(600)$ & $220(428)$ & $280(500)$ & $\mathrm{NA}$ \\
\hline 14. & $200(428)$ & $210(500)$ & $\leq 200(428)$ & NA & $240(428)$ & $\mathrm{NA}$ \\
\hline 15. & $210(428)$ & $200(428)$ & $350(600)$ & NA & $330(500)$ & $\leq 200(428)$ \\
\hline 16. & $200(428)$ & $200(428)$ & $250(500)$ & $230(428)$ & $230(500)$ & NA \\
\hline 17. & $220(500)$ & $190(428)$ & $\leq 220(500)$ & $\leq 210(500)$ & $250(500)$ & $240(428)$ \\
\hline 18. & $210(428)$ & $220(428)$ & $260(428)$ & $240(428)$ & $240(428)$ & $240(428)$ \\
\hline 19. & $270(600)$ & $210(428)$ & NA & $320(428)$ & $400 .(500)$ & NA \\
\hline 20. & $250(428)$ & $250(600)$ & NA & $320(500)$ & $310(500)$ & $460(500)$ \\
\hline 21. & $240(500)$ & $260(500)$ & $260(500)$ & $280(500)$ & $300(500)$ & $270(500)$ \\
\hline 22 & $170(500)$ & $190(428)$ & $200(600)$ & $210(428)$ & $210(500)$ & $250(500)$ \\
\hline 23. & $220(428)$ & $210(428)$ & $250(600)$ & NA & $230(510)$ & $280(500)$ \\
\hline 24. & $230(428)$ & $280(500)$ & $\leq 230(428)$ & $\leq 280(500)$ & $\leq 230(428)$ & $\mathrm{NA}$ \\
\hline 25. & $180(428)$ & $180(500)$ & $190(428)$ & $\leq 180(428)$ & $\leq 180(428)$ & $\leq 180(428)$ \\
\hline 26. & $190(600)$ & $180(428)$ & $220(500)$ & $\leq 180(428)$ & $210(500)$ & $\leq 180(428)$ \\
\hline 27. & $190(428)$ & $200(500)$ & $\leq 190(428)$ & $\mathrm{CNM}$ & $\leq 190(428)$ & $\leq 200(500)$ \\
\hline 20. & $220(428)$ & $210(428)$ & $230(500)$ & $\leq 210(428)$ & $240(428)$ & $\leq 210(428)$ \\
\hline 29. & $220(428)$ & $220(428)$ & $280(428)$ & $\leq 220(428)$ & $270(428)$ & $290(500)$ \\
\hline 30. & $200(428)$ & $200(500)$ & $\leq 200(428)$ & $\leq 200(500)$ & $\leq 200(428)$ & NA \\
\hline 31. & $230(428)$ & $190(428)$ & $250(500)$ & $210(428)$ & $\leq 230 \| 600 \pi$ & $220(428)$ \\
\hline 32 & $200(428)$ & $210(600)$ & $\leq 200(428)$ & $240(600)$ & $240(600)$ & $\leq 210(600)$ \\
\hline 39. & $200(600)$ & $220(600)$ & NA & $\leq 220(600)$ & $\leq 200(600)$ & $\leq 220(600)$ \\
\hline 34 & $200(600)$ & $200(500)$ & $210(428)$ & NA & $260(428)$ & NA \\
\hline 35. & $190(428)$ & $\| 60 \quad(428)$ & $270(428)$ & $\leq 160(428)$ & $270(428)$ & $\leq 160(428)$ \\
\hline 36. & $220(500)$ & $200(500)$ & $230(500)$ & $\leq 200(500)$ & NA & \\
\hline
\end{tabular}

Abbreviations: $\mathrm{AERP}=$ atrial elfective refractory pertod: VERP = ventricular effective refractory perlod: $A V-A E R P=$ atro-ventrlcular nodal anterograde effective refractory period: $A V-R E R P=$ His AV nodal retrograde effective relractory period; AP-AERP= accessory pathway anterograde effective refractory period: AP-RERP= accessory pathway retrograde effective refractory period: $\mathrm{PCL}=$ pacing cycle length. 
A

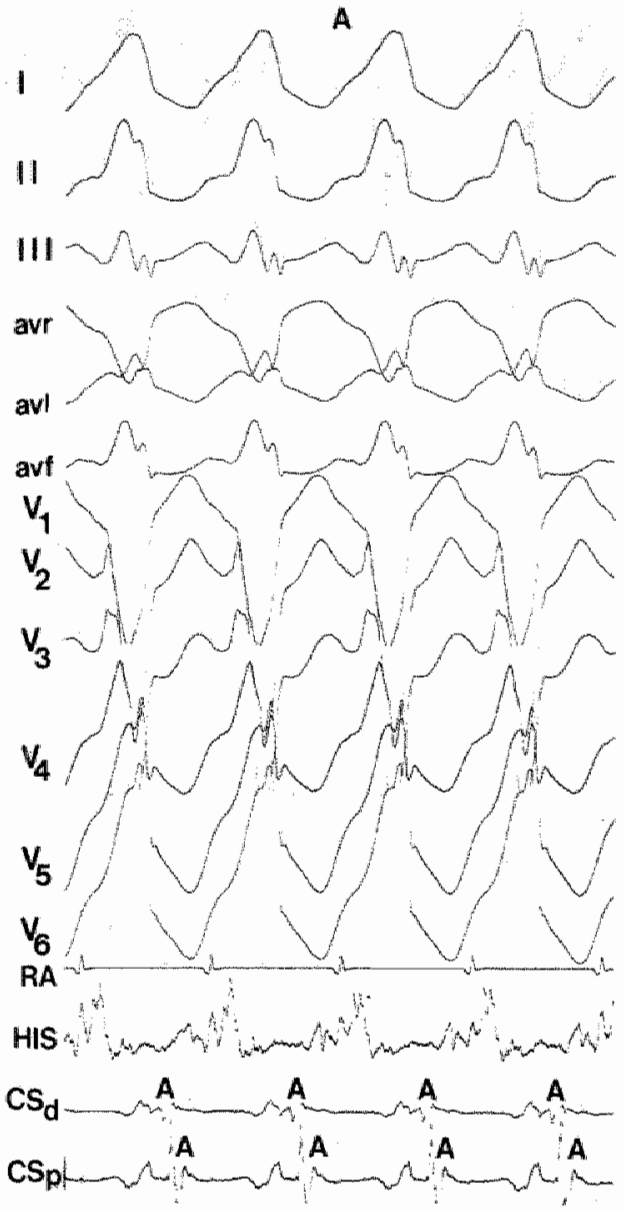

B
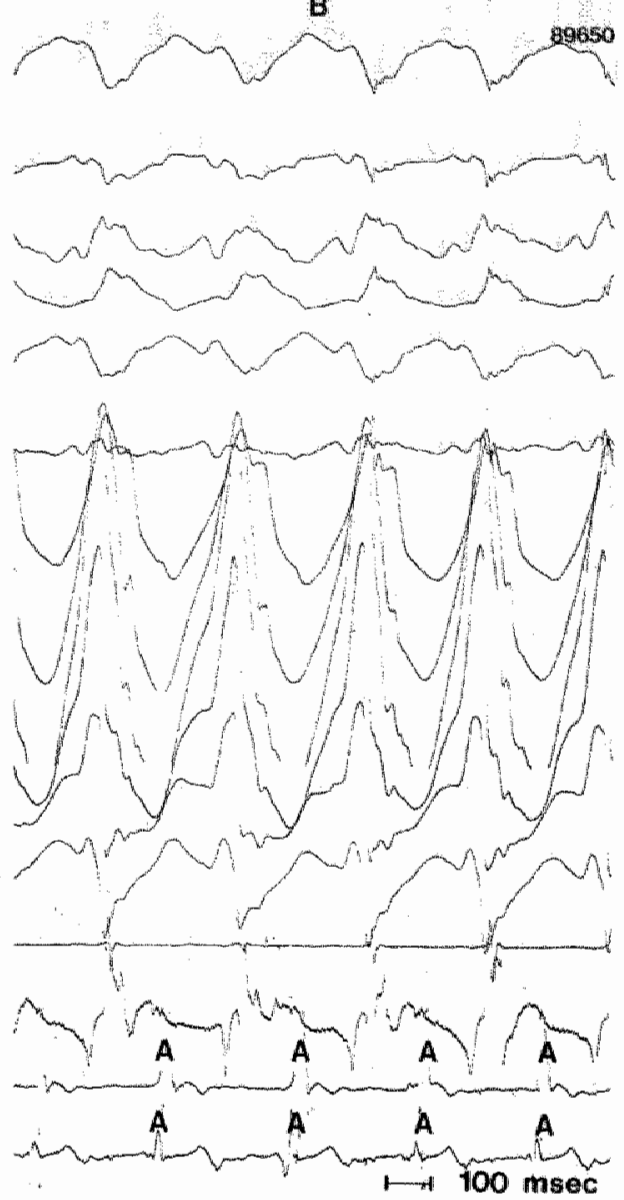

Figure 1. In panels A and B a 12 lead electrocardiogram, bipolar electrograms from the high right atrium (RA),bundle of His, coronary stnus distal (CSd) and proximal (CSp) during antidromic tachycardia are shown from the same patient. In panel A an antidromic circus movement tachycardla using anterogradely a right-sided accessory pathway and retrogradely a left-sided accessory pathway is present. Panel B shows antidromic circus movement tachycardia using anterogradely a leit-sided accessory pathway and retrogradely the normal A-V conduction system. 

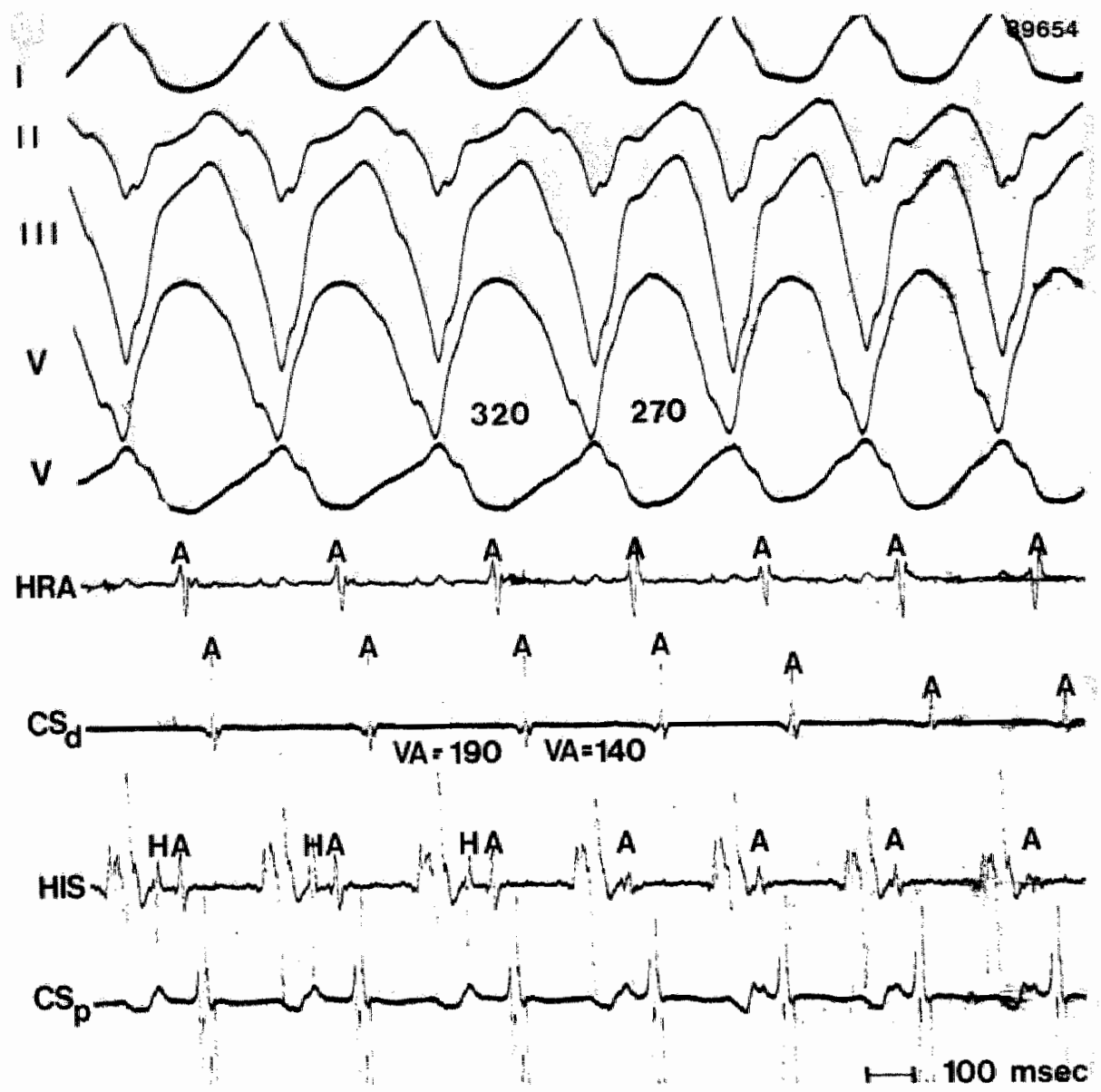

Figure 2. An anitidromic tachycardia using a right-sided accessory pathway in the anterograde direction and the AV node in the retrograde direction is shown. During the first three beats the cycle length is $320 \mathrm{~ms}$ with a V-A interval of $190 \mathrm{~ms}$. The H-A traterval is $50 \mathrm{~ms}$. The cycle length decreases suddenly to $270 \mathrm{~ms}$ with a shortening of the $\mathrm{V}$-A interval to $140 \mathrm{~ms}$, because of a sudden shortening in the $\mathrm{V}$-H interval. That is caused by disappearence of retrograde block in the bundle branch. Five surface electrocandiographlc leads and four intracardiac leads are shown. High right atrium (RA), distal coronary sinus (CSd), bundle of His (HIS) and proximal coronary sinus (CSp). 


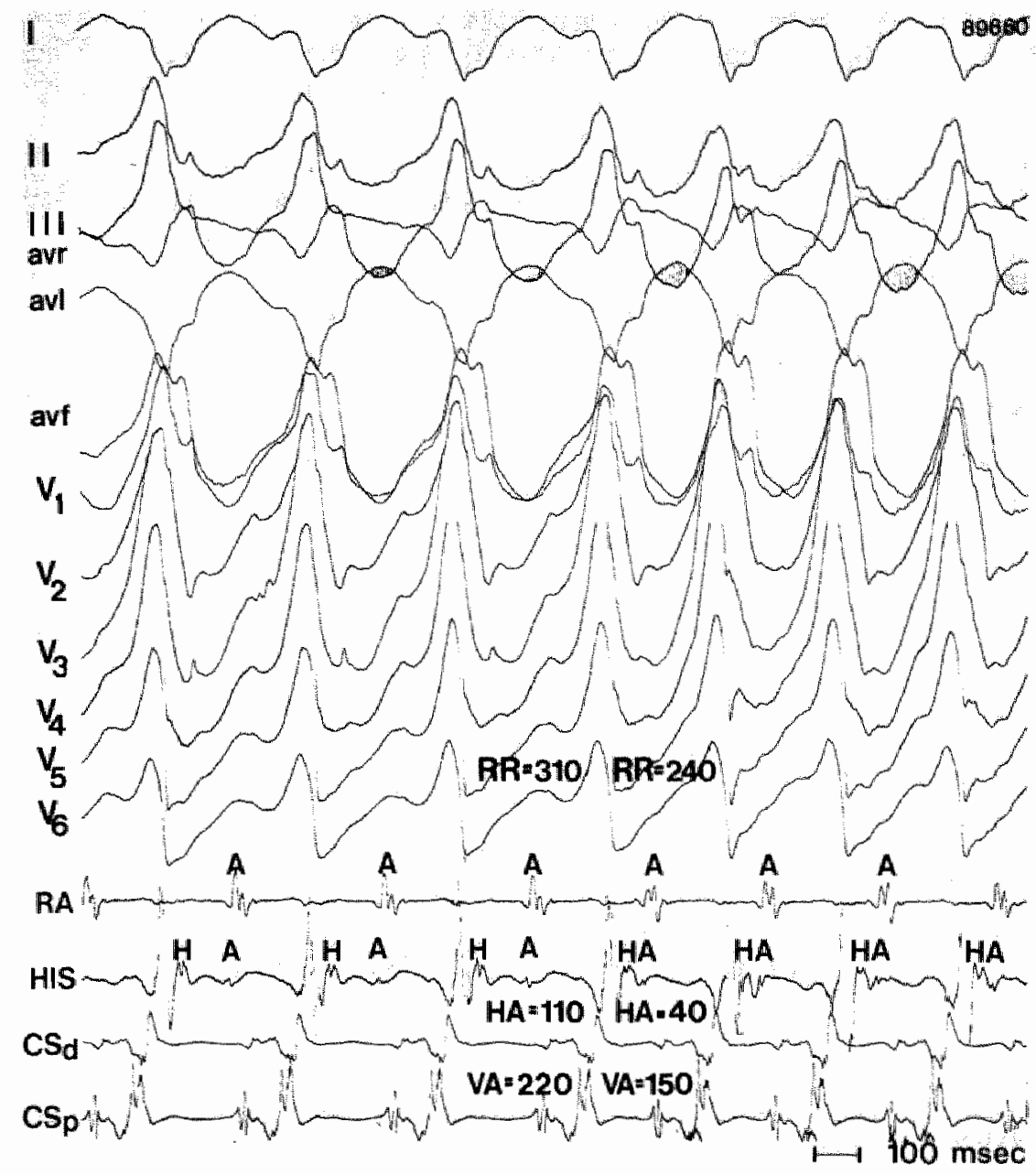

Figure 3. Twelve lead electrocardiogram and intracardtac electrograms from the high right atrium (RA), bundle of His (HIS), distal coronary sinus (CSd) and proximal coronary sinus (CSp) are shown. Antidromic circus movement tachycardia initlally having a cycle length of $310 \mathrm{~ms}$ showing shortening to $240 \mathrm{~ms}$ because of shortening in the H-A interval. Duringtachycardia with the longer cycle length, retrograde conduction occured over a slowly conducting retrograde atrio-ventricular nodal pathway. Tachycardla accelerated when retrograde conduction shifted to a faster conducting retrograde atrio-ventricular nodal pathway. 


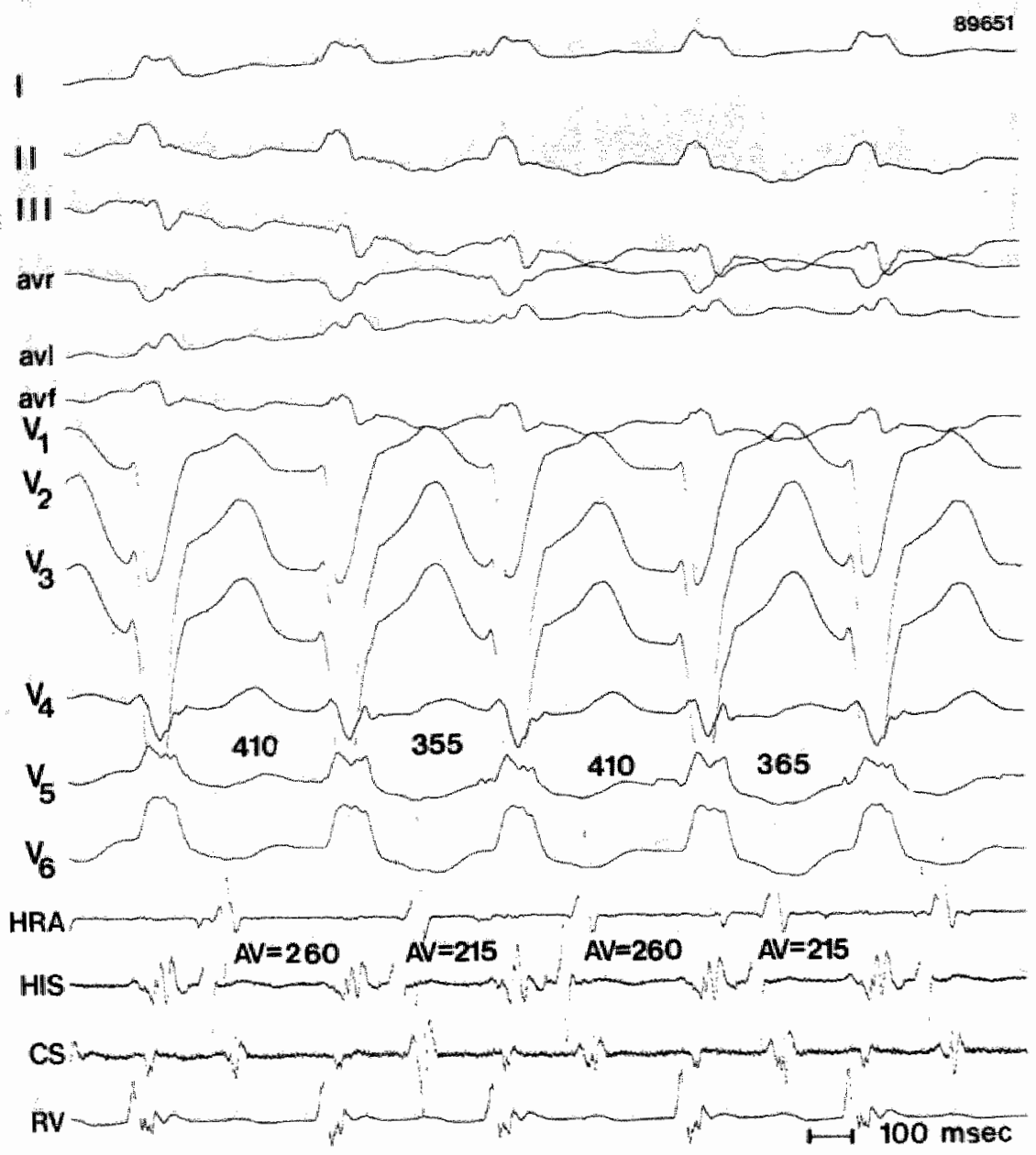

Figure 4. Twelve surface electrocardlographic leads and four intracardiac electrograms are shown. Antidromic circus movement tachycardia using anterogradely a right sided accessory pathway with long conduction time and retrogradely the AV node is shown. There is alternation in cycle length of the tachycardla of $45 \mathrm{~ms}$ because of changes in the A-V interval, without significant changes in the morphology of the gRS complex and V-A interval. This phenomenon can be explatned by elther functional longitudinal dissociation in anterograde conduction over the accessory pathway or alternating anterograde conduction over two closely adjacent located accessory pathways. 
accessory pathway. One has to realize, however, that exact measurement of the duration of the QRS complex during antidromic tachycardia is difficult. particularly in fast tachycardias.

\section{Initiation of antidromic tachycardia}

Atrial premature beat(s) initiated antidromic tachycardia in 30 patients (83\%), and ventricular premature beat(s) initiated the arrhythmia in 16 patients $(45 \%)$. In 10 patients $(28 \%)$ both atrial and ventricular premature beat(s) initiated antidromic tachycardia. There were no statistical differences in induction of antidromic tachycardia from the atrial level between patients with one or multiple accessory pathways. Ventricular premature beat (s). however, initiated the antidromic tachycardia in $67 \%$ of patients with multiple accessory pathways and in $33 \%$ of patients with a single accessory pathway ( $p<0.01$ ) (table IV). In one patient orthodromic circus movement tachycardia changed spontaneously into antidromic tachycardia (fig. 8). In three patients this phenomenon was observed after atrial or ventricular premature beats (fig. 7). In 3 patients with multiple accessory pathways, one type of antidromic tachycardia changed spontaneously to a second type of antidromic tachycardia (fig. 9). That was also observed after induced atrial or ventricular premature beats, in two patients.

Table IV. Modes of initiation of antidromic tachycardia

\begin{tabular}{|c|c|c|}
\hline $\begin{array}{l}\text { Mode of } \\
\text { Initiation }\end{array}$ & $\begin{array}{l}\text { One accessory } \\
\text { pathway } \\
\text { ( } 24 \mathrm{pts} \text { ) }\end{array}$ & $\begin{array}{l}\text { Multiple accessory } \\
\text { pathways } \\
\text { (12 pts) }\end{array}$ \\
\hline $1 \mathrm{APB}$ & 20 pts $(83 \%)$ & 8 pts (67\%) \\
\hline $2 \mathrm{APB}$ & $1 \mathrm{pt}(4 \%)$ & $1 \mathrm{pt} \quad(8 \%)$ \\
\hline $1 \mathrm{VPB}$ & $6 \mathrm{pts}(25 \%)$ & 6 pts $(50 \%)$ \\
\hline 2 VPB & 2 pts $(8 \%)$ & $2 \mathrm{pts}(17 \%)$ \\
\hline RAP & 9 pts $(37 \%)$ & $2 \operatorname{pts}(17 \%)$ \\
\hline
\end{tabular}

Abbreviations: $\mathrm{APB}=$ atrial premature beat; $\mathrm{RAP}=$ rapid atrial pacing; $\mathrm{pts}=$ patients: $\mathrm{VPB}=$ ventricular premature beat. 


\section{Termination of antidromic tachycardia}

Termination of antidromic tachycardia occurred spontaneously in 8 patients $(22 \%)$. Atrial premature beats terminated tachycardia in 23 patients and ventricular premature beats in 19 patients. In one patient antidromic tachycardia changed spontaneously into orthodromic tachycardia. Three patients showed this phenomenon following atrial or ventricular premature beats (fig. 8). In 17 patients (47\%) termination of tachycardia occurred because of block in the retrograde pathway. In 14 in the AV conduction system and in 3 in a second accessory pathway. In 19 patients (53\%) termination of tachycardia occurred because of block in the accessory pathway conducting anterogradely.

Figure 5. Diagrams illustrating the different types of antidramic circus movement tachycardias. $\mathrm{A}=$ atrlum; $\mathrm{AVN}=\mathrm{A}-\mathrm{V}$ node; $\mathrm{AP}=$ accessory atrioventricular pathway; $\mathrm{FAVN}=$ fast $\mathrm{A}-\mathrm{V}$ nodal pathway: SAVN= slow A-V nodal pathway; 1. Antidromic clrcus movement tachycardia with anterograde conductlon over an accessory atrioventricular pathway and retrograde conduction over a fast A-V nodal pathway. 2. Antidromic circus movement tachycardia with anterograde conduction over an accessory atrioventricular pathway and retrograde conduction over a slow A-V nodal pathway: 3 . Antidromic clrcus movement tachycardia with anterograde conduction over an atrioventricular accessory pathway with long conduction times and retrograde conduction over the $A-V$ node; 4 . Antidromic circus movement tachycardia with anterograde conduction via an accessory atrioventricular pathway and retrogradely over the AV node, with ipsillateral retrograde bundle branch block; 5. Antidromic circus movement tachycardia with anterograde conduction over an accessory atrioventricular accessory pathway and retrograde conductlon over a second accessory pathway: 6. Antidromic circus movement tachycardia with anterograde conduction over an accessory atrioventricular pathway with long conduction times and retrograde conduction via a second accessory pathway: 7 . Antidromlc circus mowement tachycardia with anterograde conduction over two accessory atrioventricular pathways with fusion at the ventricular level and retrograde conduction over the A-V node; 8 . Antidromic ctrcus movement tachycardla with anterograde conduction over both an accessory atrioventricular pathway and the AV node His-Purkinje system and retrograde conduction by way of a second accessory pathway: 9. Antidromic circus movement tachycardia with anterograde conduction over an accessory atrioventricular pathway and retrograde conduction over both the AV node and a second accessory pathway; 10. Preexclted reciprocating tachycardia with anterograde conduction over a nodoventricular accessory pathway and retrograde over the AV nodie: 11 . Preexcited reciprocating tachycardia with anterograde conduction over a nodoventricular accessory pathway and retrograde conduction via an accessory atrioventricular pathway: Types 10 and 11 are antidromic circus movement tachycardias using nodo-ventricular fibers and are not included in the patients described in this article. 

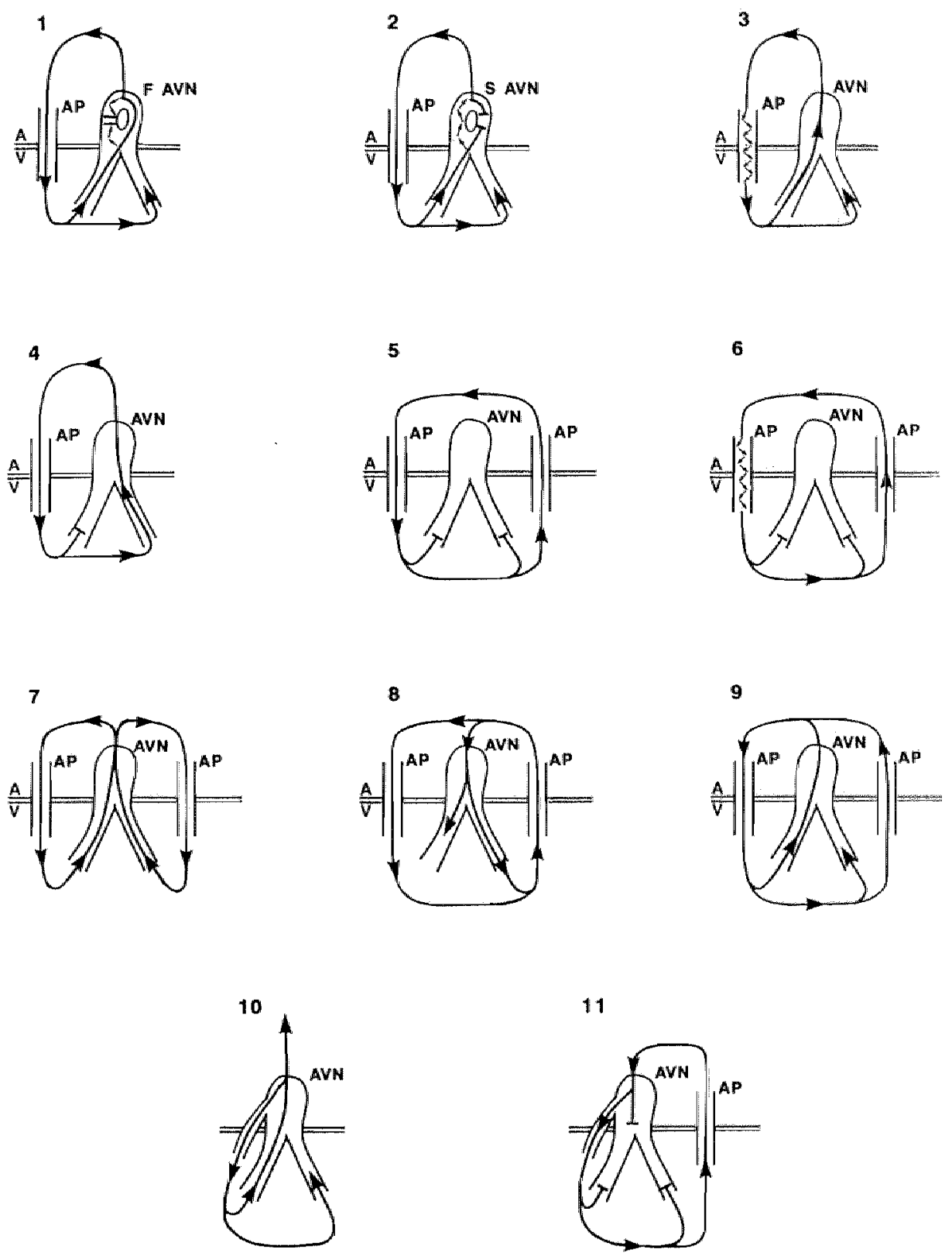

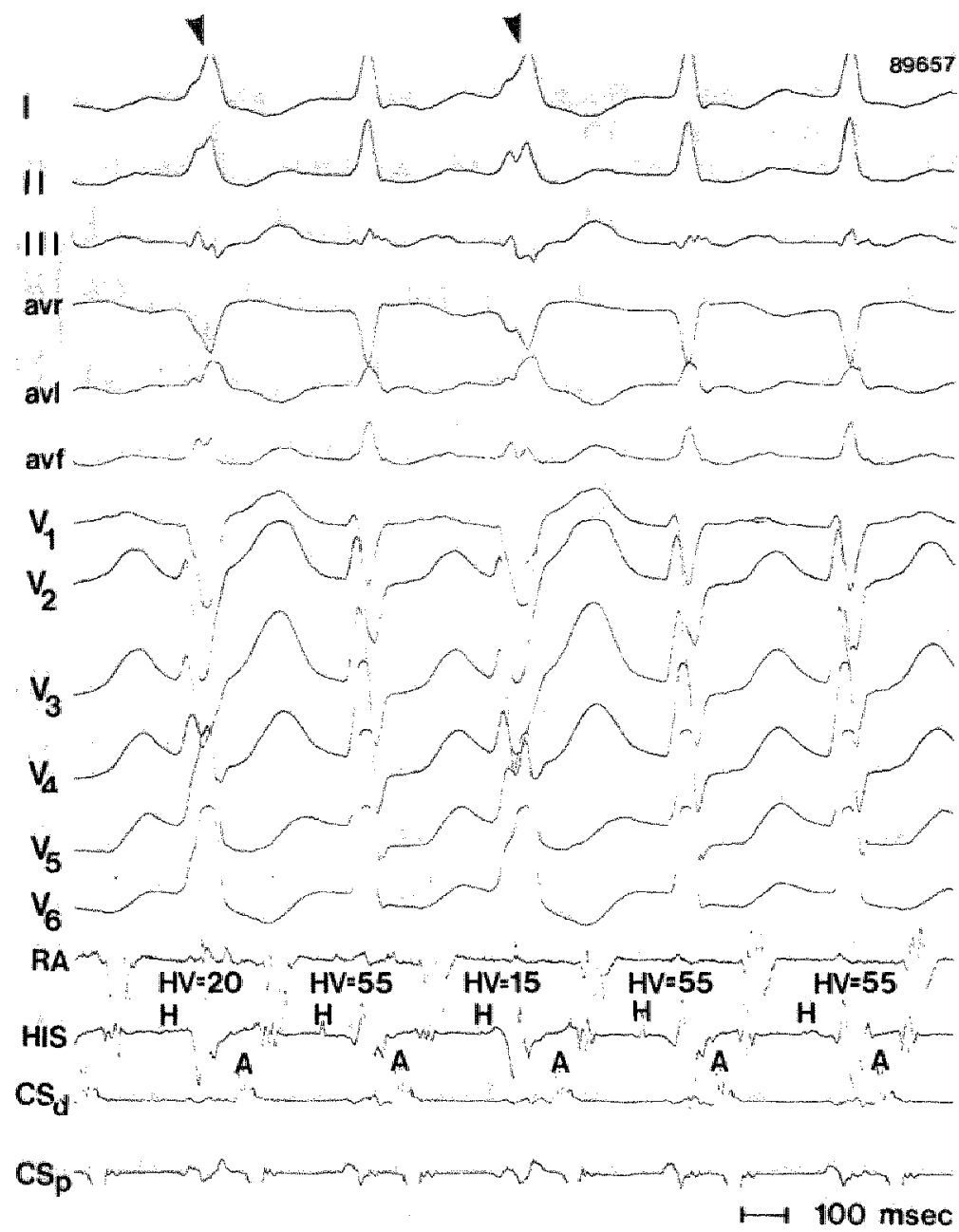

Figure 6. Twelve lead electrocardiogram and 4 intracardiac leads are shown. Orthodromic circus movement tachycardla conducting retrogradely over a left-sided accessory pathway is lllustrated. The first and third complexes (arrows) are fustion beats because of anterograde conduction over a second accessory pathway. Note the shortening in the H-V interval preceding these fustion beats. 

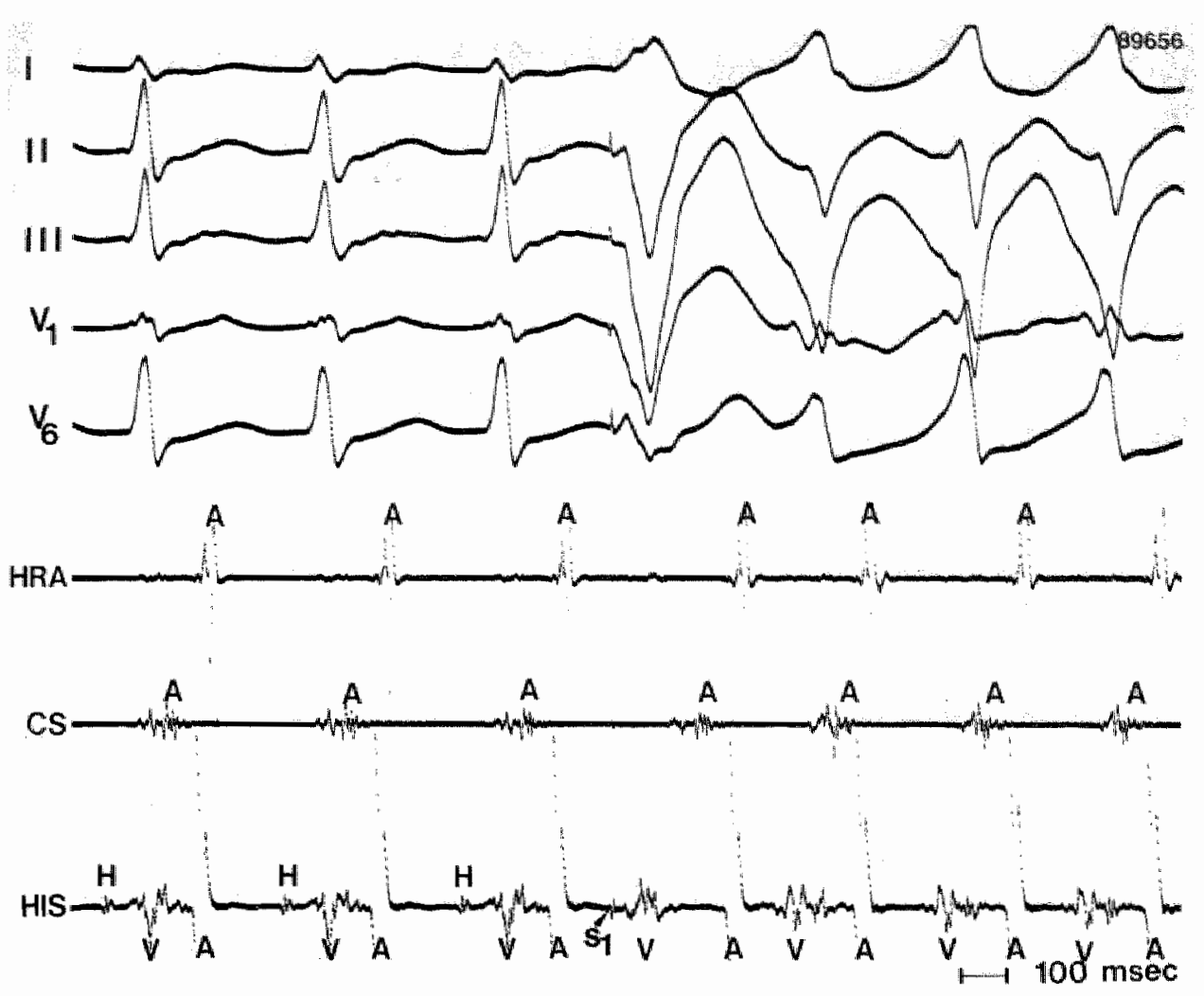

Figure 7. Five surface electrocardiographic leads and three intracardiac leads from a patient with two accessory atrloventricular pathways, one left lateral and the other left posteroseptal. One ventricular premature beat changes orthodromic circus movernent tachycardta conducting retrogradely over the left lateral accessory pathway into antidromic circus movement tachycardla with anterograde conduction over the left posteroseptal accessory pathway.

\section{Assoclated arrhythmias}

In 26 patients (72\%) orthodromic tachycardia was also induced during the study, 18 of them also having clinical documentation of orthodromic tachycardia. The mean cycle length ( $334 \pm 42 \mathrm{~ms}$ ) was longer than the cycle length of antidromic tachycardia ( $317 \pm 38 \mathrm{~ms}$ ), however, without reaching statistical significance.

No differences were found between patients with one or multiple accessory pathways concerning the cycle length of orthodromic and antidromic tachycardia in the same patient.

Dual AV nodal pathways were diagnosed in 12 patients (33\%). In 2 patients $(5 \%) \mathrm{A}-\mathrm{V}$ nodal tachycardia of the slow-fast type could be initiated. 


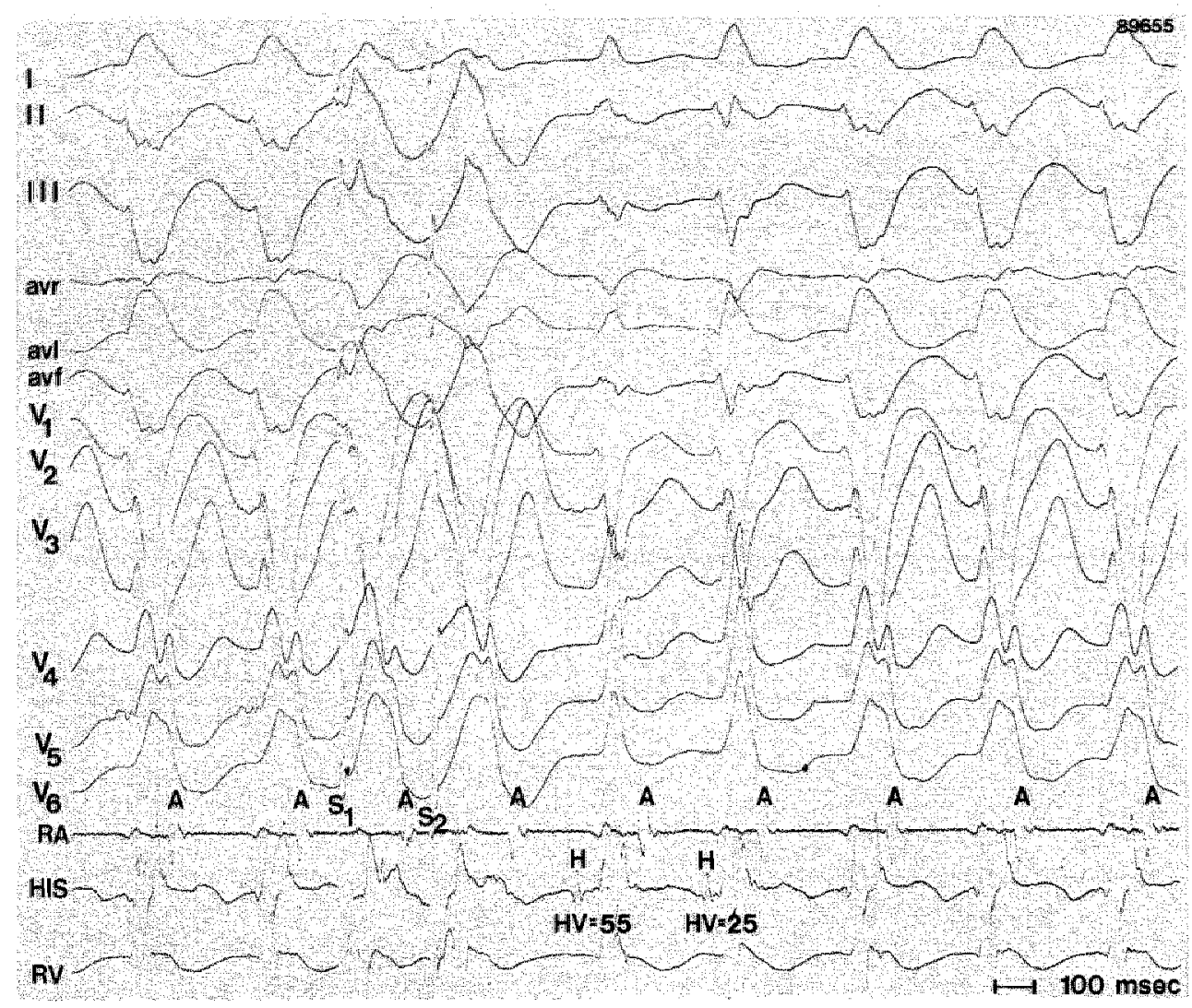

Figure 8. Twelve lead electrocardiogram and three intracardiac leads from a patient with multiple accessory pathways. Two ventricular premature beats change an antidromic clrcus movement tachycardia, conducting anteragradely over a right sided accessory pathway with long conduction times into orthodromic clrcus movement tachycardia. The second beat of the orthodinomic circus movement tachycardla is a fuslon beat resulting from conduction over the AV node and a second accessory pathway. Orthodromic tachycardla shifts spontaneously to antidromic circus movement tachycardia.

Atrial fibrillation was induced in 17 patients (47\%), and the shortest RR interval during atrial fibrillation ranged from $160 \mathrm{~ms}$ to $400 \mathrm{~ms}$ (mean $225 \pm$ $35 \mathrm{~ms})$. Initiation of atrial fibrillation was possible by one or two atrial premature beats in 4 patients $(27 \%)$ and by pacing the atria at high rates $( \pm$ 200 beats $/ \mathrm{min}$ ) in 13 patients $(73 \%)$. In one patient one ventricular premature beat during sinus rhythm induced atrial fibrillation. Spontaneous termination of atrial fibrillation was observed in $8 / 17$ patients $(47 \%)$, the remaining 9 patients $(53 \%)$ had to be cardioverted.

Four patients developed atrial flutter and one patient atrial tachycardia during the electrophysiological study. 

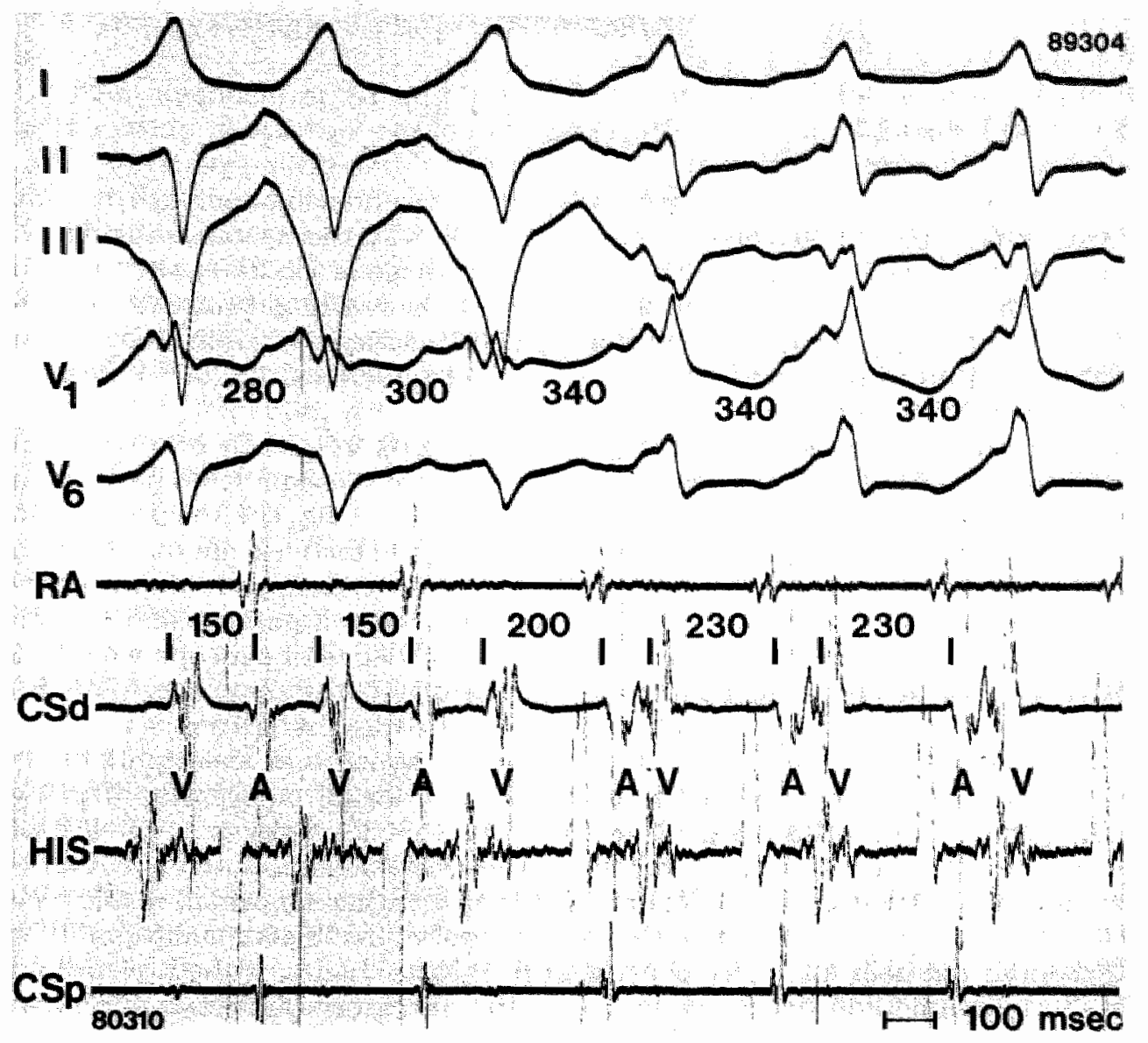

Figure 9. Five surface electrocardlographlc leads and four intracardiac leads showing a spontaneous change from one antidromic circus movement tachycardia into another antdromic circus movement tachycardia. The first three beats show anterograde conduction over a left posterior accessory pathway, and the last 3 beats over a left lateral accessory pathway.

\section{Surgery}

Twenty patients were submitted to surgical ablation of the accessory pathway. Eleven of them had a single accessory pathway, 7 two accessory pathways and 2 three accessory pathways. Three patients had to be reoperated within the first week because of a recurrence of a delta wave or tachycardia. Two patients had a reoperation 6 and 8 months after the first surgery, because of a recurrence of tachycardia. After a mean follow up of 14 \pm 6 months, one patient had a recurrence of a delta wave but did not suffer from spontaneous tachycardias. 


\section{DISCUSSION}

\section{Clinfical findings}

The age ( $26 \pm 12$ years) of our patients with antidromic tachycardia was lower but not statistically different from that of patients only having an orthodromic tachycardia. In our series the mean age of the 319 patients with only orthodromic tachycardia in the Wolff-Parkinson-White syndrome was 35 \pm 14 years. The prevalence of male patients $(72 \%)$ with antidromic tachycardia is higher than in patients with only orthodromic tachycardia $(60 \%)$. Similar findings have been previously published (18).

The onset of complaints in the antidromic group frequently occurred at a very young age (table I). Also with medical treatment these patients had a high number of tachycardia recurrences per month $(4.5 \pm 3)$. The most common symptom was palpitations. Patients with antidromic tachycardia had a much higher incidence of dizziness $(61 \%)$ and syncope $(50 \%)$ than patients with only orthodromic tachycardia (19). In the 18 patients who clinically suffered from antidromic circus movement tachycardia the incidence of syncope was $67 \%$ (12 patients), a much higher prevalence, compared with our own patients with only orthodromic tachycardia (7\%) and the literature (20).

One may suggest that one of the reasons for syncope in these patients is the abnormal pattern of ventricular contraction during tachycardia. During antidromic tachycardia the contraction of the ventricles starts at the site of insertion of the accessory pathway in the ventricle and consequently contraction of the ventricles occurs like in ventricular tachycardia, which may cause significant hemodynamic changes in some patients. Theoretically, another reason for the high incidence of syncope in these patients, is the presence of a short anterograde refractory period of the accessory pathway which can result in high ventricular rates during atrial fibrillation. However, some patients that developed syncope, had a relatively long anterograde refractory period of the accessory pathway, and most of them did not have clinical documentation of atrial fibrillation or induction of this arrhythmia during electrophysiologic study.

There was a high incidence of ventricular fibrillation in our group of patients (11\%) compared to the occurrence of this arrhythmia in the general population of Wolff-Parkinson-White syndrome $(21.22)$. Spontaneous occurrence of atrial fibrillation during antidromic tachycardia with the development of excessively rapid ventricular rates has been demonstrated (23). Although this is the most frequent mechanism of ventricular fibrillation in the Wolff-Parkinson-White syndrome, some patients with Wolff-Parkinson-White syndrome can have ventricular fibrillation secondary to other causes (coronary artery disease or long QT due to medication) (22). In our study, all four patients who suffered from ventricular fibrillation had a very short anterograde refractory period of their accessory pathway, 2 of them having multiple accessory pathways. None had other cardiac abnormalities. 


\section{Electrophysiological characteristics}

The diagnosis of an antidromic circus movement tachycardia requires information about the cardiac activation sequence during tachycardia and proof of participation of the accessory pathway in the reentrant circuit to be able to distinguish that type of tachycardia from other arrhythmias.

The incidence of antidromic tachycardia in patients with Wolff-ParkinsonWhite syndrome, varies from $7 \%$ to $15 \%$ in different studies $(18,25)$. In our series, the incidence was $11 \%$. The presence of multiple accessory pathways in patients with antidromic tachycardia was 33\% (12/36 patients). However when we consider patients who had clinically documented antidromic tachy cardia (18 patients), the incidence of multiple accessory pathways in this group rose to $61 \%$ (11 patients). Thus, the observation of a spontaneously occurring antidromic tachycardia strongly suggests the presence of multiple accessory pathways.

\section{Antidromic tachycardia}

During electrophysiological study antidromic circus movement tachycardia was generally well tolerated hemodynamically, no patient required cardioversion because of associated hypotension. The high incidence of a previous history of syncope in these patients, in spite of a low incidence of atrial fibrillation, suggests that the antidromic tachycardia might be poorly tolerated in circumstances other than in the supine position in the laboratory. We also wonder about the possibility of deterioration of an antidromic tachycardia into ventricular fibrillation. While it is generally believed that ventricular fibrillation usually occurs secondary to atrial fibrillation with a high ventricular rate because of a short anterograde refractory period of the accessory pathway, we cannot exclude that antidromic tachycardia which hemodynamically behaves like ventricular tachycardia, may deteriorate into ventricular fibrillation.

We observed 9 different pathways during antidromic tachycardia in the 56 different antidromic tachycardias induced.

A spontaneous change from orthodromic to antidromic tachycardia or one induced by atrial or ventricular premature beat occurred in 4 patients. One should realize that this type of change can only occur in the presence of three different atrioventricular pathways. All our 4 patients showing this phenomenon had multiple atrioventricular accessory pathways.

A-V nodal tachycardia with "bystander" participation of the accessory pathway can occur in patients with the Wolff-Parkinson-White syndrome $\{10,11)$ and the differential diagnosis between antidromic tachycardia can be difficult. In our study no patient with antidromic tachycardia fulfilled the criteria for A-V nodal tachycardia using the accessory pathway as a "bystander". Also none of the 20 patients in whom the accessory pathway[s] was interrupted surgically developed $\mathrm{A}-\mathrm{V}$ nodal tachycardia during follow-up. 
Another consideration, is that antidromic tachycardia was induced by ventricular premature beat(s) in 16 patients, which is an uncommon mechanism of initiation of an A-V nodal tachycardia.

In 2 patients A-V nodal tachycardia with a narrow QRS complex could be induced during programmed electrical stimulation. During the antidromic tachycardia in these 2 patients, we were able to prove participation of both atria and ventricles in the tachycardia circuit, confirming the antidromic nature of the circus movement.

Three patients presented electrophysiologic features initially suggesting a "Mahaim" type of accessory pathway. However, all three had an accessory atrioventricular pathway with long conduction times. This was demonstrated at the time of surgery or during the electrophysiologic study, by advancing ventricular activation during tachycardia by an atrial premature beat given at the time of onset of retrograde atrial activation (26).

In conclusion, antidromic circus movement tachycardia occurred in $11 \%$ of our patients with the Wolff-Parkinson-White syndrome. Clinical documentation of antidromic tachycardia occurred less frequently $(6 \%)$ and was associated with a high incidence of syncope. There is a high incidence (33\%) of multiple accessory pathways in patients in whom antidromic tachycardia can be induced, and even higher in patients with clinically documented antidromic tachycardia (61\%). Palpitations were the most common symptom, however dizziness and syncope occurred in a high percentage of patients with antidromic circus movement tachycardia. There was also a high incidence of previous ventricular fibrillation $(11 \%)$ in these patients.

Many different pathways are possible during antidromic tachycardia. Like others, we found that surgery has a high success rate in the treatment of these patients. 


\section{REFERENCES}

1. Wellens HJJ. Electrical stimulation of the heart in the study and treatment of tachycardias. Baltimore, University Park Press 1971: pp 74-121.

2. Gallagher JJ, Pritchett ELC, Sealy WC, Kasell J, Wallace AG. The preexcitation syndromes. Prog Cardlovasc Dis 1978; 20: 285-327.

3. Cosio FG. Benson DW, Anderson RW, Hession WT, Pritzer MR, Kriett JM, Benditt DG. Onset of atrial fibrillation during antidromic tachycardia: association with sudden cardiac arrest and ventricular fibrillation in a patient with Wolff-Parkinson-Whtte syndrome. Am J Cardiol 1982: 50: 353-359.

4. Heddle WF, Brugada P. Wellens HJJ. Multiple circus movement tachycardias with multiple accessory pathways. $J$ Am Coll Cardiol 1984; 4: 168-175.

5. Chung EK, Walsh TJ, Massie E. Wollt-Parkdnson-White syndrome. Am Heart J 1965; 69: 116-133.

6. Wellens HJJ, Durrer D. Patterns of ventriculo-atrial conduction in the Woll-ParkinsonWhite syndrome. Circulation 1974: 49:22-41.

7. Fontaine $\mathrm{G}_{*}$ Frank $\mathrm{R}$, Coutte $\mathrm{R}$. Vedel JP Grosgogeat $\mathrm{Y}$. Rhythme reciproque antidromique dans un syndrome de Wolf-Parkinson-White de Type A. Ann Cardiol Angeiol 1975; 24: 59-66.

8. Benditt DG, Pritchett ELC, Gallagher JJ. Spectrum of regular tachycardias with wide QRS complexes in patients with accessory atrioventricular pathways. Am J Cardilol 1978; 42: 828-838.

9. Alkhtar M. Electrophystologic bases for wide QRS complex tachycardla. Pace 1983; 6 : $81-98$

10. Smith WM, Broughton A, Reiter MJ, Benson DW, Grant AO, Gallagher JJ. Bystander accessory pathway during AV node re-entrant tachycardia. Pace 1983; 6: 537-547.

11. Zlpes DP, DeJoseph RL, Rothbaum DA. Unusual properties of accessory pathways. Circulation. 1974: 49: 1200-1214.

12. Wellens HJJ. Modes of initiation of circus movement tachycardia in 139 patients with the Wolff-Parkinson-White syndrome studied by programmed electrical stimulation. In. Reentrant Arrhythmias. Mechanisms and Treatment (Kulbertus HE, ed). Lancaster, MTP Press, 1977, p 153-169.

13. Grolleau $R$, Dufolx $\mathbb{R}$, Puech $P$, Latoue $H$. Les tachycardies par rhythme reciproque dans le syndrome de Wolff-Parkinson-White. Arch Mal Coeur 1970; 63: 74-96. 
11.4. Kuck KH. Brugada P. Wellens HuJ: Observations on the antidromic circus movement tachycardia in the Wolr-Parkinson-White syndrome. I Am Coll Cardiol 19:83: 2: 1003* 1010 .

15. Sung RI, Castellanos A, Mallon SM, Bloom MG, Gelband $H$, Myerburg RI. Mechanisms of spontaneous alternation between rectprocating tachycardia and atrial futter fibrillation In the Wolff-Parkinson-White syndrome. Circulation 1977: 56: 409-417.

16. Wellens $\mathrm{HW}_{\mathrm{J}} \mathrm{J}$, Durrer $\mathrm{D}$. The role of an accessory atrioventricular pathway in reciprocal tachycardia. Observation in patients with and without Wolff-Parkinson-White syndrome. Crrculation $1975 ; 52: 58-64$.

17. Belhassen B, Misrahi D, Shapira 1 "Laniado S. Longitudinal dissociation in an anomalous accessory atriowentricular pathway. Am Heart J 1983; 106: 1441-1443.

18. Bardy GH, Packer DL, Lawrence DG, Gallagher JJ. Preexcited reciprocating tachycardia in patients with Wolff-Parkinson-White syndrome: incidence and mechanisms. Circulation 1984: 70: $377-391$.

19. Klein GJ, Sharma AD, Mustein S. Inttal evaluation of the patient with the Wolff-Parkinson-White syndrome. In Benditt DG, Benson DW, eds: Cardiac Preexcitation Syndromes: Origin, Evaluation and Treatment. Martinus Nijhof Publishing. Boston, 1986; p 305-320.

20. Sherf $\mathrm{L}_{n}$ Neufeld HN: General consideration. In Sherf L. Neufeld HN, eds: The pre-excitation syndrome: Facts and theorles. Yorke Medical Books, New York 1978; p 1-35.

21. Papa LA, Saia JA, Chung EK et al: Ventricular flbrillation in Wolf-Parkinson-White type A: Heart Lung 1978; 7: 1015-1019.

22. Kleln GJ, Bashre JM, Seller TD. Ventrlcular fibrillation in the Wolff-Parkinson-White syndrome. N Engl J Med 1979; 301: 1080-1085.

23. Dreifus LS. Hala R. Watarabe $Y$ et al. Ventricular fbrtlation: a posslble method of sudden death in patlents with Wollf-Parkinson-White syndrome. Circulation 1971: 43: 520-527.

24. Colawita PG, Packer DL، Pressley JC, Ellenbogen KA, O'Callaghan WG, Gilbert MR, German LD. Frequency, dlagnosis and clinical characteristics of pattents with multiple accessory atrioventricular pathways. Am J Cardiol 1987; 59: 601-606.

25. Wellens HuJ. Brugada P. Value of programmed stimulation of the heart in patients with Wolff-Parkinson-White syndrome. In Josephson ME. Wellens HJJ (eds): Tachycardias Phlladelphia- Lea \& Febiger, 1984, p 189-222.

26. Atle, J, Brugada P, Smeets JLRM, Cruz FES, Penn OCKM. Wellens HJJ. Further support of the atrio-ventricular localization of so-called "Mahaim Fibers". J Am Coll Cardiol 1989: 13: 232 (Abst). 
Chapter IV

\title{
The diagnosis of multiple accessory pathways in the Wolff-Parkinson-White syndrome from the surface electrocardiogram in sinus rhythm
}

\author{
Jacoß Atié \\ Pedro Brugada \\ Fernando E.S. Cruz \\ Joep L.R.M. Smeets \\ Ayrton Peres \\ Mauricio Duque \\ Hein JJ Wellens
}




\section{The diagnosis of multiple accessory pathways in the Wolff-Parkinson-White syndrome from the surface electrocardiogram in sinus rhythm}

\section{SUMMARY}

Multiple accessory pathways are present in 5-15\% of patients with pre-excitation syndrome. The diagnosis of multiple accessory pathways is rarely made on the resting 12 lead electrocardiogram during sinus rhythm. We analyzed the 12 lead electrocardiograms of 18 patients with two or more accessory pathways and compared them with the electrocardiograms of 50 patients having only one accessory pathway. All patients had an electrophysiological study and 9 patients a peroperative epicardial mapping. In 5 of the 18 patients with multiple accessory pathways only one accessory pathway showed anterograde conduction. Comparing the polarity of the delta wave with the main frontal GRS axis, we observed that $9 / 13$ patients $(69 \%)$ having A-V conduction over more than one accessory pathway had a discordant pattern between axis of the GRS and delta wave morphology, while only 4 patients $(8 \%)$ with one accessory pathway had this discordant pattern. A qrS or qRS morphology in lead V1 was seen in $6 / 13$ patients $(46 \%)$ with $\mathrm{A}-\mathrm{V}$ conduction over more than one accessory pathway and in only 2 patients $(4 \%)$ with one accessory pathway. We conclude that the presence in the electrocardiogram during sinus rhythm of a discordant pattern between QRS axis and delta wave morphology or a qRS or qrS configuration in V1 is suggestive of multiple accessory pathways.

Accepted for presentation at the Armerican College of Cardiology in 1990

Submitted for publication 


\section{INTRODUCTION}

The accessory pathway of the Wolff-Parkinson-White syndrome may be situated anywhere around the atrio-ventricular ring (1). Knowledge of the anatomic location of the accessory atrioventricular pathway became relevant to the clinician with the advent of operative and ablative therapies $(2,3)$. Localization of such tracts on the 12 lead electrocardiogram has been facilitated by application of the knowledge derived from electrophysiologic studies (4-8). Multiple accessory pathways are present in 5-15\% of patients with pre-excitation syndromes $(9,10)$. The diagnosis of multiple accessory pathways is rarely made on the resting 12 lead electrocardiogram (6-8). The purpose of our study was to identify criteria for the diagnosis of multiple accessory pathways on the 12 lead electrocardiogram during sinus rhythm.

\section{PATIENTS AND METHODS}

The study population consisted of 18 patients with multiple atrioventricular accessory pathways and 50 consecutive patients having one atrioventricular accessory pathway. There were 57 men and 11 women, aged $26 \pm$ 13 years.

A 12 lead electrocardiogram with simultaneous recording of three. six or 12 leads was obtained for each patient during spontaneous sinus rhythm.

All patients were submitted to a complete electrophysiological study using previously described techniques (11). All patients with one accessory pathway and nine with multiple accessory pathways underwent surgical ablation of their accessory pathway(s).

\section{Electrocardlographic Classification}

We grouped accessory pathways into one of four anatomic locations (fig. 1). Anteroseptal, left free wall, right free wall and posteroseptal accessory pathway. The right and left paraseptal accessory pathways were included in the posteroseptal location.

\section{Criteria for localization}

To localize an accessory pathway on the 12 lead electrocardiogram, we required a short $\mathrm{P}$-delta interval and a width of the ventricular complex of at least $0.12 \mathrm{sec}$ to ensure a sufficient degree of pre-excitation of the ventricles. Thereafter the following steps were taken: 


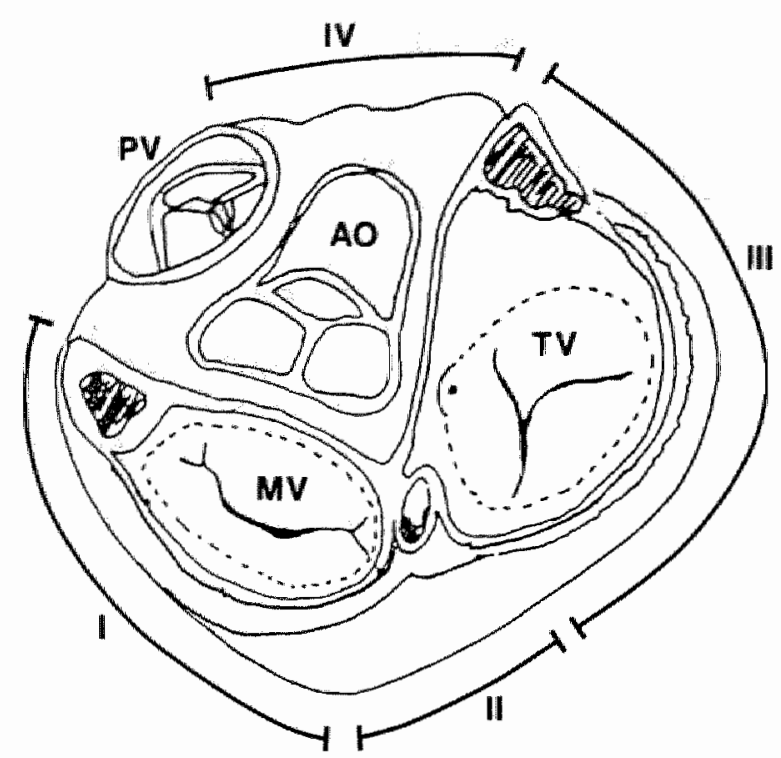

Figure 1. Cross-sectional diagram of the heart at the level of the annulus fibrosus showing the 4 anatomic regions: left lateral (I), posteroseptal (II), right free wall (III) anteroseptal (IV). Abbreviatlons: $A O=a$ arta; $M V=m i t r a l$ valve; $P V=$ pulmonare valve; $T V=$ tricuspide valve

1. Analysis of the delta wave: In the literature (7) the polarity of the delta waves in the presence of a single accessory pathway has been suggested to be as described in table I. A right lateral accessory pathway (region III) is expected to give a delta wave which is positive in leads I, aVL, II, aVF, V6, negative or isoelectric in leads V1 and V2 and positive, isoelectric or negative in lead III. A left lateral accessory pathway (region I) should give a delta wave which is negative in lead aVL, negative or isoelectric in lead 1. positive in lead. III and aVF, and isoelectric or negative in lead V6. An anteroseptal accessory pathway (region IV) is expected to show a delta wave positive in leads II, III, aVF, V6 and negative in leads VI and V2. With a posteroseptal accessory pathway (region II), the delta wave is expected to be negative in leads III, aVF and negative, isoelectric or positive in leads II. V1 and V6 (7).

2. Analysis of the frontal QRS axis: The polarity of the QRS axis in the frontal plane is illustrated in fig 2, and may help in the localization of the accessory pathway. With a right lateral accessory pathway the axis is located between $-30^{\circ}$ and $-60^{\circ}$. With a left lateral accessory pathway between $+60^{\circ}$ and $+120^{\circ}$. With an anteroseptal accessory pathway inbetween $0^{\circ}$ and $+60^{\circ}$ and with posteroseptal accessory pathways between $0^{\circ}$ and $-45^{\circ}$. 
Table I. The polarity of delta wave in the different possible localizations of accessory atrio-ventricular pathways.

\begin{tabular}{lcccc}
\hline LEADS & LL & PS & RL & AS \\
\hline I & -1 & + & + & + \\
II & + & $-1+$ & + & + \\
III & + & - & $+1-$ & + \\
aVI & - & + & + & + \\
aVF & + & - & + & + \\
V1 & + & +-1 & -1 & - \\
V2 & + & + & -1 & + \\
V6 & $-1+$ & $1+$ & + & + \\
\hline
\end{tabular}

Abbreviations: $L L=$ left lateral; $P S=$ postero septal: $R L=$ right lateral; $A S=$ anteroseptal:

$i=$ polarity of delta wave isoelectric; - = polarity of delta wave negative; + = polarity of delta wave positive. From reference 5 .

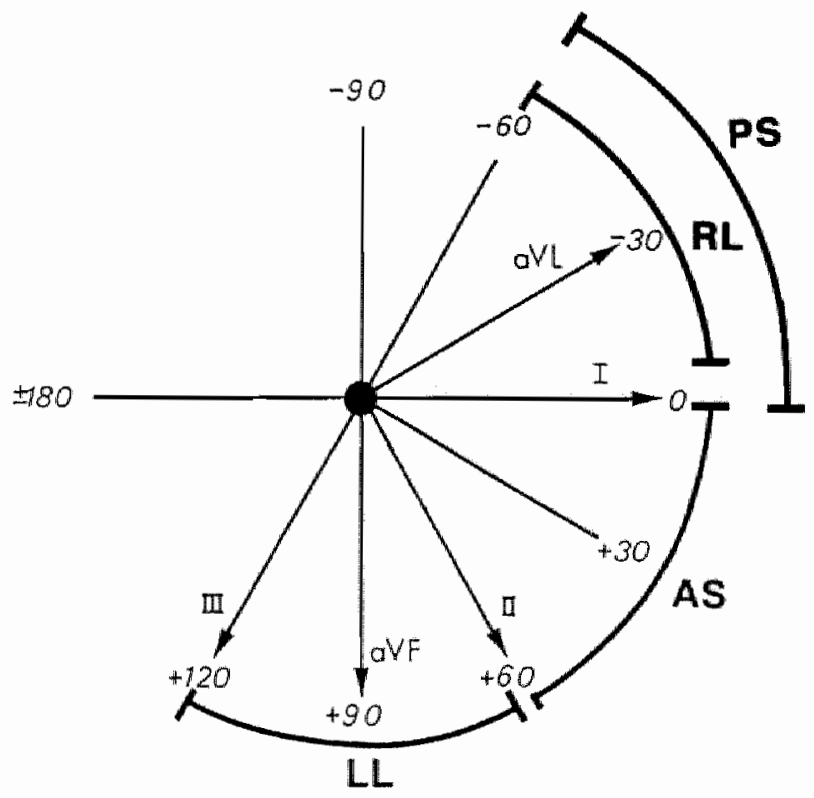

Figure 2. Diagram illustrating the frontal plane $\mathrm{gRS}$ axis in the different locations of accessory pathways in the Wolff-Parkinson-White syndrome. Abbrewiations: $\mathrm{AS}=$ antero-septal; $\mathrm{LL} \approx \mathrm{l}$ left. lateral; $P S=$ posteroseptal; $\mathrm{RL}=$ right lateral. 


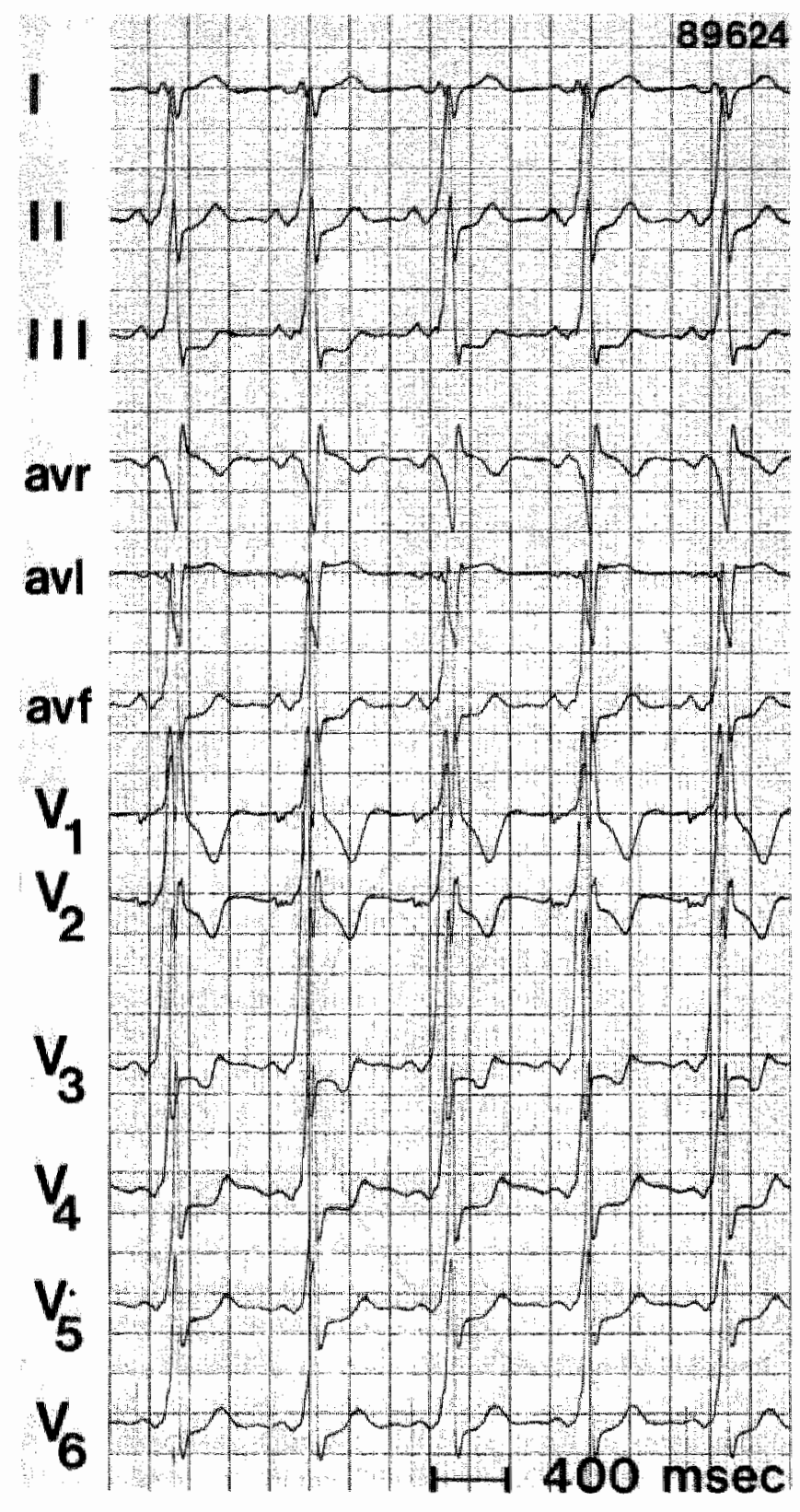

Figure 3. Electrocardio gram of the Wolff-Parkin son-White syndrome in al patient with a left lateral accessory pathway. The QRS axls is $+100^{\circ}$. A concordant pattern between delta wave and the grs axis is present (see text).

\section{Concordant Pattern}

Concordance between delta wave polarity and axis of the QRS complex in the frontal plane was diagnosed when they had the same direction (fig. 3,4 ). 


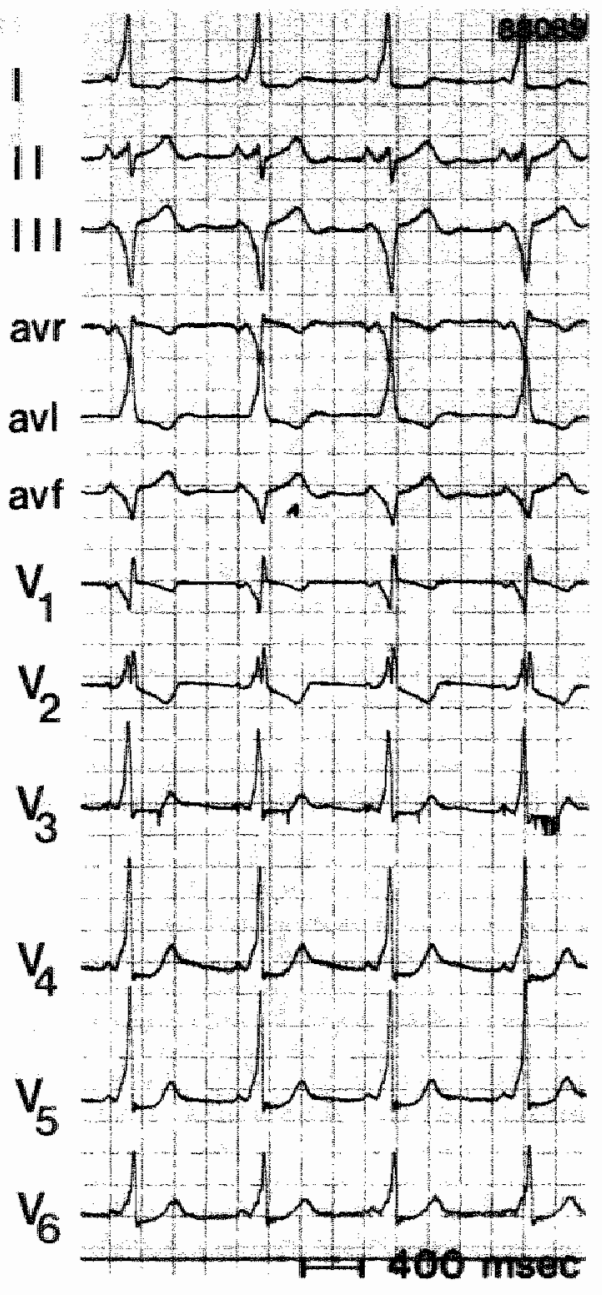

Figure 4. Electrocardiogram of a Wolff-Parkinson-White syndrome due to a right posteroseptal accessory pathway. The gRS axis is $-30^{\circ}$. There is a concordant paltern between the delta wave and the QRS axis.

\section{Discordant Pattern}

We classified pre-excitation as having a discordant pattern when the axis of the QRS complex was located in an area different from the area where the accessory pathway was localized as assessed from the polarity of the delta wave. For instance, in figure 5 the delta wave indicates a right-sided accessory pathway, however, the GRS axis is $+15^{\circ}$ which would fit with an anteroseptal accessory pathway. Thus, axis of gRS and delta wave polarity are discordant. Another example is given in figure 6.

The true location the accessory pathway(s) was confirmed at surgery (59 patients) or by electrophysiologic study (all patients). That location was compared with the predicted localization of the accessory pathway (s) using 

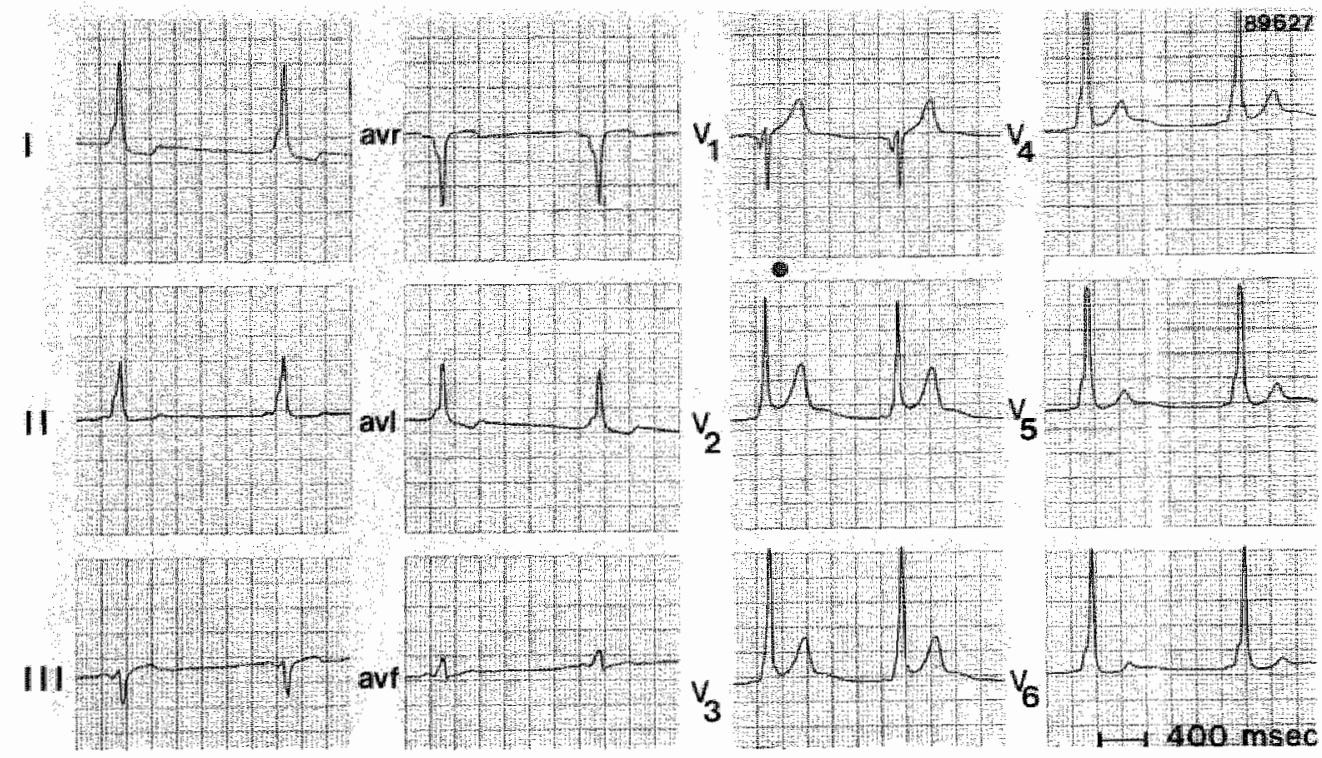

Figure 5. Electrocardlogram of Woll-Parkinson-White with 2 different accessory pathways (right lateral and left paraseptall: The delta wave polarity fits with a right sided accessory pathway, however the QRS axis is $+15^{\circ}$. Therefore a discordant pattern is present. Lead V1 shows the $\mathrm{QRS}$ morphology which is suggestive for two different accessory pathways.

the above mentioned criteria. Thereafter the 12 lead electrocardiogram during sinus rhythm was carefully studied comparing the 50 patients having one accessory pathway with the 18 patients having multiple accessory pathways.

\section{RESULTS}

The true location of the accessory pathway (s) of all patients are shown in the table II and III. Left free wall was the most prevalent Jocation in patients with a single accessory pathway $(48 \%)$.

Analyzing the 12 lead electrocardiogram from the 18 patients with two or more accessory pathways we found a discordant pattern between delta wave and QRS axis in 9 patients (50\%), while only 4 patients (8\%) out of 50 patients with a single accessory pathway had a discordant pattern between the GRS axis and the polarity of the delta wave. When we correct for the fact that in only 13 patients more than one of the multiple accessory pathways was able to conduct in $\mathrm{A}-\mathrm{V}$ direction, we come to $9 / 13$ patients (69\%) with a discordant pattern. 


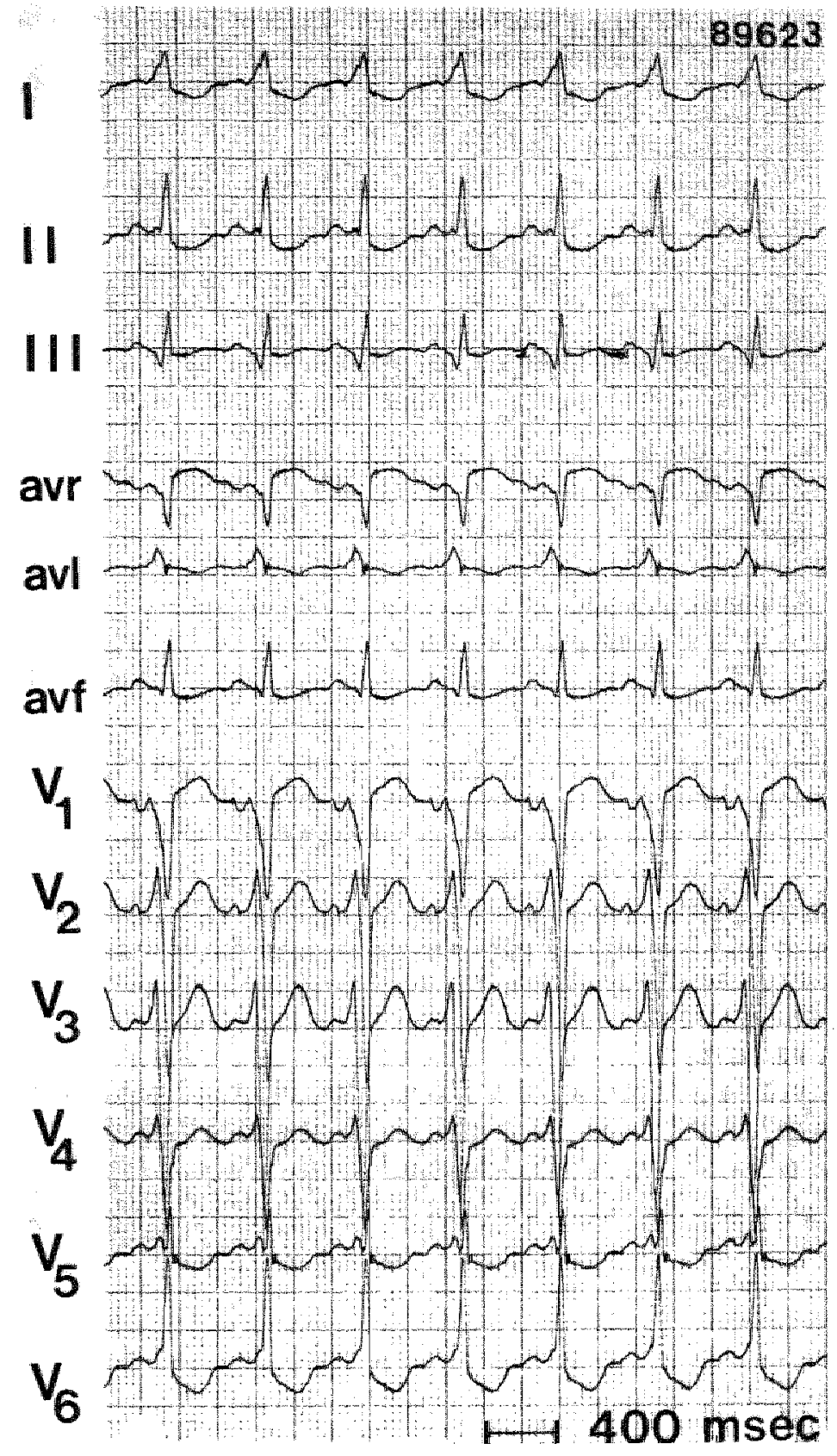

Figure 6. Electrocardiogram from a patlent with anterom grade conduction over 2 different accessory pathways lleft and right free wall). The delta wave fits with a left posteroseptal accessory path. way, however the QRS axis is +45 , ind cating a discordant pattern. 
Table II. Localization of the accessory pathway in the patients with a single accessory pathway (intracardiac mapping and mapping during surgery).

$\begin{array}{lc}\text { Left lateral } & 23 \text { patients } \\ \text { Posteroseptal } & 23 \text { patients } \\ \text { Fight lateral } & 3 \text { patients } \\ \text { Anteroseptal } & 1 \text { patient }\end{array}$

Table III. Location of the accessory pathway in the patients with multiple accessory pathways (intracardiac mapping and mapping during surgery).

$\begin{array}{ll}\text { LL + RL } & 3 \text { patients } \\ \text { LL + LPS } & 3 \text { patients } \\ \text { LL + RPS } & 2 \text { patients } \\ \text { LL + AS } & 1 \text { patient } \\ \text { LPS + RPS } & 3 \text { patients } \\ \text { LPS + RNV } & 1 \text { pattent } \\ \text { LPS + RL } & 1 \text { patient } \\ \text { LL + LPS + RPS } & 2 \text { patients } \\ \text { LL + RL + LPS } & \text { 2 pattient }\end{array}$

On studying the delta $\mathrm{GRS}$ morphology on the 12 lead electrocardiogram in all patients, we found that 6 of the 13 patients (46\%) with $\mathrm{A}-\mathrm{V}$ conduction over multiple accessory pathways had a qrS or qRS pattern in lead V1 (fig. $5,7)$, while only 2 patients (4\%) from the group with a single accessory pathway showed that pattern.

Eleven of the 13 patients $(84 \%)$ in the group with multiple accessory pathways able to conduct anterogradely had either a discordant pattern or a qRS morphology in lead V1. This was found in only 6 patients (12\%) having a single accessory pathway. A discordant pattern plus a qRS or qrS morphology in V1 was present in 4 patients (22\%) with multiple accessory pathways and in one patient $(2 \%)$ in the group with a single accessory pathway. 

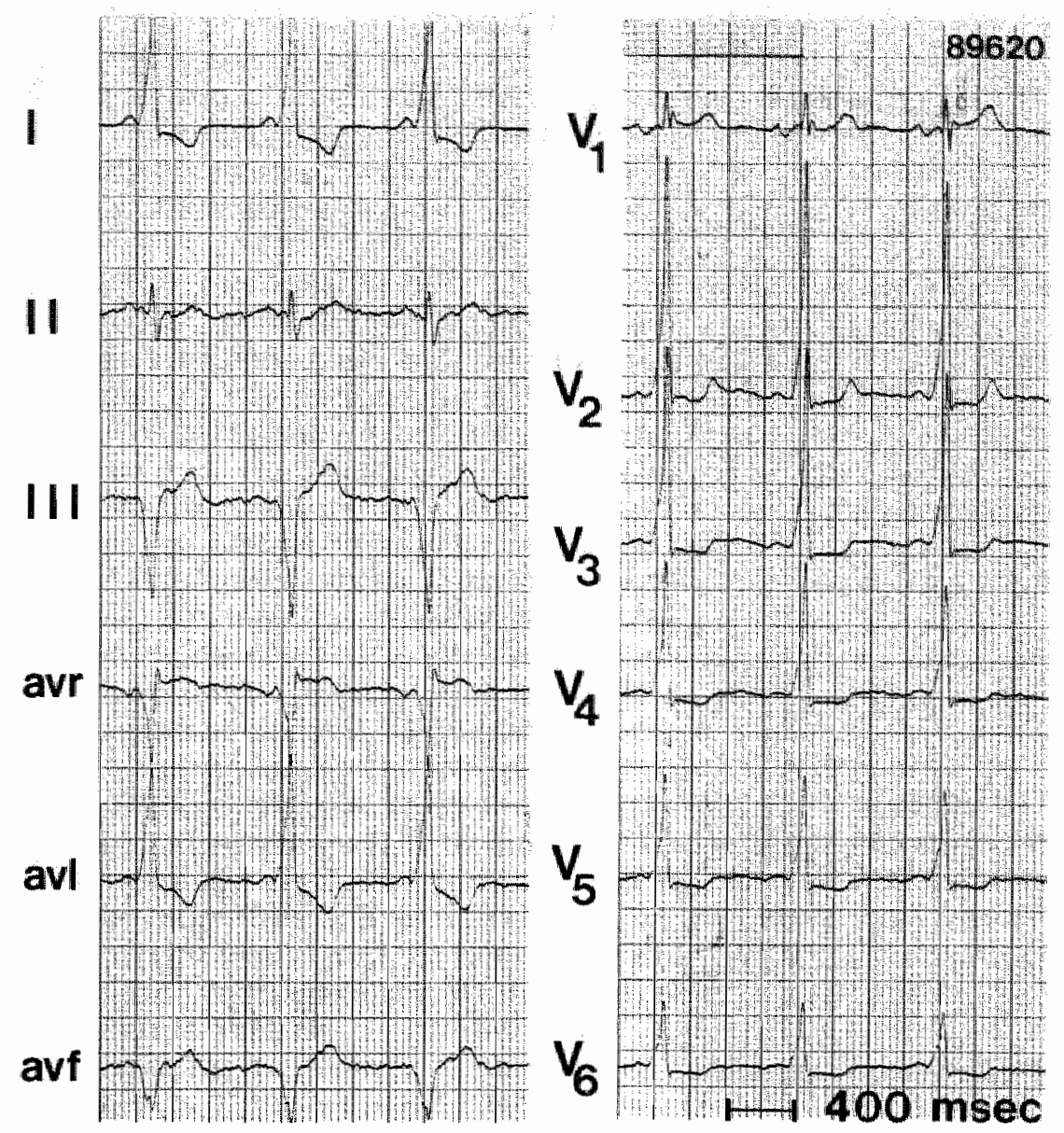

Figure 7. Electrocardiogram of a patient with anterograde conduction over 2 different accessory pathways (left lateral and right posteroseptal). The delta wave fits with a right posteroseptal accessory pathway, the $\mathrm{QRS}$ axIs $1 \mathrm{~s}-30^{\circ}$. Concordant pattern is present. The morphology of lead V1 however is very suggestive of multiple accessory pathways. 


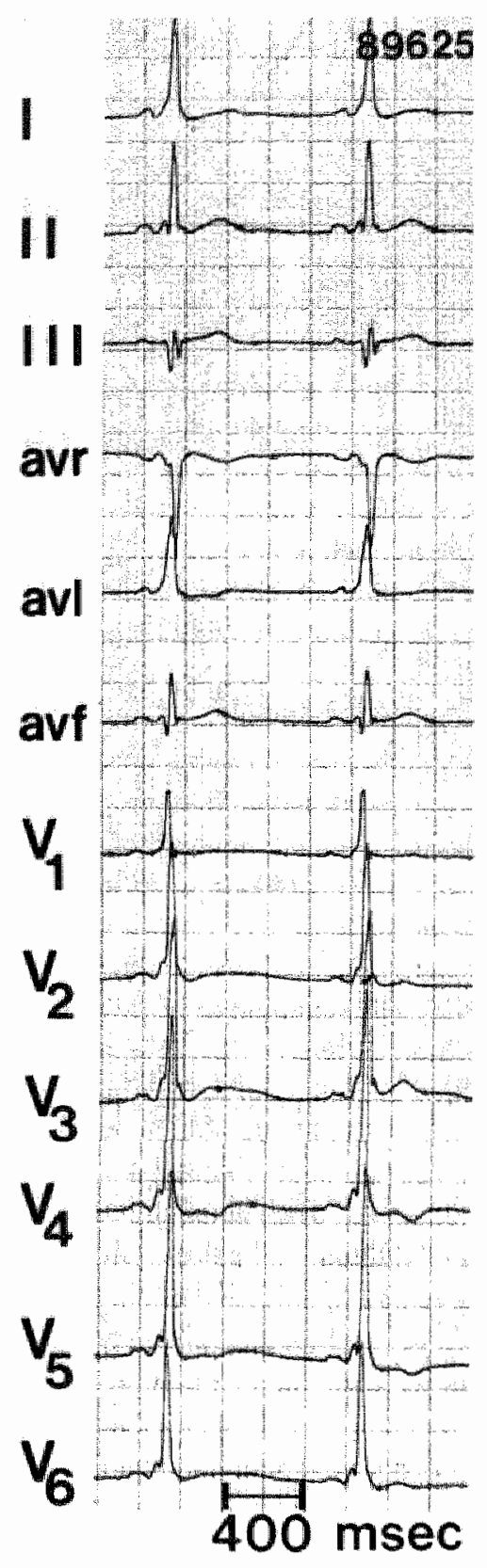

Figure 8. Electrocardiogram of a pattent with anterograde conduction over 2 different accessory pathways (left lateral and left posteroseptal). The delta wave fits with a left posteroseptal accessory pathway. however the gRS axis is $+30^{\prime \prime}$ indicating a discordant pattern. 


\section{DISCUSSION}

The stimulus to localize the site of an accessory pathway on the ECG comes from our ability to treat Wolff-Parkinson-White patients by surgical or electrical ablation of the accessory atrioventricular pathways (12-14). In those patients it would be very helpful to recognize or suspect multiple accessory pathways.

In 1945 Rosenbaum et al (15) classified electrocardiograms from patients with ventricular pre-excitation into type $A$ and $B$. The type $A$ pattern was attributed to a left sided and type B to a right sided accessory pathway. This classification did not account for a more precise localization of accessory pathways. Following the introduction of catheter and operation mapping a wide spectrum of electrocardiographic patterns from patients with WolffParkinson-White syndrome and their association with the anatomic location of the accessory pathway was reported (16.17). More recently other studies have reported different criteria to localize the anatomic position of the accessory pathway by using the 12 lead electrocardiogram (5-8).

The importance of the delta wave polarity to localize an accessory pathway in Wolff-Parkinson-White syndrome is well known $(6,7)$. The analysis of the main GRS deflection is also helpful when the mechanism of axis deviation is understood in relation to the different possible localizations of accessory pathways. During normal ventricular activation spread of activation occurs transversely and synchronously through the free walls of both ventricles from the endocardial to the epicardial surfaces. The larger QRS forces of the anatomically larger free wall tend to counteract the smaller $\mathrm{GRS}$ forces of the smaller free right wall. Thus the main resultant $Q R S$ vectors are directed to the left. In the Wolff-Parkinson-White syndrome apart from activation over the A-V node His-axis, the ventricle is excited eccentrically over the accessory pathway changing the mode and direction of excitation and disturbing the normal balance. Thus, with right lateral pre-excitation, the right free wall forces are preempted so that the left free wall forces become even more dominant leading to left axis deviation. With left lateral pre-excitation, the left free wall forces are preempted, therefore the right free wall forces tend to be less opposed, and the main QRS axis will deviate to the right. The degree of shift in frontal plane axis will be more or less marked depending upon the degree of pre-excitation. In patients with a normal PR interval and minimal pre-excitation the axis will be normal in contrast to patients with marked pre-excitation.

The analysis of axis deviation can only be used in patients who do not have conduction disturbances or underlying heart disease which produces an abnormal axis on the electrocardiogram.

Using both criteria, the delta wave polarity and the QRS axis, more precise localization of the accessory pathway should be possible. Prediction of accessory pathway localization was found to be possible in 44 out of 50 patients with a single accessory pathway (88\%). However, when anterograde conduction occurs over more than one accessory pathway, there is competition 
between pre-excitation from two or three different positions and the concordance between the polarity of the delta wave and the GRS axis is likely to disappear. In our study, from the 18 patients with more than one accessory pathway 9 patients (50\%) presented a discordant pattern between the polarity of delta wave and the QRS axis. From those 18 patients with multiple accessory pathways, 5 patients had only one accessory pathway conducting anterogradely, the other accessory pathway was conducting only in the retrograde direction. Therefore, 9 of the 13 patients $(69 \%)$ using more than one accessory pathway for A-V conduction showed a discordant pattern. It is possible that in the remaining 4 patients the pre-excited area over one of the accessory pathways was not large enough to produce the expected changes in the electrocardiogram during sinus rhythm.

A qRS or qrS pattern in lead V1 is very seldom seen in the electrocardiogram of patients with Wolff-Parkinson-White syndrome. In the 50 patients with a single accessory pathway this pattern was present in only 2 patients $(4 \%)$. However 6 of the 18 patients $(33 \%)$ with multiple accessory pathways and 6 of the $13(46 \%)$ having anterograde conduction over more than one accessory pathway showed this pattern.

From our study we conclude that the presence in the 12 lead electrocardiogram of a qRS or qrS pattern in lead V1 and discordance between the delta wave polarity and the $\mathrm{gRS}$ axis is suggestive of multiple accessory atrioventricular pathways. Such a finding should be an extra stimulus to look for more than one accessory pathway during the electrophysiologic study and during cardiac mapping. 


\section{REFERENCES}

1. Cox JL. The surgical mannagement of cardiac arrhythmias. In: Sabiston DC. Spencer FC (eds). Gibbon's Surgery of the Chest, Philadelphia, WB Saunders. 1983; 1552-1584.

2. Guiraudon GM, Klein GJ, Sharma AD, Milstein S, McLellan DG. Closed-heart techntque for Wolf-Parkinson-White syndrome: Further expertence and potentlal limitations. Annals of Thoracic Surgery 1986; 42: 651-657.

3. Wellens HJJ, Janse MJ، van Dam RTh, van Capelle FJL, Meijne NG, Mellink HM, Durrer D. Epicardial mapping and surgical treatment in Wolf-Parkinson-White syndrome type A. Am Heart J 1974; 88: 69-78.

4. Wellens HJJ, Farré J, Ross D. Vanagt EJ. Bär FW. Preoperative localization of bypass tract(s) in the Wolf-Parkinson-White syndrome. Springer Verlag 1980: 94-105.

5. Gallagher JU, Pritchett ELC. Sealy WC. Kassell J, Wallace AG. The pre-exctation syndrome. Prog. Cardiovasc. Dis. 1978; 20: 285-296.

6. Reddy GV, Schamroth L. The localization of bypass tracts in the Wolff-Parkinson-White syndrome from the surface electrocardiogram. Am Heart J 1987; 113:984-993.

7. Lindsay $\mathrm{BD}$, Crossen $\mathrm{K}_{\mathrm{*}}$ Cain ME. Concordance of distinguishing electrocardiographic features during sinus rhythm with the location of accessory pathways in the Wolf-Parkinson-White syndrome. Am Heart J 1987; 59: 1093-1102.

8. Milstein S. Sharma AD. Guiraudon GM, Klein GJ. An algorithm for the electrocardiographic localization of accessory pathways in the Wolff-Parkinson-White syndrome. PACE 1987; 10: 555-563.

9. Bardy GH. Packer DL. German LD, Gallagher JJ. Preexcited reciprocating tachycardia in patients with Wolf-Parkinson-White syndrome: Incidence and mechanisms. Circulation 1984; 70: 377-391.

10. Colavita PG. Packer DL. Pressley JC, Ellembogen KA, O'Callaghan WG, Gilbert MR. German LD. Frequency, diagnosis and clinical characteristics of patients with multiple accessory atrioventricular pathways. Am J Cardiol 1987; 59: 601-606.

11. Wellens HJJ, Durter D. The role of an accessory atuioventricular pathway in reciprocal tachycardia. Observations in patients with and without the Wolff-Parkinson-White syndrome. Circulation 1975; 52: 58-64.

12. Cox JL, Gallagher JJ, Cain ME. Experience with 118 consecutive pattents undergoing operation for the Wolff-Parkinson-White syndrome. J Thorac Cardiovasc Surg 1985; 90: 490-501. 
13. Scheinman MM, Davis JC. Catheter ablation for treatment of tachyarthythmias: present role and potentlal promise. Circulation 1986:73:10-13.

14. Morady F" Schetnman MM, DiCarlo LA, Winston SA, Davis JC, Baerman JM, Krol RB. Crevey BJ. Coexistent posteroseptal and right-sided atrioventricular bypass tracts. JACC 1985: $5: 640-646$.

15. Rosenbaum FF, Hecht HH, WUlson FN. Johnson FD. The potential vartations of the thorax and esophagus in anomalous atroventricular excltation Wolf-Parkinson-White syndrome. Am Heart J 1945: 29: 281-326.

16. Boineau JP, Moore EN, Spear JF, Sealy WC. Basis of static and dynamic electrocardiographic variations in Wolff-Parkinson-White syndrome. Anatomic and electrophysiologic observations in right and left ventricular pre-excitation. Am J Cardiol 1973; 32:32-45.

17. Tonkin AM, Wagner GS, Gallagher JJ, Cope CD, Kasell J. Wallace AG. Initiall forces of ventricular depolarization in the Wolf-Parkinson-White syndrome. Circulation 1975; 52 : $1030-1036$. 
Chapter V

\section{The electrocardiogram in multiple accessory pathways}

Hein J.J. Wellens

Jacob Atie

Joep Smeets

Fernando E. S. Cruz

Anton P.Gorgels

Pedro Brugada 


\section{The electrocardiogram in multiple accessory pathways}

\section{SUMMARY}

Twelve lead ECG findings were reviewed in 17 patients having two or more accessory pathways as documented during electrocardiophysiologic study (17 patients) and intra-operative mapping ( 8 patients).

Findings arguing for the presence of more than one AV pathway were present in 12 patients. These were: 1) More than one $P$ wave configuration during orthodromic circus movement tachycardia (4 patients); 2) A "mismatch" between the location of the ventricular and the atrial end of the accessory pathway when comparing in the same patient exclusive atrioventricular and ventriculo-atrial conduction over the accessory pathway during antidromic and orthodromic circus movement tachycardia respectively ( 7 patients); 3) Atrial fibrillation showing more than one pre-excitation pattern (6 patients); 4) A spontaneous change from orthodromic into antidromic circus movement tachycardia and vice-versa (2 patients); 5 ) a spontaneous change from one type of antidromic tachycardia to another (2 patients); 6) A change in pre-excitation pattern following the administration of drugs prolonging the anterograde refractory period of the accessory pathway (3 patients). The retrospective nature of our study does not allow conclusions as to the true value of the electrocardiogram to predict the presence of more than one accessory pathway. That has to be evaluated in a prospective study.

Accepted for publication in the Journal of the American College of Cardiology, in press. 


\section{INTRODUCTION}

Multiple accessory pathways are present in 5-15\% of patients with pre-excitation syndromes $(1,2)$. The possibility of therapies like surgery and electrical ablation to definitely interrupt conduction over accessory atrio-ventricular (AV) pathways requires the exact localization of these connections. It is essential under those circumstances to recognize patients having more than one accessory atrio-ventricular pathway. The purpose of this article is to present electrocardiographic clues which should make the physictan suspicious of that situation.

\section{MATERIAL AND METHODS}

From February 1977 to May 1989, 314 patients with accessory AV connections underwent detailed electrophysiologic evaluation in our institution. Methods used have been described elsewhere (3). Studies were performed after informed consent and approved by our instutional committee on research. Seventeen patients were found to have more than one accessory pathway during electrophysiologic study and or intracardiac mapping. We carefully reviewed their 12 lead electrocardiograms during sinus rhythm, regular narrow QRS tachycardia, regular wide GRS tachycardia, atrial fibrillation and following the intravenous injection of drugs prolonging the refractory period of the accessory AV pathway, like ajmaline and procainamide.

\section{RESULTS}

The following electrocardiographic findings were found to be of value in recognizing more than one accessory pathway:

\section{The ECG during orthodromic tachycardia}

Four patients presented orthodromic circus movement tachycardia (CMT) with two different $P$ wave configurations. Such a finding indicates that two accessory AV pathways can be used during CMT to conduct the impulse in ventriculo-atrial (V-A) direction (fig. 1).

\section{2. "Mismatch" between the atrial and ventricular end of the accessory pathway by comparing antidromic and orthodromic CMT}

When comparing in the same patient the ECG during orthodromic and antidromic CMT we discovered in 7 patients a "mismatch" between the location of the atrial and the ventricular end of the accessory pathway. The 


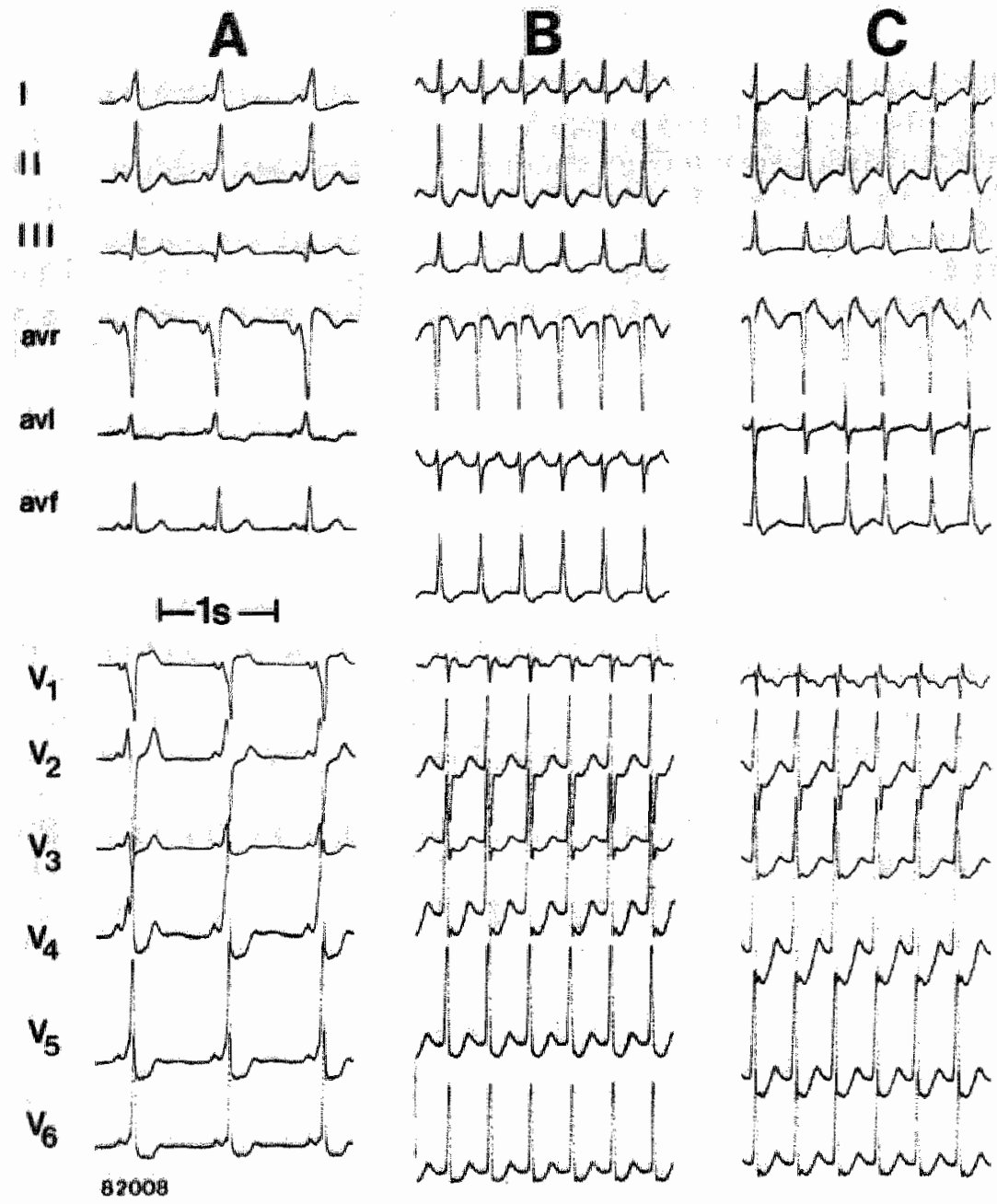

Figure 1. A patient with a right and a left free wall accessory pathway. Panel $\mathbb{B}$ shows orthodromlc CMT using a right free wall accessory pathway. Note the positue $P$ wave in leads $I$ and $A V L$. In panel $C$ a left sided free wall Ineg $P$ in lead I] is used during orthodromic CMT. Panel A shows the ECG during sinus rhythm. 
A

II

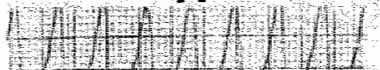

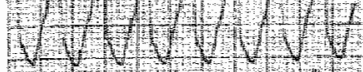

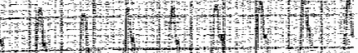
$14+1+4,4+4$

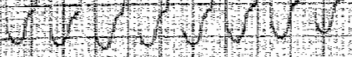

III A. A M N N N N N $x+y+4+12$ innnatent avr

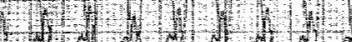
avl n. $x+4+4$

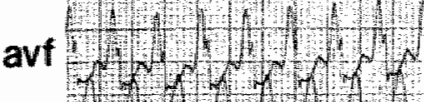

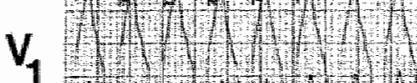

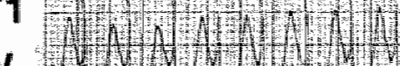

$v_{2}$

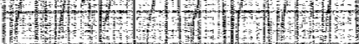
H

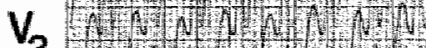

3

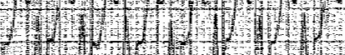

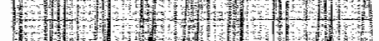

$v_{4}$ /II) (I)

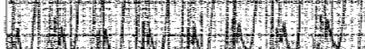
N)

-

$v_{5}$ 1) I y y

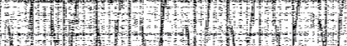

$V_{68188}(N)$
B

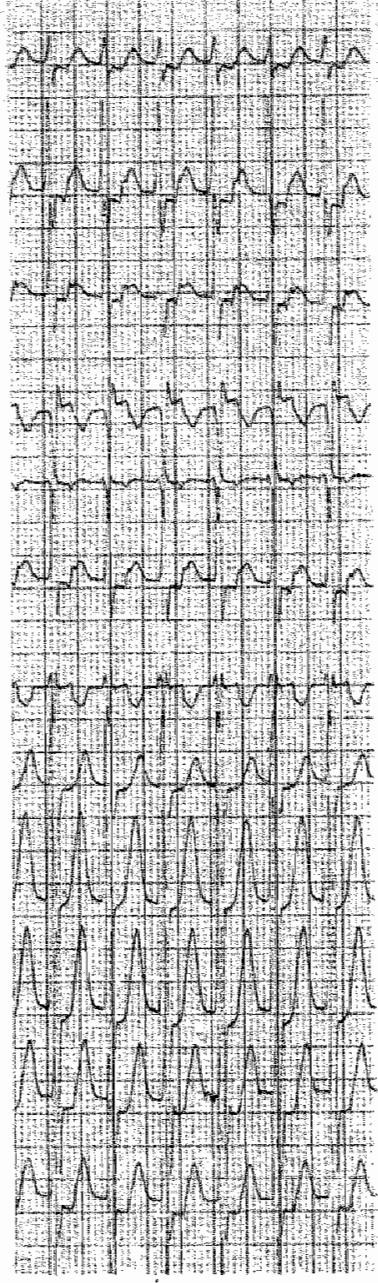

c
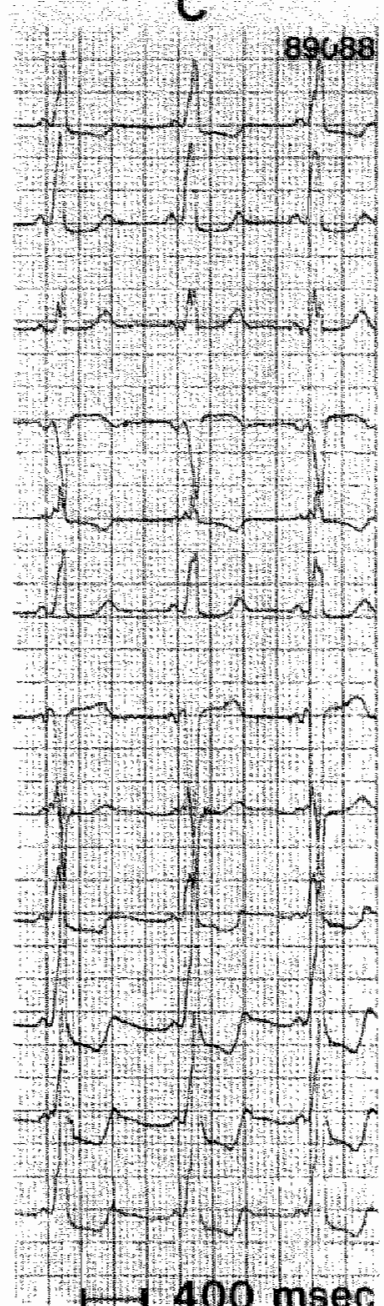

Figure 2. A patient with a right and a left free wall accessory pathway. The first one is used anterogradely during antidromic CMT (panel A). The second one is used retrogradely during orthodromic CMT (panel B). As shown the $P$ wave is negative in leads $I$ and aVL and positive in lead aVR. Panel $C$ shows the $\mathbb{E C G}$ during sinus rhythm. 


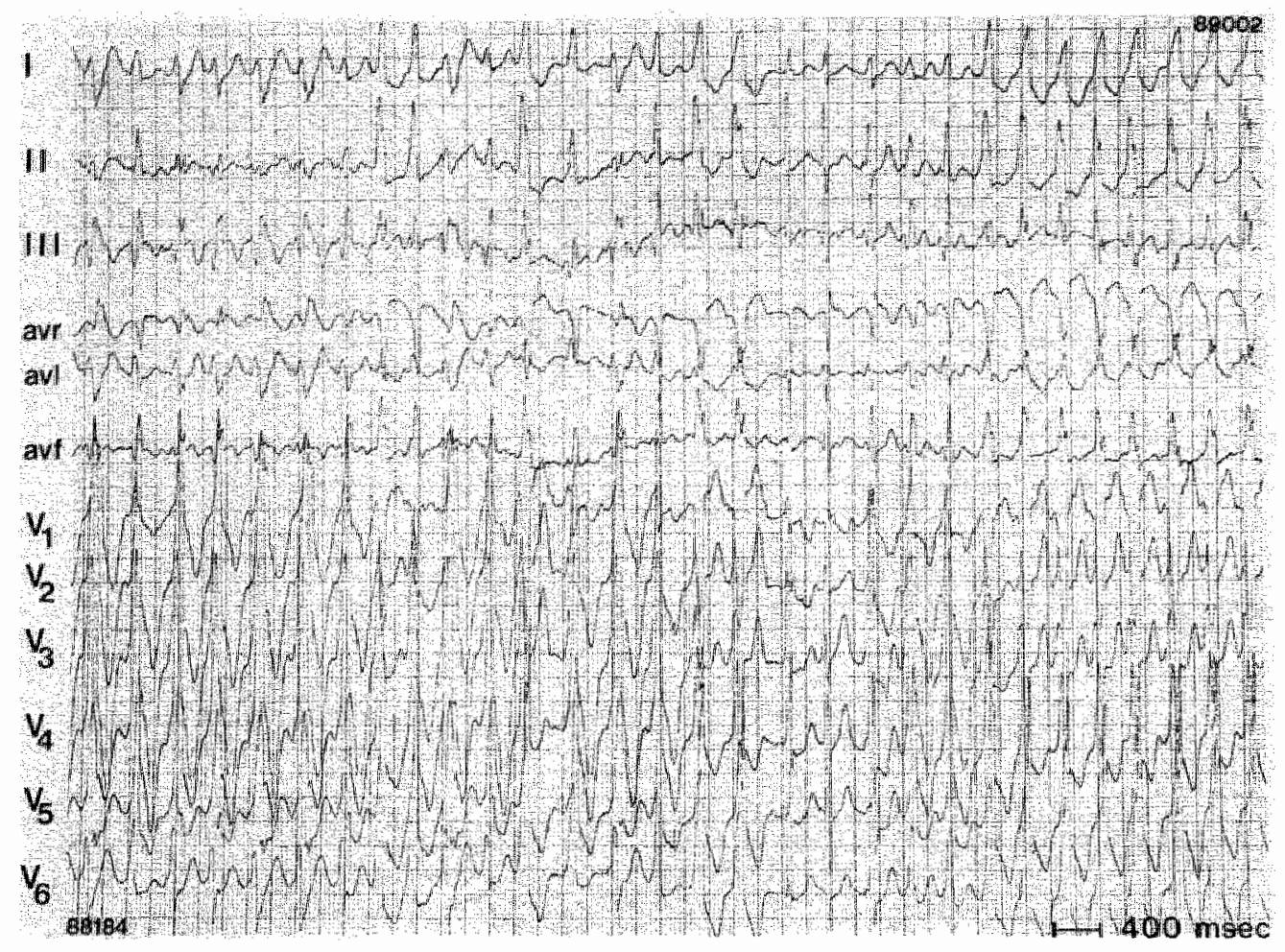

Figure 3. Atrial fibrillation with AV conduction over a left free wall (left part of figure) and right free wall accessory pathway (right part of figure). Also fusion complexes indicating anterograde conduction over both pathways can be seen.

location of the ventricular end of the accessory pathway was derived from the configuration of the delta wave during exclusive AV conduction over the accessory pathway (antidromic CMT) and the location of the atrial end from the configuration of the $\mathrm{P}$ wave during exclusive $\mathrm{V}-\mathrm{A}$ conduction over the accessory pathway (orthodromic CMT) (fig. 2).

\section{The ECG during atrial fibrillation}

When analyzing the ECG during atrial fibrillation. 6 patients presented QRS complexes showing more than one pattern of pre-excitation suggesting the presence of more than one accessory AV pathway (fig. 3).

\section{Spontaneous change from orthodromic to antidromic CMT or vice-versa}

A spontaneous change from orthodromic into antidromic CMT (or viceversal was seen in 2 patients (fig. 4). This phenomenon can only be explained by the presence of at least 2 different accessory AV pathways (fig. 5A). 


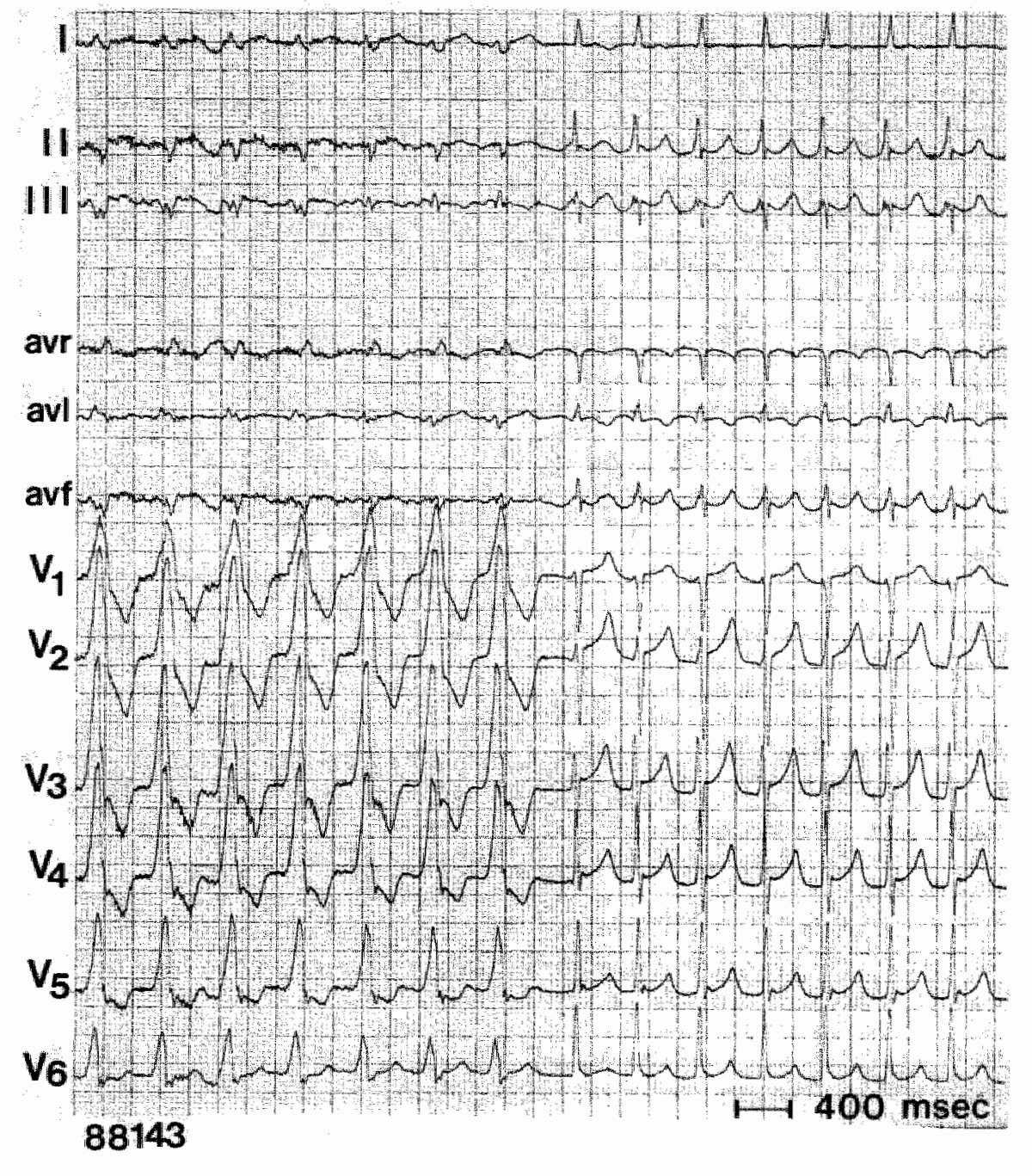

Figure 4. Spontaneous change from an antidromic CMT into an orthodromic CMT. In this patient $\mathrm{AV}$ conduction during antidromic CMT occurred over a left free wall pathway and $\mathrm{V}-\mathrm{A}$ conduction durng both antidromic and orthodromic CMT over a right sided accessory AV pathway. 
A

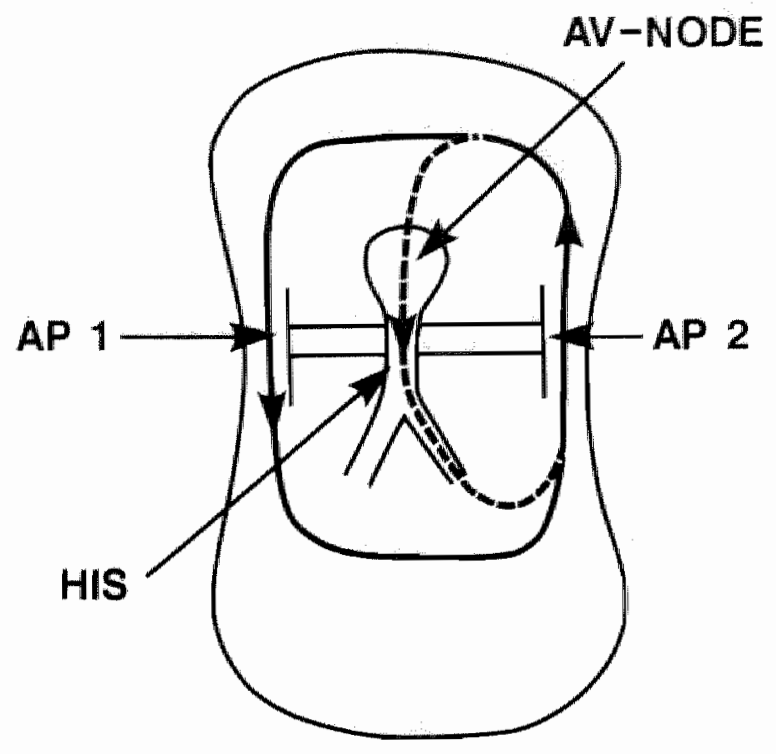

B

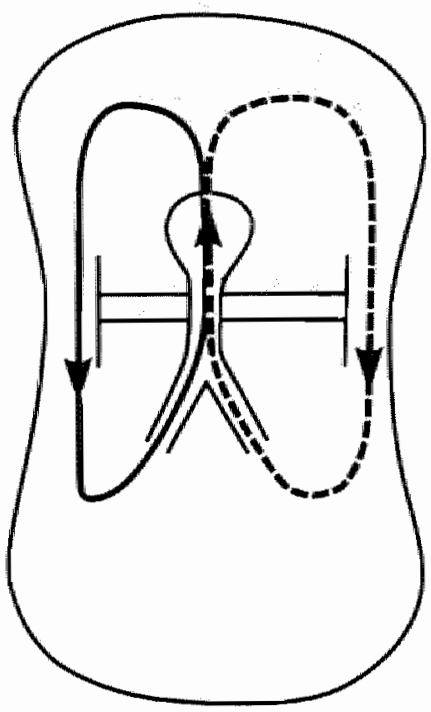

Figure 5. Scheme, lllustrating a spontaneous change from an anticiromic (solid line) into an orthodronic CMT (interrupted line) (panel A) or from one type of antidromic CMT (solid line) into another one (stippled line) (panel B). As shown, both situations require the presence of at least two accessory AV pathways. In panel B ventriculo-atrial conduction occurs over the His-AV node pathway. In the presence of a third accessory AV pathway that structure can also be used for retrograde conduction during the change from one antidromic CMT into another. Abbreviations: AP $1=$ Accessory AV pathway 1: AP 2 = Accessory AV pathway 2; AV node $=$ Atrioventricular node; His = His bundle.

\section{Spontaneous change from one type of antidromic tachycardia to another}

This was observed in 2 patients and as shown in fig. 5B can only occur in the presence of at least 2 different accessory pathways (fig. 6).

\section{Demonstration of more than one accessory AV pathway during administration of an agent prolonging the anterograde refractory period of the accessory pathway.}

Three patients showed during intravenous injection of ajmaline or procainamide a sudden change from one pre-excitation pattern to another. Depending upon the location of the accessoray pathways the change may be major (8) or minor (fig. 7). Fig. 7 stresses the necessity to record several ECG leads simultaneously to recognize the change in pre-excitation pattern. As shown in figure 7 continuation of drug administration eventually resulted in block of AV conduction in both accessory AV pathways. 


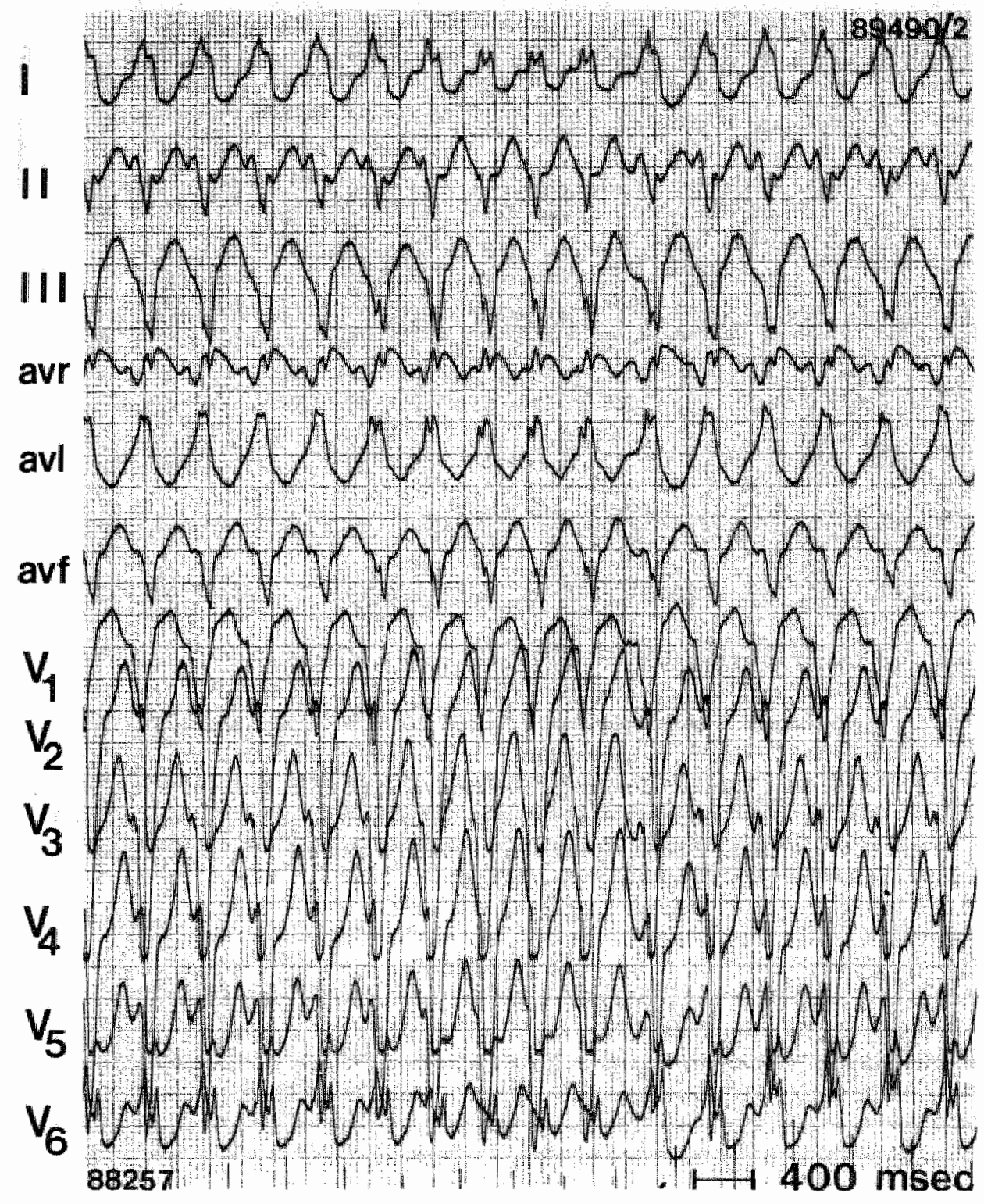

Figure 6. Example of the spontaneous change of one antidromic circus movement tachycardia to another. As shown in the middle of the figure, the QRS complex indicates a more right anterior location of the accessory pathway as during the antidromtc tachycardia in the beginning and end of the figure. Note that the cycle length of the 2 tachycardias differs by 50 ms and fusion complexes are present when the tachycardia changes from one to another. Twelve electrocardiographic leads were recorded simultaneously. 


\section{PROCAINAMIDE}

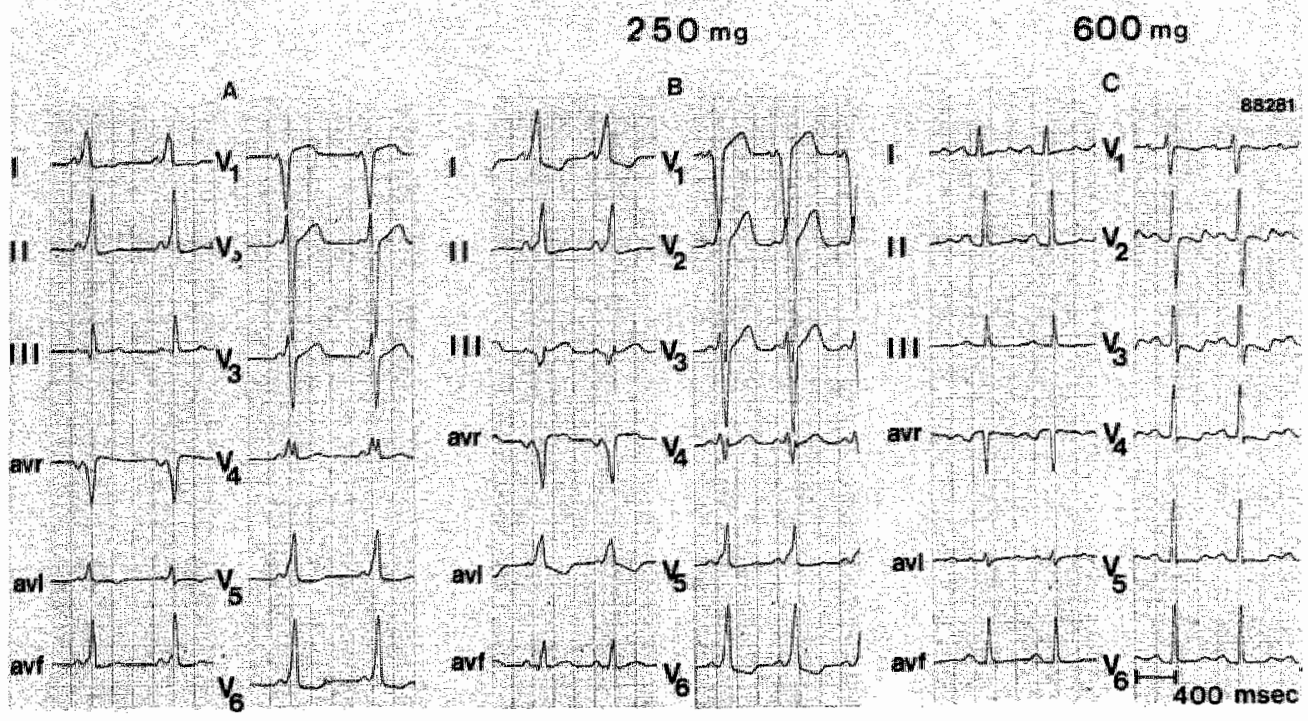

Figure 7. Exposure of two accessory AV pathways by procainamide in a patient with the Wolf-Parkinson-White syndrome. Panel A shows preexcitation pattern which in panel $B$ after $250 \mathrm{mg}$ of procatramide changes into another preexcltation pattern (most marked in lead $1 \mathrm{~m})$. Pancl $\mathrm{C}$ shows disappearance of pre-excitation after a total of $600 \mathrm{mg}$ of procainamide. The figure lllustrates how, because of different electrophysiologtc properties, the presence of two accessory atrlo-ventricular pathways can be exposed during the administration of procainamide. Subsequent epicandial mapping studies during surgery showed one pathway to be located posteroseptally and the other on the right free wall.

\section{DISCUSSION}

Programmed electrical stimulation of the heart in patients with accessory AV pathways reveals that in 10-15\% of patients studied in the catheterization laboratory more than one accessory AV pathway is present $[1,2)$.

Their recognition is of obvious importance when surgical or electrical ablation of pre-excitation is considered. Colavita et al (1) in a large series of patients with multiple accessory AV pathways indicated the importance to look during the electrophysiologic study for: 1) Different patterns of ventricular pre-excitation during induced atrial fibrillation. flutter or atrial pacing; 2) Different sites of atrial activation during right ventricular pacing or orthodromic reciprocating tachycardia, and 3) Pre-excited reciprocating tachycardia using a second pathway as the retrograde limb of the tachycardia. We decided to carefully evaluate the 12 lead electrocardiogram in patients with multiple accessory AV pathways to pick up clues to the presence of more than one accessory AV pathway. 
In reviewing that electrocardiographic information we found that the ECG should be studied during orthodromic and antidromic CMT, atrial fibrillation and during the injection of drugs prolonging the anterograde refractory period of the accessory AV pathway. Several investigators have reported on the use of the ECG during sinus rhythm to locate the accessory AV pathway in patients with pre-excitation (4-7). To be able to locate the accessory AV pathway on the 12 lead ECG sufficient pre-excitation of the ventricle over the accessory pathway should be present. This is indicated by a P-delta interval of less than 100 msec, a clear delta wave and a 8 RS width of at least 120 msec. Theoretically, if the ECG pattern during an ECG showing pre-excitation does not fit with one of the described patterns more than one accessory AV pathway may be suspected. The ECG, however may be affected by a congenital cardiac defect, ventricular hypertrophy, or muscle loss as in myocardial infarction. Prediction of anterograde AV conduction over more than one accessory AV pathway on the ECG during sinus rhythm is therefore difficult. A more useful finding indicating ventriculo-atrial conduction over more than one accessory pathway is the presence of two different types of $P$ waves during orthodromic CMT. In order to have different $P$ waves the site of atrial insertion of the accessory pathways must differ. We believe that major differences in the location of the atrial insertion site are required to lead to sufficient differences in $\mathrm{P}$ wave configuration to recognize the presence of more than one accessory AV pathway during ortodromic CMT.

It is likely that accessory AV pathways cross the AV ring in such a way that the atrial and the ventricular end are not far from one another. That leads to the assumption that the site of origin of ventricular activation during exclusive anterograde conduction over the accessory AV pathway and of the origin of atrial activation during exclusive retrograde conduction over the accessory pathway are located close together. The site of origin of the QRS during antidromic CMT and the site of origin of the P wave during orthodromic CMT should therefore "match". The findings shown in fig. 2 clearly indicate a large distance between the origin of ventricular activation and atrial activation during antidromic and orthodromic CMT respectively. Even if the accessory AV pathway would cross the AV ring obliguely one would not expect the major differences shown in fig. 2.

During atrial fibrillation rapid impulse formation is present in both atria. That allows the beginning of ventricular activation at different sites when multiple accessory AV pathways having anterograde conduction properties are present. To recognize anterograde AV conduction over more than one accessory AV pathway during atrial fibrillation sufficient spatial separation between the ventricular insertion of the accessory pathways should be present. Only under those circumstances the differences in patterns of ventricular activation can be recognized. It should be realized that AV conduction over the AV node-His pathway may result in fusion complexes falsely suggesting the presence of more than one accessory AV pathway. 
A sudden change from an antidromic to an orthodromic CMT or vice versa can only be explained by the presence of two accessory pathways. By definition the orthodromic CMT uses an accessory AV pathway for $\mathrm{V}$-A conduction. A sudden change to or from an antidromic CMT requires therefore that also the antidromic CMT uses an accessory AV pathway for retrograde conduction.

Similarly, the spontaneous change from one type of antidromic tachycardia into another can only be explained by the presence of at least 2 accessory pathways (see fig. 5,6).

We (8) have previously reported on the use of antiarrhythmic drugs that prolong the anterograde refractory period of the accessory AV pathway to diagnose the presence of more than one accessory AV pathway. Requirements to expose the presence of more than one accessory pathway by drugs like afmaline or procainamide include: 1) A difference in duration of the anterograde refractory period of the two accessory AV pathways.: 2) A relatively long anterograde refractory period of at least one of the accessory AV pathways (9,10); 3) The recording of several ECG leads simultaneously to recognize small changes in pre-excitation pattern; 4) Changes should occur in the initial portion of the QRS complex (the delta wave). Antiarrhythmic drugs may induce bundle branch block and thereby change the QRS after the delta wave. Those changes should not be interpreted as pointing to the presence of more than one accessory AV pathway.

\section{Limitations of the study}

The findings reported were obtained during a retrospective analysis in patients shown to have more than one accessory AV pathway during electrophysiologic study or intraoperative mapping. The true value of the 12 lead ECG in recognizing the presence of more than one accessory AV pathway can only be established by performing a prospective study. 


\section{REFERENCES}

1. Colavita PG. Packer DL, Pressley JC, et al: Frequency, diagnosis and clinical characteristics of patients with multiple accessory atrio:ventricular pathways. Am J Cardiol 1987: 59: $601-606$.

2. Prystowsky EN: Diagnosis and management of the preexcltation syndromes. Im: Current problems in Cardiology 1988; 13: 277-310.

3. Wellens H.JJ, Brugada P: Value of programmed stimulation of the heart in patients with the Wolf-Parkinson-White syndrome. In: Tachycardias. Josephson ME and Wellens HJJ (Eds): Philadelphia, Lea and Febiger, 1984: 199-221.

4. Gallagher JJ, Pritchett ELC, Sealy WC, Kasell J, Wallace AG: The pre-excitation syndromes. Prog Cardiowasc Dis 1978; 20: 285-327.

5. Milstein S, Sharma AD, Gutraudon GM, Klein GJ: An algorithm for the electrocardiographic localization of accessory pathways in the Wolff-Parkinson-White syndrome. PACE 1987: 10: 555-563.

6. Lemery R, Hammill SC, wood DL et al: Value of the resting 12 lead electrocardiogram and vectorcardiogram for locating the accessory pathway in patients with the Wolff-Pakrinson-" White syndrome. Brit Heart J 1987; 58: 324-332.

7. Lindsay $\mathrm{BD}$, Crossen $\mathrm{KJ}$, Cain $\mathrm{ME}$ : Concordance of distingulshing electrocardlographic features during sinus rhythm with the locatgion of accessory pathways in the Wollf-Parkinson-White syndrome. Am J Cardiol 1987: 59: 1093-1102.

8. Wellens HJJ, Brugada P. Penn OC: The management of pre-excitation syndromes. JAMA 1987; 257 no. $17: 2325-2333$.

9. Wellens HJJ, Bär FW, Gorgels AP, Vanagt EJ: Use of ajmaline in Identifying patients with the Wolff-Parkinson-White syndrome and a short refractory period of thetr accessory pathway. Am J Cardiol 1980; 45: 130-133.

10. Wellens HIJ, Braat SH, Brugada P. Gorgels AP. Bär FW: Use of procalnamide in patients with the Wolf-Parkinson-White syndrome to disclose a short refractory perlod of the accessory pathway. Am J Cardiol 1982; 50:921-925. 

Chapter VI

\title{
Clinical and electrophysiological characteristics of patients with multiple accessory pathways
}

\author{
Jacob Atié \\ Pedro Brugada \\ Joep L.R.M. Smeets \\ Fernando E.S. Cruz \\ Ayrton Peres \\ Mauricio Duque \\ Marie P. Roukens \\ Hein J.J. Wellens
}




\section{Clinical and electrophysiological characteristics of patients with multiple accessory pathways}

\section{SUMMARY}

Multiple accessory atrioventricular pathways were documented in 18 of 345 patients $(5,2 \%)$ with Wolf-Parkinson-White syndrome undergoing detalled electrophysiologic evaluation. Multiple accessory pathways were idenified during intraoperative mapping or electrophysiologic study by: 1) Different patterns of preexcitation during antidromic circus movement tachycardia, atrial fibrillation or atrial pacing (12 patients); 2) Different patterns of retrograde atrial activation during right ventricular pacing or orthodromic circus mowement tachycardia (10 patients); 3) Antidromic circus movement tachycardia using a second accessory pathway as the retrograde limb of the tachycardia (5 patients); 4) A spontaneous or induced change from antidromic circus movement tachycardia to orthodromic circus movement tachycardia or vice-versa, using different accessory pathways (4 patients); 5) Change in pre-excitation pattern following administration of drugs (4 patients). Fourteen patients $(78 \%)$ had 2 accessory pathways and 4 patients $(22 \%)$ had 3 accessory pathways. Right free wall and left posteroseptal accessory pathways were most commonly associated. In 12 out of 18 patients $(67 \%)$ with multiple accessory pathways an antidromic circus movement tachycardia could be initiated. This was possible in only $24 / 325$ patients (7.6\%) with one accessory pathway. Nine patients $(50 \%)$ had one or more episodes of syncope and 2 patients (11\%) had ventricular fibrillation. compared to an incidence of $12 \%$ and $2 \%$ in patients with only one accessory pathway. Ten patients had surgery. 3 patients (30\%) had to be reoperated, compared to $9 / 115$ pts $(8 \%)$ with only one accessory pathway. Conclusions: 1) There is a wide spectrum of findings during spontaneous or induced arrhythmias pointing to the likelihood of more than one accessory pathway in patients with multiple pathways. 2) Patients with multiple accessory pathways have more frequently syncope, antidromic tachycardia and ventricular fibrillation than patients with a single accessory pathway. 3) Reoperation rate is higher in pts with multiple accessory pathways.

Presented at the European Society of Cardiology. Eur Heart $J 1989 ; 10: 381$

Submitted for publication 


\section{INTRODUCTION}

The existence of multiple accessory atrioventricular pathways in a single patient was first demonstrated by Matter et al (1) in 1964, from the electrocardiographic observation of alternating types $A$ and $B$ preexcitation in the same patient. Afterwards multiple accessory atrioventricular pathways have been documented in an increasing number of patients during electrophysiological study and intraoperative mapping (2-7). The reported incidence of multiple accessory pathways ranges between 3.7 and $13 \%$ in different studies (7-9).

One of the reasons for failure of surgical dissection in patients with Wolff-Parkinson-White syndrome is the presence of multiple accessory pathways that were not recognized during preoperative electrophysiological study $(3,9)$.

This report reviews our experience and the clinical and electrophysiological characteristics of patients with multiple accessory pathways.

\section{PATIENTS AND METHODS}

The 18 patients in this study were selected from 345 patients seen at our institution between 1979 and august 1989, for evaluation and treatment of various pre-excitation syndromes.

The localization of the accessory pathway(s) was based on findings from endocardial catheter mapping during electrophysiologic study, and on information from intraoperative mapping in those patients who underwent surgical correction of the accessory pathway(s).

\section{Electrophysiological study}

After informed consent an electrophysiological study was performed in the resting, nonsedated state.

Four multipolar electrode catheters were inserted percutaneously and positioned under fluoroscopic guidance in the right atrium, coronary sinus, right ventricular apex, and bundle of His region. Methods of stimulation and recording used at our laboratory and the definitions used have been described in detaill (10). All patients underwent a complete electrophysiologic investigation.

\section{Definitions}

Multiple accessory pathways were considered to be present when more than one accessory pathway was found during electrophysiological study or epicardial mapping during surgery. 


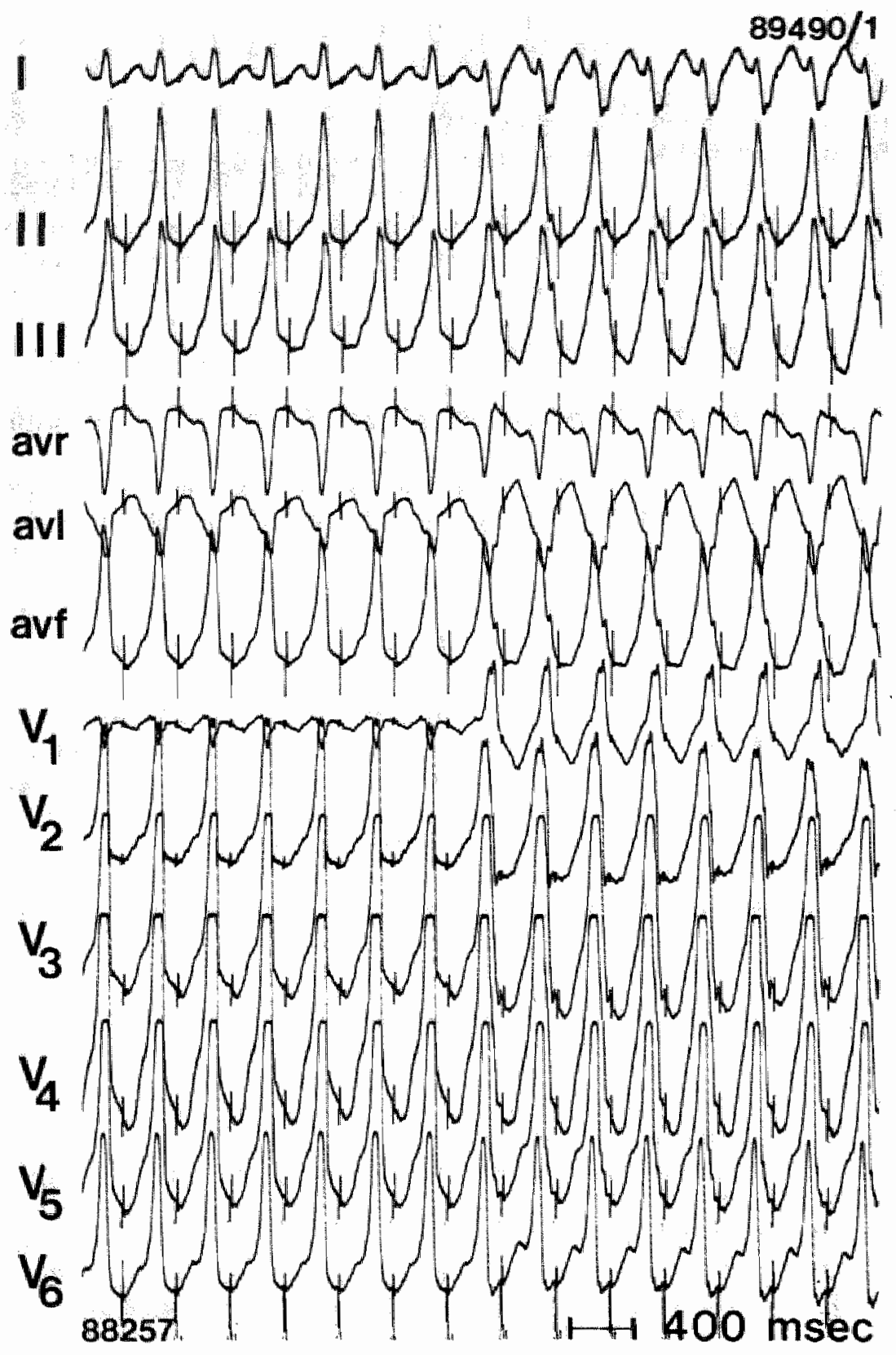

Figure 1. The 12 lead electrocardiogran during atrial pacing in a patient with the Wolf-Parkinson-White syndrome. Two different patterns of pre-excitation, one from A-V conduction over an anteroseptal accessory pathway (left part) and another with $\mathrm{A}$-V conduction over a left lateral accessory pathway (right part) are shown. 


\section{Criteria}

The following criteria were used to recognize multiple accessory pathways during electrophysiological study:

1. Two or more different patterns of preexcitation during atrial pacing (fig. 1).

2. Two or more different patterns of preexcitation during antidromic circus movement tachycardia (fig. 2). Antidromic tachycardia was defined as a reentrant tachycardia that used anterogradely an accessory atrioventricular pathway and retrogradely the A-V node system or a second accessory pathway. In all patients with antidromic circus movement tachycardia we were able to exclude atrial flutter, atrial tachycardia and dual $\mathrm{A}-\mathrm{V}$ nodal tachycardia using the accessory pathway as a "bystander".

3. Two or more different patterns of preexcitation during atrial fibrillation (fig. 3).
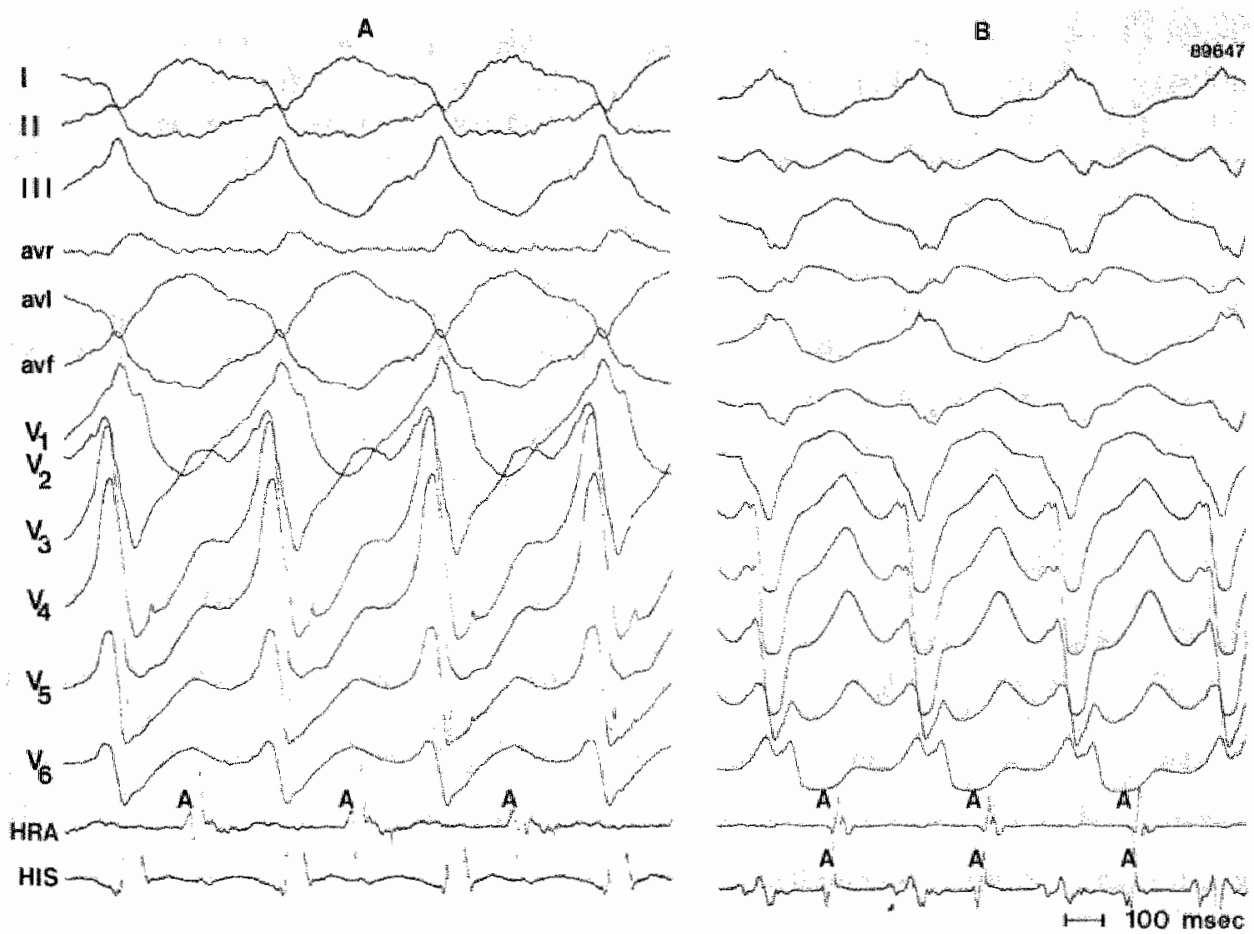

Figure 2. Two types of antidromic circus movement tacluycardia in the same pattent. Panel $A$ shows an antidromic circus movement tachycardla with anterograde conduction over a left lateral accessory pathway. Panel B an antidromic clrcus movement tachycardla with antero. grade conduction over a right sided accessory pathway. Twelve surface electrocardiographlic leads and 2 intracardiac leads from the high right atrium (RA) and bundle of His (HIS). 


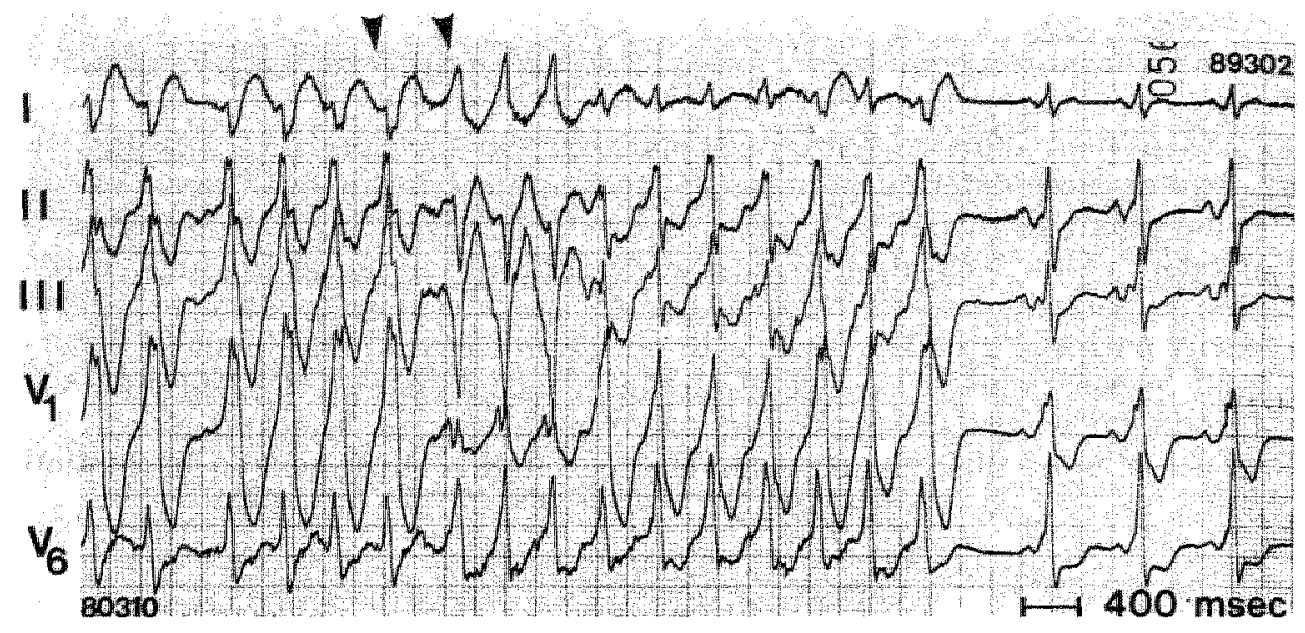

Figure 3. Five simultaneous electrocardiographic leads showing two different patterns of pre-excitation, left lateral and posteroseptal (arrows), during atrial fibrillation. Alsio fuslon complexes resulting from anterograde conduction over both accessory pathways are present. The atrial fibrilation stopped spontaneously and sinus rythm is seen in the right part of the figure.

4. Two or more different patterns of retrograde atrial activation during ventricular pacing, different from that of the AV node and confirmed to be over accessory pathways (fig. 4).

5. Two or more different patterns of retrograde atrial activation during orthodromic circus movement tachycardia over different accessory pathways (fig. 5). Orthodromic tachycardia was defined as a reentrant tachycardia that used the normal AV conduction system as the anterograde limb and an accessory pathway as the retrograde limb of the circuit.

6. A "mismatch" between the site of origin of atrial activation following retrograde activation over the accessory pathway during ventricular pacing or orthodromic tachycardia and the site of earliest ventricular activation during atrial pacing or antidromic tachycardia. Such a finding suggests that different accessory pathways were used in retrograde and anterograde direction (fig. 6).

7. A spontaneous change from an orthodromic circus movement tachycardia to an antidromic circus movement tachycardia, or viceversa (fig. 7 ). This can only be explained by the presence of two accessory pathways.

8. A change from an orthodromic circus movement tachycardia to antidromic circus movement tachycardia or viceversa after a single atrial or ventricular premature beat. It is impossible to use the same accessory pathway retrogradely and immediately thereafter anterogradely or viceversa.

9. A change from one antidromic tachycardia into another (fig. 8). 


\section{RV Pacing}
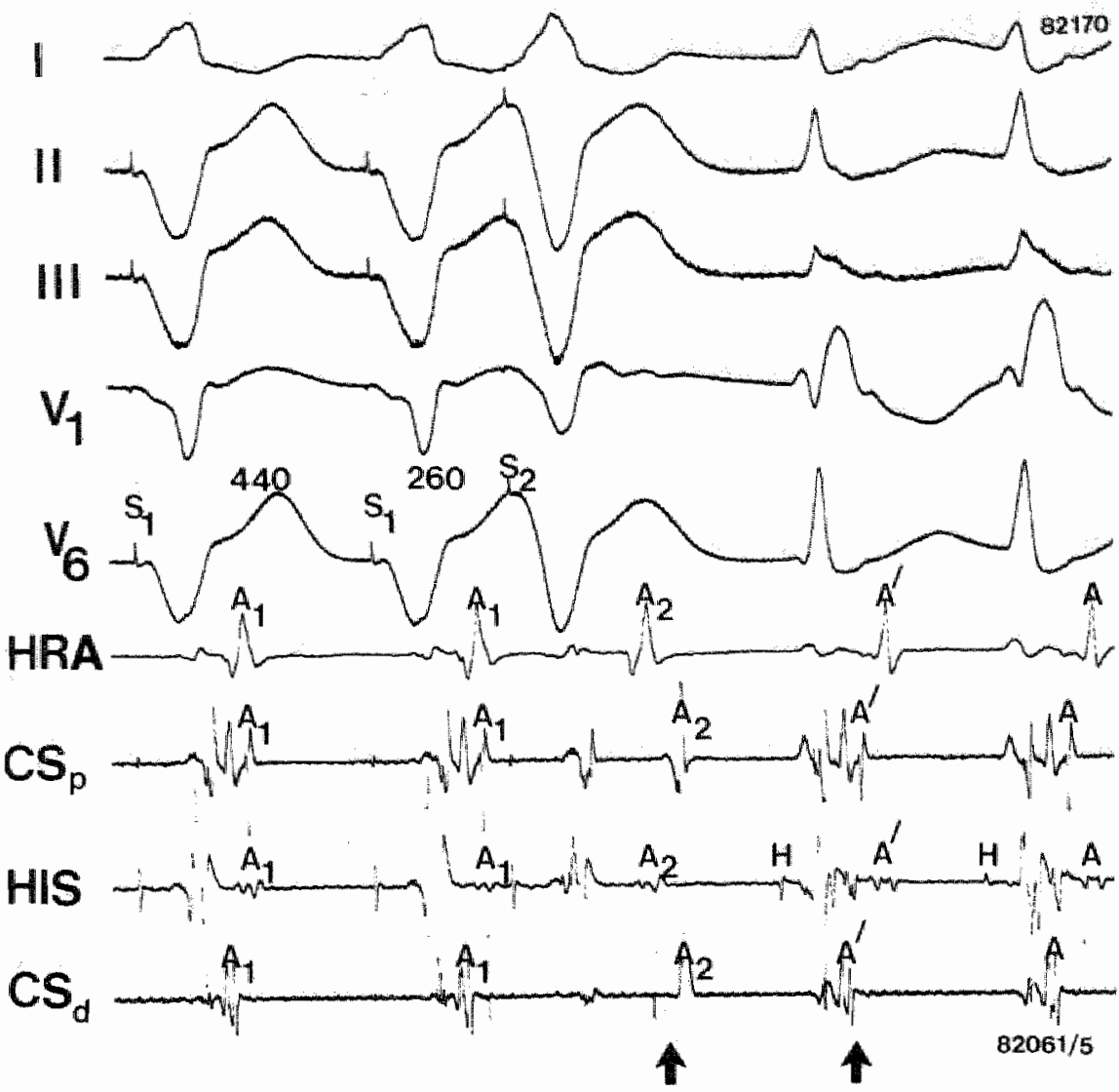

Figure 4. Initiation of orthodromic circus movernent tachycardla showing the presence of two retrogradely conducting accessory pathways. Five electrocardiographtc leads and four intracardlac leads recording from the high right alrum (HRA), proximal coronary sinus ICSp), bundle of His (HIS) and distal coronary sinus (CSd) are shown. During ventricular pacing with a cycle length of $440 \mathrm{~ms}$, atrial activation occurs almost simultaneously in all intracardiac recordings. After a wentricular premature beat given after $260 \mathrm{~ms}$, the lirst retrograde atrial activation occurs in the high right atrium by way of a right sided accessory pathway. Thereafter orthodromic circus movement tachycardia starts, with earliest retrograde atrial act ivation being recorded in the coronary sinus indicating left-sided accessory pathway. 


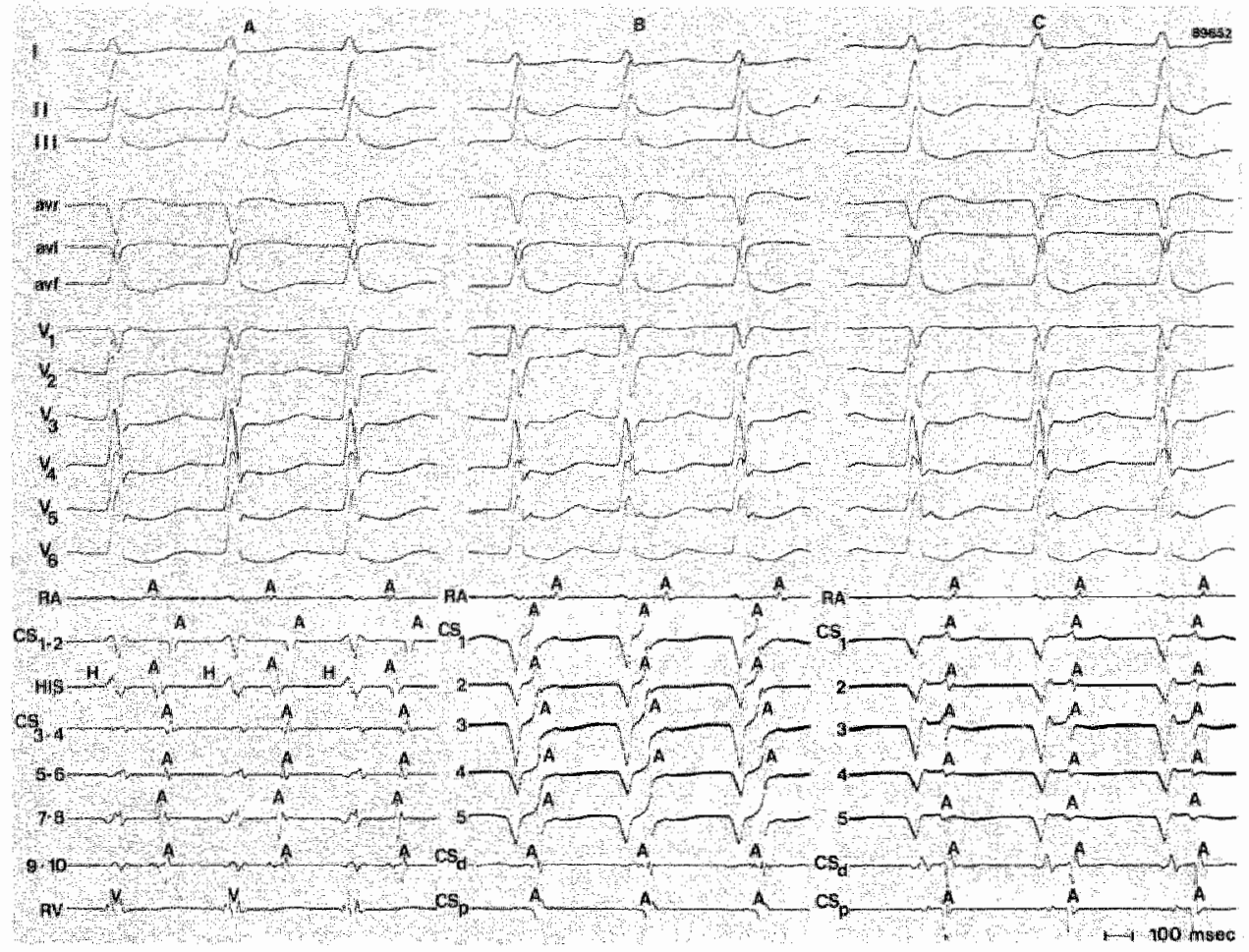

Figure 5. Orthodromic clrcus movement tachycardla showing retrograde conduction over 2 accessory pathways. In panel $A$ orthodromic circus movement tachycardia is observed, with the onset of retrograde atrial activation occurring in the right atrium (right lateral accessory pathway). In panel $B_{n}$ orthodromic circus movenent tachycardia shows earliest atrial activation in the distal ( $C S_{1}$ ) coronary sinus (left lateral accessory pathway). In panel $C$ there is almost stmultaneous retrograde atrial activation in all recordings (retrograde fusion over both accessory pathways). Apart from the 12 extracardiac leads, intracardlac recordings are shown from the high right atrium (RA), the bundle of His (HIS), the coronary sinus (CS) and the right ventricle (RV). Panel A shows bipolar and panel $B$ and $C$ unipolar recordings from the coronary sinus. 


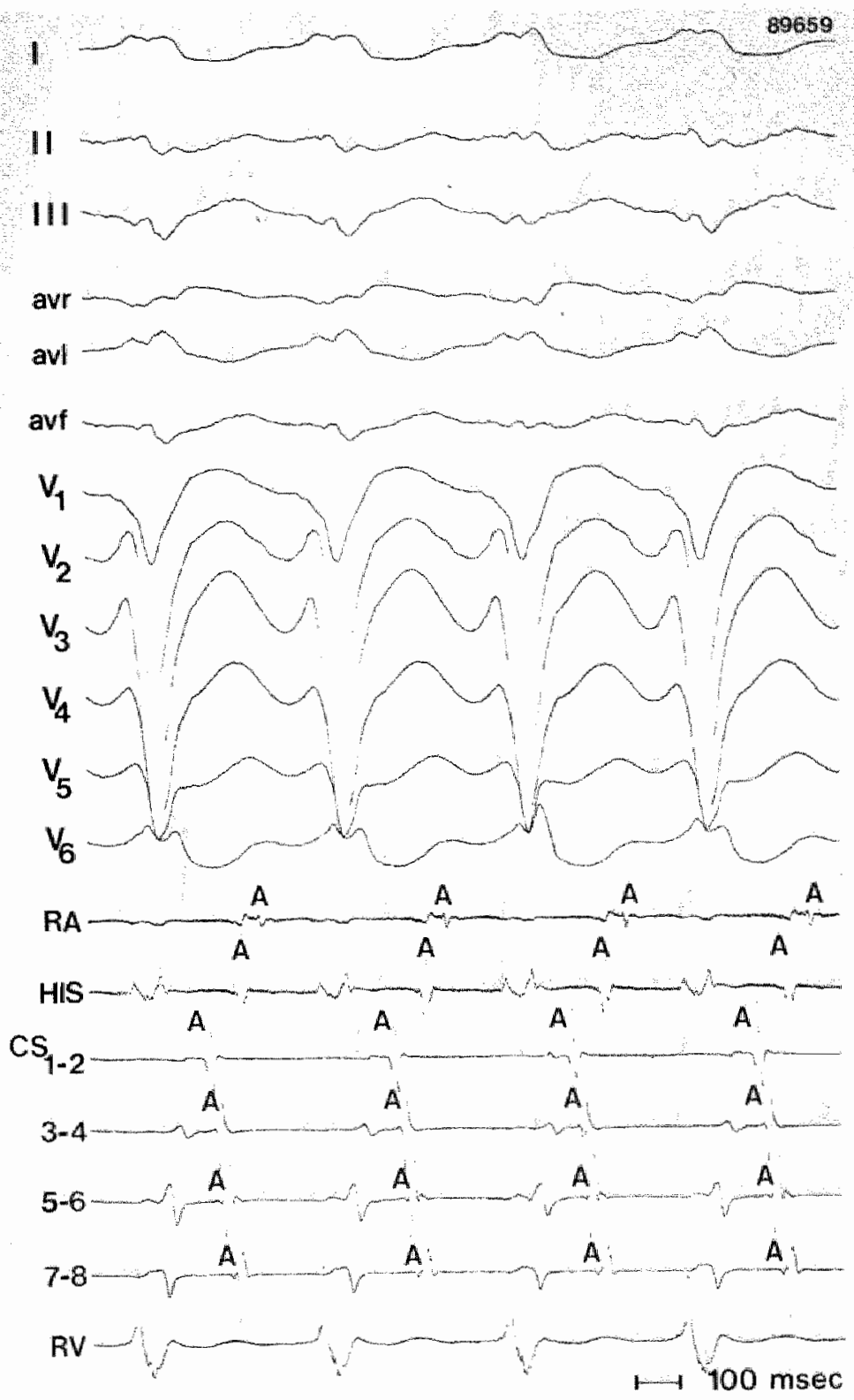

Figure 6. Example of antidromic circus movement tachycardia, using a right stded accessory pathway in the anterograde direction and a left sided accessory pathway in the retrograde direction. As shown, earliest retrograde atral activation occurs in the distal coronary sinus (CS 1-2). Twelve surface electrocardiographic leads and 7 intracardlac leads are shown, high right atrium (RA), bundle of His (HIS), four blpolar recording from the coronary sinus, from the more distal (CS 1-2) to proximal (CS 7-8) and right ventricle (RW). 

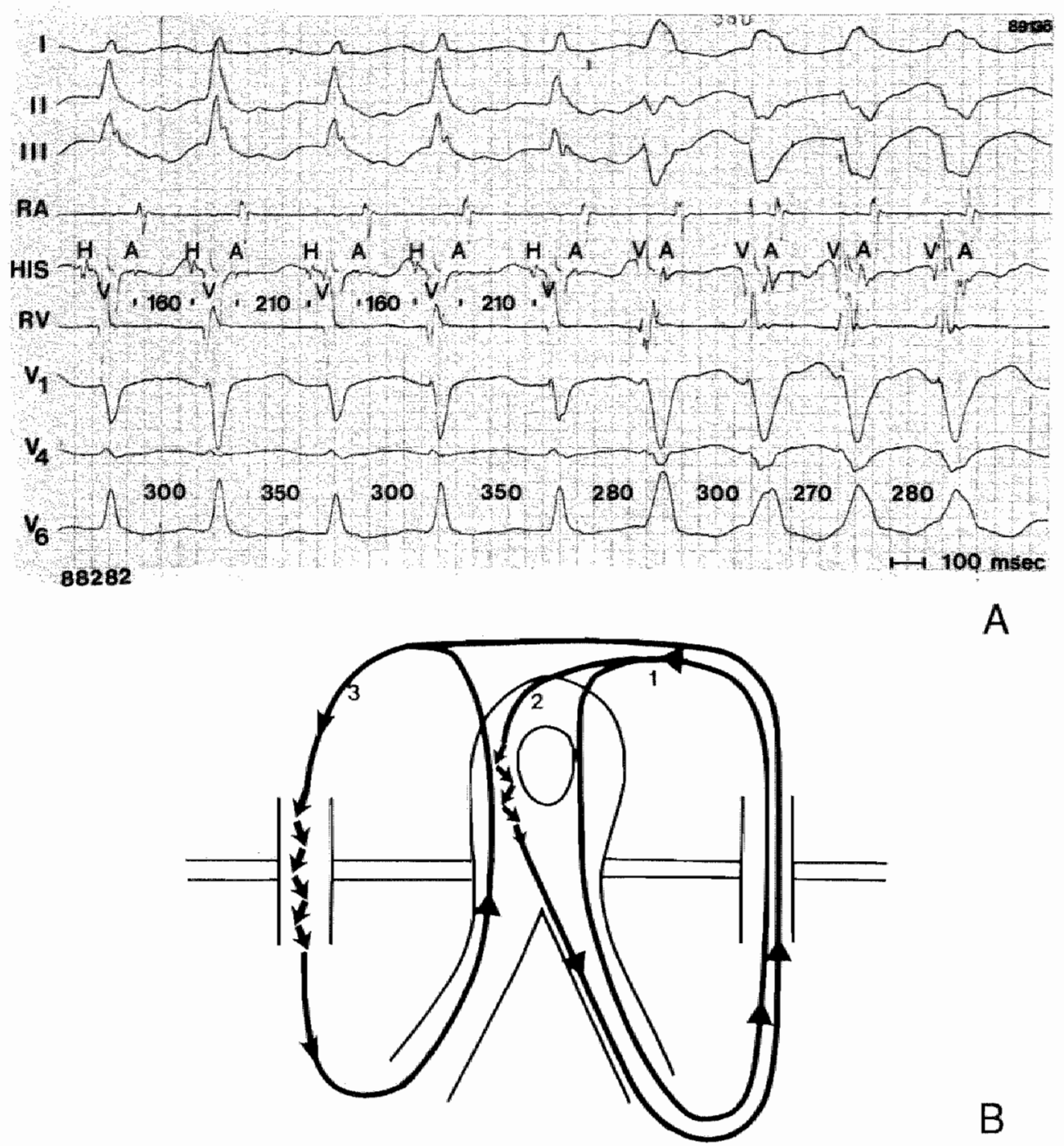

A

Figure 7. Example of a spontaneous change from orthodromic to antidromic tachycardia. The first 5 QRS complex are from an orthodromic circus movement tachycarda showing cycle length alternation of $50 \mathrm{~ms}$. Alternation is caused by alternating conduction over a fast and a slow $\mathrm{A}-\mathrm{V}$ nodal pathway. Thereafter, tachycardla changes spontaneously to antidromic circus movement tachycarda using a second atrio-ventricular accessory pathway with long anterograde conduction times. In panel B a schematic representation of the tachycardias is given. Number 1 represents orthodromic tachycardia with anterograde conduction over the fast. A-V nodal pathway. Number 2 represents orthodromic tachycardia with anterograde conduction over the slow A-V nodal pathway. In both 1 and 2 the retrograde conduction is over the left sided accessory pathway. Number 3 represents the antidromic tachycardia conducting anterogradely over an right sided accessory pathway with long conduction times. 


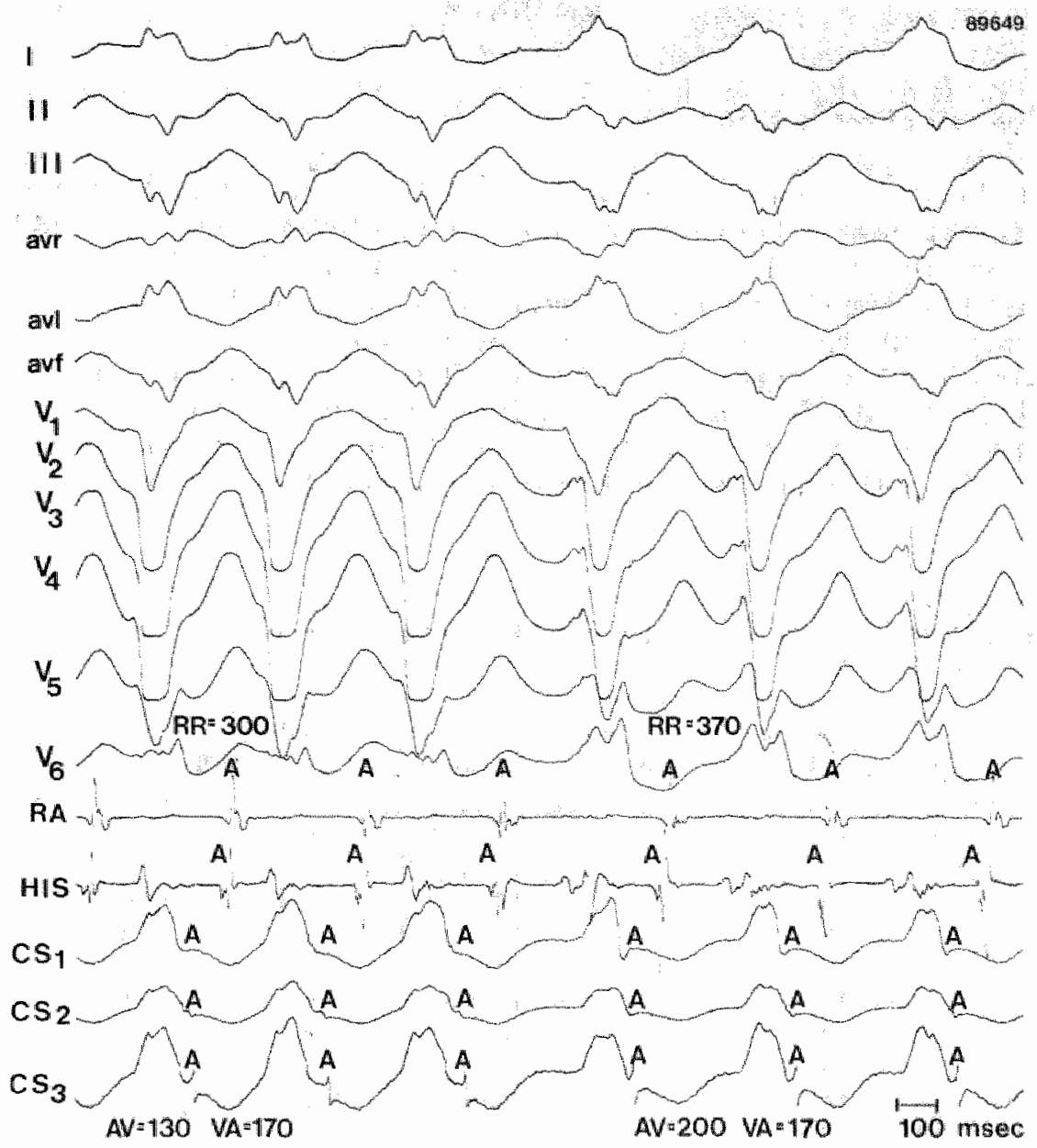

Figure 8. Spontaneous change from one antidromic tachycardla to another. "The first three $Q R S$ complexes are the result of anterograde conduction over a right posteroseptal pathway. Thereafter a right free wall accessory pathway is used for anterograde conduction. Note that: 1) A lef lateral accessory pathway is used for retrograde conduction during both tachycardlas and 2) A dufference of $70 \mathrm{~ms}$ in the cycle length between the 2 tachycardlas. The 12 lead electrocardiogram was simultaneous recorded with 5 intracardiac leads. 


\section{RESULTS}

\section{Clinical Characteristics}

Of the 345 patients studied, $18(5.2 \%)$ were found to have multiple accessory pathways. Fourteen patients had 2 pathways and 4 patients had 3 pathways. The clinical data of the 18 patients are listed in table 1 . The age of the patients ranged from 12 to 56 years (mean $25 \pm 8$ ), 14 were male and 4 female. The clinical history revealed that the first episode of an arrhythmia occurred at a mean age of $15 \pm 7$ years. The mean number of attacks per month in the last 6 month before referred was $5 \pm 3$. The most common symptom was palpitations (94\%), followed by dizziness $(66 \%)$ and syncope $(50 \%)$. Nine patients $(50 \%)$ had their tachycardia induced by exercise.

Table I. Clinical Data of 18 patients with multiple accessory pathways

\begin{tabular}{|c|c|c|c|c|c|c|c|}
\hline Pts & $\operatorname{sex}$ & Age & $\begin{array}{l}\text { Age at } \\
\text { onset of } \\
\text { arrhythmia }\end{array}$ & $\begin{array}{l}\text { Frequency } \\
\text { of attacks } \\
\text { (month) }\end{array}$ & Symptoms & $\begin{array}{l}\text { Exercise } \\
\text { induced } \\
\text { tachycardia }\end{array}$ & $\begin{array}{l}\text { Clinical } \\
\text { arrhythmia }\end{array}$ \\
\hline 1 & $M$ & $2 \mathbb{1 1}$ & 12 & 6 & $\mathrm{PL} / \mathrm{DZ} / \mathrm{SN}$ & yes & $A / O$ \\
\hline 2 & $F^{*}$ & 22 & 13 & 1 & $\mathbb{P L} / \mathrm{DZ} / \mathrm{SN}$ & yes & $\mathrm{A} / O / \mathrm{AF}$ \\
\hline 3 & M & 19 & 19 & 5 & PL/DZ/SN & yes & $\mathrm{A} / \mathrm{O} / \mathrm{VF}$ \\
\hline 4 & $F$ & 12 & 8 & 2 & $\mathrm{PL} / \mathrm{DZ} / \mathrm{SN}$ & yes & $\mathrm{A} / \mathrm{O}$ \\
\hline 5 & $M$ & 12 & 12 & 1 & $\mathrm{PL}$ & no & A \\
\hline 6 & $\mathrm{M}$ & 15 & 13 & 30 & $\mathrm{PL} / \mathrm{DZ} / \mathrm{SN}$ & yes & A \\
\hline 7 & $M$ & 18 & 18 & 1 & ASYMPT. & no & NAD \\
\hline 8 & M & 23 & 15 & 1 & $\mathrm{PL} / \mathrm{DZ} / \mathrm{SN}$ & yes & $\mathrm{A} / \mathrm{O}$ \\
\hline $\mathfrak{9}$ & $M$ & 16 & 14 & 1 & $\mathrm{PL} / \mathrm{DZ} / \mathrm{SN}$ & yes & $\mathrm{A} / \mathrm{O} / \mathrm{NF}$ \\
\hline 10 & $F$ & 30 & 20 & 5 & $\mathrm{PL} / \mathrm{DZ}$ & yes & $A F$ \\
\hline 11 & $M$ & 20 & 10 & 10 & $\mathrm{PL} / \mathrm{DZ}$ & yes & $\mathrm{O} / \mathrm{AF}^{\mathrm{a}}$ \\
\hline 12 & $F^{*}$ & 29 & 20 & 0 & $\mathrm{PL}$ & no & NAD \\
\hline 13 & $\mathrm{M}$ & 39 & 20 & 4 & PL & no & 0 \\
\hline 14 & $\mathrm{M}$ & 56 & 30 & 2 & $\mathrm{PL}$ & no & 0 \\
\hline 15 & $M$ & 29 & 12 & 7 & $\mathrm{PL} / \mathrm{DZ} / \mathrm{SN}$ & no & 0 \\
\hline 16 & $M$ & 31 & 15 & 3 & $\mathrm{PL} / \mathrm{DZ} / \mathrm{SN}$ & no & 0 \\
\hline 17 & $\mathrm{M}$ & 28 & 19 & 4 & $\mathrm{PL} / \mathrm{DZ}$ & no & 0 \\
\hline 18 & $M$ & 30 & 15 & 1 & PL. & no & 0 \\
\hline
\end{tabular}

Abbreviations: $P T S=$ patient number; $P L=$ palpitations; $D Z=$ dizzimess; $S N=$ syncope; $A s y m p t=$ asymptomatic: $\mathrm{A}=$ antidromic circus movement tachycardia; $\mathrm{O}=$ orthodromic circus movement tachycardia; $A F=$ atrial fibrillatton; $V F=$ ventricular fbrillation: $N A D=$ no arrhythmia documented; $M=$ male; $F=$ remale. 
Thirteen patients $(72 \%)$ had clinical documentation of orthodromic tachycardia and 8 patients $(44 \%)$ had a clinically documented episode of antidromic tachycardia. Seven patients (39\%) suffered from both orthodromic and antidromic tachycardia. Atrial fibrillation was documented clinically in 3 patients $(17 \%)$. Two patients (1 $1 \%)$ had a history of ventricular fibrillation.

\section{Electrophysiological Characteristics}

The location of the accessory pathways is presented in table II. The most common location was left posteroseptal $(33 \%)$, followed by right lateral (25\%). The most frequent association was right lateral with left posteroseptal (5 patients).

Table II. Location of the accessory pathways and types of induced tachycardias

\begin{tabular}{lll}
\hline Pt & Localization & Arrhythmias induced \\
\hline 1 & AS, LL, RPS & AT/OT/AFT \\
2 & LL, LPS & AT/OT/AF/AFT \\
3 & LL, LPS & AT/OT/AF/AFT/VF \\
4 & RL, LL & AT/OT/AF/AFT \\
5 & RL, LPS & AT/OT/AF \\
6 & LPS, NV & AT \\
7 & RL, NV & AT/OT \\
8 & RPS, LPS & AT/OT/AF \\
9 & RL, PS & AT/OT/AF/NF \\
10 & RL, LL. LPS & AT/OT/AF/AFT \\
11 & LPS, RPS & AT/OT/AF/AFT \\
12 & PS, LPS, RL & AT/OT/AF \\
13 & LPS, PS & OT/AF/AFT \\
14 & LL, LPS & OT/AFT \\
15 & LL, RL & OT/AF/AFT \\
16 & LPS. RL, PS & OT \\
17 & LPS, RL & OT/AF \\
18 & LPS, RL & OT/AF \\
\hline
\end{tabular}

Abbreviation: $A S=$ anteroseptal; $P S=$ posteroseptal; $L L=$ left lateral; $R L=$ right lateral; $L P S=$ left posteroseptal; $R P S=$ right posteroseptal; $N V=$ nodoventricular: $O T=$ orthodromic circus movement tachycardia; $\mathrm{AT}=$ antidromic circus movement tachycardia: $\mathrm{AF}=$ atrial fibrillation; $A F T=$ atrlal flutter; $\mathrm{VF}=$ ventricular fibrillation. 
The mean atrial refractory period was $205 \pm 24 \mathrm{~ms}$ and the mean ventricular refractory period was $198 \pm 25 \mathrm{~ms}$. The mean refractory period of the AV node measured was $215 \pm 38 \mathrm{~ms}$ anterogradely and $220 \pm 32 \mathrm{~ms}$ retrogradely. It has to be realized that the exact measurement of this values could not be obtained in all patients. The mean anterograde refractory period of the accessory pathway was $232 \pm 32 \mathrm{~ms}$, when only the accessory pathway having the shortest refractory period was considered. The atrial, ventricular, and accessory pathways refractory periods are listed in table III.

In 17 patients $(94 \%)$ orthodromic circus movement tachycardia could be induced and in 12 patients $(67 \%)$ antidromic circus movement tachycardia. Ability to induced antidromic circus movement tachycardia was significatively higher $(\mathrm{p}<0.0001)$ in patients with multiple accessory pathways $(12 / 18)$ as compared to patients (24/327) with a single accessory pathway. In $11 / 18$ patients $(61 \%)$ both an antidromic and an orthodromic tachycardia could be

Table III. Refractory perlods of atrium, ventricle and accessory pathway in the 18 patients studied

\begin{tabular}{lllrl}
\hline Pts & $\begin{array}{l}\text { AERP } \\
\text { (ms) (PCL) }\end{array}$ & $\begin{array}{l}\text { VERP } \\
(\mathrm{ms})(\mathrm{PCL})\end{array}$ & $\begin{array}{l}\text { AP AERP } \\
\text { (ms) (PCL) }\end{array}$ & $\begin{array}{l}\text { AP RERP } \\
\text { (ms) (PCL) }\end{array}$ \\
\hline 1 & $220(428)$ & $180(428)$ & $280(500)$ & $\leq 180(428)$ \\
2 & $190(600)$ & $210(428)$ & $260(500)$ & $\leq 210(428)$ \\
3 & $190(428)$ & $220(428)$ & $\leq 190(500)$ & $240(428)$ \\
4 & $210(428)$ & $200(428)$ & $330(500)$ & $\leq 200(428)$ \\
5 & $200(428)$ & $200(428)$ & $230(500)$ & NA \\
6 & $250(428)$ & $250(600)$ & $310(500)$ & $460(500)$ \\
7 & $230(428)$ & $280(500)$ & $\leq 230(428)$ & NA \\
8 & $180(428)$ & $180(500)$ & $\leq 180(428)$ & $\leq 180(428)$ \\
9 & $220(428)$ & $210(428)$ & $240(428)$ & $\leq 210(428)$ \\
10 & $200(428)$ & $200(500)$ & $\leq 200(428)$ & NA \\
11 & $200(600)$ & $200(500)$ & $260(428)$ & NA \\
12 & $190(428)$ & $160(428)$ & $270(428)$ & $\leq 160(428)$ \\
13 & NA & $200(428)$ & $280(428)$ & $\leq 200(428)$ \\
14 & $210(600)$ & $240(600)$ & $270(428)$ & $260(500)$ \\
15 & $200(500)$ & NA & $250(500)$ & NA \\
16 & $210(428)$ & $190(428)$ & $250(428)$ & $\leq 190(428)$ \\
17 & $230(500)$ & $210(600)$ & $260(500)$ & $\leq 210(600)$ \\
18 & NA & NA & $250(500)$ & NA \\
\hline
\end{tabular}

Abbreviations: $A \mathbb{E R P}$ = atrial effective refractory period: $\mathrm{VERP}=$ ventricular effective refractory pertod: $A P A E R P$ = accessory pathway anterograde effectlve refractory perlod; $A P$ RERP = accessory pathway retrograde effective refractory perlod: $\mathrm{NA}=$ not avallable. $\mathrm{PCL}=$ paced cycle length. Only the shortest refractory period is present in this table. 
initiated (table II]. The mean cycle length of the orthodromic tachycardia was longer than that of the antidromic tachycardia ( $349 \pm 24 \mathrm{~ms}$ and $309 \pm 31 \mathrm{~ms}$ respectively).

Of the 40 accessory pathways documented in our 18 patients, 28 were able to conduct both in anterograde and in retrograde direction. Twelve conducted in one direction only, 6 anterogradely and 6 retrogradely. In the 12 patients having more than one accessory pathway able to conduct anterogradely, 2 delta wave morphologies were seen during atrial flutter. atrial fibrillation (fig. 3) or atrial pacing (fig. 1). Two different patterns of preexcitation during antidromic circus movement tachycardia was observed in 7 patients (fig. 2).

In two patients, with retrograde conduction over an accessory pathway during orthodromic circus movement tachycardia, evidence of a second accessory pathway conducting anterogradely was obtained by observing fusion QRS complexes during tachycardia (fig. 9).

In one patient with antidromic circus movement tachycardia, using a second accessory pathway for retrograde conduction, evidence of a third accessory pathway was obtained because of a sudden change in the GRS morphology during antidromic tachycardia without changes in the retrograde atrial activation sequence (fig. 8 ).

In one patient the presence of two accessory pathways conducting anterogradely could only be demonstrated after the infusion of isoproterenol.

\section{Clinical Outcome}

Antiarrhythmic drug treatment was prescribed in 8 patients and surgical ablation attempted in the remaining 9 . One patient is asymptomatic without treatment. Because of a recurrence of preexcitation and tachycardias, 3 patients had to be reoperated, two during the same hospitalization and one a few months later. Two of the 3 patients had a third accessory pathway that had not been diagnosed neither during the first pre-operative electrophysiologic study nor during the first surgery.

No patient died during or after operation. 
accessory pathway. Also, a septally located accessory pathway can be missed because retrograde conduction over the AV node is assumed. Other reasons to fail to recognize an accessory pathway are its electrophysiologic properties. If the anterograde or retrograde refractory period is longer than the refractory period of the other pathway, conduction may not be observed under normal circumstances.

In conclusion, patients with multiple accessory pathways have a higher incidence of syncope and ventricular fibrillation. There are several findings both during the spontaneously occurring and induced tachycardias that help in recognition the presence of more than one accessory pathway. The incidence of failure of surgical treatment is higher than in patients with a single accessory pathway. 


\section{REFERENCES}

1. Matter BJ. Hayes WL. Wolf-Parkinson-White syndrome, report of a case with both type A and B preexcitation. Am J Cardiol 1964: 13: 284-286.

2. Portillo B, Portillo-Leon N, Zaman L, Castelyanos A. Quintuple pathways participating in three distinct types of atrioventricular reciprocating tachycardia in a patient with WollfParkinson-White syndrome Am J Cardiol 1982; 50: 347-352.

3. Sealy WC, Gallagher Ju. Surgical problems with multiple accessory pathways of atrioventricular conduction. J Thorac Cardiovase Surg 1981;81: 707-712.

4. Morady F, Scheinman ZMM, DiCarlo LA, Winstion SA, Davis JC, Baerman JM, Krol RB. Crevey BJ. Coexistent posteroseptal and right-sided atrioventricular accessory tracts. J Am Coll Cardiol 1985; 5: 540-646.

5. Heddle WF, Brugada P. Wellens HuJ. Multiple circus movement tachycardia with multiple accessory pathways. I Am Coll Cardiol 1984: 1: 168-175.

6. Cinca J, Valle V, Gutierrez L, Figueras J, Ruiz J. Reciprocating tachycardia using billateral accessory pathways: electrophysilological and clinical implicattions. Circulation 1980; 62: $657-61$.

7. Gallagher JJ, Sealy WC, Kasel J, Wallace AG. Multiple accessory pathways in patients with the pre-excitation syndrome. Circulation 1976; 54: 571-91.

8. Colavita PG, Packer DL, Pressley JC, Ellenbogen KA, O'Callaghan WG, Gllbert MR, German LD. Frequency, diagnosis and clinical characteristics of patients with multiple accessory atrioventricular pathways. Am J Cardilol 1987; 59: 601-606.

9. Iwa T, KawasujI M, Misalki T, Iwase T, Magara T. Localization and Interruption of acessory conduction pathway th the Woll-Parkmson-White syndrome. J Thorac Cardlovasc Surg 1980; $80: 271-279$.

10. Wellens HJJ, Durrer D. The role of an accessory atrioventricular pathway in reciprocal tachycardta. Observation in patients with and without Wolf-Parkinson-White syndrome. Circulation $1975 ; 52: 58 \cdot 64$.

11. Benditt DG, Pritchet ELC, Gallagher JJ. Spectrum of regular tachycardias with wide GRS complexes in patients with accessory atrioventricular pathways. Am J Cardiol 1978; 42: 826-838.

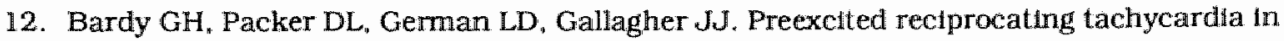
patients with Wolff-Parkinson-White syndrome: incldence and mechanisms. Circulation 1984: 70: $377-391$. 
13. Kein GJ, Bashore TM, Sellers TD, Pritchet ELC, Smith WM, Gallagher JJ. Ventricular fibrillation in the Wollf-Parkinson-White syndrome. N Engl I Med 1979:301: 1080-1085.

14. Torner PM, on behalf of the European Registry on Sudden Death in the Wolf-ParkinsonWhite syndrome. Ventricular fibrillation in the Wolf-Parkinson-White syndrome. PACE $1988 ; 11: 46$ (Abstr)

15. Gallagher JJ, Pritchet ELC, Sealy WC. Kasell J, Wallace AG. The preexcltation syndromes. Prog Cardlovisc Dis 1978; 20: 285-327. 
Chapter VII

\title{
Surgical treatment of multiple accessory pathways in the Wolff-Parkinson-White syndrome
}

\author{
Jacob Atié \\ Pedro Brugada \\ Joep L.R.M. Smeets \\ Fernando E.S. Cruz \\ Olaf C.K.M. Penn MD \\ Hein J.J. Wellens
}




\title{
Surgical treatment of multiple accessory pathways in the Wolff-Parkinson-White syndrome
}

\begin{abstract}
SUMMARY
Eight out of 134 patients who underwent surgery for the Wolff-ParkinsonWhite syndrome had multiple accessory pathways. Four were male and 4 female. the mean age was $23 \pm 9$ years (12-61). Six patients had 2 accessory pathways and 2 patients 3. A complete preoperative electrophysiological study was performed in all patients. Surgical dissection of the accessory pathways was done using an epicardial approach with the normothermic beating heart followed by cryoablation in 6 patients and using an endocardial approach with cardiopulmonary bypass and cross-clamping of the aorta with cold cardioplegia in 2 patients. Three patients $(37 \%)$ had to be reoperated because of a recurrence of preexcitation or tachycardia. The incidence of reoperation in this group of patients was significantly higher as compared to 126 operated patients with a single accessory pathway. In this last group only 9 patients ( $7 \%$ ) had to be reoperated. Two patients with multiple accessory pathways that required repeat surgery had 3 accessory pathways, and the thind accessory pathway was not diagnosed during the preoperative electrophysiological study nor during epicardial mapping. All the 8 patients had 2 accessory pathway diagnosed in the preoperative study. We conclude that patients with multiple accessory pathways can be successfully operated on. but they frequently require reoperation when the diagnosis of the second or third pathway cannot be made during the preoperative electrophysiological study.
\end{abstract}

Submitted for publication 


\section{INTRODUCTION}

In 1967, during an epicardial mapping study; Durrer demonstrated ventricular preexcitation in a patient with a right-sided atrio-ventricular accessory (1). In the same year, Burchell et al (2) tried to surgically interrupt conduction over an atrioventricular accessory pathway in a patient with the Wolff-Parkinson-White syndrome undergoing surgical correction of an atrial septal defect. Successful surgical interruption of an atrioventricular accessory pathway was achieved in 1968 by Sealy and coworkers (3). Since that time, the endocardial approach for division of accessory pathways has undergone further refinement with excellent results (4-8). In 1984, Guiraudon et al (9) reported a closed heart approach for interruption of left free wall accessory pathways. Cryoablation of the A-V junction at the site of the atrioventricular accessory pathway was thereafter included in the procedure to ensure accessory pathway interruption (10). Most of the patients submitted to surgery have a single accessory pathway $(7,11-14)$. However, all series reported on some patients having multiple accessory pathways. In those series the incidence of multiple accessory pathways varies from 3 to $20 \%$. However, there are few reports in the literature confined to surgery of patients with multiple accessory pathways in the Wolff-Parkinson-White syndrome $(13,15)$.

The purpose of this report is to describe our surgical experience in patients with multiple accessory pathways.

\section{PATIENTS AND METHODS}

\section{Patients}

One hundred and thirty four patients underwent surgical ablation of their accessory pathway at our institution from 1986 to august 1989. Eight of them had multiple accessory pathways.

\section{Methods}

\section{Electrophysiologic study}

After informed consent all patients underwent a complete pre operative electrophysiological study in the nonsedated state. Multiple electrode catheters were used to record and pace from the right atrium, the left atrium via the coronary sinus, and the right ventricle. A bipolar catheter was placed across the tricuspid valve to record a His bundle electrogram. Our techniques and protocols during an electrophysiologic study have been reported previously (16). 


\section{Surgery}

The heart was exposed via a median sternotomy in all patients. Intraoperative epicardial mapping using a 21 electrode belt placed over the atrioventricular annulus was performed during sinus rhythm, atrial pacing, ventricular pacing and orthodromic circus movement tachycardia (fig. 1). Fixed left atrial, right atrial and ventricular epicardial electrodes were used to record and pace before and after dissection of the accessory pathway(s).

Accessory pathway ablation was carried out using an epicardial approach in the normothermic beating heart with or without cardiopulmonary bypass, or by an endocardial approach with cardiopulmonary bypass and crossclamping of the aorta associated with cold cardioplegia (6), depending upon the location of the accessory pathway (10).
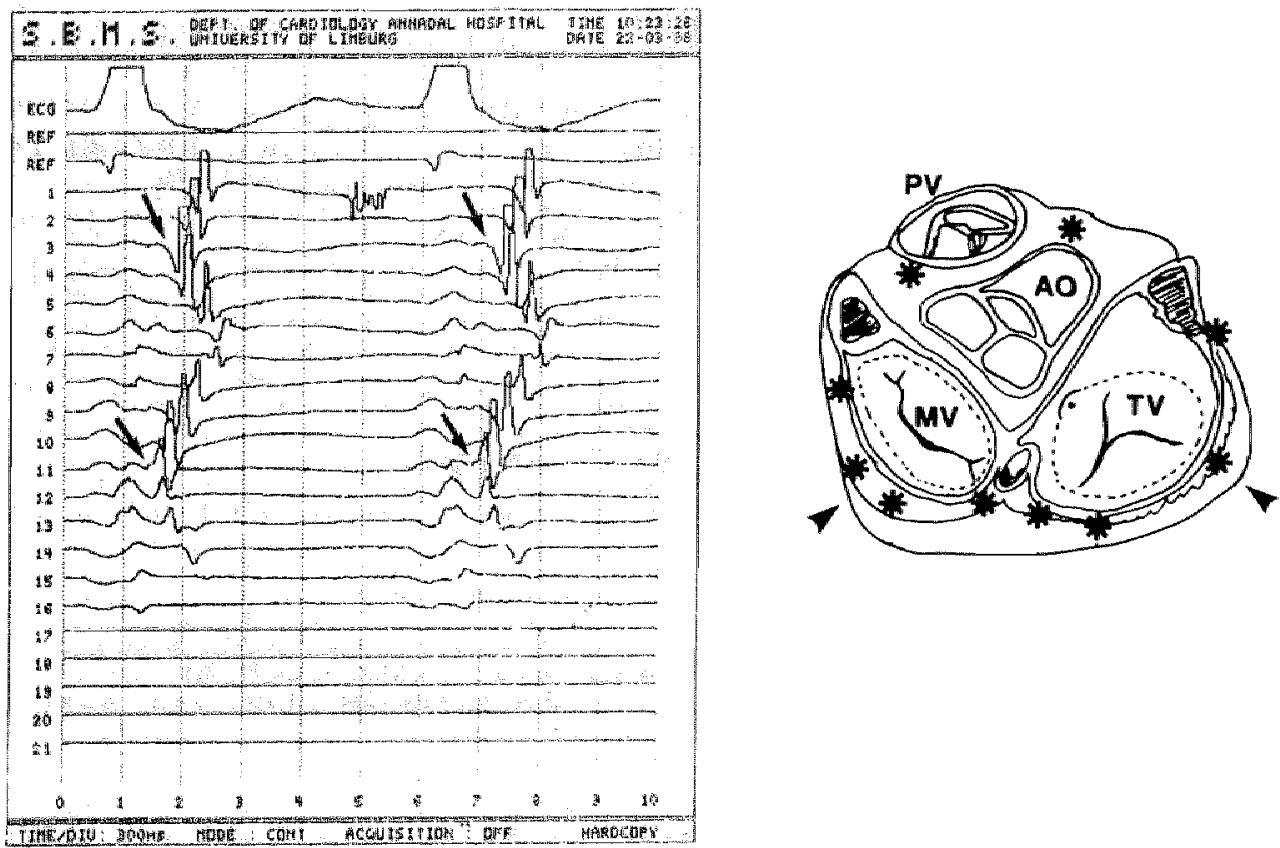

Figure 1. In the left panel "eplcardial mapping during surgery is shown. The band with multiple electrodes has been located over the atrioventricular groove at the atrlal level. During orthodromic circus movement tachycardia two different patterns of atrial activation are present simultaneously. Earliest atrial activation is recorded on electrodes 3 and 11 (arrows).

In the right panel a schematic cross-section of the ventricles at the level of the atrioventricular ring is shown. The arrows show the location of the accessory pathways where electrodes 3 and 11 were located. Abbreviation: $M V=$ mitral valve: $T V=$ tricuspid valve; $A o=$ aortic valve; $P V=$ pulmonary valve. 


\section{RESULTS}

From the 18 patients with multiple accessory pathways diagnosed at electrophysiological study. 8 patients underwent surgery. Six patients had 2 and 2 patients 3 accessory pathways. The third accessory pathway was diagnosed in the post operative electrophysiological study. All 8 patients had 2 accessory pathways diagnosed during the preoperative electrophysiological study.

The clinical data of the 8 patients are shown in table 1 . The mean age was $23 \pm 9$ years (range 13-61). There were 4 male and 4 female.

All patients had several episodes of tachycardia before surgery, and 4 patients had a history of syncopal episodes.

Table I. Clinical findings of 8 patients operated upon with multiple accessory pathways

\begin{tabular}{llllll}
\hline Patient & Sex & Age & Fp & Clinical Arrhythmia & Syncope \\
\hline 1. & M & 21 & 6 & ORT/ANT & + \\
2. & F & 23 & 3 & ORT/ANT/VF & + \\
3. & F & 16 & 5 & ORT/AF & + \\
4. & M & 28 & 4 & ORT & - \\
5. & F & 15 & 2 & ORT/ANT & + \\
6. & M & 13 & 2 & ORT/ANT & + \\
7. & M & 61 & 4 & ORT/AF & - \\
8. & F & 14 & 1 & ORT & - \\
\hline
\end{tabular}

Abbreviations: $\mathrm{AF}=$ atrial fibrillation: $\mathrm{ANT}=$ antidromic circus movement tachycardia;

$\mathrm{FP}=$ frequency of attacks of rapid palpitations a month; $\mathrm{ORT}=$ orthodromic circus movement tachycardia; VF= ventricular fibrillation: $(+)=$ present: $(-)=$ absent.

\section{Electrophysiological study}

The location of the accessory pathways as diagnosed during the electrophysiological study, and the electrophysiological properties of these pathways are shown in table II. The diagnosis of two accessory pathways was made by: 1) More than one sequence of atrial activation indicating retrograde conduction over different accessory pathways during ventricular pacing and/or orthodromic circus movement tachycardia (fig. 2), 2) More than one pattern of ventricular preexcitation during atrial pacing and/or antidromic circus movement tachycardia (fig. 3,4), 3) Atrial fibrillation showing more than one pattern of ventricular preexcitation (fig. 5). In one patient, the presence of a second accessory pathway was exposed after the infusion of isoproterenol. 
Table II. Location and electrophysiological properties of the accessory pathways

\begin{tabular}{|c|c|c|c|c|c|}
\hline Patient & Location & RAERP & VERP & APAERP & APAERP \\
\hline \multirow[t]{3}{*}{1} & $\mathrm{RL}$ & 190 & 200 & $\leq 190$ & $\leq 200$ \\
\hline & RPS & 250 & $\mathrm{NA}$ & & \\
\hline & LL* & 200 & 210 & 330 & 280 \\
\hline \multirow[t]{3}{*}{2} & RL & 250 & 250 & $\leq 250$ & NA \\
\hline & LL & NA & $\mathrm{NA}$ & & \\
\hline & LPS * & NA & 210 & 320 & 270 \\
\hline \multirow[t]{2}{*}{3} & LPS & 200 & 200 & 260 & $\mathrm{NA}$ \\
\hline & RPS ** & NA & $\mathrm{NA}$ & & \\
\hline 4 & $\begin{array}{l}\text { LL } \\
\text { LPS }\end{array}$ & 230 & 190 & $\leq 230$ & 220 \\
\hline \multirow[t]{2}{*}{5} & $\mathrm{RL}$ & 200 & 210 & 240 & $\leq 210$ \\
\hline & LL & & & & \\
\hline \multirow[t]{2}{*}{6} & $\mathrm{LL}$ & 220 & 180 & 280 & $\leq 180$ \\
\hline & RL & & & & \\
\hline 7 & $\begin{array}{l}\text { LL } \\
\text { RPS }\end{array}$ & 200 & 210 & 240 & $\leq 210$ \\
\hline 8 & $\begin{array}{l}\text { LL } \\
\text { RPS }\end{array}$ & 220 & 200 & $\leq 220$ & NA \\
\hline
\end{tabular}

" = diagnosis during post-operative electrophystologic study: ** = recurrence after first surgery. Abbreviations: RAERP $=$ right atrial effective refractory period: VERP = ventricle effective refractory period: $A P A E R P=$ accessory pathway anterograde effective refractory period; $A P R E R P=$ accessory pathway retrograde effective refractory pertiod; $\mathrm{LL}=$ left lateral; $\mathrm{RL}=\mathrm{right}$ lateral; $\mathrm{LPS}=$ left posteroseptal: $\mathrm{RPS}=$ right posteroseptal; $\mathrm{NA}=$ not avallable. All values in ms.

The isoproterenol was given to the patient because during the study only non-sustained orthodromic circus movement tachycardia occurred because of retrograde block in the accessory pathway. In none of our 8 patients 3 accessory pathways were diagnosed during the electrophysiological study.

\section{Surgery}

The surgical technique followed in our 8 patients is shown in table III. In six patients an epicardial approach with a normothermic beating heart followed by cryoablation was used, in 2 patients an endocardial approach was used to divide the accessory pathway. One patient had both epicardial and endocardial procedure. 


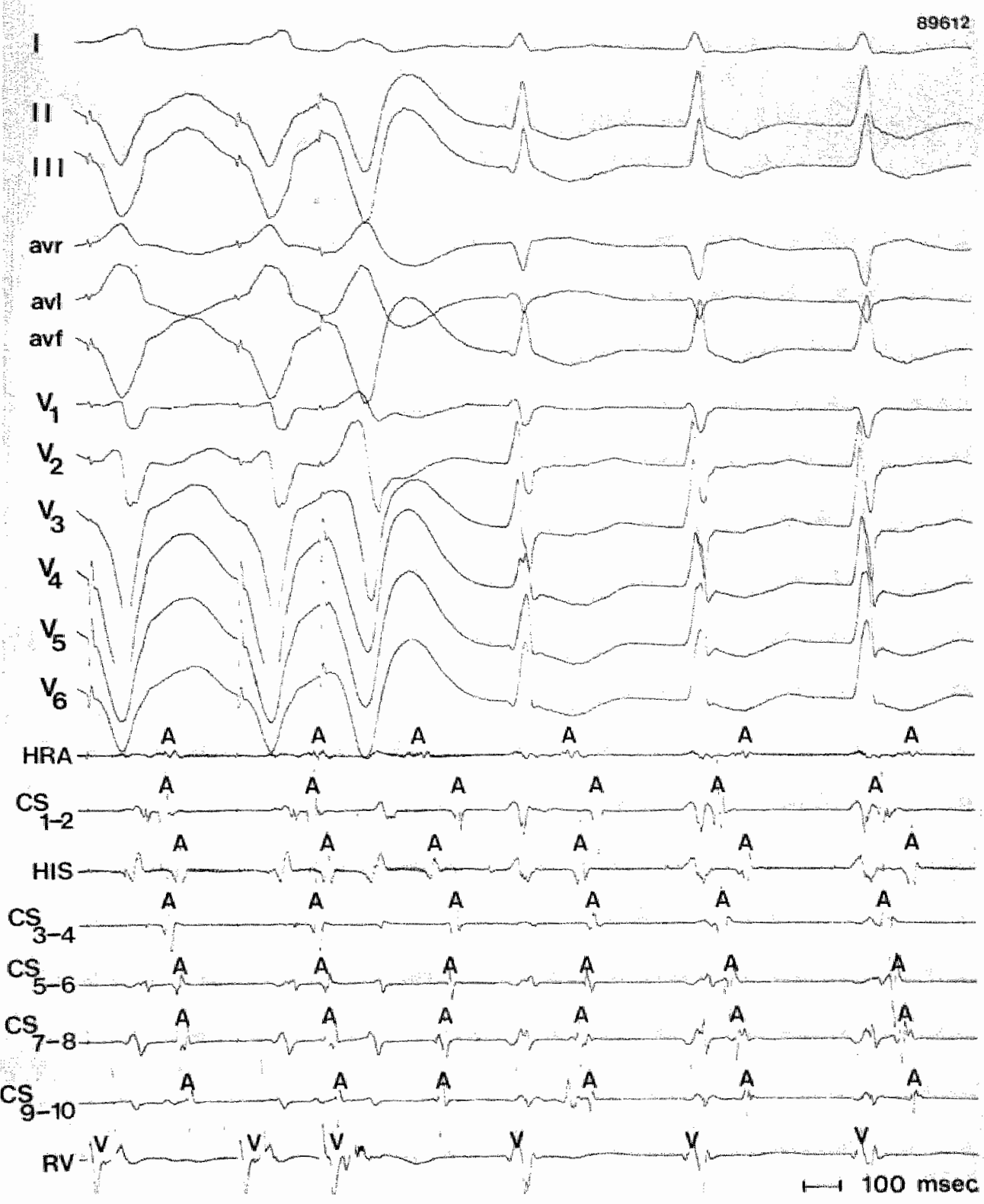

Figure 2. Twelve lead electrocardiogram and intracardlac electrograms from the high right atrium (RA), bundle of His (His). 5 bipolar electrograms from the coronary sinus and the right ventricle (RV) are shown in a patient with 2 accessory pathways. During ventricular pacing with a cycle length of $400 \mathrm{~ms}$ atrial activation starts almost simultaneously from the right atrium and the distal coronary sinus. Right atrial activation occurs first foilowing a ventricular premature beat given after an interval of $200 \mathrm{~ms}$. Orthodromic circus movement tachycardia is initiated showing that the sequence of retrograde atrial activation changes after the frst beat from high right atrium to distal coronary simus. 

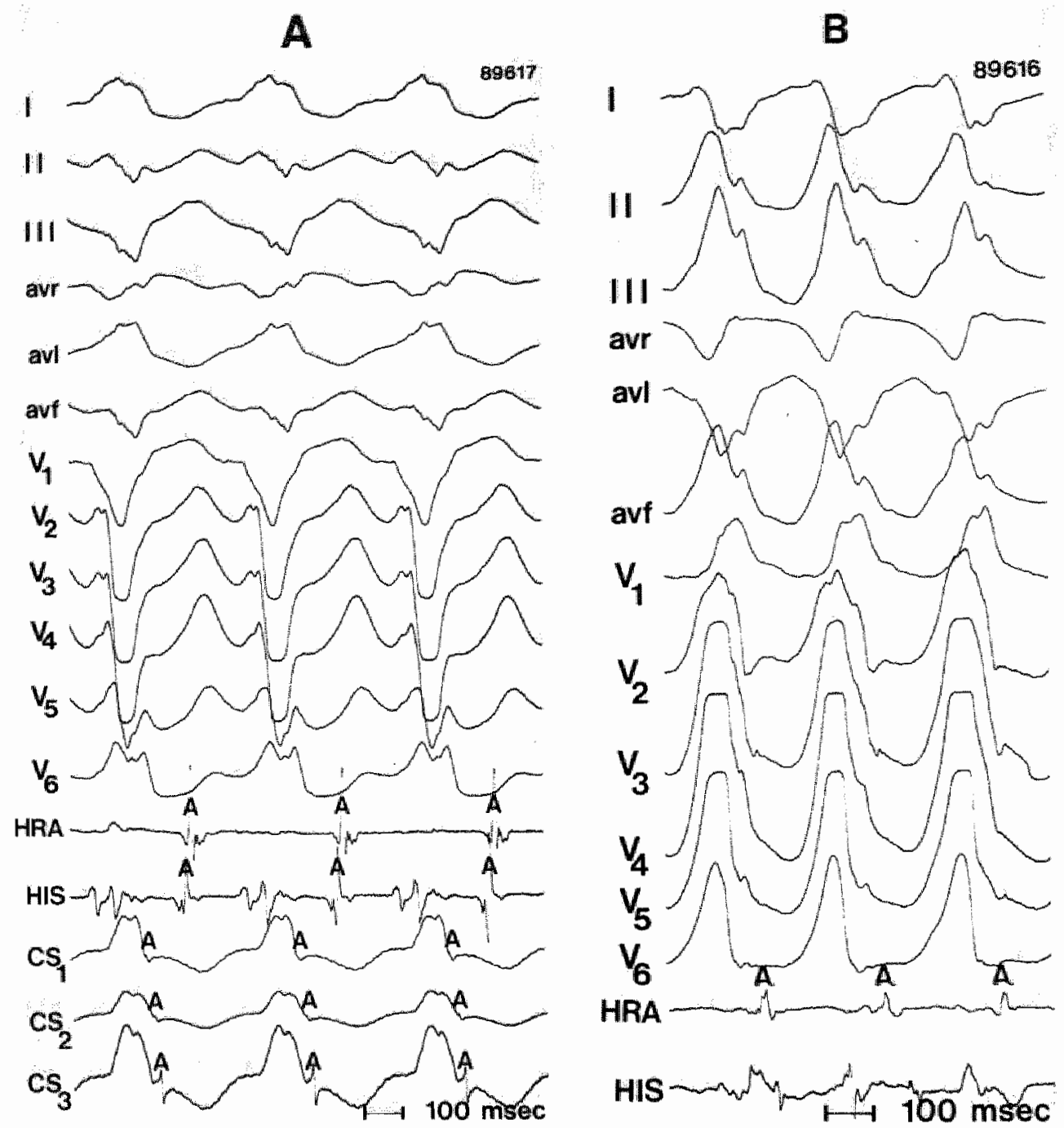

Figure 3. Panel A shows antidromic circus movement tachycardia using for anterograde conduction a right-sided accessory pathway and for retrograde atrial activation a left-sided accessory pathway (starting in the distal coronary sinus lead). In panel $B$. antidromic circus movement tachycardia using anterogradely the left sided accessory pathway is shown in the same patient. Simultaneous recordings of the 12 lead electrocardiogram and intracardiac electrograms from the high right atrium (RA). bundle of His (His) and 3 unipolar electrograms from the coronary sinus are shown 


\section{A}

1
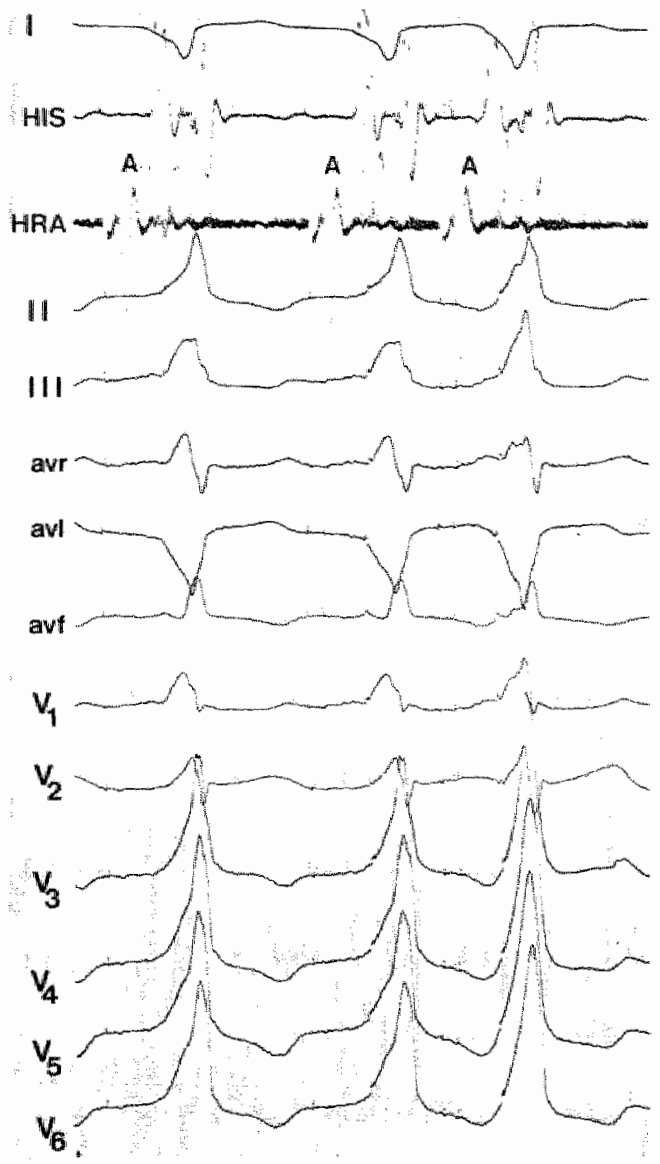

B
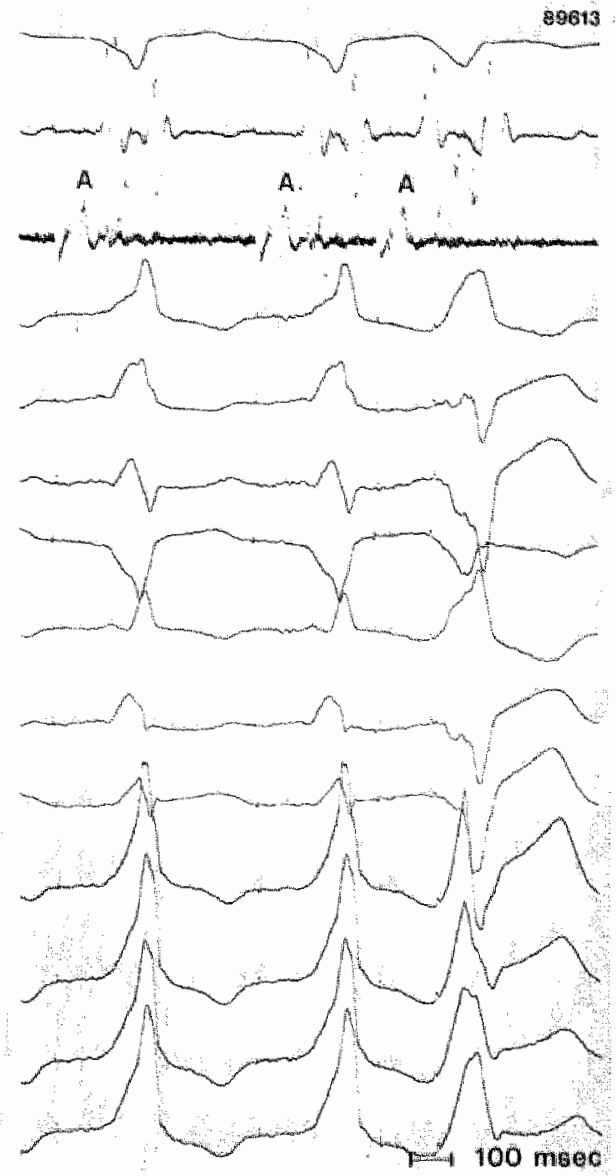

Figure 4. Atrial pacing showing anterograde conduction over two different accessory pathways in the same patient. During atrlal pacing with a cycle length of $500 \mathrm{~ms}$ the grs complex shows maximal pre-excitation with anterograde conduction over a left-sided accessory pathway. In panel A the same pre-excitation pattern is observed following anterograde concuction of an atrlal premature beat given after an interval of $300 \mathrm{~ms}$. In panel $\mathrm{B}$ a dufferent pattern of pre-excitation occurs following an atrial premature beat given after an interval of $290 \mathrm{~ms}$. The effective refractory pertiod of the left sided accessory pathway was $290 \mathrm{~ms}$. Therefore. at premature beat with intervals of $290 \mathrm{~ms}$ or less, exclusive conduction over the right-sided accessory pathway was observed. 


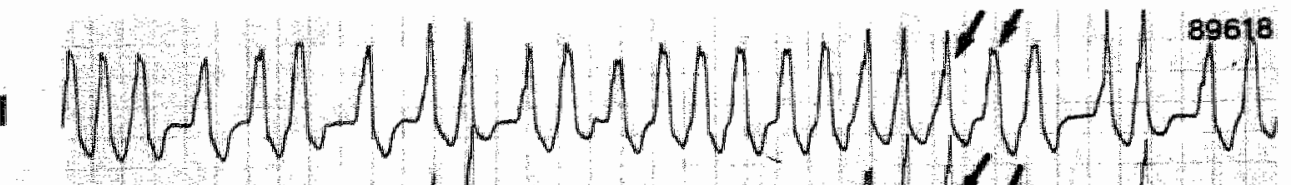

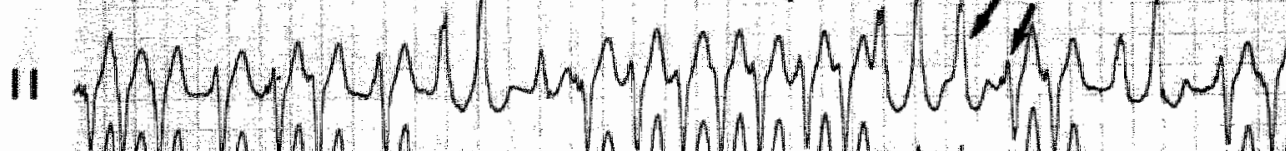

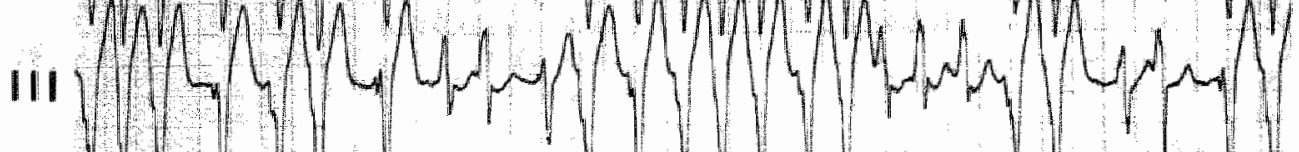

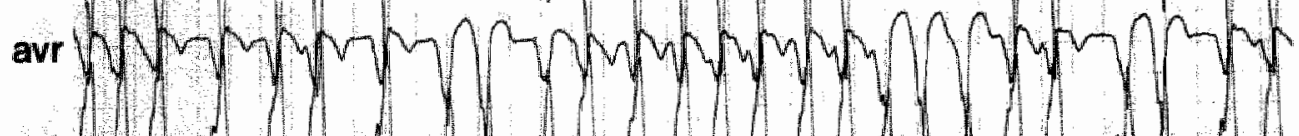

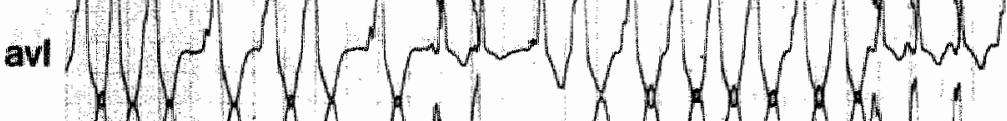

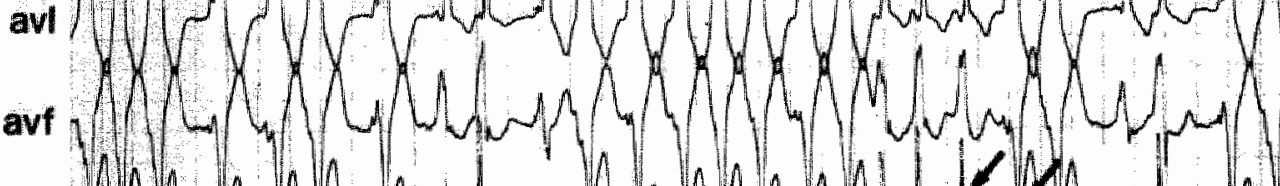

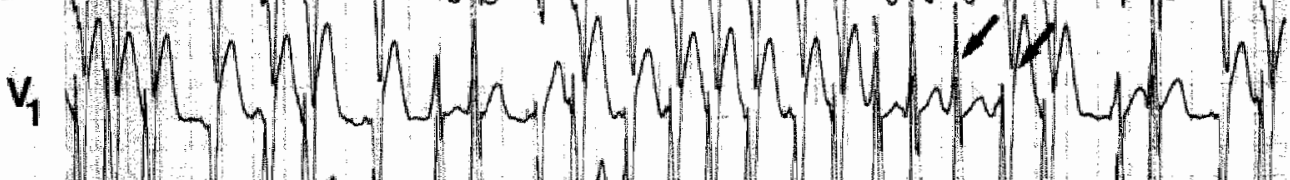

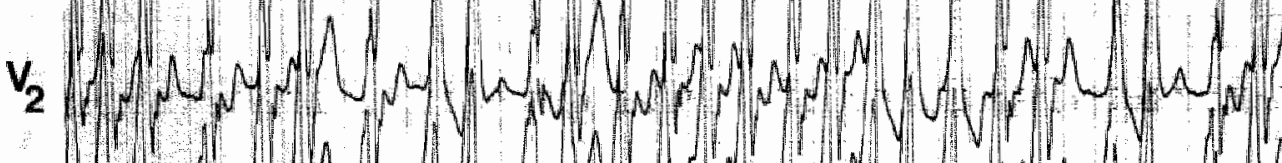

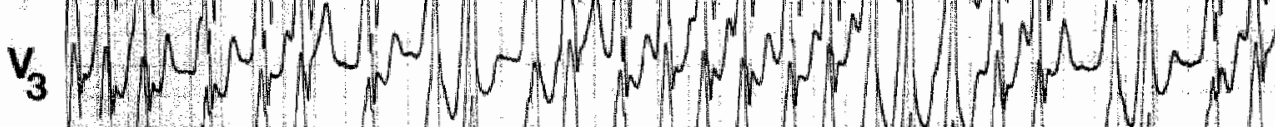

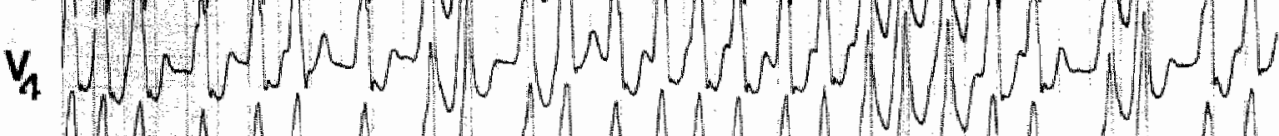

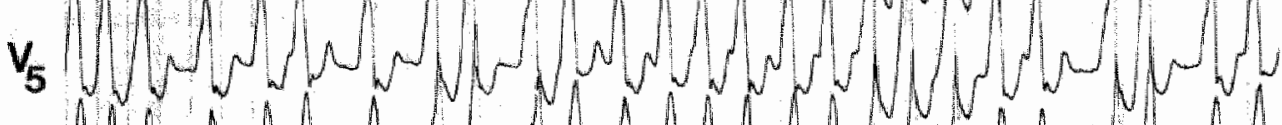

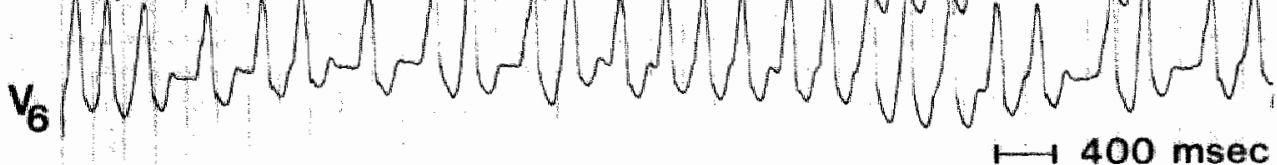

Figure 5. Twelve lead electrocardlogram during atrial fbrillation. Two patterns of ventricular pre-excitation can be seen. This example illustrates the importance of the simultaneous recording of multiple electrocardiographtc leads. While some leads do not show different patterns of ventricular excitation, it is very clear in other leads (II, aVF, V1). 
Table III. Location of accessory pathways and surgical technique

\begin{tabular}{llll}
\hline Patient & Location & First surgery & Second surgery \\
\hline 1 & RL/RPS & EPICARDLAL & \\
& & LL* & ENDOCARDLAL \\
2 & RL/LL & EPICARDLAL & \\
3 & LPS * & ENDOCARDLAL \\
4 & EPICARDIAL & ENDOCARDIAL \\
5 & RL/LL & RPS ** & \\
6 & LL/RL & EPICARDLAL + ENDO & \\
7 & LL/RPS & EPICARDLAL & \\
8 & LL/RPS & ENDOCARDLAL & \\
& & EPICARDLL &
\end{tabular}

* Diagnosis during post-operative electrophysiologic study; * recurrence after first surgery Abbreviations: $R L=$ right lateral: $L L=$ left lateral; $R P S=$ right posteroseptal; $L P S=$ left posteroseptal;

Three patients $(37 \%)$ had to be reoperated. Two patients during the same hospitalization and one a few months later because of a recurrence of preexcitation and tachycardia. During reoperation the endocardial approach was used in all 3 patients. Two of the reoperated patients had a third pathway that had not been diagnosed during the first pre-operative electrophysiological study nor during the first surgery. The third patient had recurrence of conduction over an accessory pathway a few months after the first surgery. Following reoperation all three patients are cured without preexcitation or tachycardias.

In the patient in whom isoproterenol had to be given during the preoperative electrophysiologic study, only one accessory pathway could initially be identified during intraoperative epicardial mapping. After infusion of isoproterenol the second pathway could also be located.

No patient developed A-V block, and there were no deaths during surgery or during the follow-up.

Of 126 patients with a single accessory pathway operated in our institution, 9 patients $(7 \%)$ had to be reoperated because of recurrence of preexcitation or tachycardia. Six of them were reoperated during the same hospitalization for the first surgery. After a mean follow-up of $15 \pm 6$ months, only one patient showed recurrence of preexcitation. However there was no retrograde conduction over the accessory pathway and the patient remains asymptomatic without drugs. 


\section{DISCUSSION}

In the past, only few patients with Wolff-Parkinson-White syndrome who did not respond to medical treatment or who had a high risk of ventricular fibrillation underwent surgery. However, in recent years surgical techniques have been developed having a high success rate and a low operative risk (6-13). This has influenced indications for surgery, making it more an attractive option for patients who have to be treated medically for the rest of their lives, or for patients who have professional problems because of the presence of an accessory pathway.

Multiple accessory pathways are found in 3 to $20 \%$ of patients who undergo surgery for the Wolff-Parkinson-White syndrome (11-14). In our series 8 out of 135 patients $(6.7 \%)$ who underwent surgery had multiple accessory pathways. The incidence of failure or reoperation varies from 2 to $15 \%$ in the different series (10-15). In our own series, 12 patients $(9 \%)$ needed reoperation. However, when we look at patients with multiple accessory pathways, 3 out of 8 patients ( $37 \%$ ) had to be reoperated. In 2 patients a third pathway was found only during the post-operative electrophysiological study.

These observations indicate that it is very difficult to identify the presence of a third accessory pathway during an electrophysiologic study. Several possible causes have to be mentioned: 1) The location of the accessory pathway may be such that it contributes little to ventricular activation during anterograde conduction, or atrial activation during retrograde conduction. 2) The accessory pathway may be septally located resulting in confusion with retrograde conduction over the $\mathrm{AV}$ node. 3) The dynamic nature of the electrophysiologic properties of the accessory pathway may results in absence of conduction during the electrophysiologic study or during surgery. In one patient the third pathway was located in the left posteroseptal region. In another patient the third accessory pathway was located in the left lateral region but because it had a longer anterograde and retrograde refractory period than the other 2 pathways, contributed little to anterograde or retrograde preexcitation. The third patient who was reoperated, had a very late recurrence of conduction over a right posteroseptal accessory pathway.

It is important that in one patient, a second pathway could only be demonstrated in the preoperative electrophysiologic study during the infusion of isoproterenol. Also during surgery only during isoproterenol administration, epicardial mapping revealed the second pathway. One can argue whether it is necessary to give isoproterenol to all patients during the electrophysiological study to uncover a possible second accessory pathway. We believe that this should be done in patients who have clinical findings that suggest the presence of multiple accessory pathways, like a history of syncope or clinical documentation of antidromic tachycardia (17).

We conclude that patients with multiple accessory pathways more often need reoperation because the diagnosis of one of the pathways is missed during the preoperative electrophysiological study and during the first operation. 
The findings of this study answer in part the question of Dr. Jatene "Is a second or third bundle identified mainly during the preoperative electrophysiological study or during operation?" (14). It seems that even with very detailed electrophysiological study, a second and particularly a third acces" sory pathway can be missed because of the electrophysiologic properties and location of the pathway. 


\section{REFERENCES}

l. Durrer D, Roos JP. Epicardial excitation of the ventricles in a patient with Wolff-Parkinson-White syndrome (type B). Circulation 1967; 35: 15-21.

2. Burchell HB, Frye RL, Anderson MW, McGoon DC. Atrioventricular and ventriculoatrial excitation in Wolf-Parkinson-White syndrome (type B). Circulation 1967: 36: 663-672.

3. Cobb FR, Blumenschein SD, Sealy WC. Boineau JP. Wagner GS, Wallace AG. Successful surgical interruption of the bundle of Kent in a patient with Wolf-Parkinson-White syndrome. Cfrculation 1968; 38: 1018-1029.

4. Sealy WC, Hattler BG Jr. Blumenschein SD, Cobb FR. Surgical treatment of Wolff-Parkinson-White syndrome. Ann Thorac Surg 1969; 8:1-11.

5. Iwa T, Mitsul T. Misaki T, Mukal K, Magara T, Karnata E. Radical cure of Wolff-ParkinsonWhite syndrome: The Kanazawa experience. $J$ Thorac Cardiovasc Surg 1986; 91 : 225-233.

6. Sealy $W^{\prime} C_{n}$ Gallagher JJ, Wallace A. The surgical treatment of Wollf-Parkinson-White syndrome. Evolution of improved methods for identification and interruption of Kent bundle. Ann Thorac Surg 1976: 22: 443-457.

7. Uther JW. Johnson DC. Baird DK, et al. Surgical section of accessory atrioventricular electrical connections in 108 patients. Am J Cardiol 1982; 49: 995. (Abstr).

8. Gallagher JJ, Kasell $J$, Cox JL, et al. Techniques of Intraoperative electrophysiologic mapping. Am J Cardiol 1982; 49:221-233.

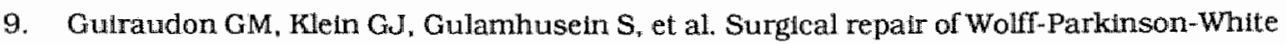
syndrome: a new closed heart technique. Ann Thorac Surg 1984; 37: 67-74.

10. Kleln GJ, Gutraudon GM, Perkins DG, et al. Surgical correction of the Wolff-ParkinsonWhite syndrome in closed heart using cryosurgery: a simplifted approach. I Amm Coll Cardiol 1984; $3: 405-428$.

11. Gallagher JJ, Sealy WC, Cox JL, et all. Results of surgery for preexcitation in 200 consecutive cases. In Levy S. Scheinman MM (eds): Cardllac Arrhythmlas from Diagnosis to Therapy. Mt. Kisco. NY. Futura, 1984, chap 18.

12. Bredikds J, Bukauskas F, Zebraustas $R$, et al. Cryosurgical ablation of right partetal and septal accessory atroventricular connections without the use of extracorporeal circulation. J Thorac Cardlovase Surg 1985; 90: 206-222.

13. Cox JL, Gallagher JJ. Cain ME: Experience with 118 consecutive patients undergoing operation for the Wolff-Parkinson-White syndrome. J Thorac Cardlovasc Surg 1985; 90 : 490-501. 
14. Jatene $\mathrm{AD}$ : Discussion of Cox et al (13).

15. Selle JG, Sealy WC, Gallagher JJ. Fedor JM, Svenson RH, Zimmern SH. Technical considerations in the surgical approach to multiple accessory pathways in the Wolf:Parkdnson-White syndrome. Ann Thorac Surg 1987; 43: 579-584.

16. Ross DL, Farre J, Bar FWHM, Vanagt EJ, Brugada P, Wiener I, Wellens HJJ: Spontaneous termination of circus movement tachycardia utilizing an atrioventricular accessory pathway: incidence, sites of block and mechanisms. Circulation 1981: 63: 1129-1137.

17. Atie $\mathrm{J}$, Brugadla $\mathrm{P}$, Smeets JLM, Cruz $\mathrm{F}$, Wellens HJJ. Incidence of multiple accessory pathways in patients with antidromic circus movement tachycandia. Eur Heart $J 1989$; 10: 381 (abstr). 


\title{
Longitudinal dissociation of atrio-ventricular accessory pathways
}

\author{
Jacob Atié \\ Pedro Brugada \\ Joep L.R.M. Smeets \\ Fernando E.S. Cruz \\ Ayrton Peres \\ Mauricio Duque \\ Hein J.J. Wellens
}




\section{Longitudinal dissociation of atrio-ventricular accessory pathways}

\section{SUMMARY}

Unusual properties of atrio-ventricular accessory pathways were found during electrophysiologic investigations in four patients, 3 male and 1 female. Anterograde longitudinal dissociation of the accessory pathway was observed in 2 patients and retrograde longitudinal dissociation in two others. Two patients had accessory pathways with slow conduction times, one in anterograde direction and one in retrograde direction. These observations further expand our knowledge on the spectrum of electrophysiologic properties of accessory atrio-ventricular pathways.

\section{INTRODUCTION}

The electrophysiologic properties of the atrio-ventricular node and atrioventricular accessory pathways have been studied extensively $(1-3)$.

Decremental conduction and functional longitudinal dissociation of the AV node is a well known phenomenon (4-8).

The classical fastly conducting accessory pathway of patients with the Wolf-Parkinson-White syndrome usually shows no or only minimal decremental conduction properties (9) , in contrast to concealed pathways with long conduction times who frequently show decremental properties in ventriculoatrial direction (10-11). Recently, anterograde slow and decremental conduction has also been demonstrated in accessory atrio-ventricular pathways simulating nodo-ventricular connections (12-13). These observations suggest that decremental conduction can occur in accessory pathways. Longitudinal dissociation of accessory atrio-ventricular pathways, however, has been reported only rarely (14-15).

In this article, four patients are described showing functional longitudinal dissociation of their accessory pathway. In two patients in retrograde direction and in anterograde direction in the other two patients.

Submitted for publication 


\section{PATIENTS AND METHODS}

The four patients in this study were selected from 314 patients seen between 1979 and May 1989 at our institution for evaluation and treatment of various preexcitation syndromes. The four patients were studied retrospectively. Three patients were male and one female. The mean age was 41 (22-72) years. Clinical data are summarized in table $\mathrm{I}$.

\section{Electrophysiologic study}

Following informed consent, an electrophysiological study was performed in all patients in the resting, postabsortive non-sedated state. Using the femoral approach, catheters were placed for stimulation and recording of intracardiac electrograms, at the right ventricular apex, tricuspid valve ring. high lateral right atrium and coronary sinus. Our methods of recording. stimulation and analysis of tracings have been described previously (16).

The criteria for the diagnosis of anterograde longitudinal dissociation in the accessory pathway were as follows: 1) Cycle length alternation, caused by a sudden change in the $A-V$ interval with a constant $V-A$ interval, without changes in QRS complex or retrograde atrial activation pattern during antidromic circus movement tachycardia (fig. 1). 2) Sudden lengthening of the cycle length of antidromic tachycardia because of prolongation of the $A-V$ interval without changes in $\mathrm{V}-\mathrm{A}$ interval, the sequence of retrograde atrial activation or the $\mathrm{QRS}$ complex.

The criteria for the diagnosis of retrograde longitudinal dissociation in the accessory pathway were: 1) Cycle length alternation because of changes in $\mathrm{V}-\mathrm{A}$ interval with the same sequence of retrograde atrial activation and the same A-V interval during orthodromic circus movement tachycardia, using the normal atrio-ventricular node in the anterograde direction and the accessory pathway in the retrograde direction (fig. 2). 2) During ventricular pacing. a sudden prolongation in the $\mathrm{V}$-A interval over the accessory pathway after minimal changes in pacing rate or premature beat interval without a change in retrograde atrial activation sequence (fig. 3 ).

\section{RESULTS}

\section{Patient 1}

During electrophysiological study, incremental atrial pacing performed from the right atrium, showed 1:1 atrio-ventricular conduction with progressive prolongation of the $\mathrm{A}-\mathrm{H}$ and $\mathrm{A}-\mathrm{V}$ intervals and increasing pre-excitation. Antidromic tachycardia with left bundle branch block morphology was induced by a single ventricular or atrial extrastimulus. Retrograde conduction 
Table 1. Age, sex and information of clinical complaints and arrhythmias in the four patients studied.

\begin{tabular}{|c|c|c|c|c|c|}
\hline Patilent & Age & $\operatorname{sex}$ & Syncope & Type of Arrhythmias & Additional abnormalities \\
\hline $\mathbb{1}$ & 24 & $M$ & yes & $\begin{array}{l}\text { atrial fibrillation } \\
\text { antidromic CMT } \\
\text { incessant tachycardia }\end{array}$ & DAVNP \\
\hline 2 & 22 & M & yes & $\begin{array}{l}\text { antidromic CMT } \\
\text { orthodromic CMT } \\
\text { atrial fibrillation }\end{array}$ & DAVNP \\
\hline 3 & 48 & $\mathbf{M}$ & yes & orthodromic CMT & \\
\hline 4 & 72 & $F$ & no & $\begin{array}{l}\text { orthodromfe CMT } \\
\text { atrial fibrillation }\end{array}$ & $\begin{array}{l}\text { coronary artery disease } \\
\text { DAVNP }\end{array}$ \\
\hline
\end{tabular}

Abbreviattons: CMT = ctrcus movement tachycardla; DAVNP= dual AV nodal pathways;

$M=$ male; $F=$ female.

to the atria occurred over the $\mathrm{A}-\mathrm{V}$ node with a pattern of retrograde atrial activation showing the beginning of atrial activation in the His electrogram, thereafter followed by activation in the proximal coronary sinus, high right atrium and distal coronary sinus.

The tachycardia which had a cycle length of $365 \mathrm{~ms}$ changed suddenly to a cycle length of $410 \mathrm{~ms}$. During tachycardia, alternation in cycle length between $365 \mathrm{~ms}$ to $410 \mathrm{~ms}$ was observed. The V-A interval was constant and the $45 \mathrm{~ms}$ alternation was caused by a change in the $\mathrm{A}-\mathrm{V}$ interval from 220 $\mathrm{ms}$ to $265 \mathrm{~ms}$. No change in the retrograde atrial activation or the morphology of the QRS complex was seen (fig. 1). Atrial pacing from the low right atrium showed more pre-excitation as compared to pacing from the high right atrium. This confirmed the diagnosis of an atrio-ventricular accessory pathway with decremental conduction, instead of a nodo-ventricular "Mahaim" fiber. This diagnosis was confirmed later during surgery. The accessory pathway was localized in the free wall of the right AV groove.

\section{Patient 2}

The electrophysiological study showed dual AV nodal pathways and two accessory pathways, one left-sided and another located postero-septally. Both pathways were able to conduct anterogradely when atrial pacing was performed. During right ventricular pacing conduction to the atria took place over the left-sided accessory pathway. Atrial activation was first recorded in the distal coronary sinus, thereafter followed by activation in the proximal coronary sinus, His bundle electrogram and high right atrium. Retrograde conduction over the AV node was also observed. but never over the posteroseptal accessory pathway. 
Both pathways were able to conduct anterogradely when atrial pacing was performed.

Four different types of circus movement tachycardia could be induced: 1) Orthodromic tachycardia with retrograde conduction over the left-sided accessory pathway; 2) Antidromic tachycardia using the postero-septal accessory pathway in the anterograde direction and the left-sided accessory pathway in the retrograde direction; 3) Antidromic tachycardia using the postero-
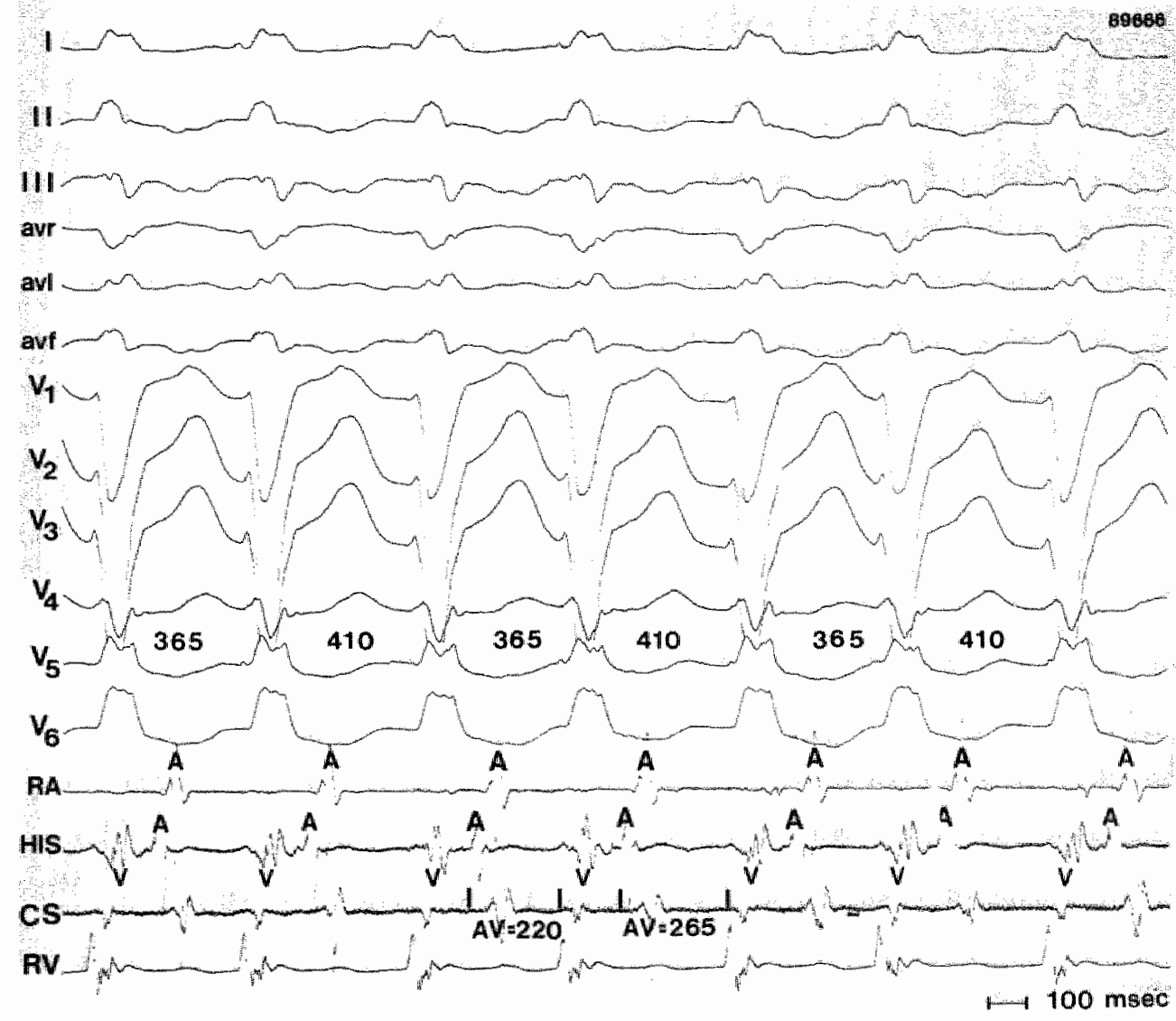

Figure 1. Patient 1. Example of antidromic circus movement tachycardia using anterogradely a right-sided accessory pathway with a long conduction time and retrogradely the nomal AV node, showing cycle length alternation. Cycle length alternation from 365 to $410 \mathrm{~ms}$ is caused by alternation in the A-V interval from 220 to $265 \mathrm{~ms}$, without changes in QRS configuration or V-A interval. Twelve electrocardiographic leads and four intracardlac electrograms from the high right atrium (RA), bundle of His (HIS), distal coronary sinus (CSd) and right ventricle (RV) were recorded simultaneously. 


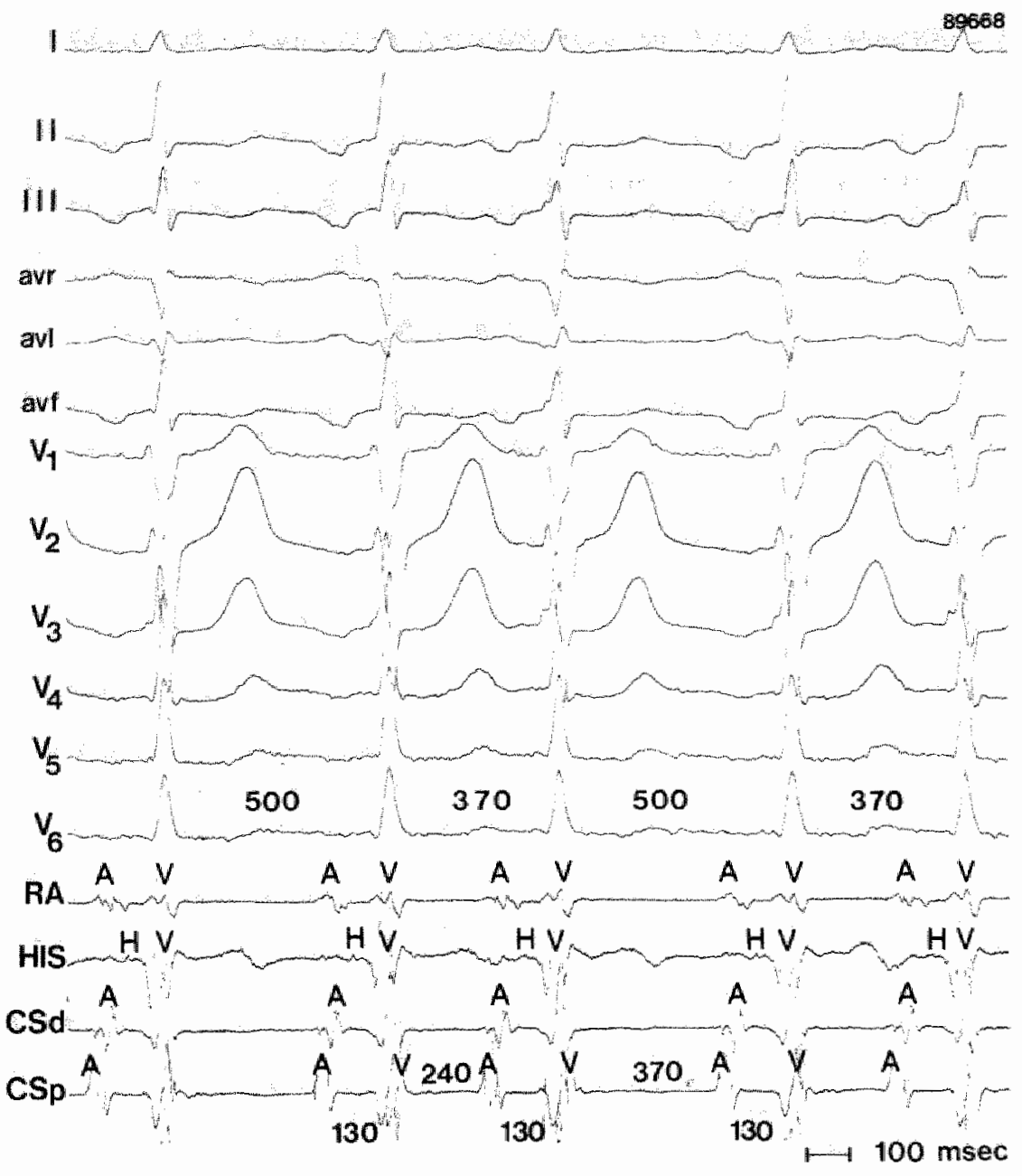

Figure 2. Patient 3. Orthodromic circus movement tachycardia using the normal AV node in the anterograde direction and a posteroseptal accessory pathway with long conduction times in the retrograde direction showing cycle length alternation. Jycle length alternation from 500 to $370 \mathrm{~ms}$ is caused by alternation in the $\mathrm{V}-\mathrm{A}$ interval from 370 to 240 mus, without changes in A-V interval and atrial activation pattern. Twelve surface electrocardiographic leads and four intracardiac electrograms are shown. 

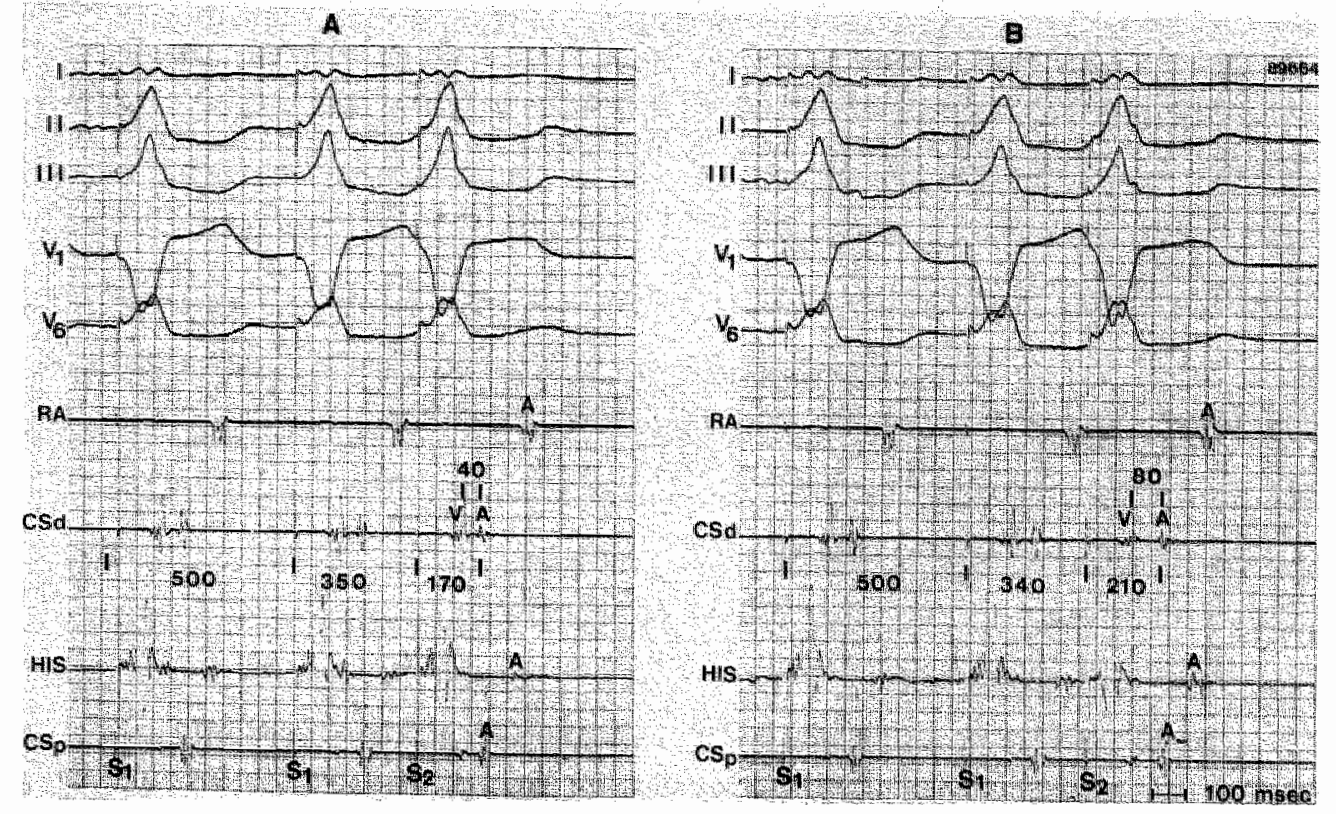

Figure 3. Patient 4. Example of longitudinal dissociation in retrograde conduction over an accessory pathway. In panel $\mathrm{A}$, a ventricular premature beat given after $350 \mathrm{~ms}$ is followed by atrial activation with a $\mathrm{V}-\mathrm{A}$ interval of $170 \mathrm{~ms}$. In panel $\mathrm{B}$, on shortening the premature beat by $10 \mathrm{~ms}$, the V-A tnterval suddenly prolongs by $40 \mathrm{~ms}$, with the same sequence of retrograde atrial activation. Five surface electrocardiographic leads were simultaneously recorded with four intracardiac electrograms.

septal accessory pathway in the anterograde direction and the normal His Purkinje system in the retrograde direction: 4) Antidromic tachycardia using the left-sided accessory pathway in the anterograde direction and the normal His Purkinje system in the retrograde direction. During the last type of tachycardia, alternation in cycle length was observed. Alternation in cycle length measured $70 \mathrm{~ms}$. Alternation was seen both in the anterograde pathway $(50 \mathrm{~ms})$ and retrograde pathway $(20 \mathrm{~ms})(\mathrm{fig} .4)$.

\section{Patient 3}

This patient had a concealed septally located accessory pathway with long conduction times and decremental conduction. During ventricular pacing conduction to the atria took place over the accessory pathway, with earliest atrial activation being recorded in the proximal coronary sinus, thereafter followed by His, distal coronary sinus and high right atrium. Retrograde conduction was also seen over the AV node. Regular ventricular pacing at increasing rates resulted in Wenckebach type V-A conduction over the acces. sory pathway. Premature ventricular beats given during ventricular pacing also showed decrenental conduction over the accessory pathway. 

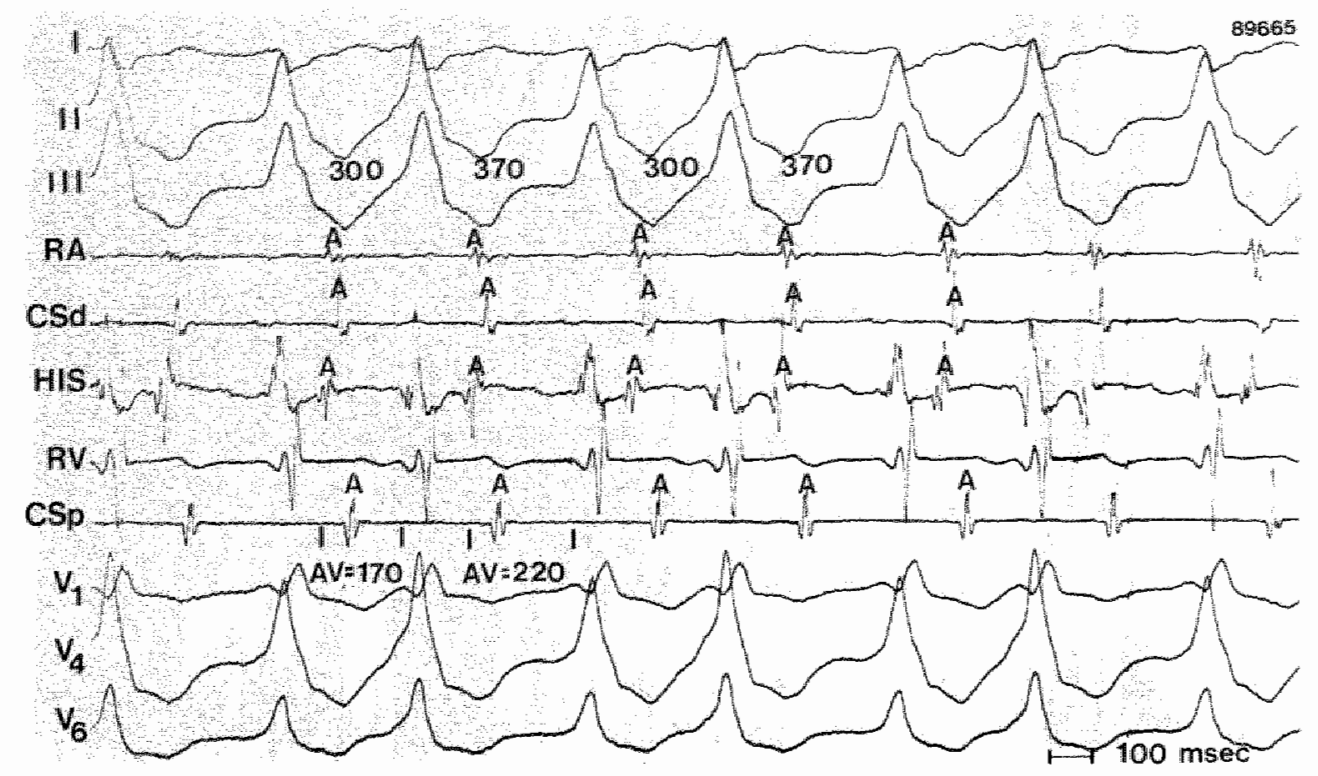

Fugure 4. Patient 2. An example of antidromic tachycardla using a left-sided accessory pathway for anterograde conduction and the normal conduction system retrogradely, showing alternation $\mathrm{m}$ both the A-V $(50 \mathrm{~ms})$ and V-A $(20 \mathrm{~ms})$ interval. As discussed in the text the alternation In A-V conduction can be explained by two closely located accessory pathways or longitudinal dissociation in a single accessory pathway. Stx surface electrocardiographic leads and 5 bipolar endocavitary recordings are shown.

During the electrophysiological study, narrow QRS complex tachycardias accurred both spontaneously and after induced atrial and ventricular premature beats. During tachycardia the PR interval was shorter than the R-P interval. Several episodes of tachycardia with alternation in cycle length were observed from 500 to $370 \mathrm{~ms}$, with VA intervals varying between $370 \mathrm{~ms}$ and $240 \mathrm{~ms}$, the A-V interval remaining constant (fig. 2).

\section{Patient 4}

During the electrophysiological study, this patient was found to have a left-sided accessory pathway and dual AV nodal pathways. Orthodromic circus movement tachycardia, atrial tachycardia, atrial fibrillation, and atrial flutter could be induced.

During sinus rhythm (cycle length $950 \mathrm{~ms}$ ) His bundle recordings, revealed an $\mathrm{A}-\mathrm{H}$ interval of $90 \mathrm{~ms}$ and an $\mathrm{H}-\mathrm{V}$ interval of $20 \mathrm{~ms}$. During ventricular stimulation an increase in V-A time of $40 \mathrm{~ms}$ over the accessory pathway was observed on slowing the premature beat interval by $10 \mathrm{~ms}$ (fig. 3). The retrograde atrial activation sequence was identical before and after the jump in retrograde conduction. 
Orthodromic circus movement tachycardia could be initiated by a single ventricular premature beat. The cycle length of tachycardia alternated from 430 to $390 \mathrm{~ms}$ as a result of changes by $65 \mathrm{~ms}$ in the A-V and $25 \mathrm{~ms}$ in the $V$-A intervals (fig. 5). Changes in A-V intervals were caused by the dual AV nodal pathways. But changes in $\mathrm{V}$-A intervals could only be explained by longitudinal dissociation of the accessory pathway.
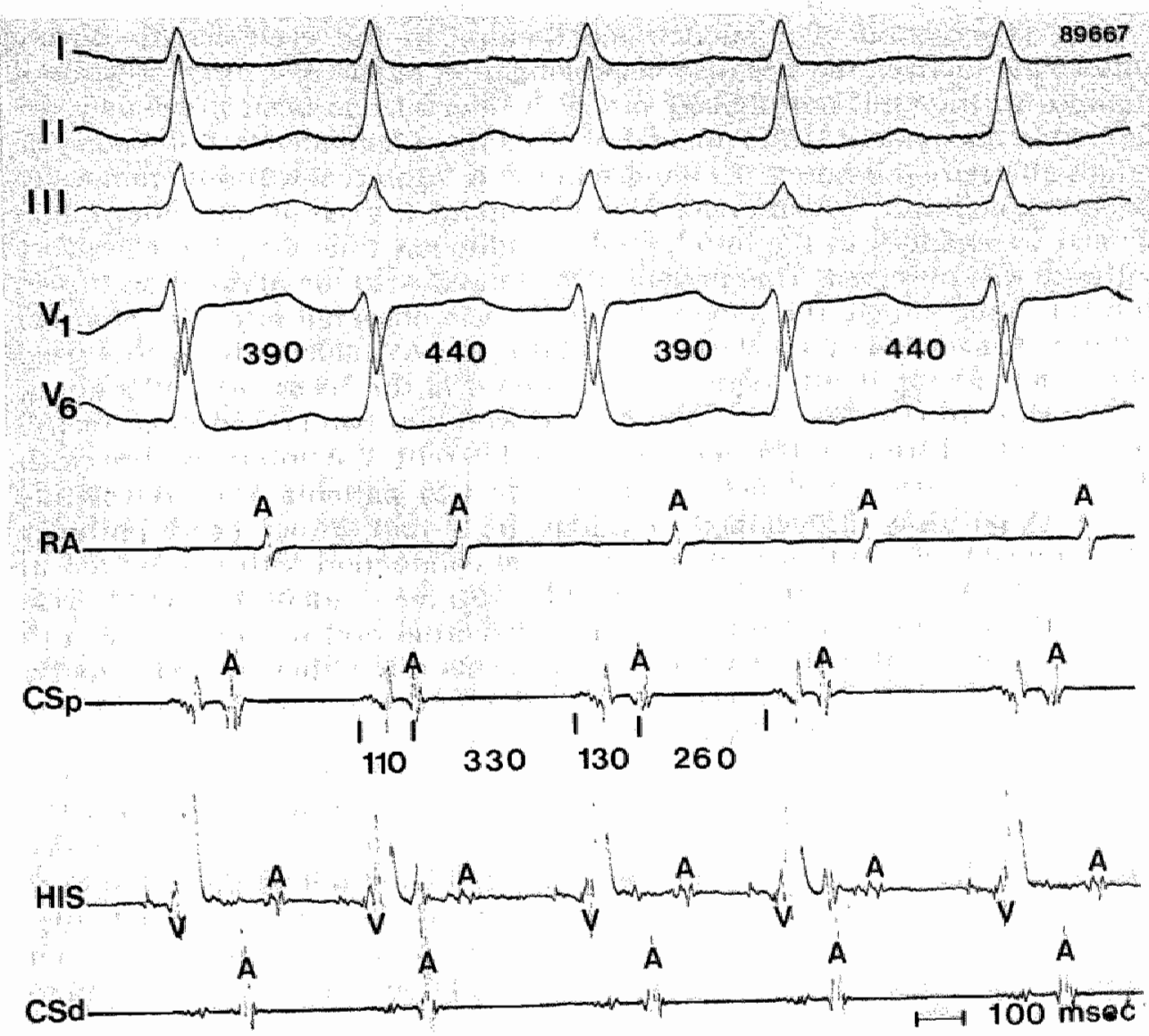

Figure 5. Pattent 4. Alternation of anterograde and retrograde conduction times during orthodromic circus movement tachycardia. As discussed in the text, this can be explained by dual pathways in the AV node and longitudinal dissociation of the slowly conducting accessory pathway. That cannot be explained by the conduction curves of an accessory pathway with decremental conduction, where long cycles should result in short V-A Intervals and short cycles in long V-A intervals. Five surface leads and 4 bipolar endocavitary electrograms are shown. 


\section{DISCUSSION}

Functional dissociation of conduction in accessory pathways has been reported only rarely during reciprocating tachycardia (17) or pacing (18). Recently Tai (14) described one patient who presented an accessory pathway with retrograde longitudinal dissociation during treatment with re anam. In our four patients the findings strongly suggest that they had functional dissociation of their accessory pathways. All were without antiarrhythmics drugs at the time of study.

The observation of a sudden lengthening in the cycle length during antidromic tachycardia because of prolongation of the A-V interval without changes in the QRS morphology and $\mathrm{V}-\mathrm{A}$ interval has been previously described in one patient (15). Patient 1 showed this phenomenon but also cycle length alternation because of changes in the $\mathrm{A}-\mathrm{V}$ interval without changes in QRS complex and $\mathrm{V}$-A interval. Also in patient 2 cycle length alternation caused by changes in the anterograde conduction time over the accessory pathway was observed. This patient also showed a $20 \mathrm{~ms}$ alternation in V-A interval. Interestingly the longest $\mathrm{V}-\mathrm{A}$ time was observed after the shortest A-V time suggesting that a slower conducting His-AV node pathway was used following more rapid anterograde conduction over the accessory pathway.

Denes et al (18) described one patient who had two orthodromic tachycardias with distinct rates and with two different V-A intervals, but with identical eccentric atrial activation. In our two patients with retrograde accessory pathway dissociation, one (patient 3) had an accessory pathway with long conduction times and decremental conduction with alternation in the cycle length and in the V-A interval by $130 \mathrm{~ms}$. Patient 4 showed cycle length alternation during orthodromic tachycardia and a jump in the V-A interval during ventricular pacing. This suggests that either two very closely located accessory pathways with long conduction time were present or one pathway with longitudinal dissociation.

Our data support findings from previous studies suggesting that longitudinal functional dissociation may occur in accessory atrio-ventricular pathways. Given the complex anatomy of the few carefully studied accessory pathways (19), this is not a surprising finding. If longitudinal dissociation of the atrio-ventricular node can be observed in approximately $20 \%$ of patients. the question is why longitudinal dissociation of accessory pathways is not observed more frequently. As already indicated, an alternative explanation to longitudinal dissociation of a single accessory pathway is the possibility of two very closely located accessory pathways. Although anatomically two closely located accessory pathways are different from a single functionally dissociated accessory pathway, their functional consequences will be the same. Two accessory pathways located very close to one another should not result in changes in the GRS complex las during anterograde longitudinal dissociation) or the retrograde atrial activation sequence (as during retrograde longitudinal dissociation). 
Our findings further extend our knowledge on the electrophysiologic properties of accessory atrio-ventricular pathways. They suggest that not only decremental conduction, but also longitudinal dissociation are not restricted to the atrio-ventricular node. 


\section{REFERENCES}

1. Wellens HJJ. Electrical stimulation of the heart. In the study and treatment of tachycardias. Baltimore. University Park Press, 1971.

2. Rosen KM, Mehta A, Miller RA. Demonstration of dual atrioventricular nodal pathways in man. Am J Cardioll 1974; 33: 291-294.

3. Coumel P. Attuel $P$. Motte $G$. Slama $R$, Bouvrain $Y$. Les tachycardies jonctionelles paroxystiques. Evaluation du point dejonction inferteur du ctrcult de reentrée. Demembrement des "rhythmes" rêciproques intra-nodaux. Arch Mal Coeur 1975; 68: 1255-1277.

4. Critelll G, Gallagher JJ, Monda V, Coltort F. Scherillo M, Rossi L. Anatomic and Electrophyslologic substrate of the permanent form of junctional reciprocating tachycardia. J Am Coll Cardiol 1984; 4: 601-610.

5. Brugada P, Vanagt E, Dassen WR, Gorgels AP. Bär FW, Wellens HJJ. Atrioventricular nodal tachycardla with and without discontinuous anterograde and retrograde atrioventricular nodal conductton curves: a reappratsal of the dual pathway concept. Eur Heart J 1980; 1: 399-407.

6. Akhtar M, Damato AN, Ruskin JN, et al. Anterograde and retrograde conduction characteristics in three patterns of paroxysmal atrioventricular junctional reentrant tachycardia. Am Heart J 1978; 95: 22-42.

7. Denes $P$. Wu $D_{\text {n }}$ Amat-y-Leon F, Dhingra R. Wyndham $C R$, Rosen KM. The determinants of atrloventricular nodal reentry with premature atrial stimulation in patients with dual A-V nodal pathways. Circulation 1977; $56: 253-259$.

8. Brugada P, Bar FW, Vanagt EJ, Friedman PL, Wellens HJJ. Observations on patients showing AV Junctlonal echoes with a shorter P-R than R-P interval. Distinction between intranodal reentry or reentry using an accessory pathway with long conduction time. Am J Cardiol 1981: 48:611-622.

9. Wellens HJJ, Durrer $D$. Combined conduction disturbances in two AV pathways in patients with Wolf-Parkinson-White syndrome. Eur Heart J 1973; 1: 23-28.

10. Coumel P. Attuel P. Mugica J. Junctional reciprocating tachycardia. The permanent form. In: Kulbertus HE, ed: Reentrant Arrhythmias. Lancaster: MTP Press. 1977; 170 183.

11. Gallagher JJ, Sealy $W C$. The permanent form of reciprocating tachycardia: Further ehcidation of the underlying mechanism. Eur J Cardiol 1978; $8: 413-430$.

12. Atle J" Brugada P, Smeets JLRM, Cruz ESF, Penn OCKM, Wellens HJJ. Further support of the atrio-ventricular localization of so-called Mahaim fibers. I Am Coll Cardiol 1989; 13: 232 labstr). 


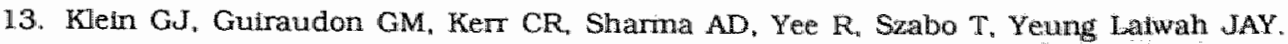
Nodo-ventricular accessory pathway: Evidence for a distinct accessory atrioventricular pathway with atrioventricular node-llke properties. J Am Coll Cardiol 1988: 11: 10351040 .

14. Tal YT, Campbell RWF, McComb JM. Latent functional duality in an accessory pathway. Eur Heart J 1989; 10: 380-384.

15. Belhassen $B$, Misrahi D, Shapira I, Laniado S. Longitudinal dissociation in an anomalous accessory atrioventricular pathway. Am Heart $J$ 1983; 106: 1441-1443.

16. Ross DL, Farte J. Bar FWHM, Vanagt EJ, Brugada P, Wiener I. Wellens HJJ: Spontaneous termination of circus movement tachycardia utilizing an atrioventricular accessory pathway: incidence, sites of block and mechanisms. Circulation 1981; 63: 1129-1138.

17. Klein GJ. Prystowsky EN, Pritchett ELC. Davis D, Gallagher JJ. Atypical patterns of retrograde conduction over accessory atrioventricular pathways in Wolf-Parkinson-White syndrome. Circulation 1979; 60: 1477-1486.

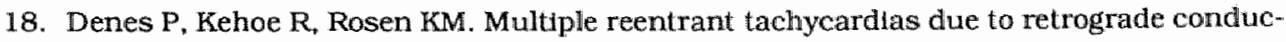
tion of dual atrioventricular bundles with atrioventricular nodal-like properties. Am J Cardiol 1979; 44: 162-170.

19. Becker AE. Morphologic characteristics of arrhythmias, In Brugada P, Wellens HJJ (eds): Cardiac Arthythmias: Where to Go From Here? Mount Kisco, NY. Futura Publishing Co. 1987, pp 435-456. 

Chapter IX

\section{General conclusions, recommendations and implications for daily practice}




\section{General conclusions, recommendations and implications for daily practice}

This thesis addresses particular problems encountered in patients with accessory pathways. The Wolff-Parkinson-White syndrome was for years considered some sort of electrocardiographic curiosity. Recognition of its clinical relevance, the complications which it could produce and the impact of the arrhythmia episodes on quality of life has required many years of study.

Nowadays all these factors are well understood and extremely successful therapies have become available. Among them, surgical interruption of an accessory pathway offers a definitive solution to the problem. However, before surgical correction is undertaken an accurate diagnosis is required. This diagnosis must include not only the exact localization and properties of the accessory pathway but also understanding of the different types of tachycardias present in one patient and most important, whether more than one accessory pathway is present.

As described in this thesis, multiple accessory pathways are not a rarity and an important cause of reoperation. We found multiple accessory pathways in $5.2 \%$ of our patients initially diagnosed as having at least one accessory pathway. Of importance, these were the patients who presented the most severe symptoms and a high incidence (11\%) of spontaneous ventricular fibrillation. They also suffered more often from antidromic circus movement tachycardia. The reverse was also true, that is, patients with antidromic circus movement tachycardia, particularly when spontaneous, had a high incidence of multiple accessory pathways. The electrocardiogram during sinus rhythm offered also some clues to the diagnosis of multiple accessory pathways. A discordance in the axis in the frontal plane of the delta wave and the main QRS complex and a qRS or qrS pattern in lead VI should suggest that diagnosis.

In the electrophysiology laboratory, but also in the electrocardiogram, other clues to the diagnosis of multiple accessory pathway were: 1) more than one $\mathrm{P}$ wave configuration during orthodromic circus movement tachycardia; 2) A "mismatch" between the location of the atrial and ventricular end of the accessory pathway as determined from the $\mathrm{P}$ wave during circus movement tachycardia and the preexcitation pattern during sinus rhythm or antidromic tachycardia: 3) More than one preexcitation pattern during atrial fibrillation, atrial pacing or antidromic circus movement tachycardia; 4) A spontaneous change from antidromic tachycardia to another with a different preexcitation pattern; 5l A spontaneous change from antidromic to orthodromic circus movement tachycardia or vice-versa within one cycle; 6) Demonstration of two patterns of preexcitation during administration of an agent prolonging or 
shortening the anterograde refractory period of the accessory pathway: 7] More than one pattern of retrograde atrial activation over different accessory pathways during ventricular pacing or orthodromic circus movement tachycardia.

A group of patients of particular interest were patients with a "Mahaim" accessory pathway. It has been considered that "Mahaim" fibers were nodoventricular accessory pathways. Physicians were reluctant to indicate surgical correction of these accessory pathways which were thought difficult to accurately localize. Previous studies and data presented in this thesis indicate that "Mahaim" fibers are accessory atrio-ventricular pathways localized in the right ventricular free wall. They behave similarly to nodo-ventricular fibers because they have special electrophysiology properties suggesting implantation of their proximal part in the atrio-ventricular node. Frequently it has been stated that they implanted in a "slow" atrioventricular nodal pathway. In reality , they are accessory atrioventricular pathways with simply slow anterograde conduction. This slow anterograde conduction is similar to what is found in certain types of concealed accessory pathways which conduct slowly in retrograde direction. These new insights have completely changed the therapeutic approach to "Mahaim" fibers. These accessory pathways can be operated on as easily as any type of accessory atrioventricular pathway.

The last problems addressed in this thesis were some unusual electrophysiologic properties of accessory pathways as observed during electrophysiologic examination. Longitudinal dissociation of an accessory pathway should be recognized by the electrophysiologist and differentiated from multiple accessory pathways.

Our findings have several important implications for daily practice:

1. Multiple accessory pathways are not a rarity. The physician looking after a patient with an accessory pathway has always to think of the possibility of multiple accessory pathways if the patient has symptoms such as syncope, spontaneous ventricular fibrillation, antidromic tachycardia or electrocardiographic clues as here described.

2. Multiple accessory pathways are not a contraindication to surgery. On the contrary. because of the severe symptoms they may cause, surgery should be the treatment of choice.

3. "Nodo-ventricular fibers" (Mahaim) are accessory atrioventricular pathways with slow anterograde conduction. They can be operated on as easily and successfully as any other type of accessory atrio-ventricular pathway. 


\section{Summary}

The aim of this thesis was to analyze new aspects of the preexcitation syndromes. These include the diagnosis and mechanisms of antidromic circus movement tachycardia, incidence, diagnosis and mechanisms of tachycardias in patients with multiple accessory pathways and observations in patients with accessory pathways with unusual electrophysiologic properties. It also described the results of treatment in these patients. Although emphasis was on invasive electrophysiologic techniques, necessary for the correct diagnosis, attention was also given to the value of the 12-lead electrocardiogram in diagnosing these abnormalities. This resulted in a further increase in the diagnostic power of this simple and inexpensive tool.

In Chapter I, the anatomic, electrocardiographic and electrophysiologic aspects of cardiac preexcitation were reviewed.

Chapter II described findings in patients with atrioventricular accessory pathways with long anterograde conduction times. These accessory pathways behave similarly to nodo-ventricular ("Mahaim") accessory pathways.

In Chapter III the clinical and electrophysiologic characteristics of 36 patients with antidromic circus movement tachycardia were presented. These patients had a high incidence of multiple accessory pathways and ventricular fibrillation.

In Chapter IV the 12-lead electrocardiogram during sinus rhythm was studied in patients with multiple accessory pathways. We concluded that the presence of a qRS or qrS pattern in lead VI and a discordance between delta wave polarity and the QRS axis in the frontal plane is suggestive of the presence of multiple accessory pathways.

In Chapter V several findings were reported on the 12-lead electrocardiogram during tachycardias or after antiarrhythmic drug administration that indicated the presence of multiple accessory pathways.

In Chapter VI the clinical and electrophysiologic characteristics of 18 patients with multiple accessory pathways were presented.

In Chapter VII the results of surgical treatment in patients with multiple accessory pathways were presented. Patients with multiple accessory pathways could be operated on successfully, but they more often required reoperation because the diagnosis of a third pathway could not be made during the preoperative electrophysiological study.

In Chapter VIII evidences for functional longitudinal dissociation of the accessory pathway were presented. This very unusual finding was observed in 2 patients in anterograde and in 2 patients in retrograde direction. 



\section{Samenvatting}

Dit proefschrift beschrijft nieuwe bevindingen bij patiënten met pre-excitatie. Het gaat over de diagnose en mechanismen van antidrome cirkeltachycardie; de incidentie, de diagnose en mechanismen van tachycardieën bij patiënten met meerdere extraverbindingen en pattënten met extraverbindingen met bijzondere electrofysiologische eigenschappen. Ook worden tevens de resultaten beschreven van de behandeling van deze patiënten. Hoewel de nadruk ligt op invasieve electrofysiologische technieken, wordt ook aandacht besteed aan de waarde van het 12-kanaals ECG bij het diagnostiseren van deze afwijkingen. Het laatste omdat dit leidt tot een verdere toename van de diagnostische waarde van deze eenvoudige en goedkope techniek.

In hoofdstuk I wordt een overzicht gegeven van de anatomische, electrocardiografische en electrofysiologische aspecten van cardiale preexcitatie.

Hoofdlstuk II beschrijft bevindingen bij patiënten met atrio-ventriculaire extraverbindingen met lange anterograde geleidingstijden. Het blijkt dat deze extraverbindingen zich hetzelfde gedragen als nodo-ventriculaire ("Mahaim") extraverbindingen.

In hoofdstuk III worden de klinische en electrofysiologische karakteristieken van 36 patiënten met antidrome cirkeltachycardieën gepresenteerd. Bij deze patiënten is er een hoge incidentie van multipele extraverbindingen en kamerfibrilleren.

Hoofdstuk IV geeft de bevindingen van het 12-kanaals electrocardiogram gedurende sinusritme bij patiënten met multipele extraverbindingen. Hieruit blijkt dat de aanwezigheid van een qRS of qrS patroon in afleiding V1 en een discordantie tussen deltagolf polariteit en de QRS-as in het frontale vlak suggestief is voor de aanwezigheid van multipele extraverbindingen.

Hoofdstuk $\mathrm{V}$ beschrifft de waarde van het 12-kanaals electrocardiogram gedurende tachycardie of ná administratie van antiaritmische medicatie om de aanwezigheid van multipele extraverbindingen vast te stellen.

Hoofdstuk VI beschrijft de klinische en electrofysiologische karakteristieken van 18 patiënten met meerdere extraverbindingen.

In hoofdstuk VII worden de resultaten van chirurgische behandeling van patiënten met meerdere extraverbindingen gegeven. Het blijkt hierbij dat bij deze patiënten vaker dan bij patiënten met een enkel extraverbinding een heroperatie noodzakelijk is geweest omdat het moeilijk is de diagnose van een derde extra-verbinding vast te stellen tijdens het pre-operatieve electrofysiologisch onderzoek.

In hoofdstuk VIII worden 4 patiênten gepresenteerd met functionele dissociatie van een extraverbinding. 


\section{Acknowledgment}

Many people supported and continue to support me during the work preceding. involving and following the publication of this thesis.

It is fantastic to have that many friends. The disadvantage is that one cannot mention them all in such a limited space.

I thank my parents, my dear "pais" who from the beginning lead me in all those apparently irrelevant things, which, however, determine one's personality and approach to life. They lead me to study and to interest in every little detail of my work. Without that excellent leadership my life could have been a completely different one.

Angela, please, just keep being the same way you are.

I thank my teachers Pedro Brugada who since my arrival in Maastricht stimulated me and showed me the ways to Rhythmology and Electrophysiology, and Prof. Wellens who with his dynamic and scientific personality contributed a lot to my learning process.

Also Joep Smeets, who with his excellent work, his patience and good feelings, always had that "second" to teach and help me.

Also Simon Braat, that together with Joep are my "Paraninfs" in this thesis.

I thank the members of the "Committee", Prof. Reneman, Prof. Allessie, Prof. Penn. Prof. Meijler and Prof. Janse, and the "Foreign Referees", Prof. Saad and Dr. Farré.

My colleagues in Maastricht, the Research Fellows of the Clinical Electrophysiology Laboratory contributed as much to my scientific as to my social life. Fernando Cruz, Ayrton Peres, Josep Brugada, Tamer Seixas. Mauricio Duque, the "president" Shi, Rodolfo Oyarzun, Lluis Mont. Luz Maria Rodrigues, I also thank you for your help with this thesis.

Rodolpho Rocco, master of masters, and friend who guided me since early days in Medicine. I express you all my gratitude.

Edson Saad, I thank you for all the stimulus and the extra "kick" you gave me."

Adalberto Lorga and Ivan Maia contributed in different and unexpected ways to my life. Adalberto, fax up, fax down. looked with microscope to every single word in this thesis. Ivan did the same with a telescope, because of the distance. I am looking forward to be again face to face next to each other and provide the best of our care to the many patients we have in Brazil.

Louis Peters and Heloisa Castelo Branco, for all the support and help they gave me.

Anton Gorgels and Marc Vos who directly and indirectly contributed a lot to this thesis. 
I thank also Marie Pauline Roukens, that help me not only in this thesis, but also in other investigations.

Rob Mulleneers has indirectly introduced the informatics in our Department in Brazil. You may not know that, but you started in someway, a little revolution. We count on you to continue our computerized work from a far distance.

I thank also Patricia Krekels, not only for the secretarial help, but also for her perpetual smile.

Also Adri Van den Dool and all members of the Photographic Department of the Hospital for their help with the illustrations.

I thank the CNPq and UFRJ for their support in my endeavour. Certainly without their support I would not have been able to perform this doctoral thesis in the Netherlands. 


\section{Curriculum vitae}

\section{JACOB ATIÉ}

Born Tel-Aviv, Israel, January 28, 1953

Nationality Brazilian

1971-1976 Medical School, Federal University of Rio de Janeiro, Brazil.

1978-1980 Master in Cardiology, Pontificia Universidade Católica, Rio de Janeiro, Brazil.

1981 Specialist in Cardiology (Brazil).

1982-1990 Staff Member, Hospital Clementino Fraga Filho, Federal University of Rio de Janeiro, Brazil.

1988-1990 Research Fellow in Clinical Cardiac Electrophysiology. University of Limburg, Maastricht, The Netherlands. 